\title{
Cortical development and myelination in the absence of Schizophrenia susceptibility gene Neuregulin1
}

\author{
$\mathrm{PhD}$ Thesis \\ in partial fulfilment of the requirements \\ for the degree "Doctor of Philosophy (PhD)/Dr. rer. nat." \\ in the Neuroscience Program \\ at the Georg August University Göttingen, \\ Faculty of Biology
}

submitted by

Amit Agarwal

born in

Koderma (India)

Goettingen, March 2008 
First Referee: $\quad$ Prof. Dr. Klaus-Armin Nave

Director, Department of Neurogenetics

Max Plank Institute of Experimental Medicine

37075 Göttingen, Germany

Second Referee: $\quad$ Prof. Dr. Mathias Bähr

Director, Department of Neurology

University of Göttingen, Robert-Koch-Str. 40

37075 Göttingen, Germany

Third Referee: $\quad$ Prof. Dr. Markus Missler

Director, Department of Anatomy and Molecular Neurobiology

Westfälische Wilhemlms-University

48149 Münster, Germany

Date of submission of the PhD thesis: $28^{\text {th }}$ of March 2008 


\section{Declaration}

I hereby declare that I prepared the Ph.D. thesis "Cortical development and myelination in the absence of Schizophrenia susceptibility gene Neuregulin1 " on my own and with no other sources and aids than quoted. I would like to gratefully acknowledge collaborations with Prof. Hannelore Ehrenreich and Dr. Konstantin Radyushkin (mouse behavioral analysis), Dr. Weiqi Zhang (electrophysiological recordings), Bastian Brinkamm (electron microscopy), Christian Humml (sciatic nerve confocal microscopy data), Ulli Bode (ES cell culture), as also indicated in the text. The first chapter of my result section is adapted from the manuscript "Neuregulin-1/ErbB signaling serves distinct functions in myelination of the peripheral and central nervous system", currently in revision in Neuron, and summarizes my own contribution to the manuscript. 


\section{DEDICATED \\ TO \\ MY PARENTS}




\section{Acknowledgements}

I wish to express deep sense of gratitude to my project supervisor Prof. Klaus-Armin Nave for giving me an opportunity to work on such an interesting and challenging project. I'm greatly indebted to him for introducing me to the whole new world of mouse genetics, providing me with great ideas and immense freedom. It was a nice experience to work with him and to learn both scientific and non-scientific skills needed to survive in science. I wish, I could learn more from him and his experiences.

I'm grateful to Dr. Markus H. Schwab for his guidance, invaluable suggestions and support as and when required. I am very thankful to him specially for giving his critical remarks over this thesis. It was fun to work with him and to have some great discussion.

I would like to thank Prof. Mathias Bähr, Prof. Markus Missler, Prof. Hannelore Ehrenreich, Dr. Cary Lai, Dr. Weiqi Zhang and Dr. Konstantin Radyushkin for their helpful discussions, advice and support over this project.

I am thankful to Dr. Sandra Göbbels, Dr. Ajit Singh Dhaunchak, Dr. Ursula Fünfschilling, Ingo Bormuth, Christian Humml and Sven Wichert for helping me out in any technical problems and providing some useful experimental tips and tricks. I would like to give special thanks to Endo Gabriele for making my life easier by taking care of any bureaucratic hurdles. It was great to have an excellent team of Neuroscience graduate program coordinators, Prof. Michael Hörner, Dr. Steffen Burkhardt, Sandra Drube and Dr. Simone Cardoso de Oliviera for their administrative support and making this program a great success.

It was great to have Annette Fahrenholz, Ulli Bode and Carolin Stünkel, always around in the lab for their technical support in daily hassles of science. I would also like to thank Cornelia Casper, Daniel Flemming, Monika Schindler, Tanja Leinert and Rainer Libal for providing an excellent mouse house and transgenic facility. I am grateful to Hajo Horn, Rolf Merker, Lothar Demel and Beate Beschke for taking care of my computer crashes and disasters.

Last but not the least, it was fun to have my fellow graduate students, Schanila, Burcu, Derya, Patricia, Susanne, Alex, Jan, Minou, Maike, Robert, Anna, Anja, Viki and Foteini always around for their moral support, help and making life a fun during my stay in the lab. I would like to extend especial to thanks Sergi, Tobias, Aiman, Patricia, Jasmin and Govind for proof reading my thesis, pointing out the possible mistakes and give some helpful comments.

Above all I am indebted from the depth of my heart to my parents and especially to Jasmin, for their immense support, love and care. 
Table of Content

I. List of Figures ........................................................................................................................................... 4

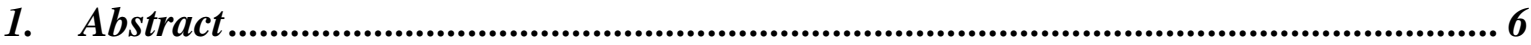

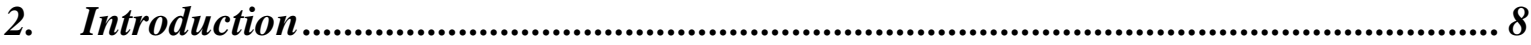

2.1 Myelination-Origin and molecular players.......................................................................... 9

2.1.1 What is myelination and why investigate it? .......................................................................... 9

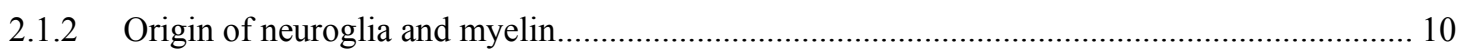

2.1.3 A brief history of myelin ................................................................................................... 11

2.1.4 Differences between CNS and PNS myelination.................................................................... 12

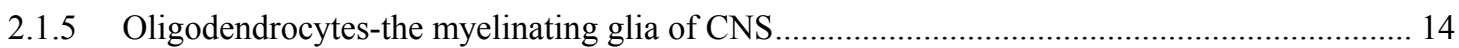

2.2 Neuregulin1-a gene with multiple functions ...................................................................... 17

2.2.1 Neuregulin1 signals to ErbB receptors ……………........................................................ 17

2.2.2 Neuregulin1- the 'master regulator' of PNS myelination .......................................................... 19

2.2.3 Neuregulin1 in synaptic plasticity- a controversial issue........................................................... 21

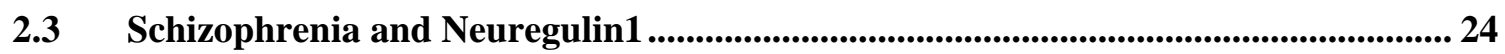

2.3.1 Neuregulin1 at risk haplotype for Schizophrenia ........................................................... 24

2.3.2 Schizophrenia and white matter- does Neuregulin1 matter? ............................................ 25

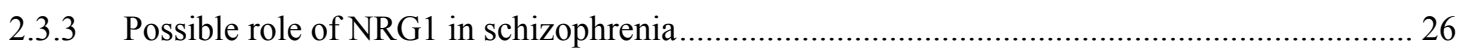

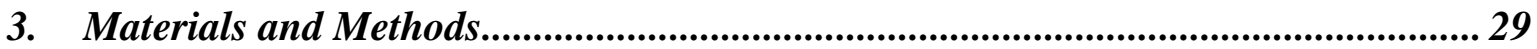

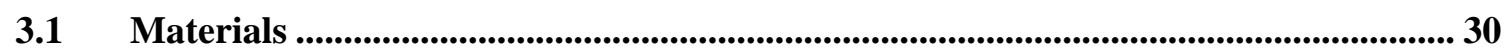

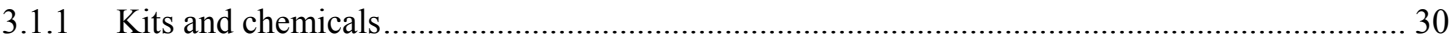

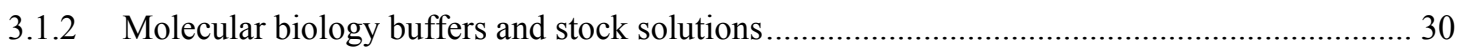

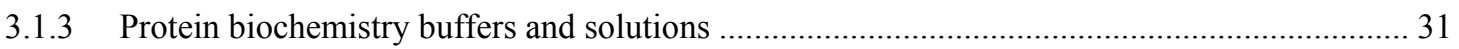

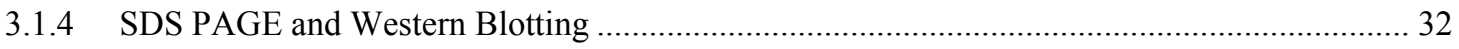

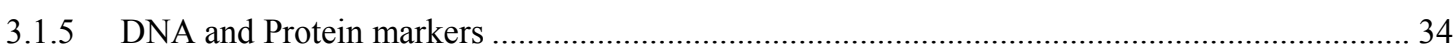

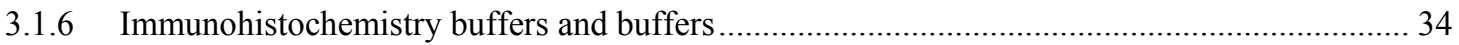

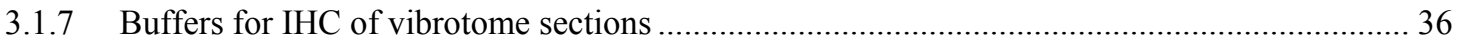

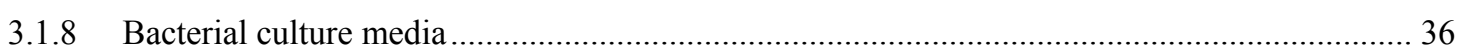

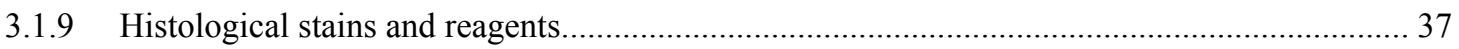

3.1.10 Reagents for Gallyas silver impregnation for myelin...................................................... 38

3.1.11 Reagents for Bielschowsky silver impregnation of axons.................................................. 38

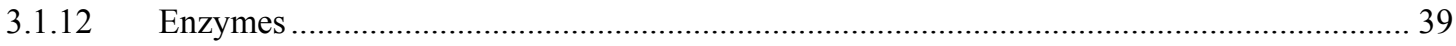

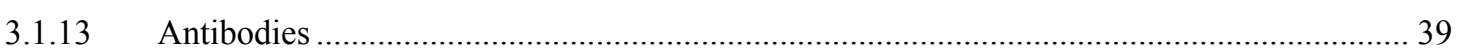

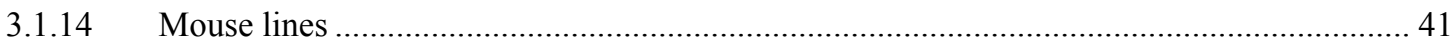




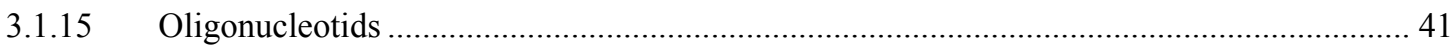

3.1.16 Genotyping primer for various mouse lines ............................................................. 41

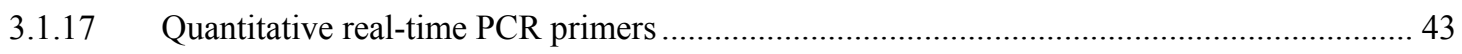

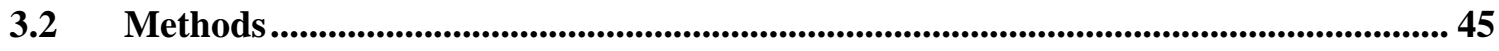

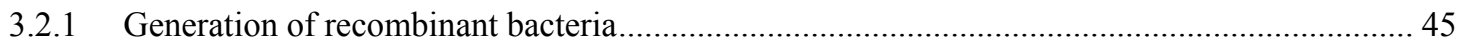

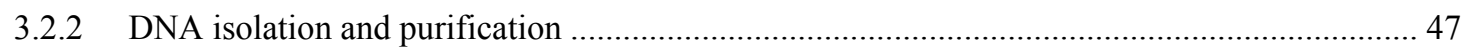

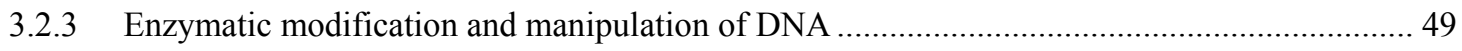

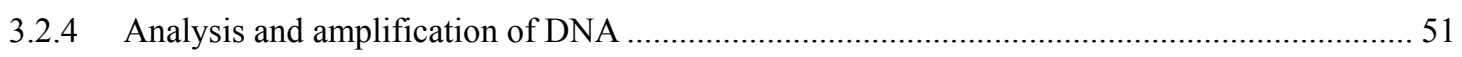

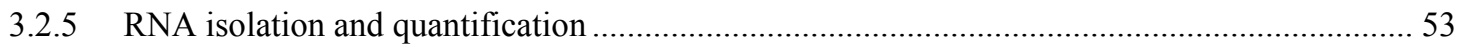

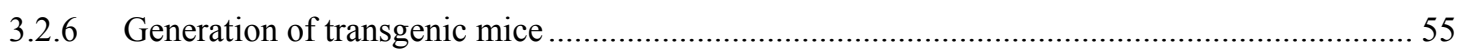

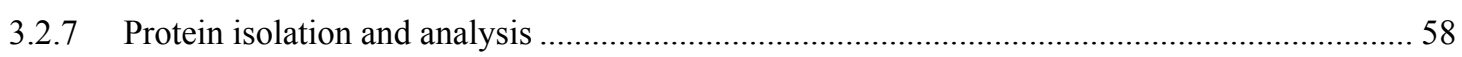

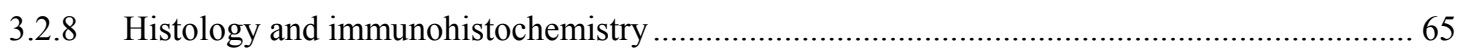

3.2.9 Electrophysiological procedure for LTP measurement ..................................................... 72

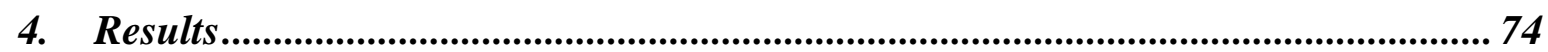

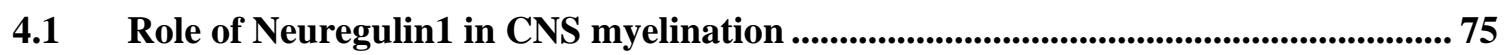

4.1.1 Consequence of NRG1 haploinsufficiency on the maintenance of white matter .................... 75

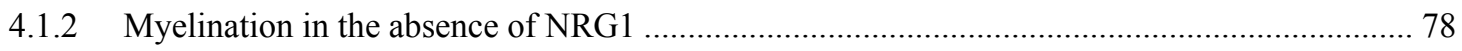

4.1.3 Ectopic myelination in response to NRG1 type I and type III overexpression........................ 93

4.1.4 Myelination in the absence of ErbB signaling ................................................................ 95

4.2 Neuregulin1 and synaptic function ...................................................................96

4.2.1 Consequences of postnatal inactivation of $\mathrm{Nrg} 1$ in principal projection neurons..................... 96

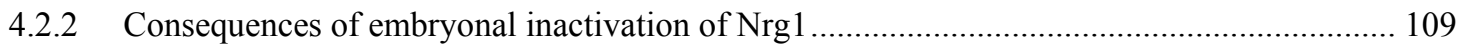

4.2.3 Embryonic inactivation of $\mathrm{Nrg} 1$ in post-mitotic projection neurons ................................... 110

4.2.4 Embryonic inactivation of $\mathrm{Nrg} 1$ in forebrain neurons, astrocytes and oligodendrocytes ........ 114

4.3 Generation of a NEX-CreERT2 knock-in mouse line ........................................ 121

4.3.1 Cloning of 'pAA-NEXCreERT2' gene targeting vector.................................................... 122

4.3.2 Gene targeting in ES cells by homologous recombination ................................................ 125

4.3.3 Characterization of NexCreERT2 mice.................................................................... 125

5. Discussion.......................................................................................................................... 129

$5.1 \quad$ Neuregulin1 and myelination ................................................................................ 130

5.1.1 The role of Neuregulins and ErbB receptors in myelination ............................................... 130

5.1.2 Possible roles of NRG1/ErbB signaling in oligodendrocytes .......................................... 132

5.2 Neuregulin1 and synaptic function ................................................................... 134

5.2.1 Behavioral consequences of forebrain specific inactivation of NRG1 ............................... 134

5.2.2 NRG1/ErbB signaling in the regulation of neurotransmitter receptors ............................... 137 


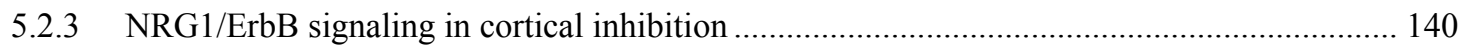

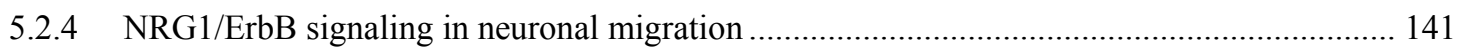

5.2.5 NRG1/ErbB signaling in neuropsychiatric disorders ...................................................... 142

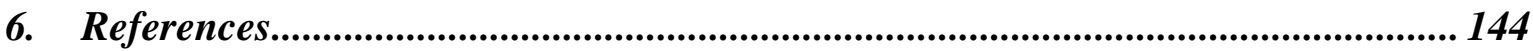

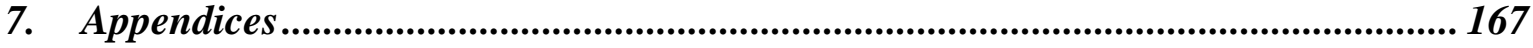

7.1 Appendix A: Abbreviations .......................................................................................... 168

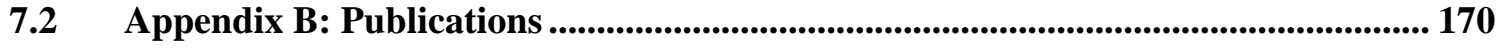

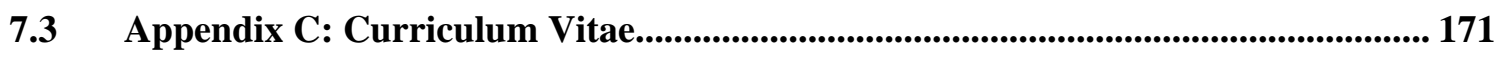




\section{List of Figures:}

Fig. 1. Structure of myelinated axons.

Fig. 2. NRG1 isoforms: membrane topology and signalling.

Fig. 3. Axonal NRG1 regulates successive steps of Schwann cell differentiation.

Fig. 4. Possible relationships between NRG1 function and schizophrenia endophenotypes........27

Fig. 5. Absence of neurodegeneration in mice with reduced Nrg1 gene dosage ..........................77

Fig. 6. Conditional inactivation of $\mathrm{Nrg} 1$ in postnatal forebrain projection neurons

Fig. 7. Reduced NRG1 and normal levels of myelin protein in mice lacking NRG1 in postmitotic forebrain projection neurons

Fig. 8. Normal myelination in the absence of projection neuron derived NRG1 .82

Fig. 9. Figure 9: Myelin ultrastructure and onset of myelination in the absence of projection neuron derived NRG1

Fig. 10. Conditional inactivation of $\mathrm{Nrg} 1$ in Emx1+ cell linage at embryonic stage. .85

Fig. 11. Normal myelination and cell survival in the absence of NRG1 from forebrain .86

Fig. 12. Nestin-Cre driven recombination of floxed genes in brain and spinal cord .88

Fig. 13. Impaired peripheral myelination in Nestin-Cre*NRG1 flox/flox mutants . .89

Fig. 14. Normal cortical development but increased apoptosis in the absence of NRG1 .91

Fig. 15. Oligodendrocytes develop on schedule in the absence of NRG1

Fig. 16. Oligodendrocyte morphology in NRG1 mutants and overexpressors.

Fig. 17. Reduced motor activity in mice with postnatal-onset, projection neuron-restricted NRG1 inactivation

Fig. 18. Mice lacking NRG1 in their projection neuron showed impaired behavior after aging and pharmacological treatment.

Fig. 19. Loss of NRG1 from pyramidal neurons leads to suppression of LTP induction at hippocampal Sch-CA1 synapses. 
Fig. 20. Reduced levels of NRG1 but unaltered levels of synaptic proteins in cortical lysates and in 'synaptic vesicles' prepared from 15 mo old mice.

Fig. 21. Unaltered levels of synaptic proteins in the cortical lysates prepared from mice that have undergone behavioral analysis and were treated with MK-801

Fig. 22. Reduced number of synaptic boutons in mutants that have undergone behavioral analysis and were treated with MK-801

Fig. 23. Normal levels of ongoing neurodegeneration in the aged mice lacking NRG1 in their projection neurons.

Fig. 24. Normal histology and no major axonal degeneration in mice lacking NRG1 embryonically from post-mitotic neurons

Fig. 25. Normal development of the parvalbumin+ and calbindin+ interneuron lineage in the absence of projection neuron-derived NRG1

Fig. 26. Increased expression of ErbB3 and parvalbumin but decreased expression of calretinin and ErbB2 in mutants lacking NRG1 from their projection neurons

Fig. 27. Characteristic features of "handling-induced seizures" in mice lacking NRG1 from neural precursors.

Fig. 28. Undisturbed cortical layering and hippocampal morphology in mice lacking NRG1 from neural precursors

Fig. 29. Unaltered protein levels in cortical lysates and "synaptic vesicles" prepared from mice lacking NRG1 from neural precursors

Fig. 30. Increased parv + but decreased GAD67+ interneuron numbers in mice lacking NRG1 from neural precursors

Fig. 31. Strategy to knock in CreERT2 into the murine Nex gene

Fig. 32. Characterization of the targeting vector and PCR based strategy for the screening of homologously targeted ES cells.

Fig. 33. :Tamoxifen induced gene recombination in hippocampal projection neuron. 126

Fig. 34. Tamoxifen induced gene recombination in cortical projection neuron. 128 
1. Abstract 
Neuregulin1 (NRG1), a gene on human chromosome $8 \mathrm{p}$, encodes a family of widely expressed EGF-like growth factors that signal via ErbB receptors tyrosine kinases. The best understood function of murine NRG1 is the control of myelination in the peripheral nervous system (PNS). The identification of human NRG1 as a susceptibility gene for schizophrenia has renewed interest in the contribution of NRG1/ErbB signaling in brain development. Based on in vitro studies, multiple functions of NRG1 have been suggested for the CNS, including oligodendrocyte differentiation and myelination, neuronal migration and synaptic plasticity. However, functional in vivo data are lacking as NRG1 mutant mice die embryonically.

As a first step to understand NRG1 function in vivo we generated a series of conditional mouse mutants that completely lack NRG1 expression beginning at different stages of neural development. Surprisingly, conditional null mutants with loss of NRG1 expression in forebrain progenitor cells at E10 (Emx1-Cre) and in cortical and hippocampal projection neurons beginning at E12 (Nex-Cre) and P5 (CamKII-Cre), exhibit no obvious defect of cortical development, oligodendrocyte differentiation, and cortical and subcortical myelination. In the complete absence of neural NRG1 (Nestin-Cre) mutant mice die due to loss of PNS function but perinatal oligodendrocyte development is largely unaffected. These observations suggest that the CNS has evolved a NRG1 independent mechanism of myelination control.

The impact of the human NRG1 at risk polymorphism on schizophrenia is still controversial. Our forebrain specific conditional mutants are a valuable tool to address these questions. Mice with postnatal inactivation of NRG1 in projection neuron (CamKIICre) displayed a reduction of sensory motor gating (prepulse inhibition) and impairments in memory and learning similar to findings in patients with schizophrenia. When these mice were injected with MK-801, a drug that induces psychosis like symptoms, they appeared to be "protected" from the drug effect. Mouse mutants lacking NRG1 from all forebrain neural cells except interneurons (Emx1-Cre) suffer from seizures and have defects in the sub-population of GABAergic interneurons. These results point towards a crucial role of NRG1 in fine-tuning of excitatory and/or inhibitory brain circuits. 
2. Introduction 


\subsection{Myelination-Origin and molecular players}

\subsubsection{What is myelination and why investigate it?}

Myelination is the process by which glial cells enwrap axons with several layers of membrane sheaths. Myelin sheaths are enormous membranous extensions made by glial cells, which include oligodendrocytes (OL) in the central nervous system (CNS) and Schwann cells (SC) in the peripheral nervous system (PNS). The sheaths insulate axons and thereby ensure the rapid propagation of electrical impulses with millisecond precision (reviewed in Waxman, 1997). The process of myelination is one of the most impressive and least understood examples of cellular interaction invented by nature.

The speed of an electrical impulse propagated by a myelinated axon is directly proportional to the diameter of the fiber. In contrast, impulse propagation speed by an unmyelinated axon is proportional to the square root of axonal diameter (Hursh, 1939; Rushton, 1951). This startling effect of myelination can be illustrated by the fact that an unmyelinated squid giant axon (diameter of $\sim 500 \mu \mathrm{m}$ ) and a mammalian myelinated axon (outer diameter of $\sim 4 \mu \mathrm{m}$ ) both propagate electrical impulses at a speed of about $20 \mathrm{~m} / \mathrm{sec}$ (Ritchie, 1984; Tasaki, 1982). For a given length the squid axon occupies up to 15,000 times more volume compared to myelinated mammalian axons. Moreover, the squid giant axon consumes 5,000 times more energy than a myelinated frog axon with a diameter of 12 $\mu \mathrm{m}$, although the latter conducts more rapidly (Morell and Norton, 1980; Ritchie, 1984). Thus, in addition to high conduction velocity, the evolution of the mammalian myelinated axon has resulted in a remarkable savings of space and energy. These observations suggest that for the CNS to evolve, with its colossal computation power and space constraints, myelination was a necessary and critical process. However, myelination involves a high level of developmental, structural, metabolic and electrophysiological complexity. This makes the whole process highly vulnerable to cellular and molecular disturbances that may result in severe neurological disorders. Currently, most of the patients affected by a myelin-related disorder cannot be effectively treated. Therefore, deciphering the mechanisms and key players involved in the formation and maintenance of the myelin sheath is critical to an improved understanding of the pathophysiology of myelin-related disorders. 


\subsubsection{Origin of neuroglia and myelin}

Hildebrand et al., (1993) and Rosenbluth (1999) have meticulously reviewed the saga of the birth of myelin and its enticing history respectively. In the section that follows, I have presented some fascinating excerpts from both reviews and scores of interesting research articles.

Coelenterates and nematodes were the first animals to possess a simple nervous system in the animal kingdom. Their nervous system consists primarily of neurons (soma and processes) without any glial cells (Bullock and Horridge, 1965; Lentz and Barrnett, 1965). During the course of evolution, the nervous system gained complexity that was accompanied by the emergence of glial cells. In higher invertebrates, such as annelids, arthropods and molluscs, the nervous system became cephalized, that is rostrally localized with a centralized collection of neurons and neuroglia (Lane, 1981). Even with the advent of neuroglia most primitive invertebrate axons lack glial ensheathments. In higher invertebrates, such as polychaetes and some insects, axons are either surrounded by a single row of elongated sheath cells or by multilayered glial lamellae wrapped in a loose spiral (Edwards et al., 1958). Generally, the number of glial lamellae tend to be proportional to the size of axons, i.e. the larger the axonal cross-section, the greater the number of lamellae. The number of lamellae varies considerably and can range from a few to several hundred.

At later evolutionary stages the formation of increasingly complex glial sheaths was accompanied by an axolemmal reorganization, with the electrogenic capability of the axon membrane localized to a few "hot spots" in unensheathed areas. Interestingly, axons in lower invertebrates such as median giant axon in the earthworm and the large axons of the prawn exhibit specialized electrically active nodes endowing them with a conduction velocity of 5-30 m/sec (Gunther, 1976; Hama, 1966; Heuser and Doggenweiler, 1966; Kusano and LaVail, 1971). These compacted lamellate sheaths and accompanying specialized nodes seem to have evolved as an excellent solution to the axonal conduction velocity problem (Bullock and Horridge, 1965; Levi et al., 1966). Although this specialized interaction between axons and glial cells has been identified in some invertebrates, it is a characteristic feature of vertebrates. 


\subsubsection{A brief history of myelin}

The first description of myelinated nerve fibers came as early as 1717 , from the microscopic analyses of animal tissues and nerves, by Leeuwenhoek (Clarke and O'Malley, 1968). In 1791, Galvani stated, in De viribus electricitatis, '.... nerve performs the function of a conductor (of electricity)...'. According to Galvani, the inner 'tenuous lymph' of the nerve conducts electricity and the outer oily layer prevents dispersion of this electricity (reviewed in Clarke and O'Malley, 1968). For a long time this oily substance surrounding nerves was believed to be secreted within the nerve fiber and was thought to be analogous to the bone marrow ('Markstoff'). These nerve fibers containing 'Markstoff' were referred to as 'markhaltige Nervenfasern'. In 1858, based on this erroneous belief, Virchow hellenized 'Markstoff' to 'myeline' from the Greek myelos, marrow, and 'medullated' nerve fibers henceforth were christened as 'myelinated' nerve fibers. Remak and Ramon y Cajal were among the authoritative advocates of the concept that myelin was secreted by axons. This dogma held sway for almost a century until Penfield, in (1932), put forth his hypothesis that myelin is chiefly maintained by oligodendroglia.

In 1871 Ranvier reported that myelin sheaths were discontinuous and exhibited periodic interruptions, associated with axonal constrictions (Ranvier, 1871). He also reported that immediately adjacent to these 'nodes' one could observe transverse striations in the axon. Not long after Ranvier's description of nodal striations, Schmidt (1874) and Lanterman (1877) described in detail these striations as "oblique slits" traversing the myelin sheath between nodes. Later, J. David Robertson (1958) demonstrated the detailed structure of the Schmidt-Lanterman incisures that he referred to as the 'shearing defect' in the myelin sheath. These clefts are truncated-cone-shaped regions in which the compact lamellae split to enclose a column of SC cytoplasm extending helically around the axon from the outermost to the innermost layer. Tasaki (1939) and later Huxley \& Staempfli (1949) demonstrated nodes of Ranvier to be the "Hot spots" on myelinated axons where rapid exchange of ions takes place. The myelin sheath between these nodes serves as an insulator to increase the resistance and reduce the capacitance. This membrane specialization permits the electrical impulses to 'jump' from node to node very rapidly, resulting in a saltatory mode of conduction.

Electron microscopic and X-ray diffraction studies revealed that the myelin sheath has a regular layered structure (Schmidt, 1936; Schmitt, 1941). In order to solve the longstanding mystery of myelin genesis, Betty Ben Geren (1954) used electron microscopy to evaluate various stages of myelin formation in the chick nerve. Her studies were the first to reveal that myelin forms by the elongation and spiral wrapping of SC membrane around 
the axon. This landmark discovery provided the key to the understanding of myelin structure and development. The whole new concept by Geren completely changed the way myelin was looked at, since it was not mere an oily sheath secreted by the axon but was produced as a result of complex interactions between neurons and glial cells (Geren and Raskind, 1953; Geren and Schmitt, 1954).

\subsubsection{Differences between CNS and PNS myelination}

Most of the initial studies on myelination were performed in peripheral nerves. But, shortly after the revolutionizing findings of Geren concerning the genesis and structure of peripheral myelin, Maturana (1960) and Peters (1960) reported that central myelin also consists of membrane spirals. Each segment of CNS myelin could be traced back to a single process of an OL and surprisingly each OL can give rise to multiple myelin segments belonging to different axons (Bunge et al., 1962; Bunge, 1968). This result was in contrast to the situation in the PNS, where SCs can form only single myelin segments and further implied that the damage of an OL would result in more extensive demyelination than that of a SC (Fig. 1).

While the basic ultrastructure of internodes, nodes and paranodes are comparable in the CNS and PNS, several differences in fine structure have been identified (Fig. 1A, B) (Peters et al., 1991). In the mammalian PNS all axons with a diameter of about $1 \mu \mathrm{m}$ or more are myelinated. This observation laid the foundation for the "critical axon diameter" concept (Duncan, 1934). This idea was further supported by the observation that unmyelinated PNS axons become myelinated if their diameter is experimentally increased (Voyvodic, 1989). Originally, it was assumed that also in the CNS a "critical axon diameter" exists for axons to become myelinated (Fleischhauer and Wartenberg, 1967). However, in the CNS unmyelinated axons with diameters of up to $0.8 \mu \mathrm{m}$ exist, while myelinated axons below $0.2 \mu \mathrm{m}$ in diameter can also be found. In addition, the minimal diameter of myelinated CNS axons decreases with development (Fraher et al., 1988; Matthews and Duncan, 1971; Remahl and Hildebrand, 1982). Thus, in contrast to the PNS, the size spectrum of myelinated and unmyelinated axons overlap considerably in the CNS (Hildebrand and Waxman, 1984). To some extent, the overlapping diameter ranges of unmyelinated, ensheathed and myelinated CNS axons may be explained by longitudinal diameter variations of axons along their length (Greenberg et al., 1990; Seggie and Berry, 1972). In short, it seems that there is a fundamental difference between CNS and PNS axons, with respect to the determinants of whether an axon will become ensheathed and myelinated. 
A

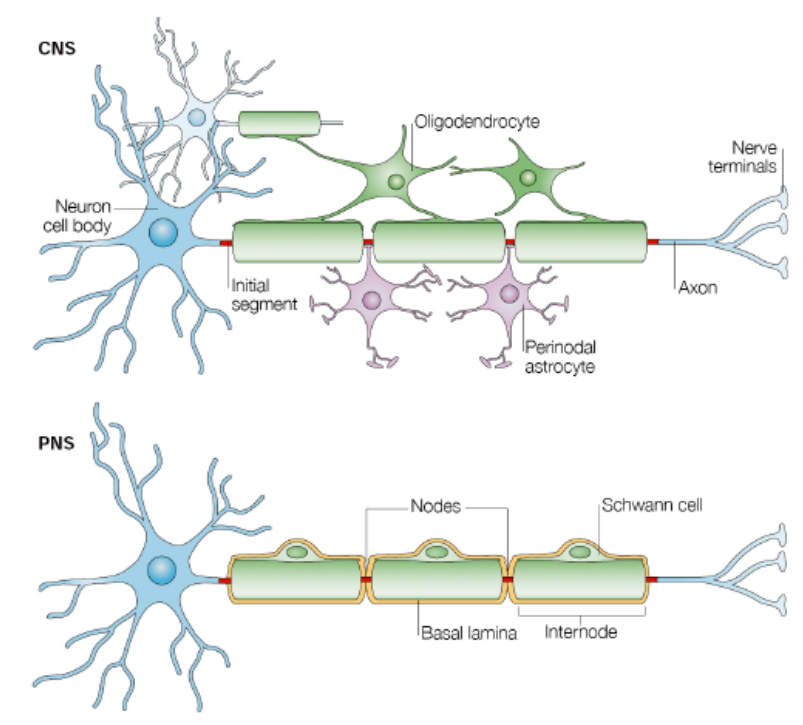

B

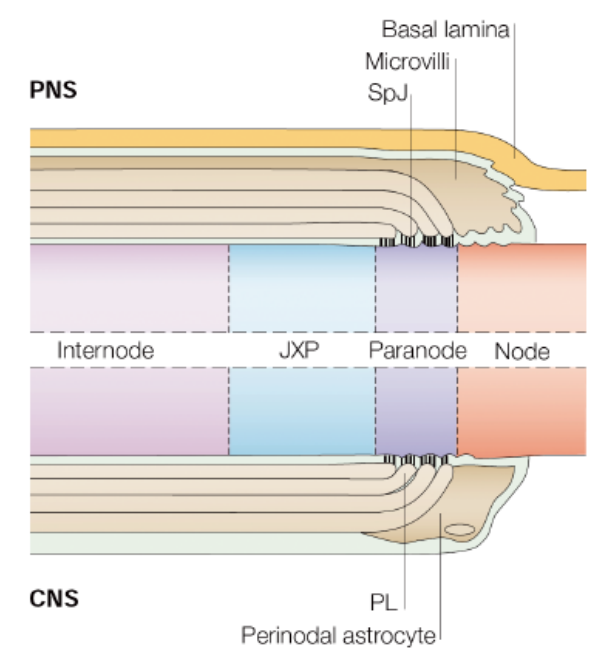

Fig. 1. Structure of myelinated axons.

(A) Oligodendrocytes (OL) in CNS and Schwann cells (SC) in the PNS form the myelin sheath by enwrapping axons with several layers of membrane sheaths. Myelin covers the axon at intervals (internodes), leaving bare gaps - the nodes of Ranvier. OL myelinate upto 40 axons and several internodes per axon, whereas SC myelinate a single internode in a single axon. (B) Schematic longitudinal cut through a myelinated fibre at a node of Ranvier (shown is only a heminode). The node, paranode, juxtaparanode (JXP) and internode are shown. The node is contacted by SC microvilli in the PNS and by processes from perinodal astrocytes in the CNS. Myelinated fibres in the PNS are covered by a basal lamina. The paranodal loops form a septate-like junction (SpJ) with the axon (modified from Poliak and Peles, 2003).

Both the radial and longitudinal dimensions of CNS myelin are coupled to the axon diameter. The number of myelin lamellae is related to axon diameter according to a curvilinear function and varies between species (Hildebrand and Hahn, 1978). The longitudinal extension of adult CNS internodes has been reported to increase from $100 \mu \mathrm{m}$ to $1700 \mu \mathrm{m}$, as fiber diameter increases from $1 \mu \mathrm{m}$ to $17 \mu \mathrm{m}$ (Gledhill and McDonald, 1977; Hess and Young, 1952; McDonald and Ohlrich, 1971; Murray and Blakemore, 1980). Amazingly, both in the PNS and CNS, the nodal length is quite constant and ranges between 0.8-1.1 $\mu \mathrm{m}$ (Berthold, 1968a, b; Conradi, 1969; Hildebrand, 1971; Hildebrand and Waxman, 1984; Rydmark and Berthold, 1983). Moreover, large mature CNS myelin sheaths exhibit prominent incisures of Schmidt and Lanterman (Blakemore, 1969; Conradi and Skoglund, 1969; Hildebrand, 1971), but such clefts are rare in thin sheaths. This feature is in contrast to the PNS where most of the myelin sheaths contain Schmidt and Lanterman incisures.

In the PNS the lateral borders of the SC cytoplasm are tipped with microvilli. The tips of these microvilli contact the nodal axolemma and may act as 'ion-sinks' by accumulating $\mathrm{K}^{+}$ions during axonal activity (Ichimura and Ellisman, 1991; Mi et al., 1996; 
Raine, 1982). Interestingly, in the CNS astrocytes are recruited to myelin nodes (Fig. 1B). These "perinodal astrocytes" extend their processes to surround the node of myelinated axons (Black and Waxman, 1988). The nodal axon of large CNS fibers is completely shielded by a mantle of astrocytic cytoplasm while nodes of small CNS fibers are less well shielded (Hildebrand, 1971; Hildebrand and Waxman, 1984). Observations in the white matter of cats indicate that a single astrocyte may send processes to more than one node, and that a single node may receive processes from more than one astrocyte (Hildebrand, 1971). Nodal shielding by astrocytic processes adds to yet another level of complexity in CNS myelination.

\subsubsection{Oligodendrocytes-the myelinating glia of CNS}

The techniques of heavy metal impregnation developed by Ramon y Cajal (gold impregnation) and Rio Hortega (silver impregnation) have been instrumental in the characterization of glial cells. It was Rio Hortega who coined the term 'oligodendroglia' to define a glial cell population that exhibited few processes in his silver impregnated brain sections. Hortega divided 'oligodendroglia' into four categories (type I-IV) based on the number of processes (reviewed in Baumann and Pham-Dinh, 2001). Butt et al., have also distinguished four types of myelinating OL: small cells producing short internodes and thin myelin sheaths around 15-30 small diameter axons (type I, optic nerve of the rat), large cells forming long internodes and thicker myelin sheaths around 1-3 large diameter axons (type IV, spinal cord of the cat) as well as intermediate types (type II and III) (Butt et al., 1995). When compared to other neural cells OL have very distinctive features, such as small soma size, glycogen-rich cytoplasm, a nucleus with dense chromatin and processes that contain microtubules ( $25 \mathrm{~nm}$ ) but no intermediate filaments (Lunn et al., 1997).

OL originate from mitotic and migratory precursors and mature into post-mitotitc myelinating glia. Maturation and differentiation usually involve the loss of certain surface or intracellular antigens and the acquisition of new ones. This coordinated change in the expression of antigens can be monitored by antibodies and used to identify the developmental status of the OL lineage. The sequential steps of OL differentiation and maturation are a prerequisite for the initiation of myelination (Hardy and Reynolds, 1993; Pfeiffer et al., 1993). The number of mature OL is determined by the proliferative rate of their progenitors and by programmed cell death that occurs mainly during development (Barres et al., 1994). Signals derived from astrocytes and neurons (mainly axons) greatly influence differentiation and the precise numbers of OL that are necessary to myelinate the entire CNS (Barres and Raff, 1999; Hardy and Reynolds, 1993; Richardson et al., 2000). In vitro studies have shown that many growth factors regulate the proliferation, 
differentiation, and maturation of the OL lineage (Barres et al., 1994; Canoll et al., 1999; Canoll et al., 1996; Hardy and Reynolds, 1991, 1993; McKinnon et al., 1990; McMorris and Dubois-Dalcq, 1988; Pfeiffer et al., 1993; Raff et al., 1988; Richardson et al., 1988; Yasuda et al., 1995) including Platelet-Derived Growth Factor (PDGF), Fibroblast Growth Factors (FGFs), Insulin-like Growth Factors (IGF), Neurotrophins, and Neuregulins (NRGs) (see below) (Bansal, 2002; Grinspan, 2002; Hempstead and Salzer, 2002). Also circulating cytokines, steroids, and thyroid hormone have been implicated in the control and timing of OL differentiation (Aloisi, 2003; Baulieu and Schumacher, 2000; RodriguezPena, 1999). These studies are difficult to extrapolate to the in vivo situation, as several growth factors act in an orchestrated way to achieve the fine regulation of OL development and myelination. Furthermore, each of these factors has multiple effects during the developmental process. Moreover, when combined these factors often produce effects that are significantly different from those seen with any single factor alone (McMorris and McKinnon, 1996).

A major source of signals that regulates OL differentiation is the axon itself. During nervous system development, OL numbers need to be matched to the number of axons requiring myelination. Axonal signals and electrical activity regulate the proliferation and survival of OL, enhance myelin-gene expression, and induce terminal differentiation (Barres and Barde, 2000; Barres and Raff, 1999; Bozzali and Wrabetz, 2004). Negative axonal regulators include Jagged-1 and F3/contactin that signal to the oligodendroglial Notch receptor (Hu et al., 2003; Wang et al., 1998). Mice with reduced Notch1 gene dosage exhibit premature OL differentiation and myelination, suggesting that Notch1 may inhibit the differentiation of $\mathrm{OL}$ in the optic nerve and spinal cord during late developmental stages (Genoud et al., 2002; Givogri et al., 2002; Wang et al., 1998). Axonal expression of PSA-NCAM also inhibits myelination, and its disappearance during development coincidences with the initiation of myelination (Charles et al., 2000).

OL not only receive signals from axons but also sense axonal signals and thereby contribute to axonal function and their long-term integrity (Edgar and Garbern, 2004; Poliak and Peles, 2003; Salzer, 2003). The dependency of axonal integrity on glial support is illustrated by the observation of a late-onset axonal pathology in mice lacking the myelin proteins proteolipid protein (PLP) and 2'3'-cyclic nucleotide 3'-phosphodiesterase (CNP) (Griffiths et al., 1998; Lappe-Siefke et al., 2003). The nature of these glial signals remains unclear, but they are likely to be relevant in axonal pathologies observed in demyelinating 
diseases. An emerging concept in axon-glia communication is that adhesive interactions may be stage-specific modulators of the OL response to growth factors. For example, the binding of axonal laminin to glial integrin receptors has been proposed to "switch" $\mathrm{NRG/ErbB}$ signaling from promoting OL proliferation to OL survival and differentiation (Colognato et al., 2002). Thus, when presented in the right context, NRG1 may be a positive regulator of CNS myelination. 


\subsection{Neuregulin1-a gene with multiple functions}

\subsubsection{Neuregulin1 signals to ErbB receptors}

Neuregulins are a family of membrane-associated growth factors with an epidermal growth factor (EGF)-like signaling domain. Four genes (NRG1 to NRG4) have been identified in mammals, but only NRG1 has been studied in detail. Human NRG1, located on chromosome $8 \mathrm{p} 22$, is one of the largest genes known. Due to alternative promoter usage and mRNA splicing, at least 15 NRG1 isoforms are generated (Steinthorsdottir et al., 2004). All NRG1 subtypes share an epidermal growth factor (EGF)-like signaling domain that is necessary and sufficient for activation of their receptors (Fig. 2). They can be classified into subgroups based upon their different amino-termini (Falls, 2003b). NRG1 type I (heregulin, neu differentiation factor, or acetylcholine receptor-inducing activity [ARIA]) and NRG1 type II (glial growth factor [GGF]) have N-terminal Ig-like domains and a single transmembrane domain (Fig. 2A, B).

Upon proteolytic cleavage by BACE ( $\beta$-site APP-cleaving enzyme) and metalloproteinases (MP), such as TACE (tumor-necrosis factor- $\alpha$-converting enzyme) (Horiuchi et al., 2005), both isoforms can be shed and released as soluble proteins from the neuronal cell surface and function as paracrine signaling molecules (Fig. 2B). NRG1 type III is characterized by a cysteine-rich domain (CRD) and 2 transmembrane domains. It is tightly associated with axonal membranes even after MP cleavage in the stalk region and most likely functions as a juxtacrine signal (Fig. 2B) (Esper et al., 2006; Nave and Salzer, 2006). Within the nervous system, types I and III are the most abundant NRG1 isoforms and have been detected in many projection neurons, most notably in spinal motor neurons and dorsal root ganglia (DRG) neurons, but has also been identified in OL and astrocytes (Adlkofer and Lai, 2000; Falls, 2003b). Many NRG1-expressing neurons also express transcripts for NRG2 and NRG3, two structurally related factors, whose function in the nervous system remains largely unknown (Adlkofer and Lai, 2000; Britto et al., 2004).

Binding of the EGF-like domain (present in all NRG1 isoforms) leads to the activation of ErbB receptor tyrosine kinases. The basic structure of all four members of the ErbB receptor family (ErbB1-4) includes two extracellular cysteine-rich ligand-binding domains, a transmembrane region, the tyrosine kinase domain (inactive in ErbB3), and a carboxyl-terminal domain. NRG1 directly binds to ErbB3 and ErbB4. 
A

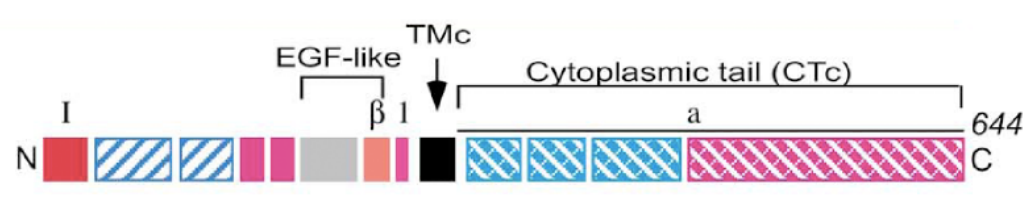

II $\quad \beta 1 \quad$ a 859

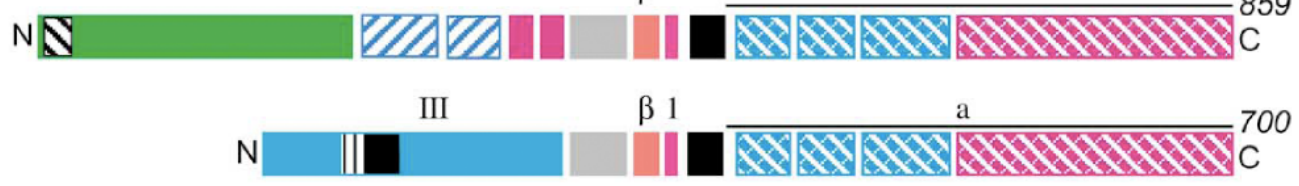

B

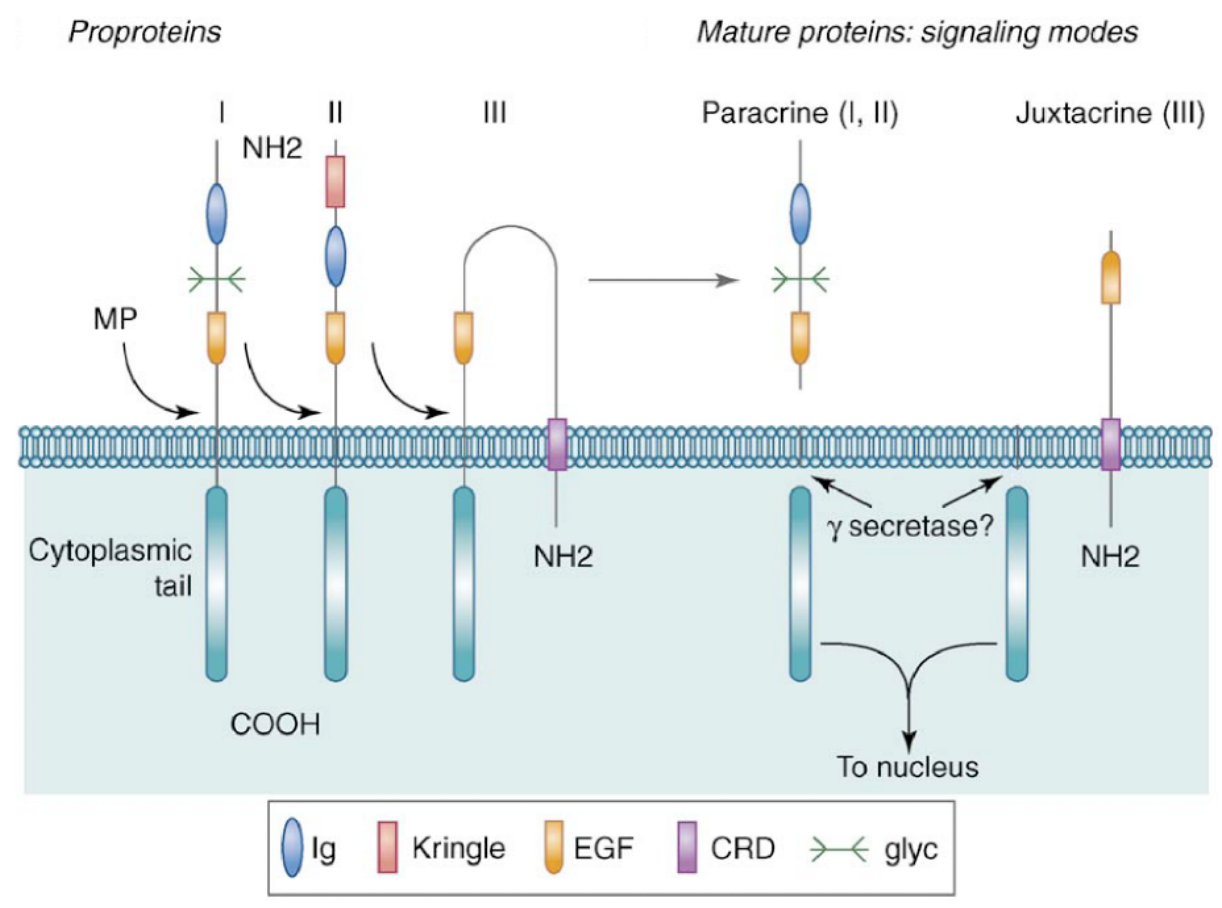

Fig. 2. NRG1 isoforms: membrane topology and signalling.

(A) Domain structure of $\mathrm{Nrg} 1$ isoforms. Based on distinct N-terminal protein domains, $\mathrm{Nrg} 1$ isoforms are sub-grouped into types I (red N-terminus), II (green), and III (blue). Minor variants exist in the stalk region (between the EGF-like and transmembrane domain), within the EGF-like domain and in the cytoplasmic tail. For all types the most common form in the nervous system is the $\beta 1$ a variant. (adapted from Falls, 2003b) (B) Nrg1 types I and II are synthesized as single pass transmembrane proteins; type III has two transmembrane domains. With metalloproteinase (MP) cleavage, types I and II are shed as paracrine signals while type III remains tethered to the membrane due to its cysteine rich domain (CRD) and acts as a juxtacrine signal. The cytoplasmic domain might undergo further cleavage by $\gamma$-secretase (stimulated by binding of ErbB recept ors to NRG1), followed by translocation to the nucleus. (adapted from Nave and Salzer, 2006)

ErbB2 appears to lack an activating ligand and is thought to be the preferred dimerization partner for ErbB3 and ErbB4. Ligand binding and receptor dimerization leads to tyrosine 
autophosphorylation in trans, recruitment of SH2 and PTB domain-containing adapter proteins, and activation of multiple downstream signaling pathways (Buonanno and Fischbach, 2001; Yarden and Sliwkowski, 2001).

Several observations suggest that NRG/ErbB signaling is bidirectional. When NRG1 binds to its receptor, the cytoplasmic C-terminal domain (ICD) is proteolytically cleaved (Bao et al., 2003). After transport to the nucleus the ICD was shown to repress expression of several regulators of apoptosis, resulting in increased neuronal survival (Bao et al., 2003). A similar "back signaling" mechanism was observed in the murine cochlea, where synaptic activity leads to nuclear accumulation of the ICD, which interacts with a zinc-finger transcription factor to stimulate PSD-95 expression (Bao et al., 2004). Nuclear localization has also been observed for the cytoplasmic domain of ErbB4 (after NRG1 binding), suggesting that both, receptor and ligand, can function as regulators of gene expression (Ni et al., 2001; Sardi et al., 2006).

\subsubsection{Neuregulin1- the 'master regulator' of PNS myelination}

$\mathrm{NRG/ErbB}$ signaling is involved in many processes, including heart, skeletal muscle and nervous system development (reviewed in Falls, 2003b). A critical role for NRG1 in the PNS has been established through the analysis of mouse mutants. Mutant mice lacking all NRG1 isoforms (pan NRG) die around E10.5 as a result of abnormal cardiac development. In addition, many neural crest-derived cells, including peripheral neurons and SC precursors, are not properly formed (Meyer and Birchmeier, 1995). Likewise, ErbB2 mice die at E10.5 and lack SC precursors. Moreover ErbB3 null mutants die between E11.5 and P0 (Lee et al., 1995; Morris et al., 1999; Riethmacher et al., 1997). Importantly, mice with an isoform-specific NRG1 type I/II-mutation also die of heart failure at E10.5, but have normal numbers of SC precursors (Kramer et al., 1996; Meyer et al., 1997). In contrast, the absence of the NRG1 type III isoform causes a severe reduction of SC precursors without affecting heart development (Wolpowitz et al., 2000). Cre-mediated ablation of ErbB2 in SC causes severe dysmyelination (Garratt et al., 2000a). Taken together, these data point to a critical function of NRG1 type III/ErbB2 signaling in SC development.

Two recent studies have highlighted the essential function of NRG1 type III as a central regulator of SC fate and PNS myelination (Fig. 3A, B) (reviewed by Nave and Salzer, 2006). One of the studies exhibited the functional relationship between NRG1 signaling and PNS myelination in vivo, focusing on the role of individual NRG1 isoforms and on quantifiable glial parameters, such as myelin sheath thickness (Michailov et al., 2004). Through the analysis of multiple loss-of-function and gain-of-function mutants of NRG1 it 
was proposed that myelin-forming SC may utilize axonal NRG1 signals as a biochemical measure of axon size (Michailov et al., 2004). Indeed, reduced NRG1 expression (but not ErbB2 expression) was associated with thinner myelin sheaths (increased g-ratios) and reduced nerve conduction velocity, without affecting axonal size or SC number. In contrast, neuronal overexpression of NRG1 type III (but not type I) induce a peripheral hypermyelination in transgenic mice (Fig. 3B) (Michailov et al., 2004).

The essential role of NRG1 type III in PNS myelination was shown using dorsal root ganglia (DRG)/SC cocultures, in which myelination can be induced in vitro. Sensory neurons from NRG1 type III deficient mice completely fail to myelinate (Fig. 3B). Moreover, viral expression of NRG1 type III induces myelination of normally unmyelinated axons of sympathetic neurons (Taveggia et al., 2005). These results indicated that the levels of NRG1 type III, independent of axon diameter, provided a key instructive signal that determines the ensheathment fate of axon.

The in vivo analysis of NRG1 function during CNS myelination has been hampered by the early embryonic death of NRG1 null mutant mice. However, indirect evidence suggests an important role of NRG1 also during OL development. First insights came from in vitro studies, in which soluble NRG1 type I or type II was shown to promote either proliferation (Canoll et al., 1996) or differentiation of oligodendroglial cells (Raabe et al., 1997b; Vartanian et al., 1994), depending on the culture conditions and the developmental stage. Several studies on OL support the concept that NRG1 serves a survival function, which is mediated through PI3-kinase (Canoll et al., 1996; Flores et al., 2000; Raabe et al., 1997a; Raabe et al., 1997b). NRG1 also promotes OL survival in the developing rat optic nerve in vivo (Fernandez et al., 2000). Importantly, in spinal cord explants prepared from NRG1 null mutant embryos, immature OL $(\mathrm{O} 4+)$ could not be detected. Inhibition of NRG1 signaling in spinal cord cultures from wild-type mice has similar effects (Vartanian et al., 1999). .

The exact roles of ErbB receptors in OL development and myelination are not known. OL express at least three (ErbB2-4) receptors (Canoll et al., 1996; Raabe et al., 1997b). In spinal cord explants from ErbB2 null mutant mice, normal numbers of immature OL cells are present, but a severe reduction of differentiated $\mathrm{OL}(\mathrm{O} 1+)$ is observed at later times (Park et al., 2001). Similarly, transgenic overexpression of a dominant-negative ErbB2 receptor in OL perturbes differentiation and causes hypomyelination (Kim et al., 2003). In contrast, spinal cord explants from ErbB4 null mutants contain an increased number of differentiated OL, suggesting that ErbB4 mediates suppression of OL maturation (Sussman et al., 2005). Surprisingly, and in contrast to SC, the absence of ErbB3 has no obvious effect on OL development or CNS myelination (Schmucker et al., 2003). These 
observations clearly indicate an important function for NRG1/ErbB signaling during early stages of OL development and myelination.

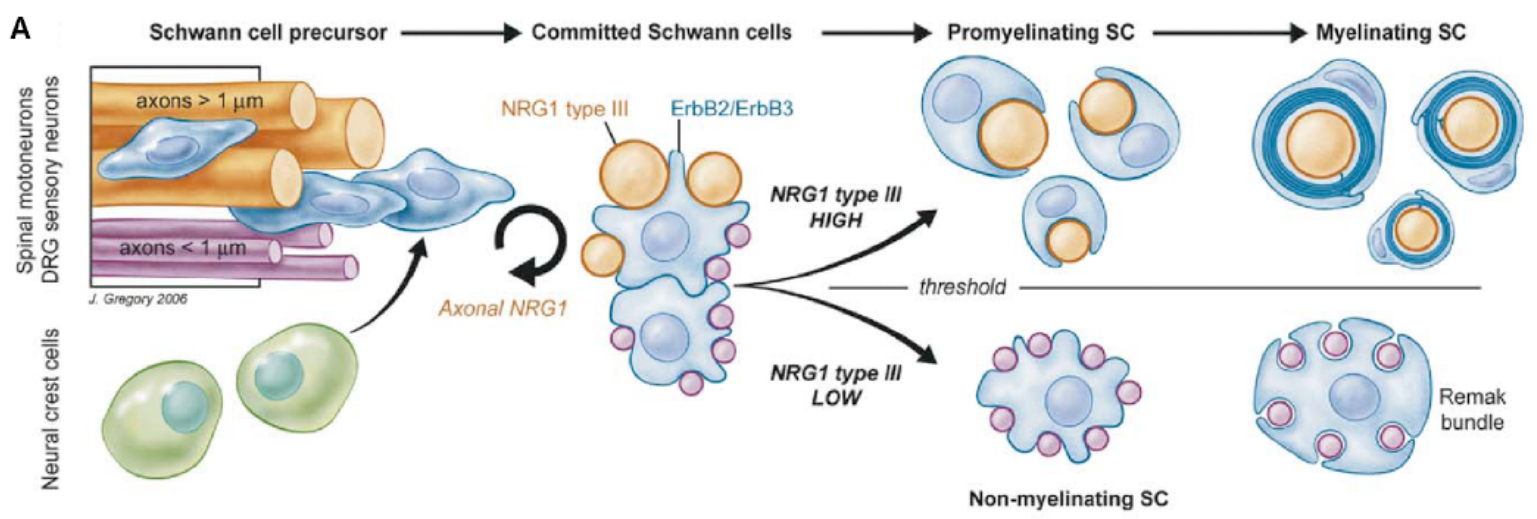

B
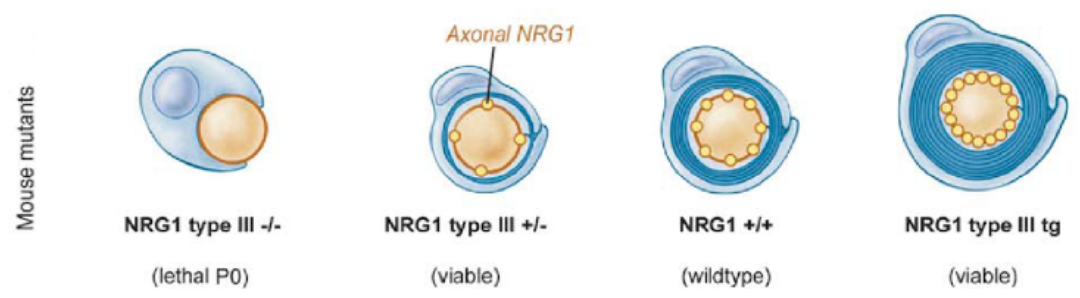

Fig. 3. Axonal NRG1 regulates successive steps of Schwann cell differentiation.

(A) Schwann cells (SC, in blue) arise from neural crest precursor cells (in green) and interact with both large and small caliber axons of spinal motor and sensory neurons. During embryogenesis, neuronal NRG1 regulates SC development by activating ErbB signaling cascades, thereby promoting SC differentiation and expansion. The amount of NRG1 type III on the axon detected by committed SC, which is a function of axon size and NRG1 levels, then drives them either into segregating single axons and myelination (top), or into a non-myelinating phenotype and formation of a Remak bundle (bottom). Above threshold levels, NRG1 type III signals axon size to SC to adjust myelin sheath thickness. (B) In mouse mutants lacking NRG1 (-/-), in heterozygous NRG1 (+/-) mice, and in transgenic NRG1 overexpressing mice, the amount of myelin made by $\mathrm{SC}$ varies directly as a function of axonal NRG1 type III levels (indicated by yellow dots) rather than as a function of axon diameter. (adapted from Nave and Salzer, 2006)

\subsubsection{Neuregulin1 in synaptic plasticity- a controversial issue}

NRG1 is expressed in the adult brain of both man and mouse (Law et al., 2004; Woo et al., 2007). In humans, NRG1 mRNA and protein have been shown to be localized to prefrontal cortex (PFC), hippocampal formation, cerebellum, and substantia nigra (Law et al., 2004). In mice, NRG1 and ErbB receptors are expressed in most of the neural cells of the adult CNS (Cannella et al., 1999; Deadwyler et al., 2000; Esper et al., 2006). NRG1/ErbB signaling appears to be critical for the normal development, fate 
determination and spatial distribution of many neural cells. In vitro NRG1 promotes the proliferation, migration, and survival of neural precursors (Lai and Feng, 2004; Rio et al., 1997). Cortical interneurons depend on NRG1 for proper migration within the telencephalon and outward toward the cortex (Flames et al., 2004). NRG1 is involved in mediating axonal pathfinding by providing a chemoattractive corridor, both paracrine and juxtacrine, for the guidance of thalamocortical projections (Lopez-Bendito et al., 2006). Finally, cultured hippocampal neurons increase neurite outgrowth, area, length, and branching when exposed to NRG1 (Gerecke et al., 2004). Studies with NRG1 mutants have also demonstrated the importance of NRG1/ErbB signaling for the generation of radial glia and their transformation into astrocytes in the cerebral cortex explant cultures (Schmid et al., 2003). While developmental studies have been essential to understand many functions of NRG1 in the nervous system, much work is still needed to determine the precise role of NRG1 in the adult CNS.

NRG1 is expressed highly in hippocampal CA3 pyramidal neurons that project to CA1 and is processed and released at synapses in an activity dependent manner (Loeb et al., 2002; Okada and Corfas, 2004). In pyramidal neurons the ErbB4 receptor is enriched in the postsynaptic density (PSD) and associates with PSD95 (Huang et al., 2000). It has been shown that PSD95 forms a ternary complex with a pair of ErbB4 receptors, suggesting that PSD95 facilitates ErbB4 dimerization. Heterologous expression of PSD95 enhanced the NRG1-mediated activation of ErbB4 and MAP kinase (Huang et al., 2000). Conversely, inhibiting the expression of PSD95 in neurons attenuated NRG1 mediated activation of MAP kinase. These observations suggest NRG1/ErbB4 signaling is regulated by PSD95 and may modulate synaptic functions (Garcia et al., 2000; Huang et al., 2000). Consistently, a number of in vitro models have suggested that NRG1/ErbB signaling modulates the expression and function of several neurotransmitter receptors in the CNS. For example, addition of recombinant NRG1 increased the mRNA levels of the NR2C subunit of the NMDA receptor (NMDAR) by over 100-fold in cerebellar slices (Ozaki et al., 1997). Another study demonstrated that bath perfusion of NRG1 significantly reduced whole-cell NMDA receptor currents in acutely isolated PFC and cultured pyramidal neurons (Gu et al., 2005). Furthermore, NRG1/ErbB4 signaling, through activation of Fyn and Pyk2 kinases, stimulates phosphorylation of a tyrosine residue (Y1472) on the NR2B subunit of NMDAR, a key regulatory site that modulates channel properties (Bjarnadottir et al., 2007). However, Kwon et al., have shown that NRG1 stimulates the internalization of surface GluR1 containing AMPA receptors and selectively reduces AMPA, but not NMDA, receptor EPSCs (Kwon et al., 2005). Moreover, Li et al. demonstrated that NRG/ErbB4 signaling is required for activity-dependent AMPA receptor synaptic 
incorporation and stabilization as well as maintenance of spine structure (Li et al., 2007). Nevertheless, NRG1 suppressed induction of long-term potentiation in the hippocampal CA1 region without affecting basal synaptic transmission (Huang et al., 2000; Kwon et al., 2005).

The significance of NRG1/ErbB signaling is beginning to be revealed not only at excitatory but also at inhibitory synapses. Accordingly, NRG1 has been shown to reduce the expression of the $\mathrm{GABA}_{\mathrm{A}}$ receptor $\alpha$ subunit and to induce the expression of the $\mathrm{GABA}_{\mathrm{A}} \beta 2$ subunits in hippocampal slices and cultured rat cerebellar granule neurons (Rieff et al., 1999; Xie et al., 2004). Recently, Woo et al., have shown that NRG1 enhances GABA release from interneurons in the prefrontal cortex. They found that ErbB4 receptors are concentrated in GABAergic nerve terminals in brain slices prepared from the PFC. NRG1 induced an increased release from the readily releasable GABA vesicle pool. Interestingly, the effect of NRG1 on GABAergic nerve terminals was dependent on activity. There was no effect of NRG1 in unstimulated preparations or on spontaneous miniature IPSPs (Woo et al., 2007). In addition, long-term exposure to NRG1 increases the number of $\alpha 7$ subunit of nicotinic acetylcholine receptors (nACh) on GABAergic interneurons in hippocampal slices (Liu et al., 2001), but short-term exposure, on a scale of seconds to minutes, decreases $\alpha 7$ currents and EPSCs (Chang and Fischbach, 2006).

Although it seems that NRG1 plays multiple function at synapses, in vivo relevance of these studies remains controversial. For instance, one of the isoform of NRG1 (acetylcholine receptor inducing activity, ARIA) was discovered as a presynaptic membrane protein of motor neurons and was shown to be essential for inducing expression and localization of acetylcholine receptors (Ach) at the neuromuscular junction (NMJ) synapse (Buonanno and Fischbach, 2001; Falls et al., 1993; Sandrock et al., 1997; Sandrock et al., 1995; Schaeffer et al., 2001). In contrast, two recent in vivo studies, using conditional null mutants of ErbB2/ErbB4 receptors, have shown that NRG/ErbB signaling is completely dispensable for NMJ synapse formation (Escher et al., 2005; Jaworski and Burden, 2006). In addition, mice lacking ErbB4 (in the nervous system) are completely normal and exhibit very subtle phenotypes (Golub et al., 2004; Thuret et al., 2004), which was quite surprising based on the several in vitro observations. Moreover, due to the embryonic lethality of the NRG1 null mutants, to understand the adult function of NRG1 several studies were carried in cell culture and on brain slices in the presence of highly potent EGF domain that might result in in vitro 'artifacts'. Furthermore, these in vitro data were extrapolated far beyond the possible physiological role of NRG1. In order to resolve some of the controversial issue and to shed some light on the physiological functions of NRG1, studies in cell-type and stage-specific conditional null mutant mice are necessary. 


\subsection{Schizophrenia and Neuregulin1}

\subsubsection{Neuregulin1 at risk haplotype for Schizophrenia}

Schizophrenia $(\mathrm{SCH})$ remains one of the mysterious and elusive diseases of the nervous system. An estimated $0.5-1 \%$ of the world's population is afflicted with severe psychological and cognitive impairments that are grouped into positive (delusions, hallucinations) and negative symptoms (social withdrawal, cognitive deficits). Currently $\mathrm{SCH}$ is considered a syndrome with no clearly reproducible neuropathological hallmarks, causative agents, or precisely defined biological markers (reviewed in Harrison, 1999; Owen et al., 2003). Although the causes of SCH are unknown, twin studies have strongly suggested that $\mathrm{SCH}$ has a genetic component as evidenced by the $\sim 50 \%$ concordance in monozygotic twins. Twin studies have also shown that SCH has a heritability of $\sim 80 \%$ (Gottesman, 1991; Owen et al., 2003). Several theories have been put forward to describe the biological components of the disease. Some studies portray SCH as a neurodegenerative disorder, while most established data suggest $\mathrm{SCH}$ to be a late onset neurodevelopmental disorder affecting (directly or indirectly) glutamatergic, dopaminergic and GABAergic cortical microcircuits, grey and white matter (Harrison and Weinberger, 2005; Owen et al., 2005a).

A relationship between NRG1 and $\mathrm{SCH}$ is not so obvious, however, the recent linkage to NRG1 in a number of schizophrenic families has led to an increased interest in NRG1 as a susceptibility factor for this psychiatric disorder (Harrison and Owen, 2003; Stefansson et al., 2002). In 2002, NRG1 was identified as a SCH susceptibility gene in a genome wide scan for SCH in families of Icelandic origin (Stefansson et al., 2002). Fine mapping of the identified locus on chromosome 8 p22 and a haplotype association analysis revealed a "core at-risk" region in the 5 ' region of the gene. This "Icelandic haplotype" surrounds the exon that encodes the NRG1 type II-specific domain. Several (but not all) subsequent studies have replicated, at least partially, the association of NRG1 and SCH in different populations (Harrison and Weinberger, 2005). However, none of the identified atrisk haplotypes maps to the coding region of the NRG1 gene, suggesting that changes in NRG1 expression levels, rather than altered protein function, contribute to disease susceptibility. It is important to note that overall only up to $15 \%$ of schizophrenic patients carry the at-risk haplotype (as compared to $5-7 \%$ in healthy controls), clearly demonstrating that additional genetic and environmental risk factors must contribute to the onset of the disorder. Moreover, such association studies only demonstrate that a given genetic locus is associated with $\mathrm{SCH}$, and do not necessarily implicate a direct causal 
effect of the gene or its protein products. In order to dissect the genetic component of the disease mechanism one simple approach is to study genes identified by genome wide scans that have biological roles overlapping with current ideas of SCH etiology (Fig. 4).

How might variations in the NRG1 gene impact on an increased susceptibility for schizophrenia? Intriguingly, the spectrum of CNS functions assigned to NRG1 (based mostly on in vitro observations) implies that NRG1 acts as a regulator of several developmental processes (e. g. neuronal migration, synaptogenesis, myelination and synaptic plasticity), which might be altered in SCH (Fig. 4) (see reviews by Corfas et al., 2004; Owen et al., 2005b; Stefansson et al., 2004; Weinberger, 2005).

\subsubsection{Schizophrenia and white matter- does Neuregulin1 matter?}

Although patients suffering from SCH don't have clear white matter pathology, there are several evidences that support possible damages in the white matter of certain brain areas. In the human brain myelination continues well into adulthood, most evidently in frontal and temporal lobes (Bartzokis, 2002). Several recent studies have suggested white matter changes in $\mathrm{SCH}$, including a reduction in OL number and myelin content and damage in myelin sheath lamellae in the neocortex (Corfas et al., 2004; Stewart and Davis, 2004). In the PFC of SCH patients, light and electron microscopic studies have revealed a significant decrease in the density of OL mitochondria, as well as signs of apoptosis and necrosis of OL (Uranova et al., 2001). A recent stereologic analysis of OL in cortical layer 3 and gyral white matter of area 9 showed 30\% fewer OL in $\mathrm{SCH}$ patients compared to healthy controls (Hof et al., 2002; Hof et al., 2003). Furthermore, OL exhibited a less clustered arrangement and were reduced by $25 \%$ in cortical layer 6 of schizophrenic patients (Hof et al., 2003). Magnetic resonance imaging and diffusion tensor magnetic resonance (an imaging technique to quantify anisotropic diffusion in white matter) have also revealed alterations in white matter integrity as well as a reduction of myelin content in the temporal and frontal lobes (Bartzokis et al., 2003; Flynn et al., 2003; Foong et al., 2002). In addition to structural alterations in white matter, microarray analysis has revealed a downregulation of oligodendrocyte-related mRNA species within the dorsolateral prefrontal cortex of SCH patients (Hakak et al., 2001). Genes involved in the compaction of myelin and axon-glia interactions showed reduced expression in affected individuals, further supporting a role for OL in SCH (Pongrac et al., 2002; Tkachev et al., 2003). There is some in vitro evidence that support NRG1/ErbB signaling plays a role in OL development and CNS myelination (Calaora et al., 2001; Canoll et al., 1996; Raabe et al., 1997b; Sussman et al., 2005). Thus defective NRG1/ErbB signaling might result in alterations of OL development and abnormal myelination, possibly contributing to the some of the 
pathophysiological features of SCH.

\subsubsection{Possible role of NRG1 in schizophrenia}

The observed effects of NRG1 on the regulation of neurotransmitter receptors makes it an attractive candidate gene to further examine its role in SCH. Parallels exist between the effects of NRG1 on the expression of NMDA receptors and reduced levels of NMDA receptor subunits in several regions of brain tissue from those with $\mathrm{SCH}$ (Akbarian et al., 1996; Carlsson and Carlsson, 1990). In addition, behavioral studies on mice support a potential role of NRG1 in the susceptibility to $\mathrm{SCH}$. Mutant mice heterozygous for either NRG1 or ErbB4 showed a behavioral phenotype that overlapped with pharmacologically induced "mouse models" of SCH (Boucher et al., 2007; Karl et al., 2007; O'Tuathaigh et al., 2007a; O'Tuathaigh et al., 2007b; O'Tuathaigh et al., 2008; Stefansson et al., 2002). This includes hyperactivity and deficiencies in prepulse inhibition, a measure of sensory gating that is abnormal in SCH. These behavioural phenotypes of NRG1 hypomorphs were partially reversible with clozapine, an atypical antipsychotic drug used to treat $\mathrm{SCH}$.

In line with the described function of NRG1 in regulation of NMDA receptors, NRG1 hypomorphic mice had 16\% less functional NMDA receptors compared to wildtype controls (Stefansson et al., 2002). Moreover it was shown that the NR2B subunit of the NMDAR (at Y1472) is hypophosphorylated in NRG1 and ErbB4 hypomorphs, which can be recovered by the treatment with clozapine at doses that reverse behavioral abnormalities. NRG1 hypomorphs also show altered hippocampal short-term synaptic plasticity and impaired theta-burst long-term potentiation. Incubation of hippocampal slices from these mice with NRG1 reversed those effects (Bjarnadottir et al., 2007). Recently, Roy et al., have analyzed transgenic mice that overexpress a dominant negative form of ErbB4 receptors and therefore lack normal NRG/ErbB signaling. These mice have increased levels of dopamine receptors and transporters and exhibit behavioral phenotype overlapping with that of SCH "mouse models" (Roy et al., 2007). 


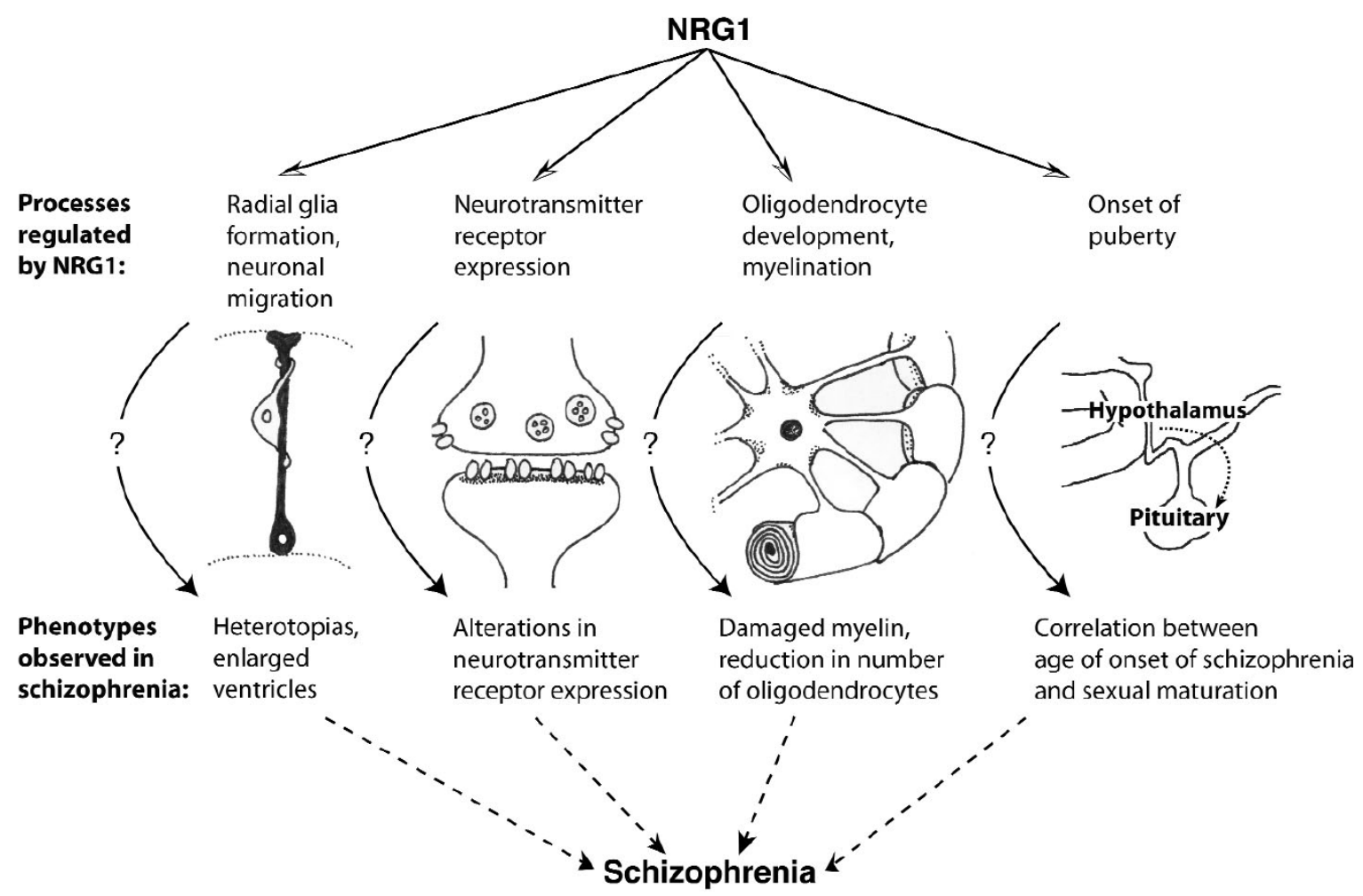

Fig. 4. Possible relationships between NRG1 function and schizophrenia endophenotypes.

NRG1 has been implicated in cortical development by regulating radial glia morphology and neuronal migration, in synapse formation and function by regulating the expression of glutamate, GABA and Ach receptors, in myelination by regulating oligodendrocyte proliferation and differentiation, and in the control of the onset of puberty through the induction of LHRH release in the hypothalamus. All these developmental processes have been proposed to be altered in schizophrenia. Thus, defects in NRG1/ErbB signaling can potentially contribute to schizophrenia (or some aspects of the disease) by altering one or more of these processes. Question marks indicate the current hypothetical nature of these possible links between NRG1 function and schizophrenia (adapted from Corfas et al., 2004).

In addition to glutamate and dopamine, there is some evidence that implicates GABA hypofunction in SCH (Lewis and Moghaddam, 2006). In one very speculative scenario, the SCH risk haplotypes might result in NRG1 hypofunction, leading to a decrease in the efficacy of glutamate and GABA-mediated synaptic transmission in the prefrontal cortex (discussed above). This impairment would then produce desynchronized firing of pyramidal neurons, the loss of gamma waves recorded from the brain surface, and behavioral deficits in working memory. Likewise, other neurotransmitters are certainly involved in the full complex of symptoms that comprise $\mathrm{SCH}$. Neuroleptic drugs that relieve psychotic and other positive symptoms of $\mathrm{SCH}$ are dopamine-receptor antagonists, and dopamine is a prime suspect in the striatum and PFC (Fischbach, 2007). Thus, the exact role for NRG1 in the etiology or treatment of $\mathrm{SCH}$ is not clear. Future studies will be needed to develop a better understanding of the effects of local NRG1 expression in the 
CNS and on its downstream signaling pathways.

In summary, we can conclude that NRG1/ErbB signaling in the CNS has a broad spectrum of functions including myelination, neuronal migration, axonal pathfinding, synaptogenesis and synaptic function (Corfas et al., 2004; Esper et al., 2006; Flames et al., 2004; Hahn et al., 2006; Lopez-Bendito et al., 2006; Nave and Salzer, 2006). Unfortunately, understanding the in vivo relevance of NRG1/ErbB signaling has been greatly hampered by the embryonic lethality of null mutations of NRG1 and its receptors (Adlkofer and Lai, 2000; Garratt et al., 2000b). To determine the consequences of altered NRG1/ErbB signaling on brain development we generated and analyzed a large battery of mice with various conditional Nrg1 null mutations (defined by Cre-recombination at different stages of development). 
3. Materials and Methods 


\subsection{Materials}

\subsubsection{Kits and chemicals}

All chemicals were purchased from the Sigma-Aldrich and Merck unless stated otherwise. DNA purification kits and other molecular biology kits were purchased from Qiagen, Invitek, Promega, Stratagene and Sigma-Aldrich. General laboratory materials were from Falcon, Nunc and Eppendorf was used.

Websites referred for online protocols

http://mrw.interscience.wiley.com/emrw/9780471142300/home/ (Neuroscience) http://mrw.interscience.wiley.com/emrw/9780471142720/home/ (Molecular biology) http://mrw.interscience.wiley.com/emrw/9780471140863/home/ (Protein Science)

\subsubsection{Molecular biology buffers and stock solutions}

50x TAE buffer

$2.0 \mathrm{M}$

Tris-Acetate, $\mathrm{pH} 8.0$

$50 \mathrm{mM}$ EDTA

$57.1 \mathrm{ml}$ glacial acetic acid

Adjust volume to $1000 \mathrm{ml}$ with $\mathrm{H}_{2} \mathrm{O}$

1x TE buffer

$10 \mathrm{mM}$

Tris-HCl, $\mathrm{pH} 8.0$

$1.0 \mathrm{mM}$

EDTA

10x modified Gitschier buffer (MGB)
$6.7 \mathrm{ml}$
1M Tris- $\mathrm{HCl}, \mathrm{pH} 8.8$
$1.66 \mathrm{ml}$
$1 \mathrm{M}(\mathrm{NH} 4) 2 \mathrm{SO} 4$
$650 \mu 1$
$1 \mathrm{M} \mathrm{MgCl} 2$

Adjust final volume to $10 \mathrm{ml}$ with $\mathrm{H} 2 \mathrm{O}$

1x MGB buffer (Working solution)

$1 \mathrm{ml} \quad 10 \mathrm{x}$ MGB

$100 \mu 1 \quad \beta$-mercaptoethanol

$500 \mu 1 \quad 10 \%$ Triton X-100

$8.4 \mathrm{ml} \quad \mathrm{H}_{2} \mathrm{O}$ 
TENS buffer

$50 \mathrm{mM}$

Tris-HCl, $\mathrm{pH} 8.0$

$0.1 \mathrm{M}$

EDTA

$0.1 \mathrm{M}$

sodium chloride

$1.0 \%$

SDS

$1 \%$ Ethidiumbromide (stock)

$1 \mu \mathrm{l} / \mathrm{ml}$ of agarose gels (in $1 \mathrm{x}$ TAE)

$100 \mathrm{mM}$ dNTP (stock)

$25 \mathrm{mM}$ each dATP, dCTP, dGTP, dTTP

\subsubsection{Protein biochemistry buffers and solutions}

Modified RIPA buffer (protein lysis buffer)

$\begin{array}{ll}50 \mathrm{mM} & \text { Tris-HCl, } \mathrm{pH} 7.4 \\ 150 \mathrm{mM} & \text { sodium chloride } \\ 1.0 \mathrm{mM} & \text { EDTA } \\ 0.1 \% & \text { SDS } \\ 1.0 \% & \text { sodium deoxycholate } \\ 1.0 \% & \text { TritonX-100 }\end{array}$

Phosphatase inhibitors
$1.0 \mathrm{mM}$
sodium orthovanadate
$0.5 \mathrm{mM}$
zinc chloride
$4.0 \mathrm{mM}$
sodium pyrophosphate
$1.0 \mathrm{mM}$
sodium fluoride

Protease inhibitors
$1.0 \mathrm{mM}$
PMSF
1.0 tablet
Complete Mini protease inhibitor (Roche)

* phosphatase and protease inhibitors are added freshly to the RIPA buffer before use.

Homogenization Buffer (complete)

$\begin{array}{ll}4.0 \mathrm{mM} & \text { Hepes} / \mathrm{HaOH} \mathrm{pH} 7.4 \\ 320 \mathrm{mM} & \text { Sucrose } \\ 5.0 \mathrm{mM} & \text { EDTA }\end{array}$

* phosphatase and protease inhibitors are added freshly to the buffer before use.

* $5 \mathrm{ml}$ of Homogenization buffer is sufficient for a mouse brains. 
1X IP buffer

$20 \mathrm{mM}$

Hepes/HaOH pH 7.4

$150 \mathrm{mM}$

$\mathrm{NaCl}$

$5 \mathrm{mM}$

EDTA

$1 \%$

Triton X-100

* phosphatase and protease inhibitors are added freshly to the buffer before use.

2X IP buffer

$40 \mathrm{mM}$

Hepes/HaOH pH 7.4

$300 \mathrm{mM}$

$\mathrm{NaCl}$

$2 \%$

Triton X-100

$10 \mathrm{mM}$

EDTA

*phosphatase and protease inhibitors are added freshly (in $2 \mathrm{x}$ conc.) to the buffer before use.

\subsubsection{SDS PAGE and Western Blotting}

$4 \mathrm{x}$ Tris-HCl/SDS (Separating gel buffer)

$1.5 \mathrm{M} \quad$ Tris-HCl, $\mathrm{pH} 8.8$

$0.4 \% \quad$ sodium dodecyl sulphate (SDS)

$4 \mathrm{x}$ Tris-HCl/SDS (Stacking gel buffer)

$0.5 \mathrm{M} \quad$ Tris-HCl, $\mathrm{pH} 6.8$

$0.4 \% \quad$ sodium dodecyl sulphate (SDS)

$8.0 \%$ Polyacrylamide separating gel (4 gels of $0.75 \mathrm{~mm}$ thick)

$9.1 \mathrm{ml}$

$\mathrm{H}_{2} \mathrm{O}$

$5.0 \mathrm{ml} \quad 30 \%$ acrylamide/bis-acrylamide (29:1)-sigma

$4.7 \mathrm{ml} \quad 4 \mathrm{x}$ Tris-HCl/SDS (Separating gel buffer)

$50 \mu \mathrm{l} \quad 10 \%$ ammonium persulphate (APS)

$10 \mu 1 \quad$ TEMED (Biorad)

$0.13 \%$ Polyacrylamide stacking gel (4 gels of $0.75 \mathrm{~mm}$ thick)

$3.05 \mathrm{ml}$

$650 \mu 1$

$1.25 \mathrm{ml}$

$25 \mu 1$

$10 \mu 1$
$\mathrm{H}_{2} \mathrm{O}$

30\% acrylamide/bis-acrylamide (29:1)-sigma

4x Tris-HCl/SDS (Stacking gel buffer)

$10 \%$ ammonium persulphate (APS)

TEMED (Biorad) 
6x SDS sample buffer

$7.0 \mathrm{ml}$

0.5M Tris- $\mathrm{HCl}$ buffer, $\mathrm{pH} 6.8$

$3.0 \mathrm{ml}$

glycerol (30\% f.c.)

$1.0 \mathrm{~g}$

SDS

$1.2 \mathrm{ml}$

1\% Bromophenol Blue

Store in $1 \mathrm{ml}$ aliquots at $-20^{\circ} \mathrm{C}$

10x SDS running buffer (Laemmli buffer)

$\begin{array}{ll}250 \mathrm{mM} & \text { Tris base } \\ 1.92 \mathrm{M} & \text { glycine } \\ 1.0 \% & \text { SDS }\end{array}$

Do not adjust $\mathrm{pH}$

Coomassie blue (Staining solution)

$2.0 \mathrm{~g} \quad$ coomassie brilliant blue (R-250)

$1.0 \mathrm{~L}$ methanol

$200 \mathrm{ml} \quad$ acetic acid

$800 \mathrm{ml} \quad \mathrm{H}_{2} \mathrm{O}$

Stir for a minimum overnight and filter through Whatman paper.

Destaining solution

$50 \mathrm{ml}$

methanol

$10 \mathrm{ml}$

acetic acid and

$40 \mathrm{ml}$

$\mathrm{H}_{2} \mathrm{O}$

1x Transfer buffer

$48 \mathrm{mM}$

Tris base

$39 \mathrm{mM}$

glycine

$20 \%$

methanol

20x Tris buffered saline (TBS)
$1.0 \mathrm{M}$
Tris base
$3.0 \mathrm{M}$
sodium chloride

Adjust pH 7.4 (fuming $\mathrm{HCl}$ )

1x TBS with Tween-20 (TBST)

$50 \mathrm{mM}$

Tris- $\mathrm{HCl}(\mathrm{pH}$ 7.4-7.6)

$150 \mathrm{mM}$

sodium chloride

$0.05 \%$

Tween-20 
10x Phosphate buffered saline (PBS)
$1.7 \mathrm{M}$
sodium chloride
$34 \mathrm{mM}$
potassium chloride
$40 \mathrm{mM}$
di-sodiumhydrogenphosphate. $2 \mathrm{H}_{2} \mathrm{O}$
$18 \mathrm{mM}$
potassiumdihydrogenphosphate

Adjust pH 7.2 with $1 \mathrm{~N} \mathrm{NaOH}$.

Western blot stripping buffer
$0.2 \mathrm{M}$
Glycine- $\mathrm{HCl}, \mathrm{pH} 2.5$
$0.1 \%$
Tween-20

Blocking buffer

$5 \%$ non-fat dry Milk powder in 1x TBS or 1x TBST

$10 \%$ ammonium persulfate (APS)

* Labile do not store more than a week at $4{ }^{\circ} \mathrm{C}$.

\subsubsection{DNA and Protein markers}

DNA-marker Lambda/HindIII

Promega

GeneRuler $1 \mathrm{~kb}$ DNA ladder

Fermentas

GeneRuler 100 bp DNA ladder

Fermentas

Precision Plus prestained protein standard

BioRad

\subsubsection{Immunohistochemistry buffers and buffers}

Phosphate buffer (Stock Solutions)

$0.2 \mathrm{M}$

sodiumdihydrogenphosphate $\left(\mathrm{NaH}_{2} \mathrm{PO}_{4}\right)$

$0.2 \mathrm{M}$

di-sodiumhydrogenphosphate $\left(\mathrm{Na}_{2} \mathrm{HPO}_{4}\right)$

Working Solution ( $\mathrm{pH} 7.4$ )

$20 \mathrm{ml}$

$0.2 \mathrm{M}$ sodiumdihydrogenphosphate $\left(\mathrm{NaH}_{2} \mathrm{PO}_{4}\right)$

$80 \mathrm{ml}$

$0.2 \mathrm{M}$ di-sodiumhydrogenphosphate $\left(\mathrm{Na}_{2} \mathrm{HPO}_{4}\right)$

$100 \mathrm{ml}$

$\mathrm{H}_{2} \mathrm{O}$

Bovine Serum Albumin (PBS/BSA)

$20 \mathrm{ml}$

$0.2 \mathrm{M}$ Sodiumdihydrogenphosphate $\left(\mathrm{NaH}_{2} \mathrm{PO}_{4}\right)$

$80 \mathrm{ml}$

$0.2 \mathrm{M}$ di-Sodiumhydrogenphosphate $\left(\mathrm{Na}_{2} \mathrm{HPO}_{4}\right)$

$1.8 \mathrm{~g}$ sodium chloride

$1.0 \mathrm{~g}$

Bovines Serum Albumin (BSA) and

$100 \mathrm{ml}$

$\mathrm{H}_{2} \mathrm{O}$ 


$$
\begin{array}{ll}
4 \% \text { Paraformaldehye (PFA) } \\
100 \mathrm{ml} & 0.2 \mathrm{M} \text { Sodiumdihydrogenphosphate } \\
400 \mathrm{ml} & 0.2 \mathrm{M} \text { di-Sodiumhydrogenphosphate } \\
108 \mathrm{ml} & 37 \% \text { formalin } \\
392 \mathrm{ml} & \mathrm{H}_{2} \mathrm{O}
\end{array}
$$

Filtered through $500 \mathrm{ml}$ Nalgene sterile filter unit.

Karlsson-Schultz Fixative (Electron Microscopy):

$20 \mathrm{ml} \quad 0.2 \mathrm{M}$ Sodiumdihydrogenphosphate $\left(\mathrm{NaH}_{2} \mathrm{PO}_{4}\right)$

$80 \mathrm{ml} \quad 0.2 \mathrm{M}$ di-Sodiumhydrogenphosphate $\left(\mathrm{Na}_{2} \mathrm{HPO}_{4}\right)$

$1.0 \mathrm{~g} \quad$ sodium chloride (f.c. $0.5 \%$ )

$50 \mathrm{ml} \quad 16 \%$ PFA (f.c. $4 \%$ )

$20 \mathrm{ml} \quad 25 \%$ Glutraldehyde (f.c. $2.5 \%$ )

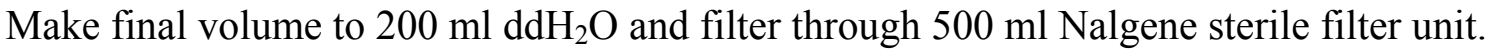
$16 \%$ PFA is freshly prepared.

Citrate Buffer (Stock Solutions)
$0.1 \mathrm{M}$
citric acid $\left(\mathrm{C}_{6} \mathrm{H}_{8} \mathrm{O}_{7} \cdot \mathrm{H}_{2} \mathrm{O}\right)$
$0.1 \mathrm{M}$
sodium citrate $\left(\mathrm{C}_{6} \mathrm{H}_{5} \mathrm{O}_{7} \mathrm{Na}_{3} .2 \mathrm{H}_{2} \mathrm{O}\right)$

*Stored at $4{ }^{\circ} \mathrm{C}$.

Working Solution (0.01 M pH 6.0)

$9.0 \mathrm{ml}$

$0.1 \mathrm{M}$ citric acid $\left(\mathrm{C}_{6} \mathrm{H}_{8} \mathrm{O}_{7} . \mathrm{H}_{2} \mathrm{O}\right)$

$41 \mathrm{ml}$

$0.1 \mathrm{M}$ sodium citrate $\left(\mathrm{C}_{6} \mathrm{H}_{5} \mathrm{O}_{7} \mathrm{Na}_{3} .2 \mathrm{H}_{2} \mathrm{O}\right)$

$450 \mathrm{ml}$

$\mathrm{H}_{2} \mathrm{O}$

*Always prepared freshly

Tris Buffer (Stock Solution)

$0.5 \mathrm{M} \quad$ Tris base

Adjust $\mathrm{pH} 7.6$ with $\mathrm{HCl}$. Store at $4{ }^{\circ} \mathrm{C}$.

Working Solution

$\begin{array}{ll}100 \mathrm{ml} & 0.5 \mathrm{M} \text { Tris base }(\mathrm{pH} \mathrm{7.6)} \\ 9.0 \mathrm{~g} & \text { sodium chloride }\end{array}$

Adjust the final volume to $1000 \mathrm{ml}$ with $\mathrm{H}_{2} \mathrm{O}$ and always prepared freshly.

2\% Milk-powder in Tris Buffer

$20 \mathrm{~g}$ of Fat free milk powder and adjust final volume to $1000 \mathrm{ml}$ with working solution of Tris buffer. 


\subsubsection{Buffers for IHC of vibrotome sections}

Permeabilization buffer

$0.4 \%$ Triton ( $1 \mathrm{x}$ PBS)

$4 \mathrm{ml}$

4\% TritonX-100

$36 \mathrm{ml}$

1x PBS

Blocking buffer

$4 \%$ Horse-Serum (HS) in $0.2 \%$ TritonX-100

$800 \mu 1 \quad$ HS

$10 \mathrm{ml} \quad 0.4 \%$ TritonX-100 (1x PBS)

$9.2 \mathrm{ml} \quad 1 \times$ PBS

Primary antibody diluent

$1 \%$ HS in $0.05 \%$ TritonX-100

$2.5 \mathrm{ml}$

$4 \% \mathrm{HS}$ in $0.2 \%$ Triton

$7.5 \mathrm{ml}$

1x PBS

Secondary antibody diluent

$1.5 \%$ HS (1x PBS)

$150 \mu 1 \quad$ HS

$9850 \mu 1 \quad 1 x$ PBS

\subsubsection{Bacterial culture media}

LB medium

$\begin{array}{ll}1 \% & \text { Bacto Tryptone } \\ 0.5 \% & \text { Bacto Yeast extract } \\ 1 \% & \mathrm{NaCl}\end{array}$

Make $1000 \mathrm{ml}$ with $\mathrm{H}_{2} \mathrm{O}$, set $\mathrm{pH}$ 7,5 with $10 \mathrm{~N} \mathrm{NaOH}$ and autoclave.

For selective LB media the following antibiotics were used:

$\begin{array}{ll}150 \mathrm{mg} / 1 & \text { Ampicillin } \\ 50 \mathrm{mg} / 1 & \text { Chloramphenicol } \\ 25 \mathrm{mg} / 1 & \text { Kanamycin }\end{array}$

LB plates

$1.2 \% \quad$ Bacto-agar

Autoclave, cool to $\sim 55^{\circ} \mathrm{C}$ in a waterbath, add desired antibiotic. Store plates at $4^{\circ} \mathrm{C}$.

Bacterial strains

Escherichia coli DH5a, XL1-Blue and EL-250 
Plasmids

pBluescript KS Fermentas

pFRTNeo Stratagene

\subsubsection{Histological stains and reagents}

Mayer's Haematoxylin solution

$1.0 \mathrm{~g}$ Haematoxylin in $1000 \mathrm{ml} \mathrm{H}_{2} \mathrm{O}$ was dissolved. $0.2 \mathrm{~g}$ sodium iodate and $50 \mathrm{~g}$ potassium aluminium sulphate $\left(\mathrm{K}_{2} \mathrm{Al}_{2}\left(\mathrm{SO}_{4}\right)_{4} \cdot 24 \mathrm{H}_{2} \mathrm{O}\right)$ was added under constant shaking whereby solution takes a violet blue hue. Finally, $50 \mathrm{~g}$ chloralhydrate and $1 \mathrm{~g}$ citric acid was added, this makes blue colouration of the solution permanent. Always filter the solution before use.

* Mayer's Haematoxylin solution purchased from Merck.

Eosin solution

10x Stock Solution: Dissolve $10 \mathrm{~g}$ of Eosin in $100 \mathrm{ml}$ of MiliQ water and leave the above solution for maturation.

Working Solution: To $250 \mathrm{ml}$ of $\mathrm{ddH}_{2} \mathrm{O}$ water add $2.5 \mathrm{ml}$ of stock solution and 12 drops of glacial acetic.

Scott's solution

$2 \mathrm{~g} \quad$ potassiumhydrogencarbonate

$20 \mathrm{~g} \quad$ magnesium sulphate

Adjust final volume to $1000 \mathrm{ml}$ with $\mathrm{H}_{2} \mathrm{O}$

HCl- Alcohol

$\begin{array}{ll}1.25 \mathrm{ml} & \mathrm{HCl} \\ 350 \mathrm{ml} & \text { ethanol } \\ 150 \mathrm{ml} & \mathrm{H}_{2} \mathrm{O}\end{array}$

$0.5 \%$ Cresyl violet (Nissl Stain)

$2.5 \mathrm{~g} \quad$ cresyl violet

$100 \mathrm{ml} \quad 2.72 \%$ sodium acetate

$400 \mathrm{ml} \quad 1.2 \%$ acetic acid

Filter freshly before use. $\mathrm{pH} \sim 3.8-4.0$ 


\subsubsection{Reagents for Gallyas silver impregnation for myelin}

Incubation solution
$1.0 \mathrm{~g}$
ammonium nitrate
$1.0 \mathrm{~g}$
silver nitrate

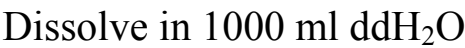

$3.0 \mathrm{ml} \quad 4 \%$ sodium hydroxide $(\mathrm{pH} 7.4-7.6)$

*brown precipitate formed can be dissolved by shaking. Solution can be used for 8-10 weeks.

Physical developer

Solution A

$5 \%$ sodium carbonate (dehydrated) in $\mathrm{H}_{2} \mathrm{O}$

Solution B

$2.0 \mathrm{~g} \quad$ ammonium nitrate

$2.0 \mathrm{~g} \quad$ silver nitrate

$10 \mathrm{~g} \quad$ wolframosilicic acid (silicotungstic acid)

Dissolve in $1000 \mathrm{ml} \mathrm{ddH_{2 } \mathrm { O }}$

Solution C

$2.0 \mathrm{~g} \quad$ ammonium nitrate

$2.0 \mathrm{~g} \quad$ silver nitrate

$10 \mathrm{~g} \quad$ wolframosilicic acid (silicotungstic acid)

$7.0 \mathrm{ml} \quad$ formalin (37\% paraformaldehyde)

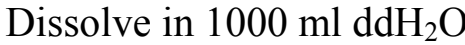

*To reconstitute physical developer, take $100 \mathrm{ml}$ of solution A in a clean flask, add $70 \mathrm{ml}$ of solution B with constant and gentle shaking and then slowly add solution $\mathrm{C}$ with gently shaking.

Fixing solution

$2 \%$ sodium thiosulphate

\subsubsection{Reagents for Bielschowsky silver impregnation of axons}

$10 \%$ silver nitrate

$10 \mathrm{~g}$ silver nitrate dissolved in $100 \mathrm{ml} \mathrm{dd} \mathrm{H}_{2} \mathrm{O}$

Developer

$20 \mathrm{ml}$ formalin (37\% paraformaldehyde)

$100 \mathrm{ml}$ $\mathrm{ddH}_{2} \mathrm{O}$ 
$\begin{array}{ll}1 \text { drop } & \text { nitric acid (conc.) } \\ 0.5 \mathrm{~g} & \text { citric acid }\end{array}$

Fixing solution

$5 \%$ sodium thiosulphate

$\beta$-gal staining buffer (stock solutions)

$500 \mathrm{mM}$ potassium ferricyanid (in PBS)

$500 \mathrm{mM}$ potassium ferrocyanid (in $\mathrm{PBS}$ )

$2 \mathrm{mM}$ magnesium chloride $\left(\mathrm{MgCl}_{2}\right)$

$20 \mathrm{mg} / \mathrm{ml}$ $\mathrm{X}$-gal (in DMSO)

Working solution

$5 \mathrm{mM}$

potassium ferricyanid

$5 \mathrm{mM}$ potassium ferrocyanid

$2 \mathrm{mM}$ $\mathrm{MgCl}_{2}$

$600 \mu 1$ X-gal (f.c. $1.2 \mathrm{mg} / \mathrm{ml}$ )

Adjust final volume to $10 \mathrm{ml}$ with 1x PBS

\subsubsection{Enzymes}

All Restriction enzymes used were purchased from New England Biolabs (NEB) and Promega. Enzymes were provided with their optimal 10x buffers and 100x BSA (if needed). Other enzymes used for molecular cloning were purchased from the vendors mentioned beside each of them.

Pfu high fidelity DNA polymerase

RedTaq DNA polymerase

Stratagene

GoTaq DNA polymerase

HotStar Hifidelity DNA polymerase

Sigma

Promega

Power SYBR Green PCR master mix

Qiagen

T4 DNA ligase

Applied Biosystems

T4 polynucleotide kinase

Promega

CIP (alkaline phosphatase) $(1 \mathrm{U} / \mu \mathrm{l})$

Promega

Roche

\subsubsection{Antibodies}

\begin{tabular}{|c|c|c|c|c|}
\hline Antibody & Species & Dilution & Purpose & Vendor \\
\hline APP & $\mathrm{mM}$ & $1: 750$ & IHC & Chemicon \\
\hline Calretinin & $\mathrm{pRb}$ & $1: 1000$ & IHC & Chemicon \\
\hline Cam KinaseII $\alpha$ & $\mathrm{mM}$ & $1: 10,000$ & IB & Santa cruz biotechnology \\
\hline CNP & $\mathrm{mM}$ & $1: 150,1: 5000$ & IHC/IB & Sigma \\
\hline
\end{tabular}




\begin{tabular}{|c|c|c|c|c|}
\hline ErbB2 & $\mathrm{pRb}$ & $1: 1000$ & IB & Cell signalling \\
\hline ErbB4 & $\mathrm{pRb}$ & $1: 1000$ & IB/IP & Santa cruz \\
\hline FNP7 & $\mathrm{mM}$ & $1: 100$ & $\mathrm{IHC}$ & Zytomed systems \\
\hline $\mathrm{GABA}_{\mathrm{A}} \mathrm{R} \alpha 1$ & goat & $1: 150$ & IB & Santa cruz biotechnology \\
\hline GAD65 & $\mathrm{pRb}$ & $1: 10,000$ (IB) & IB & Chemicon \\
\hline GAD67 & $\mathrm{mM}$ & $1: 1000,1: 5000(\mathrm{IB})$ & $\mathrm{IHC} / \mathrm{IB}$ & Chemicon \\
\hline GAPDH & $\mathrm{mM}$ & $1: 2000$ & IB & Advanced Immunochem \\
\hline GFAP & $\mathrm{pRb}$ & $1: 200$ & $\mathrm{IHC}$ & DAKO \\
\hline GluR1 & $\mathrm{pRb}$ & $1: 1000$ & IB & Chemicon \\
\hline GluRD & $\mathrm{pRb}$ & $1: 600$ & IB & Chemicon \\
\hline Krox 20 & $\mathrm{pRb}$ & $1: 400$ & IHC & Dies Meijer \\
\hline Mac3 & mRat & $1: 500$ & IHC & Pharmingen \\
\hline MAG & $\mathrm{mM}$ & $1: 1000$ & IB & Chemicon \\
\hline MBP & $\mathrm{pRb}$ & $1: 200,1: 5000$ (IB) & $\mathrm{IHC} / \mathrm{IB}$ & DAKO \\
\hline nAcetylcholine $\alpha 7$ & $\mathrm{mM}$ & $1: 1000$ & IB & Covance \\
\hline NeuN & $\mathrm{mM}$ & $1: 100$ & IHC & Chemicon \\
\hline NF200 & $\mathrm{pRb}$ & $1: 200$ & IHC & Sigma \\
\hline NMDAR1 & $\mathrm{mM}$ & $1: 7000$ & IB & Synaptic Systems \\
\hline NMDAR2B & $\mathrm{pRb}$ & $1: 2000$ & IB & Chemicon \\
\hline NMDAR2B(phos) & $\mathrm{pRb}$ & $1: 1000$ & IB & Chemicon \\
\hline NRG1 & $\mathrm{pRb}$ & $1: 500$ & IB & Santa cruz biotechnology \\
\hline Olig2 & $\mathrm{pRb}$ & $1: 20,000$ & $\mathrm{IHC}$ & C. Stiles \\
\hline P0 & $\mathrm{mM}$ & $1: 000$ & $\mathrm{IHC}$ & J.J Archelos \\
\hline pAkt (ser473) & $\mathrm{pRb}$ & $1: 1000$ & IB & Cell signalling \\
\hline Parvalbumin & $\mathrm{pRb}$ & $1: 200 / 1: 1000$ (IB) & $\mathrm{IHC} / \mathrm{IB}$ & Swant \\
\hline PLP (A431) & $\mathrm{pRb}$ & $1: 600$ & IHC & K.-A. Nave \\
\hline PLP(3F4) & $\mathrm{mM}$ & $1: 100$ & IB & M. Lees \\
\hline PSD95 & $\mathrm{mM}$ & $1: 10,000$ & IB & Upstate \\
\hline Synaptophysin & $\mathrm{mM}$ & $1: 10,000$ & IB & Synaptic Systems \\
\hline$\alpha$-tubulin & $\mathrm{mM}$ & $1: 5000$ & IB & Sigma \\
\hline Vglut2 & gp & $1: 4000$ & $\mathrm{IHC}$ & Chemicon \\
\hline$\alpha$-rabbit-HRP & goat & $1: 5000$ & IHC & Dianova \\
\hline$\alpha$-rabbit-cy3/cy2 & goat & $1: 1000 / 1: 100$ & IHC & Dianova \\
\hline$\alpha$-mouse-HRP & goat & $1: 10,000$ & IHC & Dianova \\
\hline$\alpha$-mouse-cy3/cy2 & goat & $1: 1000 / 1: 100$ & IHC & Dianova \\
\hline
\end{tabular}

*IB-immnuoblotting, IHC-immunohistochemistry 


\subsubsection{Mouse lines}

\begin{tabular}{|c|c|c|c|}
\hline Mouse line & Expression time & Expression pattern & Publication \\
\hline Nestin-Cre & $\sim$ E9 & Subventricular zone cells & (Tronche et al., 1999) \\
\hline Emx1-Cre & $\sim$ E10.5 & Forebrain precursors & (Gorski et al., 2002) \\
\hline Nex-Cre & $\sim$ E12.5 & Postmitotic neurons & (Goebbels et al., 2006) \\
\hline Cam KinaseII $\alpha-C r e$ & $\sim$ P10 & Pyramindal neurons & (Minichiello et al., 1999) \\
\hline Nex-CreERT2 & Inducible & Postmitotic neurons & Current study \\
\hline pan NeuregulinI & - & - & (Meyer and Birchmeier, 1995) \\
\hline NeuregulinI type III & - & - & (Wolpowitz et al., 2000) \\
\hline floxed NeuregulinI & - & - & (Li et al., 2002a) \\
\hline Stop-floxed EYFP & - & - & (Srinivas et al., 2001) \\
\hline
\end{tabular}

\subsubsection{Oligonucleotids}

Oligonucleotides were synthesized and were ordered from the service facility of the MaxPlanck-Institute of Experimental Medicine.

\subsubsection{Genotyping primer for various mouse lines}

Cam KinaseII $\alpha$-Cre

Forward: 5'-CGAGTGGCCCCTAGTTCTGGGGGCAGC-3'

Reverse: 5'-CGTTGCATCGACCGGTAATGCAGGC-3'

Amplification product: $\sim 450 \mathrm{bp}$

Emx1-Cre (Ella-Cre PCR)

Forward: 5'-CCTGGAAAATGCTTCTGTCCG-3'

Reverse: 5'-CAGGGTGTTATAAGCAATCCC-3'

Amplification product: $\sim 400 \mathrm{bp}$

Nestin-Cre

Forward: 5'-CCAGCCGGCGGGAGTATGAAT-3'

Reverse: 5'-CAGCCCGGACCGACGATGAA-3'

Amplification product: $\sim 600 \mathrm{bp}$

Nex-Cre and Nex-CreERT2

Forward: 5'-GAGTCCTGGAATCAGTCTTTTTC-3'

Reverse: 5'-AGAATGTGGAGTAGGGTGAC-3'

Reverse: 5'-CCGCATAACCAGTGAAACAG-3' 
Amplification product: 770 bp (mutant) and 525 bp (wildtype).

Nex-CreERT2 screening PCR

Outer primer pair

Forward: 5'-CCCTATCAGTCTAACCTCCTGTGTTG-3'

Reverse: 5'-TTCTTGCGAACCTCATCACTCG-3'

Inner primer pair

Forward: 5'-CCACTTACAGGGATGCCAGATGATC-3'

Reverse: 5'-CGTTGCATCGACCGGTAATGCAGGC-3'

Amplification product: $1634 \mathrm{bp}$

Nex-CreERT2 (specific)

Forward: 5'-CCCTATCAGTCTAACCTCCTGTGTTG-3'

Reverse: 5'-GGGGGCTCAGCATCCAACAAG-3'

Amplification product: $\sim 3.0 \mathrm{~kb}$

panNeuregulin I

Forward: 5'-CTGCAAGGCGATTAAGTTGGGTAACG -3'

Reverse: 5'-GGATTTAGGAGAGTGAGGATCACAGG -3'

Amplification product: $\sim 1250 \mathrm{bp}$

panNeuregulin I (modified)

Forward: 5'-GTTGGCAGTCAGACACTTTGTTATCAG-3'

Reverse: 5'-CTGCAAGGCGATTAAGTTGGGTAACG-3'

Amplification product: $390 \mathrm{bp}$

Neuregulin I type III

Forward: 5'-TTTACTCTTCCTTACGGTCTA -3'

Reverse: 5'-ACTTTCTTCTTCCCATTCTGT -3'

Reverse: 5'-TTTCTCTTGATTCCCACTTTG -3'

Amplification product: $550 \mathrm{bp}$ (mutant) and $880 \mathrm{bp}$ (wildtype).

floxed Neuregulin1

Forward: 5'-TCCTTTTGTGTGTGTTCAGCACCGG-3'

Reverse: 5'-GCACCAAGTGGTTGCGATTGTTGCT-3'

Amplification product: $400 \mathrm{bp}$ (floxed) and $260 \mathrm{bp}$ (wildtype).

Recombined Neuregulin1

Forward: 5'-TCCTTTTGTGTGTGTTCAGCACCGG-3'

Reverse: 5'-TCACTATGTAGCTCTGGCTGGCATC-3'

Amplification product: $\sim 600 \mathrm{bp}$ 
Stop floxed EYFP

Forward: 5'-AAAGTCGCTCTGAGTTGTTAT-3'

Reverse: 5'-CGAAGAGTTTGTCCTCAACC-3'

Reverse: 5'-GGAGCGGGAGAAATGGATATG-3'

Amplification product: $250 \mathrm{bp}$ (mutant) and $500 \mathrm{bp}$ (wildtype).

\subsubsection{Quantitative real-time PCR primers}

18RNA

Forward: 5'-AAATCAGTTATGGTTCCTTTGGTC-3'

Reverse: 5'-GCTCTAGAATTACCACAGTTATCCAA-3'

$\beta$-actin

Forward: 5'-CTTCCTCCCTGGAGAAGAGC-3'

Reverse: 5'-ATGCCACAGGATTCCATACC-3'

Calretinin

Forward: 5'-CGAAGAGAATTTCCTTTTGTGC-3'

Reverse: 5'-TGTGTCATACTTCCGCCAAG-3'

ErbB2

Forward: 5'-CGCTTTGTGGTCATCCAGA-3'

Reverse: 5'-CGGTAGAAGGTGCTGTCCAT-3'

ErbB3

Forward: 5'-CGGAGACAGTGCGATTTCA -3'

Reverse: 5'- AGGGGAGGGTGTCTGTCTC-3'

ErbB4

Forward: 5'-GAACTTGGATTAAAGAACCTGACC-3'

Reverse: 5'-AACATAGGAATTTGTTCTGGTCTACA-3'

GABAAR $\alpha 2$

Forward: 5'-ACAAAAAGAGGATGGGCTTG-3'

Reverse: 5'-TCATGACGGAGCCTTTCTCT-3'

GAD65

Forward: 5'-CAAGTTCTGTTCAGGTCATGGT-3'

Reverse: 5'-AGCGCCCTCTGCTTTATTTT-3' 
GAD67

Forward: 5'-TGGAGATGCGAACCATGAG-3'

Reverse: 5'-GAAGGGTTCCTGGTTTAGCC-3'

GluRA

Forward: 5'-GCCCAATGCAGAGCTCAC-3'

Reverse: 5'-GTCACTCCACTCGAGGTAACG-3'

Neuregulin (EGF domain)

Forward: 5'-GTGTGCGGAGAAGGAGAAAACT-3'

Reverse: 5'-TGGCAACGATCACCAGTAAACTCA-3'

Neuregulin type III

Forward: 5'-TGAGAACACCCAAGTCAGGA -3'

Reverse: 5'-CCCAGTCGTGGATGTAGATGT-3'

NMDAR1

Forward: 5'-CGTGATATCAGTGGGATGGTACT-3'

Reverse: 5'-GCTTTTGCAGCCGTGAAC-3'

Parvalbumin

Forward: 5'-GGCAAGATTGGGGTTGAAG-3'

Reverse: 5'-CGAGAAGGGCTGAGATGG-3'

PLP

Forward: 5'-TCAGTCTATTGCCTTCCCTAGC-3'

Reverse: 5'-AGCATTCCATGGGAGAACAC-3' 


\subsection{Methods}

\subsubsection{Generation of recombinant bacteria}

\subsubsection{Generation of electro-competent bacterial cells}

An overnight $(\mathrm{ON})$ culture of the desired bacterial strain (EL250, EL350) was inoculated from a single colony or directly from a glycerol stock into $4 \mathrm{ml}$ of LB or LB-tetracycline $(10 \mu \mathrm{g} / \mathrm{ml})$ medium (for XL-1 blue). $500 \mu \mathrm{l}$ of this ON culture was further inoculated into $50 \mathrm{ml}$ of LB medium and incubated at $37^{\circ} \mathrm{C}$ (or $32^{\circ} \mathrm{C}$ for EL250, EL350) with constant shaking. The bacteria were grown till $\mathrm{OD}_{600} \sim 0.5$ and then spun down at $5000 \mathrm{~g}$ for $10 \mathrm{~min}$ at $4^{\circ} \mathrm{C}$. The supernatant was carefully removed and the bacterial pellet was re-suspended in $50 \mathrm{ml}$ of ice-cold $10 \%$ glycerol in $\mathrm{ddH}_{2} \mathrm{O}$. The bacteria were washed two more times with $10 \%$ glycerol (in $\mathrm{ddH}_{2} \mathrm{O}$ ) and after the final wash the bacterial pellet was re-suspended in $100-150 \mu \mathrm{l}$ of $10 \%$ glycerol (in $\mathrm{ddH}_{2} \mathrm{O}$ ) and snap-frozen in liquid nitrogen. These electrocompetent cells were then stored at $-70^{\circ} \mathrm{C}$. The competence of the bacterial cells was tested by transformation of super-coiled pUC18 plasmid DNA and this usually resulted in $5 \times 10^{7}$ $8 \times 10^{8}$ transformants/ $\mu \mathrm{g}$ pUC18 DNA.

\subsubsection{Generation of recombination competent EL250 and EL350 bacterial strain}

To obtain recombination-competent EL250 or EL350 bacterial strain, $50 \mathrm{ml}$ cultures were grown in $\mathrm{LB}$ medium (see 1.1) to an $\mathrm{OD}_{600} \sim 0.5$. At this point the bacteria were heat shocked in a water bath for $15 \mathrm{~min}$ at $42^{\circ} \mathrm{C}$ under gentle agitation (for uniform heating). The bacteria were then chilled on ice for $15 \mathrm{~min}$, washed and frozen as described (see 1.1). The competence of EL250, EL350 bacterial cells was usually $5 \times 10^{7}-8 \times 10^{8}$ transformants/ $\mu \mathrm{g}$ pUC18 DNA.

\subsubsection{Generation of chemical competent E. coli (XL-1 blue)}

A $4 \mathrm{ml} \mathrm{ON}$ culture of $E$.coli XL-1 blue grown in LB-tetracycline medium $(10 \mu \mathrm{g} / \mathrm{ml})$ was further inoculated into a $200 \mathrm{ml}$ of LB-tetracycline medium (1:50). The culture was then incubated $\mathrm{ON}$ at $37^{\circ} \mathrm{C}$ with gentle shaking. The bacteria were grown till $\mathrm{OD}_{600} \sim 0.5$ and then spun down at $5000 \mathrm{~g}$ for $10 \mathrm{~min}$ at $4^{\circ} \mathrm{C}$. The supernatant was carefully removed and the bacterial pellet was re-suspended in 1/15th of the volume in TSB and incubated on ice for $10 \mathrm{~min}$. The bacterial cells were then snap frozen in $100 \mu \mathrm{l}$ aliquots and stored at $-70^{\circ} \mathrm{C}$. The competence of these cells was usually lower than for the electro-competent cells 
$\left(4 \times 10^{7}-1 \times 10^{8} / \mu \mathrm{g}\right.$ pUC18 DNA), but sufficient for standard cloning procedures.

\subsubsection{Electroporation of E. coli}

Electro-competent E. coli were thawn on ice and $40 \mu 1$ were pipetted into a pre-cooled electroporation cuvette (gap size: $1 \mathrm{~mm}$ ) togather with the DNA to be transformed. The bacteria and DNA were mixed in the cuvette, followed by 15 min incubation on ice. The cuvette was placed in the electroporation chamber of a "GenePulserII" (BioRad) and electroporated with the following settings: $1.75 \mathrm{kV}, 200 \mathrm{ohms}$, and $25 \mu \mathrm{F}$. The bacteria were then re-suspended in 800-1000 $\mu \mathrm{LB}$ or SOC medium, transferred into a microfuge tube and incubated for $30-45 \mathrm{~min}$ at $37^{\circ} \mathrm{C}\left(90 \mathrm{~min}\right.$ at $32^{\circ} \mathrm{C}$ for EL250/350) in an orbital shaker. After recovery the bacterial cells were then plated on LB plates containing the appropriate antibiotic.

\subsubsection{Transformation of chemical competent bacteria}

50-100 $\mu \mathrm{l}$ of chemical competent E.coli were pretreated with $1.7 \mu 1$ of $\beta$-mercaptoethanol (2-ME) for $5 \mathrm{~min}$ on ice. Then, $50 \mathrm{ng}$ of plasmid DNA or 5-10 $\mu \mathrm{l}$ of ligation mixture was added and incubated for $15 \mathrm{~min}$ on ice. After a heat shock for $30 \mathrm{sec}$ at $42^{\circ} \mathrm{C}$ and incubation for $1 \mathrm{~min}$ on ice, the bacteria were directly plated onto LB plates containing an appropriate antibiotic. For some ligation mixtures, 1000-800 $\mu 1$ of LB was added and the bacteria were incubated at $37^{\circ} \mathrm{C}$ for $30-45$ min with constant shaking. $50-200 \mu 1$ of bacteria were then plated onto LB plates containing an appropriate antibiotic. These LB plates were then incubated at $37^{\circ} \mathrm{C}$ for $\mathrm{ON}$.

\subsubsection{Homologous recombination in bacteria}

Lee et al., constructed several E.coli strains capable of efficient homologous recombination (Lee et al., 2001). These bacterial strains carry a defective $\lambda$-prophage gene encoding the Red proteins (exo, bet and gam) under the transcriptional control of a temperature-sensitive $\lambda$-repressor. The bacterial strains such as EL250 and EL35 carry inducible cre and flpe site-specific recombinases under the transcriptional control of the PBAD promoter. The promoter activity can be induced by L-arabinose $(0.5 \% \mathrm{w} / \mathrm{v})$. The cre and flpe recombinases can excise the gene of interest franked by either loxP or FRT sites respectively. For the recombination of the gene of interest, an $\mathrm{ON}$ culture of the desired clone was grown at $32^{\circ} \mathrm{C} .2 \mathrm{ml}$ of LB medium was then inoculated with $20 \mu \mathrm{l}$ of the ON culture and grown till $\mathrm{OD}_{600} \sim 0.5$. At this point $50 \mu \mathrm{l}$ of a $20 \% \mathrm{w} / \mathrm{v}$ L-arabinose solution, to a final concentration of $0.5 \%$, was added to the culture. The bacterial cells were further 
grown for an hour at $32^{\circ} \mathrm{C}$. From this culture, fresh $2 \mathrm{ml} \mathrm{LB}$ medium was inoculated (1:50) and the bacteria were grown for another hour. 5-10 $\mu 1$ of this culture was then plated on LB-Ampicillin plates and incubated $\mathrm{ON}$ at $32^{\circ} \mathrm{C}$. The next day 5-10 clones were picked into $3 \mathrm{ml}$ of LB-Ampicillin and grown $\mathrm{ON}$ at $32^{\circ} \mathrm{C} .1 \mu \mathrm{l}$ of each culture was used in a PCR screen to verify the excision of the gene of interest.

\subsubsection{Maintenance and revival of bacterial glycerol stocks}

Genetically modified E. coli were stored as glycerol stocks (30\% glycerol (v/v) in LB medium) at $-80^{\circ} \mathrm{C}$. For revival of culture, $4-5 \mathrm{ml}$ of LB medium was inoculated by tiny amount of glycerol stock using an inoculation loop or autoclaved toothpick. The inoculated $\mathrm{LB}$ medium was incubated $\mathrm{ON}$ at $37^{\circ} \mathrm{C}$ with gentle shaking.

\subsubsection{DNA isolation and purification}

\subsubsection{Small scale DNA purification ("mini preps")}

The small scale plasmid DNA preparations were carried out using Qiagen's 'QIAprep 8 Miniprep kit'. The DNA preparation is carried out by a modified 'alkaline lysis' protocol (Birnboim and Doly, 1979) followed by binding of the DNA to an anion-exchange resin under appropriate $\mathrm{pH}$ and low-salt conditions and subsequent wash and elution steps.

In brief, $3 \mathrm{ml}$ of LB media containing an appropriate antibiotic was inoculated with a single colony and incubated $\mathrm{ON}$ at $37^{\circ} \mathrm{C}$ with gentle shaking. Cultures were transferred into $2 \mathrm{ml}$ microfuge tubes and bacteria were pelleted by centrifugation at $3000 \mathrm{rpm}$ for 3 min at RT. Plasmids were isolated from this bacterial pellet according to the manufacturer's protocol. The bound plasmid DNA was eluted from anion-exchange resin columns in $100-200 \mu \mathrm{l}$ of prewarmed $\left(50^{\circ} \mathrm{C}\right) \mathrm{ddH}_{2} 0$.

\subsubsection{Large scale plasmid DNA preparations ("midi/maxi preps")}

Preparative purification of plasmid DNA was carried out using Qiagen's 'Plasmid midi kit' or 'Plasmid maxi kit' that are based on an 'alkaline lysis' procedure (Birnboim and Doly, 1979) coupled to anion exchange resin purification under appropriate low-salt and $\mathrm{pH}$ conditions. The contaminating RNAs and low-molecular weight impurities are removed by medium salt washes. The plasmid DNA is then eluted from the resin by a high-salt buffer and precipitated with isopropanol followed by several washes to remove residual salt from the elution buffer.

In brief, the glycerol stock of the bacterial strain was used to inoculate $3 \mathrm{ml}$ of LB medium 
(with antibiotic) and incubated at $37^{\circ} \mathrm{C}$ with gentle shaking for 4-6 hours. Then $200 \mu \mathrm{l}$ of above starter culture was used to inoculate $200 \mathrm{ml}$ of LB medium (with antibiotic), incubated overnight at $37^{\circ} \mathrm{C}$ on constant agitation. Bacteria were pelleted by centrifugation at $6,000 \mathrm{~g}$ for $15 \mathrm{~min}$ at $4^{\circ} \mathrm{C}$ (SLA-1500 rotor). Plasmids were isolated from the bacterial pellet according to the manufacturer's protocol. Finally, the plasmid pellet was resuspended in $500 \mu \mathrm{l}$ of prewarmed $\left(50^{\circ} \mathrm{C}\right)$ Tris- $\mathrm{HCl}(10 \mathrm{mM}, \mathrm{pH} 8.0)$. The concentration and purity of DNA was determined by UV spectrophotometer at $280 \mathrm{~nm}$ wavelength.

\subsubsection{Preparation of mouse genomic DNA for Southern blotting}

For the preparation of mouse genomic DNA for Southern blotting $200 \mathrm{mg}$ of tissue (liver or tail) were digested in $700 \mu 1$ TENS buffer supplemented with proteinase K (final conc. $0.5 \mu \mathrm{g} / \mu \mathrm{l}) \mathrm{ON}$ at $52^{\circ} \mathrm{C}$. The undigested debris was pelleted by centrifugation for $5 \mathrm{~min}$ at $10,000 \mathrm{~g}$ and the supernatant was transferred to a fresh microfuge tube. An equal volume of phenol:chloroform:isoamylalcohol (49:49:2), pH8.0, was added and vortexed for 20-30 sec. The aqueous phase was separated by centrifugation at $10,000 \mathrm{~g}$ for $10 \mathrm{~min}$ and transferred into a fresh tube. An equal volume of isopropanol was carefully pipetted onto the sample and the genomic DNA was spooled onto a glass rod by stirring and twisting. The DNA was then washed twice by stirring the glass rod in $70 \%$ ethanol, followed by a wash in $100 \%$ ethanol to facilitate drying. The tip of the glass rod was broken into a new tube and the DNA re-suspended in $200 \mu \mathrm{l}$ of TE buffer. This method usually yielded 150 $200 \mu \mathrm{g}$ of genomic DNA.

\subsubsection{Preparation of mouse genomic DNA for genotyping ('quick n dirty method')}

For the preparation of mouse genomic DNA for genotyping, 2-3 $\mathrm{mm}$ of tail snippets were placed in microfuge tubes. $180 \mu \mathrm{l}$ of $1 \mathrm{X}$ MGB and $20 \mu \mathrm{l}$ of proteinase $\mathrm{K}(10 \mathrm{mg} / \mathrm{ml})$ were added to each tube and were closed tightly. These tubes were then incubated at $52^{\circ} \mathrm{C}$ for 3 hours to $\mathrm{ON}$ with vigorous shaking. Once tails were dissolved, proteinase $\mathrm{K}$ was heat inactivated by incubating the DNA lysate at $95^{\circ} \mathrm{C}$ for $10 \mathrm{~min}$. The DNA lysate was then centrifuged at $13,000 \mathrm{~g}$ for $1 \mathrm{~min}$ to pellet all the undigested material. The supernatant was collected in fresh tube and was diluted by $\mathrm{ddH}_{2} 0$ (1:3). 1-2 $\mu$ l of this diluted DNA preps can directly be used for genotyping PCR amplification.

\subsubsection{Purification and concentration of nucleic acids}

Crude DNA preparations such as genomic DNA isolated from tail snippets contain lot of impurities (proteins and salts). These impurities can be removed by phenol-chloroform 
extraction and ethanol/isopropanol precipitation of DNA.

An equal volume of phenol:chloroform:isoamylalcohol (49:49:2), pH8.0, was added to the sample. The resulting sample was mixed gently by inversion for $30 \mathrm{sec}$ and then centrifuged at $15,000 \mathrm{~g}$ for $10-20 \mathrm{~min}$. The aqueous phase was carefully transferred into a new tube and $1 / 10$ volume of $3 \mathrm{M}$ sodium acetate $(\mathrm{pH} 5.0)$ was added. The DNA was precipitated with 2 volumes of $100 \%$ ethanol or isopropanol by incubation at $-20^{\circ} \mathrm{C}$ for 1 hour. The precipitate was pelleted by centrifugation at $15,000 \mathrm{~g}$ for $10 \mathrm{~min}$. The pellet was washed twice with $70 \%$ ethanol with each washing step followed by centrifugation at $15,000 \mathrm{~g}$ for 2-5 $\mathrm{min}$. The final pellet was air dried to remove any residual ethanol and was re-suspended in prewarmed $\left(50^{\circ} \mathrm{C}\right) \mathrm{ddH}_{2} \mathrm{O}$ or TE buffer. If the expected yield of DNA was $<100 \mathrm{ng} / \mathrm{ml}$, carrier substances such as tRNA or glycogen can be added to the sample in order to enhance precipitation and to help visualize the resulting pellet.

\subsubsection{Extraction of DNA from agarose gels}

DNA fragments between 200bp-12kb were extracted from agarose gels using Qiagen's "QIAquick Gel Extraction kit". The kit is based on the ability of DNA fragments to bind to silica-membranes under high-salt conditions at a $\mathrm{pH} 7.5$.

In brief, the desired DNA fragment was cut out of the agarose gel on a UV screen and placed into a microfuge tube. DNA fragments were isolated from agarose according to the manufactures protocol. Finally, the DNA was eluted in $30-50 \mu$ of prewarmed $\left(50{ }^{\circ} \mathrm{C}\right)$ Tris- $\mathrm{HCl}$ (10 mM, pH 8.0).

\subsubsection{Enzymatic modification and manipulation of DNA}

\subsubsection{Restriction digestion of DNA}

Restriction endonucleases are enzymes that recognize specific sequences within dsDNA and cut both DNA strands. Smith and Nathans (1975) discovered and characterized the restriction endonucleases that are commonly used in the molecular cloning. These enzymes cleave at specific sites within their recognition sequence that ranges from 4-8 bp in length and is in most cases palindromic. The hydrolysis of both dsDNA strands can generate 5'protruding, 3'-protruding or blunt ends. The 5' ends are always phosphorylated and the 3' ends are hydroxylated. These characteristics make them a useful tool in molecular biology for sequence specific fragmentation of DNA. One unit is defined as the amount of enzyme required to cut $1 \mu \mathrm{g}$ of DNA in 1 hour at $37^{\circ} \mathrm{C}$. For analytical DNA digests, usually 500 ng- $\mu$ g of DNA was digested with 1-10 units of the corresponding enzyme at $37^{\circ} \mathrm{C}$ for $1-2$ 
hours. For double digests involving enzymes requiring incompatible buffers, the DNA was digested sequentially. Restriction enzymes can be inactivated at $65^{\circ} \mathrm{C}$ for $20 \mathrm{~min}$ (for heat sensitive enzymes), or the enzymes can be removed either by phenol-chloroform extraction or by purifying the DNA fragment after electrophoretic separation in an agarose gel using a Qiagen 'QIAQuick gel extraction' kit.

\subsubsection{Dephosphorylation of DNA digested with restriction}

Terminal 5'-phosphoryl groups can be enzymatically removed by treating dsDNA with calf intestinal phosphatase (CIP), thereby preventing unwanted re-ligation of restriction digested DNA. One unit of CIP is defined as the amount of enzyme required to hydrolyze $1 \mu \mathrm{M}$ p-nitrophenolphosphate to nitrophenol in $1 \mathrm{~min}$ at $37^{\circ} \mathrm{C}$. The CIP used was active in the buffers used for restriction enzymes. To remove 5'phosphoryl groups, 1-2U of CIP was added to a heat inactivated 'restriction digest' and incubated for $30 \mathrm{~min}$ at $37^{\circ} \mathrm{C}$. Since CIP cannot be heat inactivated, the treated DNA was subsequently gel purified using the 'QIAquick gel extraction kit'.

\subsubsection{Phosphorylation of 5' hydroxyl ends of oligonucleotide}

Polynucleotide kinase (PNK) catalyzes the transfer and exchange of a $\gamma$-Pi from ATP to the 5'-hydroxyl end of dsDNA, ssDNA (oligonucleotide) and RNA. For quantitative phosphorylation of ssDNA, ATP is added to the reaction mixture at a final concentration of $1 \mathrm{mM}$ to strongly favor the transfer of a $\gamma$-Pi onto the 5 '-OH ends of the ssDNA. Usually for Kinasing reaction, a mixture of 5 pmol ssDNA and $1 \mathrm{mM}$ dATP is used. $4 \mu 1$ of $10 \mathrm{x}$ PNK buffer and 10U of PNK were further added. The reaction mix was brought to a final volume of $40 \mu \mathrm{l}$ with $\mathrm{ddH}_{2} \mathrm{O}$ and was incubated for $30 \mathrm{~min}$ at $37^{\circ} \mathrm{C}$. The reaction was stopped by a heat inactivation of PNK at $70^{\circ} \mathrm{C}$ for $15 \mathrm{~min}$. Finally the phosphorylated ssDNA was purified using a S-400 sepharose column.

\subsubsection{Ligation of DNA-fragments}

The bacteriophage T4-encoded enzyme 'DNA ligase' catalyses the formation of phosphodiester bonds between neighboring 3'-hydroxyl- and 5'-phosphoryl-termini. It requires $\mathrm{Mg}^{2+}$ ions and ATP as co-factors. The efficacy of a ligation reaction is influenced by several factors, e.g. incubation temperature, reaction volume and the concentration of DNA termini. Addition of polyethylene glycol in the ligation buffer enhances the ligation efficacy and reduces the incubation time. The enzymatic activity is measured as the 'cohesive end ligation unit', and is defined as the amount of enzyme required to achieve a 
$50 \%$ ligation of HindIII digested $\lambda$-DNA in $30 \mathrm{~min}$ at $16^{\circ} \mathrm{C}$ in $20 \mu 1$ reaction volume and a 5 ' termini concentration of $0.12 \mu \mathrm{M}(300 \mu \mathrm{g} / \mathrm{ml})$.

DNA fragments were ligated by mixing 25-50 ng vector DNA with a threefold excess of insert DNA. $0.5 \mu \mathrm{l}$ of T4-ligase and $1 \mu \mathrm{l}$ of 10x ligation buffer were added and the reaction mixture was brought to a final volume of $10 \mu \mathrm{l}$ with $\mathrm{ddH}_{2} \mathrm{O}$. The reaction was incubated either for 2 hours at RT or ON at $4^{\circ} \mathrm{C}$. "Blunt" end ligations were carried out at $16^{\circ} \mathrm{C}$ for $>12$ hours. The reaction mixture was used directly for transformation without any further purification.

\subsubsection{Analysis and amplification of DNA}

\subsubsection{Agarose gel electrophoresis for the separation of DNA fragments}

For the separation of DNA fragments ranging from $100 \mathrm{bp}$ to $15 \mathrm{~kb}$ agarose gels ranging from $0.7 \%$ to $3.0 \%$ were used. The desired amount of agarose was dissolved in 1xTAE buffer by heating in a microwave. After the agarose had cooled to approximately $60^{\circ} \mathrm{C}$, ethidiumbromide $(1 \mu \mathrm{g} / \mathrm{ml})$ was added. The warm agarose was slowly poured into a gel tank and combs were inserted. The set was kept undisturbed till the agarose polymerized. Then 1xTAE buffer was poured slowly into the tank till the buffer level stands $0.5-0.8 \mathrm{~cm}$ above the gel surface. Wells were formed by gently lifting the combs. Standard DNA marker (100bp or $1 \mathrm{~kb}$ ladder) and DNA samples (containing glycerol and tracking dye) were loaded into the well. After loading, the set up was connected to power supply and voltage was set to $120 \mathrm{~V}$ (or 8 to $10 \mathrm{~V} / \mathrm{cm}$ length). The gel was run until the tracking dye bromophenol blue has reached $3 / 4$ of the gel length or until the desired separation was achieved. For documentation, snapshots of UV-transilluminated gels were taken.

\subsubsection{Determination of DNA concentrations}

According to the Lambert-Beer law the absorption of an aqueous solution of a substance is directly proportional to its concentration, $\mathrm{A}=\varepsilon \mathrm{cl}$, where $\varepsilon$ is the molar extinction coefficient $\left(\mathrm{M}^{-1} \mathrm{~cm}^{-1}\right)$, c the concentration $(\mathrm{M})$ and 1 is the path length of the light through the sample $(\mathrm{cm})$. The absorption is measured at $260 \mathrm{~nm}$ and $280 \mathrm{~nm}$, which represent the absorption maxima for nucleic acids and proteins, respectively. The measured absorption is the sum of the absorptions of all the bases in the solution.

For working purposes the following $\mathrm{OD}_{260}$ - concentration relations were used:
$1 \mathrm{OD}_{260}$ for dsDNA
$: 50 \mu \mathrm{g} / \mu \mathrm{l}$
$1 \mathrm{OD}_{260}$ for RNA
$: 40 \mu \mathrm{g} / \mu 1$
$1 \mathrm{OD}_{260}$ for ss-oligonucleotides
$: 33 \mu \mathrm{g} / \mu 1$ 
To determine the concentration, DNA was diluted 1:50 with $\mathrm{ddH}_{2} \mathrm{O}$ and was pipetted into a $50 \mu 1$ cuvette (quartz). The absorbance was measured at $260 \mathrm{~nm}, 280 \mathrm{~nm}$ and $320 \mathrm{~nm}$. The purity of the DNA preparation was estimated by calculating the ratio of absorbances at 260nm and $280 \mathrm{~nm}\left(\mathrm{~A}_{260} / \mathrm{A}_{280}\right)$. For RNA: $\mathrm{A}_{260} / \mathrm{A}_{280}=2.0$, DNA: $\mathrm{A}_{260} / \mathrm{A}_{280}=1.8$ and protein: $\mathrm{A}_{260} / \mathrm{A}_{280}=0.6$. A ratio of $1.8-2.0$ is desired when purifying nucleic acids. If the ratio is less than 1.7 the solution is probably contaminated by protein or phenol.

DNA samples and molecular weight standard (1 kb ladder or HindIII digested $\lambda$ phage DNA)were subjected to agarose gel electrophoresis to check the integrity of DNA prior to molecular cloning experiments. The concentration of DNA can be calculated by comparing the intensity of the band of interest to the intensity of the band of molecular weight standard.

\subsubsection{DNA Sequencing}

$16 \mu \mathrm{l}$ of DNA (f.c. $100 \mathrm{ng} / \mu \mathrm{l}$ ) diluted in $\mathrm{ddH}_{2} \mathrm{O}$ was submitted to the sequence facility of the Max Planck Institute of Experimental Medicine. The obtained sequencing data was analyzed using DNAStar (SeqManII) software package. Sequences were also verified on public domain databases such as ENSEMBL (http://www.ensembl.org) and BLAST at 'National Centre for Biotechnology Information' (NCBI)

(http://www.ncbi.nlm.nih.gov/blast/Blast.cgi).

\subsubsection{PCR primer designing}

Sense and antisense PCR primers (24-32 oligonucleotides) were manually designed. To achieve a melting point between $50-65^{\circ} \mathrm{C}$ the length of the primers was varied accordingly. Designed primers were proofread using DNAStar "EditSeq, SeqmanII and PrimerSelect" software packages. The oligonucleotides (primers) were synthesized by phosphoramiditebased chemical reaction (Caruthers et al., 1983). All primers were synthesized at the 'Oligo Synthesis Lab' of Max Planck Institute of Experimental Medicine. The oligonucleotide stocks $(50 \mathrm{pM})$ received were immediately diluted to $10 \mathrm{pM}$ in PCR grade $\mathrm{ddH}_{2} \mathrm{O}$. 
3.2.4.5 Amplification of DNA fragments in vitro using polymerase chain reaction (PCR)

The polymerase chain reaction allows the in vitro amplification of a specific DNA sequence (Mullis et al., 1986). DNA synthesis starts at two primers that are flanking the sequence to be amplified. One of the primers anneals to the sense and the other one to the anti-sense strand of the amplicon. DNA polymerase of the thermophilic bacterium Thermus aquaticus (taq polymerase) catalyzes the synthesis reaction at a temperature of $72^{\circ} \mathrm{C}$ and is stable at $95^{\circ} \mathrm{C}$. DNA synthesis is carried out in a thermocycler shifting temperatures between $95^{\circ} \mathrm{C}$, the specific annealing temperature of the primers and $72^{\circ} \mathrm{C}$ for the synthesis reaction. The reaction mixture contains DNA template, primers dNTPs and taq polymerase with corresponding salt and optimal $\mathrm{pH}$ conditions. Usually, 24-40 cycles are necessary to obtain sufficient quantities of the PCR product for subsequent steps. For current projects Sigma "RedTaq polymerase" was used. Standard PCR reactions were setup as follows:

$\begin{array}{ll}2 \mu \mathrm{l} & \text { 10x Red Taq Buffer } \\ 1 \mu \mathrm{l} & \text { primer } 1(10 \mathrm{pmol} / \mu \mathrm{l}) \\ 1 \mu \mathrm{l} & \text { primer } 2(10 \mathrm{pmol} / \mu \mathrm{l}) \\ 2 \mu \mathrm{l} & \text { DNA template }(100 \mathrm{pg}-25 \mathrm{ng}) \\ 1 \mu \mathrm{l} & \text { Red Taq Polymerase }(1 \mathrm{U} / \mu \mathrm{l}) \\ 13 \mu \mathrm{l} & \left.\mathrm{ddH}_{2} \mathrm{O} \text { (or final volume } 20 \mu \mathrm{l}\right)\end{array}$

The Taq polymerase does not possess a 3'-5' exonuclease activity ('proofreading'), which on average leads to the introduction of single mutation every $1.3 \times 10^{5}$ nucleotides. For high-fidelity amplifications, the DNA polymerase of pyrococcus furiosus (pfu polymerase) was used, which has a proofreading activity that results in a $>10$-fold reduced mutation rate. PCR products were separated on an agarose gel for either visualization or purification followed by gel extraction. Alternatively, DNA fragments were purified using a S-200 spin column.

\subsubsection{RNA isolation and quantification}

\subsubsection{Small scale RNA purification ('RNeasy mini prep')}

The small scale 'RNeasy mini preps' were used to purify up to $100 \mu \mathrm{g}$ of total RNA from tissue samples. The kit is based on a selective binding of RNAs $>200$ bases to a silica-gelbased membrane under high-salt conditions, which excludes 5S, 5.8S and tRNAs. RNAs 
were purified following the manufacturer's instructions.

In brief, specific micro-dissected brain regions were lysed and homogenized with an UltraTurrax (20-30sec) in the presence of a highly denaturing guanidine isothiocyanate containing buffer, which immediately inactivates RNases. Ethanol was added to provide appropriate binding conditions, and the homogenate was then applied to an RNeasy mini column where total RNA binds to the membrane and contaminants are efficiently washed away. The RNA was eluted from the column by adding 30-50 $\mu$ l of RNase-free $d_{d d} \mathrm{H}_{2} \mathrm{O}$. RNA quality was assessed by gel electrophoresis or by analysis on an Agilent 2100 Bioanalyzer.

\subsubsection{First strand cDNA synthesis}

cDNA synthesis is based on the characteristic feature of eukaryotic messenger RNAs to harbor defined polyadenylated tail on the $3^{\prime}$ end. First-strand cDNA was mainly synthesized for quantitative RT-PCR. Total RNA is mixed with a random nonamer and oligo-dT primers. The amplification reaction is carried out by Superscript III reverse transcriptase (Gerard et al., 1986; Kotewicz et al., 1985) at $55^{\circ} \mathrm{C}$ providing high specificity and yields of cDNA (from $100 \mathrm{bp}$ to $>12 \mathrm{~kb}$ ).

To co-precipitate RNA and primers, 75 pmol of random primers and $1 \mu \mathrm{g}$ total RNA were added to a nuclease-free microfuge tube. The mixture was heated to $70^{\circ} \mathrm{C}$ for $10 \mathrm{~min}$ and incubated on ice for $2 \mathrm{~min} .5 \mu \mathrm{l}$ of $5 \mathrm{X}$ First-Strand Buffer, $1 \mu \mathrm{l}$ of $0.1 \mathrm{M}$ DTT and $2 \mu \mathrm{l}$ of $10 \mathrm{mM}$ dNTP were added to the tubes and final volume of the mix was adjusted to $24 \mu \mathrm{l}$ with $\mathrm{ddH}_{2} \mathrm{O}$. The reaction mixture was incubated at $42^{\circ} \mathrm{C}$ for $5 \mathrm{~min}$. Finally $1 \mu \mathrm{l}$ of SuperScript ${ }^{\text {TM }}$ III RT (200 units/ $\mu$ l) was added to complete the synthesis reaction mixture. This mix was incubated in the thermocycler with the following settings: $25^{\circ} \mathrm{C}$ for $10 \mathrm{~min}$, then $50^{\circ} \mathrm{C}$ for $45 \mathrm{~min}, 55^{\circ} \mathrm{C}$ for $30 \mathrm{~min}$ (difficult templates or templates with high secondary structure) and finally the reaction was terminated by heating at $70^{\circ} \mathrm{C}$ for $15 \mathrm{~min}$. The cDNA can now be used as a template for amplification in PCR. To obtain pure cDNA, required for PCR amplification, the mixture was incubated with $1 \mu \mathrm{l}$ ( 2 units) of E. coli RNase $\mathrm{H}$ at $37^{\circ} \mathrm{C}$ for 20 min to remove $>1 \mathrm{~kb}$ RNA. 


\subsubsection{Quantitative real-time PCR for mRNA expression}

Real-time PCR was carried out using the ABI Prism 7700 Sequence Detection System and SYBR Green Master Mix according to the manufacturer (Applied Biosystems). For each gene expression assay, $5 \mu 1$ of SYBR green master mix, 1pmol of forward and reverse primer pair and $20 \mathrm{ng}$ of cDNA were mixed in a 96well plate. The PCR reaction was carried out for 40 cycles at the following temperature conditions: $10 \mathrm{sec}-95^{\circ} \mathrm{C}, 25 \mathrm{sec}-$ $60^{\circ} \mathrm{C}$ and $35 \mathrm{sec}-72^{\circ} \mathrm{C}$. The SYBR green fluorescence was read at the $72^{\circ} \mathrm{C}$ step. All reactions were carried out in triplicates resulting in an almost complete overlap of the amplification plots. The relative quantity (RQ) of RNA with respect to the housekeeping genes ( $\beta$-actin and 18sRNA) was calculated using 7500 Fast System SDS software Ver 1.3 (Applied Biosystems) and Excel based rt-PRC anylysis software qBase (Hellemans et al., 2007). Results were depicted as histograms (generated by Microsoft-Excel 2003) of normalized RQ values, with maximum RQ value in a given group normalized to $100 \%$.

\subsubsection{Generation of transgenic mice}

All animals used for this thesis were kept and treated in the mouse facilities of MaxPlanck-Institute of Experimental Medicine, in accordance with the guidelines for animal welfare.

\subsubsection{DNA preparation for embryonic stem (ES) cell electroporation}

The 'targeting vector' was linearized by ON digestion of $150 \mu \mathrm{g}$ plasmid DNA (from maxi prep) by SacII restriction enzyme $(20 \mathrm{U})$ at $37^{\circ} \mathrm{C}$. The completion of linearization was confirmed by electrophoretic separation of a small aliquot of the digested DNA $(\sim 2 \mu 1)$ on a $0.7 \%$ agarose gel. The presence of a single band of about $13 \mathrm{~kb}$, with no other bands representing partially digested DNA (super coiled or nicked plasmid), confirmed the complete linearization of the targeting vector. The linearized vector was then purified by isopropanol precipitation and column filtration as follows.

To $600 \mu 1$ of linearized vector an equal volume of pure isopropanol was added and gently mixed. The precipitated DNA fragments were pelleted by centrifugation at 13,000 rpm for 10 min at RT. The resulting pellet was washed twice with $70 \%$ ethanol, each washing step followed by centrifugation at $13,000 \mathrm{rpm}$ for $3 \mathrm{~min}$ at RT. All traces of ethanol were 
removed by air-drying the pellet at RT for 20-30 min. Finally, the pellet was dissolved in $80 \mu \mathrm{l}$ of $10 \mathrm{mM}$ Tris- $\mathrm{HCl}(\mathrm{pH} 8.5)$ at $50^{\circ} \mathrm{C}$ for $30 \mathrm{~min}$ on gentle shaking.

For the column filtration purification step, C-30 columns from BioRad were used according to manufacturer's protocol. In brief, after breaking the tip of the column they were centrifuged at $2000 \mathrm{rpm}$ for $3 \mathrm{~min}$ to drain out the storage buffer. $80 \mu 1$ of linearized DNA was added on C-30 column and centrifuged at $2000 \mathrm{rpm}$ for $3 \mathrm{~min}$. The eluted fraction was collected in the microfuge tube. $40 \mu \mathrm{l}$ of $10 \mathrm{mM}$ Tris- $\mathrm{HCl}(\mathrm{pH} 8.5)$ was again added on C-30 column and centrifuged at $2000 \mathrm{rpm}$ for $3 \mathrm{~min}$. The eluted fraction was collected in the same microfuge tube as the previous fraction. Finally to recover any remaining DNA, again $40 \mu \mathrm{l}$ of $10 \mathrm{mM}$ Tris- $\mathrm{HCl}(\mathrm{pH} 8.5)$ was added on column and centrifuged at $2000 \mathrm{rpm}$ for $3 \mathrm{~min}$. This fraction was collected in a fresh microfuge tube and stored at $-20^{\circ} \mathrm{C}$. The DNA concentration was measured spectrophotometrically at 260 $\mathrm{nm}$ and $280 \mathrm{~nm}$ and $1 \mu \mathrm{l}$ was separated on a $0.7 \%$ agarose gel for reconfirmation of concentration and integrity of the DNA. The linearized fragment $(\sim 50 \mu \mathrm{g})$ is ready for the electroporation in ES cells.

\subsubsection{Transfection and selection of ES cells}

2-3 days prior to electroporation, ES cells $\left(2 \times 10^{6}\right)$ under normal culture conditions were plated on $10 \mathrm{~cm}$ culture dish to get a cell density of $10-15 \times 10^{6} \mathrm{ES}$ cells/plate (i.e. confluent plate). In case of frozen stock, one vial of ES cells $\left(5 \times 10^{6}\right.$ cells) was plated on a $6 \mathrm{~cm}$ dish and incubated for $36-48$ hours at $37^{\circ} \mathrm{C}$ and $5 \% \mathrm{CO}_{2}$. Cells were then split on two $10 \mathrm{~cm}$ dishes and kept in culture for 2-3 days providing sufficient cells for 3 transfections. The medium was changed several hours before transfection, as actively growing cells reaching $70 \%$ confluency is an absolute necessity for successful transfection. Cells were trypsinized ( $2 \mathrm{ml} / \mathrm{dish}$ ) and spun down at $900 \mathrm{rpm}$ for $5 \mathrm{~min}$. The cell pellet was re-suspended in the medium, pre-plated on gelatinized $10 \mathrm{~cm}$ dishes to get rid of feeders (fibroblast cells) and incubated for $45 \mathrm{~min}$ at $37^{\circ} \mathrm{C}$ and $5 \% \mathrm{CO}_{2}$. The supernatant medium containing mainly ES cells, as feeders attach very well to the gelatin, was transferred to a $15 \mathrm{ml}$ falcon tube. ES cells were spun down at $900 \mathrm{rpm}$ for $5 \mathrm{~min}$ and the pellet was immediately re-suspended in $1 \mathrm{ml}$ of ice-chilled PBS. Cells were counted using a Neubauer chamber and the cell number was adjusted to about $10-14 \times 10^{6}$ cells $/ \mathrm{ml}$. $0.7 \mathrm{ml}$ (i.e. $7-10 \times 10^{6}$ cells) of this cell suspension was transferred to a microfuge tube on ice. $100 \mu \mathrm{l}(0.5 \mu \mathrm{g} / \mu \mathrm{l})$ of linearized 
targeting vector DNA was added and mixed well. This mix was transferred to an electroporation cuvette (pre-incubated on ice for about $20 \mathrm{~min}$ ) and was pulsed (240 V, $500 \mu \mathrm{F})$ on BioRad electroporator. After the pulse the cuvette was incubated on ice $\left(4^{\circ} \mathrm{C}\right)$ for $20 \mathrm{~min}$. The cell suspension was then transferred to a fresh tube, $30 \mathrm{ml}$ of medium was added and cells were plated on 3 dishes $(10 \mathrm{~cm}) .24$ hours later the medium was changed and selection was started with G418 (f.c. $300 \mu \mathrm{g} / \mathrm{ml}$ ). After around 10 days of selection, >300 large isolated ES cell clones were picked up.

\subsubsection{Isolation of DNA from ES cell for genotyping}

Cells were pelleted by centrifugation at $13,000 \mathrm{rpm}$ for $10-15 \mathrm{~min}$ at RT. The medium was aspirated out very carefully and the pellet was washed with $100 \mu$ of sterile 1x DPBS. Cells were re-pelleted by centrifugation at 13,000 rpm for $5 \mathrm{~min}$ at RT and the resulting pellet was re-suspended in $50 \mu \mathrm{l}$ of $\mathrm{ddH}_{2} \mathrm{O}$. This cell suspension was boiled at $95^{\circ} \mathrm{C}$ for 10 min and centrifuged shortly to spin down the evaporated liquid. After cooling down on ice $\left(4^{\circ} \mathrm{C}\right)$, cells were digested with $1 \mu \mathrm{l}$ of proteinaseK $(20 \mu \mathrm{g} / \mu \mathrm{l})$ at $56^{\circ} \mathrm{C}$ for $30 \mathrm{~min}$, with vigorous shaking. Cells were then incubated at $95^{\circ} \mathrm{C}$ for $15 \mathrm{~min}$ to heat inactivate proteinaseK and were centrifuged shortly to spin down the evaporated liquid. $5 \mu$ of this crude DNA preps were used for PCR amplification.

3.2.6.4 PCR amplification for selection of ES cells targeted by homologous recombination

To screen ES cells targeted by homologous recombination, a nested PCR based screening strategy was designed. For designing and testing of primer pairs capable of efficient amplification of a homologously recombined target sequence, a new plasmid was cloned. This plasmid, termed as control plasmid, bears $1.16 \mathrm{~kb}$ sequence upstream of $\mathrm{kpn} 1$ restriction site located $5^{\prime}$ of exon 1 and $\sim 800$ bp of irrelevant $\left(\mathrm{Neo}^{\mathrm{R}}\right.$ gene) DNA cloned after the Nex ORF in exon 2. The nested PCR is a two-step reaction in which the amplification product of the outer primer pair is used as the template for the amplification reaction of the inner primer pair (sequence of primers are in section 3.1.16). The nested PCR amplification, with the most efficient primer pairs, using the control plasmid as template yielded a product of about $1900 \mathrm{bp}$ whereas the homologously recombined ES genomic DNA as a template yielded a product of 1634bp. 
The PCR reaction mix:

$5 \mu 1 \quad 10 X$ Taq-Polymerase Buffer

$5 \mu 1 \quad 2 \mathrm{mM}$ dNTP mix

$1 \mu 1 \quad 10 \mathrm{pmol} / \mu 1$ Primer1

$1 \mu 1 \quad 10 \mathrm{pmol} / \mu 1$ Primer2

$1 \mu 1 \quad 25 \mathrm{mM} \mathrm{MgCl}_{2}$

$5 \mu 1 \quad$ template DNA

$1 \mu 1 \quad$ Red Taq-Polymerase

$31 \mu \mathrm{l} \quad \mathrm{ddH}_{2} \mathrm{O}$

PCR for detection of the homologous recombination (Nested PCR)

$95.0^{\circ} \mathrm{C} \quad 5 \mathrm{~min}$

$95.0^{\circ} \mathrm{C} \quad 45 \mathrm{sec}$

$54.7^{\circ} \mathrm{C} \quad 45 \mathrm{sec}$

$72.0^{\circ} \mathrm{C} \quad 2 \mathrm{~min}$ (to step 2,19 cycles)

$4.0^{\circ} \mathrm{C} \quad$ Pause

$95.0^{\circ} \mathrm{C} \quad 5 \mathrm{~min}$

$95.0^{\circ} \mathrm{C} \quad 45 \mathrm{sec}$

$58.0^{\circ} \mathrm{C} \quad 35 \mathrm{sec}$

$72.0^{\circ} \mathrm{C} \quad 1 \min 49 \sec$ (to step 7, 32 cycles)

$58.0^{\circ} \mathrm{C} \quad 1 \mathrm{~min}$

$72.0^{\circ} \mathrm{C} \quad 10 \mathrm{~min}$

$4.0^{\circ} \mathrm{C} \quad$ Pause

For the first step of the nested PCR, the outer primer pair (8250/8251) and 5 $\mu 1$ ES cell genomic DNA was used as a template. The amplification reaction was carried out till step 5. Then for the next step, the inner primer pair $(8039 / 7963)$ and $5 \mu 1$ of the reaction product form the first step was used as the template. The amplification reaction was carried out till step 12. The presence of the amplification product of $1634 \mathrm{bp}$ in the screening PCR confirmed the ES clone to be homologously targeted.

\subsubsection{Protein isolation and analysis}

\subsubsection{Preparation of protein lysates from the mouse brain}

Mice were sacrificed by cervical spinal cord dislocation and were instantly decapitated using sharp scissors. Brains were removed as quickly as possible in order to minimize any post-mortem changes. Each brain, immersed in chilled 1X PBS, was micro dissected under 
binoculars. The various brain regions such as prefrontal cortex, hippocampus, cerebellum and brain stem were collected in $2 \mathrm{ml}$ microfuge tubes, snap frozen in liquid Nitrogen and stored at $-70^{\circ} \mathrm{C}$ until further processing. For every $100 \mathrm{mg}$ of tissue $1 \mathrm{ml}$ of 'modified RIPA Buffer' was used for homogenization. Protein lysates were prepared using an Ultraturrax (T8) at highest settings (20-30s). After incubation of lysates for about 20-30 min on ice the insoluble cellular debris were pelleted by centrifugation at $16,000 \mathrm{~g}$ at $4^{\circ} \mathrm{C}$ for $30 \mathrm{~min}$ and the supernatant was used for further analysis or stored at $-70^{\circ} \mathrm{C}$.

\subsubsection{Preparation of 'enriched' synaptic vesicles}

Synaptic vesicles are secretory organelles that store neurotransmitter in presynaptic nerve endings. They are very abundant in the brain with total of about $10^{17}$ vesicles in the human CNS, thereby contributing about $5 \%$ to the total amount of CNS protein (Jahn and Sudhof, 1993). Being very small (50 $\mathrm{nm}$ in diameter) and homogeneous in shape and size they can be isolated by size fractionation techniques. The protocol used in this study is modified from the protocol outlined in detail by Hell and Jahn (1994). It involves the preparation of isolated nerve terminals (synaptosomes) by differential centrifugation steps (Nagy et al., 1976). These isolated synaptosomes were lysed by osmotic shock to release synaptic vesicles into the medium. The sedimentation by an ultra centrifugation step results in five to six fold enrichment of the synaptic vesicles in the resulting pellet. This pellet can be further resuspended in Hepes buffer and subjected to western blotting. The detailed steps for the isolation of synaptic vesicles are as follows.

- Mice were sacrificed by cervical spinal cord dislocation and were decapitated. Brains were instantly removed and were micro dissected in chilled 1X PBS to isolate forebrain by cutting out olfactory bulb, midbrain, hindbrain and cerebellum.

- Each dissected forebrain was placed into a glass potter containing $1.4 \mathrm{ml}$ of homogenization buffer and was gently homogenized using a glass-Teflon homogenizer (12 strokes, $900 \mathrm{rpm}$ ). The pistil was further rinsed with $1.4 \mathrm{ml}$ of homogenization buffer for complete recovery of homogenate.

- The homogenate $(\mathrm{H})$ was centrifuged at $1000_{\text {gmax }}$ (2,700 rpm in Sorval SS34 rotor) for $10 \mathrm{~min}$ at $4^{\circ} \mathrm{C}$. The resulting pellet $\mathrm{P} 1$ containing large cell fragments and nuclei was discarded and the supernatant S1 was collected.

- The supernatant S1 was centrifuged at $12,000_{\text {gmax }}(10,000 \mathrm{rpm}$ in Sorval SS34 
rotor) for $15 \mathrm{~min}$ at $4^{\circ} \mathrm{C}$. The supernatant $\mathrm{S} 2$ containing microsomes or small myelin fragments and soluble proteins was discarded. The pellet was re-suspended in $1 \mathrm{ml}$ of homogenization buffer and was centrifuged at $12,000_{\operatorname{gmax}}(10,000 \mathrm{rpm}$ in Sorval SS34 rotor) for $15 \mathrm{~min}$ at $4^{\circ} \mathrm{C}$. The resulting pellet $\mathrm{P} 2$ represents a crude synaptosomal fraction and the supernatant S2' was discarded.

- The pellet P2 was re-suspended in $250 \mu \mathrm{l}$ of homogenization buffer and was transferred to the glass-Teflon homogenizer. To release synaptic vesicles from synaptosomes, the re-suspended P2 was osmotically shocked by adding $2.25 \mathrm{ml}$ of ice-cold $4 \mathrm{mM}$ Hepes buffer and was homogenized immediately at max speed of $1500 \mathrm{rpm}$ (10 strokes).

- The suspension was centrifuged at $27,000_{\text {gmax }}$ (15,000 rpm in Sorval SS34 rotor) for $20 \mathrm{~min}$ at $4^{\circ} \mathrm{C}$ to yield lysate pellet LP1 (lysed synaptosomal membranes) and lysate supernatant LS1. LS1 was immediately and carefully removed without disturbing LP1, as contamination with LP1 can affect the purity of the final vesicle fraction.

- The lysate supernatant LS1 was ultra-centrifuged at $265,000_{\text {gmax }}(70,000 \mathrm{rpm}$ in Beckman TLA 100.3 rotor) for 2 hours at $4^{\circ} \mathrm{C}$. The supernatant LS2 (cytosolic synaptosomal fraction) was discarded and the pellet LP2 (crude synaptic vesicle fraction) was resuspended in $250 \mu 1$ of homogenization buffer with a 27 -gauge needle attached to $1 \mathrm{ml}$ syringe. LP2 represents enriched synaptic vesicle fraction.

* Small aliquots of all fractions were collected for a quality control of the subcellular fractionation process.

\subsubsection{Co-immunoprecipitation of synaptic proteins}

The use of antibodies for immunoprecipitation has its origin in the precipitin reaction (Nisonoff, 1984). The precipitin reaction is a spontaneous precipitation of antigen-antibody complexes formed by interactions of certain polyclonal antibodies with their antigens. In immunoprecipitation reaction binding of an antigen to a specific antibody (attached to a sedimentable matrix) can be isolated as antigen-antibody complexes. Immunoprecipitation protocols consist of three main steps. First, the antigen is solubilized by lysing cells or tissues. Sec, a specific antibody is attached to a sedimentable immunoadsorbent such as proteinA- or proteinG- sepharose, to allow separation by low-speed centrifugation. Finally, 
immunoprecipitation is achieved by incubating the solubilized antigen with the immobilized antibody, followed by extensive washing and centrifugation steps to remove unbound proteins. The protocol used in the current study is modified from (Bonifacino et al., 1999) and is outlined below.

- Mouse brain homogenate was prepared as described in section 7.2 (first three steps).

- The supernatant S1 was centrifuged at $31,000_{\operatorname{gmax}}(16,000 \mathrm{rpm}$ in Sorval SS34 rotor) for $60 \mathrm{~min}$ at $4^{\circ} \mathrm{C}$. The supernatant $\mathrm{S} 2$ containing microsomes or small myelin fragments and soluble proteins was discarded. The resulting pellet P2 represents a crude synaptosomal fraction.

- The pellet P2 was re-suspended in $1 \mathrm{ml}$ of homogenization buffer. The protein concentration was determined as described in section 3.2.7.4.

- $1.5 \mathrm{ml}$ of immunoprecipitation (IP) solution was reconstituted to a final concentration of $1 \mathrm{mg} / \mathrm{ml}$ by mixing the appropriate volume of re-suspended $\mathrm{P} 2$ fraction with 2X IP buffer (plus dd $\mathrm{H}_{2} \mathrm{O}$ ).

- The IP solution (containing non-denaturating detergent) was incubated at $4^{\circ} \mathrm{C}$ for 2 hours on Intelli-Mix $(\mathrm{C} 1,16 \mathrm{rmp})$ in order to solubilize membrane proteins.

- Solubilized proteins were ultracentrifuged at $166,000_{\operatorname{gmax}}$ for 1.5 hour at $4^{\circ} \mathrm{C}$ (at 44,000rpm in rotor TLS-55 Beckman). The resulting pellet represents insoluble postsynaptic density proteins and was re-suspended in homogenization buffer for further use. The solubilized P2 fraction (supernatant) was collected in a $1.5 \mathrm{ml}$ microfuge tube for immunoprecipitation.

- The primary antibody (in the concentration recommended on datasheet) was added to $1.2 \mathrm{ml}$ of solubilized $\mathrm{P} 2$ fraction and was incubated $\mathrm{ON}$ at $4^{\circ} \mathrm{C}$ on Intelli-Mix (C1, $30 \mathrm{rmp})$.

- $50 \mu 1$ of washed ProteinA- or ProteinG-Sepharose beads were added and incubated at $4^{\circ} \mathrm{C}$ for 2 hours on Intelli-Mix (C1, $\left.30 \mathrm{rmp}\right)$.

- Beads containing bound antigens were pelleted at $16,000 \mathrm{~g}$ for $30 \mathrm{sec}$ at $4^{\circ} \mathrm{C}$ and were washed three times with $1 \mathrm{ml}$ of chilled IP buffer. Finally beads were washed with $1 \mathrm{ml}$ of ice-cold PBS and were pelleted.

- Beads were dried by removing PBS with a 27 -gauge needle attached to a $1 \mathrm{ml}$ syringe. Dried beads were immediately re-suspended in 40-50 $\mu 12$ X Laemli Buffer. 


\subsubsection{Protein concentration measurement by the Lowry method}

The Protein concentration was measured using the Bio-Rad DC Protein Assay kit according to the manufacturer's 'microplate assay' protocol. The absorbance was read at $650 \mathrm{~nm}$ in a microtitre plate reader.

The working principle of the kit is similar to the well-documented Lowry assay (Lowry et al., 1951). The assay is based on the reaction of proteins with an alkaline copper tartrate solution and Folin reagent. There are two steps that lead to a color development: the reaction between protein and copper in an alkaline medium and the subsequent reduction of Folin reagent by the copper-treated protein. The color development is primarily due to the amino acids tyrosine and tryptophan, and to a lesser extent cystine, cysteine and histidine (Lowry et al., 1951; Peterson, 1979). Proteins lead to a reduction of the Folin reagent by loss of 1,2 , or 3 oxygen atoms, producing one or several reduced species that have a characteristic blue color with maximum absorbance at $750 \mathrm{~nm}$ and minimum absorbance at $405 \mathrm{~nm}$.

\subsubsection{Separation of proteins through discontinuous SDS-PAGE}

The most widely used denaturing and discontinuous polyacrylamide gel electrophoresis (SDS-PAGE) method for protein separation was described by Laemmli (Laemmli, 1970). In this method buffers of distinctive $\mathrm{pH}$ and composition generate a discontinuous $\mathrm{pH}$ and voltage gradient in the gel. The discontinuity in $\mathrm{pH}$ and voltage concentrates proteins in each sample into narrow bands thereby allowing the separation of very dilute samples. The protocol primarily relies on denaturing proteins by heating in the presence of SDS and $\beta$ mercaptoethanol ( $\beta-\mathrm{ME})$. Under these conditions, the subunits of proteins are dissociated and their biological activities are lost. Most proteins bind SDS in a constant-weight ratio, leading to identical charge densities for the denatured proteins. Thus, the SDS-protein complexes migrate in the polyacrylamide gel according to size, not charge. Most proteins are resolved on polyacrylamide gels containing from $5 \%$ to $15 \%$ acrylamide and $0.2 \%$ to $0.5 \%$ bisacrylamide. The detailed theory and protocol for one dimensional gel electrophoresis has been described in following references (Gallagher, 2006; Hames, 1990).

A glass plate and a $0.75-\mathrm{mm}$ spacer plate sandwich of the electrophoresis apparatus was assembled according to Bio-Rad instructions. The separating gel solution of desired 
percentage of acrylamide ( $8 \%$ for proteins $>50 \mathrm{kDa}$ and $12 \%$ for proteins $<50 \mathrm{kDa}$ ) was prepared freshly and poured along an edge of one of the spacers until the height of the solution between the glass plates is $2 / 3^{\text {rd }}$ of the maximum height of the glass plates. The top of the gel was slowly covered with a layer $\left(1 \mathrm{~cm}\right.$ thick) of $\mathrm{H}_{2} \mathrm{O}$-saturated isobutyl alcohol. The gel was allowed to polymerize for $30 \mathrm{~min}$ at RT. Once the gel has polymerized the layer of isobutyl alcohol was poured off and was twice rinsed with $\mathrm{ddH}_{2} \mathrm{O}$ to remove any residual isobutyl alcohol. The stacking gel solution was freshly prepared and was poured slowly on top of the polymerized separating gel along an edge of one of the spacers until the solution reaches the top of the plates. A $0.75 \mathrm{~mm}$ Teflon comb (10 or 15 teeth) was inserted into the layer of stacking gel solution. The stacking gel solution was allowed to polymerize for 30 to $45 \mathrm{~min}$ at RT. A portion of the protein lysate to be analyzed was diluted with $6 \mathrm{X}$ SDS sample buffer containing $1 \% \beta$-ME to a final concentration of $4 \mu \mathrm{g} / \mu \mathrm{l}$ and was heated for $10 \mathrm{~min}$ at $90^{\circ} \mathrm{C}$ in a $1.5 \mathrm{ml}$ microfuge tube. The Teflon comb was removed carefully tearing the edges of the polyacrylamide wells. After the comb was removed, wells were rinsed with 1X SDS electrophoresis buffer. The gel chamber should be submerged with 1X SDS electrophoresis buffer such that wells of the stacking gel are filled with buffer. 5-15 $\mu 1$ of denatured protein sample(s) were loaded into one or more wells by carefully applying the sample as a thin layer at the bottom of the wells. The control well was loaded with molecular weight standards. Equal volume of $1 \mathrm{X}$ SDS sample buffer was added to any empty wells to prevent spreading of adjoining lanes. The power supply was connected to the chamber and was run at $10 \mathrm{~mA}$ of constant current. Once the bromphenol blue tracking dye enters the separating gel the current was increased to $15 \mathrm{~mA}$. After the bromphenol blue has eluted out of the separating gel the power supply was disconnected. The gel was carefully removed and preceded with protein blotting.

\subsubsection{Western blotting}

Western blotting allows the immunological detection of proteins in biological samples and was first introduced by Towbin and colleagues (Towbin et al., 1979). In this technique proteins resolved with SDS-PAGE are transferred onto a PVDF membrane. When an electric current is applied to the blotting module, the negatively charge proteins migrate from the cathode to the anode and are retained on the PVDF membrane by electrostatic and hydrophobic interactions. 
In current study the technique was used to detect endogenous levels of NRG1/ErbB signaling cascade proteins, myelin proteins, several neurotransmitter receptors and synaptic proteins, in protein lysates prepared from transgenic and control mice. Blotting was carried out in a "XCellSureLock" wet blotting chamber (Invitrogen, Carlsbad, CA). Before setting up the blot, the PVDF membrane (Amersham/Millipore, pore size $0.45 \mu \mathrm{m}$ ) was activated in $100 \%$ methanol for $30 \mathrm{sec}$, rinsed shortly in water and then incubated in transfer buffer for about 5-15 min. Blotting paper and blotting pads presoaked in transfer buffer were assembled according to the manufacturer's protocol. Note that the blotting buffer used differs from the manufacturers recommended. Proteins were transferred at a constant voltage of $38 \mathrm{~V}$ and a maximum current of $275 \mathrm{~mA}$, for 45-70 min (depending on the size of protein and thickness of the gel) at $4^{\circ} \mathrm{C}$.

\subsubsection{Immunodetection of blotted proteins}

The western blotted PVDF membrane was immediately placed in blocking buffer (5\% non-fat dry milk in TBS) for 1 hour at RT. The blocked membrane was incubated with the primary antibody diluted in blocking buffer (containing $0.05 \%$ tween-20, TBS-T) for about 1 hour at RT (or overnight at $4{ }^{\circ} \mathrm{C}$ ) with constant and gentle shaking. After four washes of each $10 \mathrm{~min}$ in TBS-T, the secary HRP-coupled antibody diluted in TBS-T was then applied to the membrane. The incubation was carried out for 1 hour at RT followed by six washes of each $10 \mathrm{~min}$ in TBS-T. After the washing steps, the membrane was incubated for $60 \mathrm{sec}$ in Enhanced Chemiluminescence Detection (ECL) solution according to the manufacturer's recommendations (Western Lightning ${ }^{\mathrm{TM}}$, Western Blot Chemiluminescence Reagent Plus, PerkinElmer Life Sciences, Inc.). The membrane was then covered with a transparent film and an ECL photographic film (Hyperfilm ${ }^{\mathrm{TM}}$, Amersham Biosciences) was exposed to the membrane. The time of exposure varied from $1 \mathrm{sec}$ to $15 \mathrm{~min}$ depending on the signal intensity. The films were then developed in a KODAK X-OMAT developer. For re-probing of the membrane with a second antibody, the membrane was placed into 'WB stripping buffer' for 1 hours at $60^{\circ} \mathrm{C}$ with rigorous shaking. After 3 washes of each 2 min with TBS-T, the membrane was incubated in blocking buffer for about $30 \mathrm{~min}$ at RT. Then the membrane was ready to be probed with a second primary antibody. 


\subsubsection{Densitometric quantification of band intensity}

For densitometric analysis only films exposed at non-saturating levels were used. These films were scanned at greyscale (300 dpi resolution) using a regular image scanner (UMAX, Astra). Scanned images were cropped for the bands of interest and were auto contrasted using Photoshop CS. These images were then exported as TIF-files for band intensity analysis using QuantityOne ${ }^{\circledR}$ software from BioRad or ImageJ. The integrated density or mean grey values for the band of interest was calculated by ImageJ and was normalized to the integrated density or mean grey values of GAPDH, actin or tubulin. The normalized values $( \pm$ SEM) were depicted as histograms using Microsoft-Excel 2003. The analysis for statistical significance (unpaired t-test) was performed using the GraphPad Prism software package.

\subsubsection{Histology and immunohistochemistry}

\subsubsection{Perfusion fixation of mouse tissue for immunohistochemistry}

All data of perfused mice like date of birth, perfusion day, parents, genotype, sex, date of tailing and the marked number of the mouse, were documented. Mice was deeply anaesthetized by injecting $2.5 \%$ Avertin $(0.017 \mathrm{ml}$ per gram body weight of mouse $\mathrm{x} 4)$ intraperitoneally. After anesthesia mice were stretch out ventrally on a Styrofoam board with needles and were wiped with $70 \%$ ethanol. After removing the skin from the ventral side a transversal cut was made just below the diaphragm. The diaphragm was cut through just till the edge of the chest and after that it was opened by two lateral cuts along the rib cage. Finally the rib cage was flexed forward and fixed with a needle to give a good access to the heart. Quickly a piece of tail snippet was cut with a clean pair of scissors (PCR!). This piece was stored at $-20^{\circ} \mathrm{C}$ immediately and can be used for re-genotyping of the mouse. A new needle (27 gauge) was inserted into the left ventricle and just after starting the perfusion a small incision was made in the right auricle to let the blood to flow out (of the body) instead of recirculating in the body. The position of the needle was tightly controlled so that it doesn't pierce through the ventricle. Perfusion was carried out with warm HBSS that was forced through the aorta using a peristaltic pump, to clean blood vessels. The tubing of the pump was changed carefully from HBBS to fixative (freshly prepared 4\% paraformaldehyde in PBS) without introducing any air bubbles into the 
system. The perfusion was carried out with about 30-50 $\mathrm{ml}$ of fixation solution and during this phase of perfusion the mouse will go through some convulsions and then turn stiff quickly. The brain, spinal cord, sciatic nerve, optic nerve with adhering eye and/or other tissue required were removed carefully. The collected tissue samples were immediately dropped into a vial (a scintillation plastic vial well suited) with cold perfusion fluid. The tissue samples were stored at $4{ }^{\circ} \mathrm{C}$ until needed. It is suggested to process them as soon as possible as storing tissues in $4 \%$ paraformaldehyde for long time can render them unsuitable for immunohistochemistry. If the mice were required for further analysis the perfusion fixed carcasses could be stored in a tightly sealed plastic bag with a perfusion/fixation solution.

\subsubsection{Paraplast impregnation and embedding of tissue}

After the post-fixation, 4\% PFA was poured off and was replaced by $1 \mathrm{X}$ PBS. Brains were cut into 3-4 mm pieces in coronal plane of section and were transferred to plastic chambers for dehydration and paraplast impregnation. Brains were dehydrated by incubating them in increasing alcohol concentration as follows: $50 \%$ ethanol for 1 hour, twice in $70 \%$ ethanol for 2 hours each, twice in $96 \%$ ethanol for 1 hour each and twice in $100 \%$ ethanol for 1 hour each, at RT. 100\% ethanol was replaced by isopropanol for 1 hour and then incubated twice in Xylene for 2 hours each. Finally brains were impregnated two times with paraplast at $60^{\circ} \mathrm{C}$ for 2 hours each. Then brains were ready for embedding. Embedding molds were filled with molten paraplast. Brains were immediately transferred to the paraplast-filled embedding molds using hot forceps. Properly labeled casts were placed on the molds and were filled with paraplast. Tissue blocks with casts were left on the cold plate to harden completely. Blocks were removed from the molds and can now be stored stably and for years a dry place at RT.

\subsubsection{Haematoxylin-Eosin (HE) staining}

5-7 $\mu \mathrm{m}$ thick sections were cut from the paraffinised block of brain using a microtome. The brain sections were floated on a warm water bath $\left(42^{\circ} \mathrm{C}\right)$, placed on silanized or positively charged glass slides and were dried $\mathrm{ON}$ at $37^{\circ} \mathrm{C}$. They were deparaffinised by dipping them twice in Xylol and once in Xylol/Isopropanol (1:1) for 10 min each. They were rehydrated by incubating them in the decreasing concentration of alcohol $(100 \%$, 
$90 \%, 70 \%$, and $50 \%$ ) for 5 min each and then rinsed in $\mathrm{ddH}_{2} \mathrm{O}$.

The brain sections were stained with $0.1 \%$ Haematoxylin for 5 min. Haematoxylin stains gives a blue coloration to the basic nuclear compartment of the cell. The excessive dye was washed off from the sections by rinsing them twice with $d_{d d} \mathrm{H}_{2} \mathrm{O}$. The blue coloration was differentiated by dipping sections once for 5-10 sec in HCl-Alcohol leaching solution. For arresting the differentiation process and proper development of the blue staining, sections were incubated for $5 \mathrm{~min}$ in Scott's blueing solution. They were shortly rinsed with $\mathrm{ddH}_{2} \mathrm{O}$ to remove excessive salts. They were counterstained with $0.1 \%$ Eosin for 3-5 min to reveal cellular details. Eosin is usually taken up intensely by acidic tissue compartments. The excessive dye was rinsed with $\mathrm{ddH}_{2} \mathrm{O}$. Sections were dehydrated by incubating them in the increasing concentration of alcohol $(50 \%, 70 \%, 90 \%$, and 100\%) for 2 min each (or sometimes depending upon the stability of the Eosin stain very short dipping for 10-30 sec in alcohol is done). Sections were then dipped for $5 \mathrm{~min}$ in Xylol/Isopropanol (1:1) and twice for 5 min each in Xylol. Finally, they were mounted carefully, without trapping of air bubbles, with Xylol based mounting medium 'Eukitt'.

\subsubsection{Cresyl violet or Nissl Staining}

Cresyl violet staining is used for the detection of Nissl bodies in the cytoplasm of neurons and are stained purple-blue. This stain is commonly used for identifying the basic neuronal structure in brain or spinal cord. The paraffinised brain sections were cut (5-7 $\mu \mathrm{m}$ thick), deparaffinized and rehydrated as described in section 8.3. Sections were stained with freshly filtered $0.5 \%$ cresyl violet for 5-10 min. They were shortly dipped in $0.5 \%$ acetic acid in order to differentiate staining. Slides were then rinsed by dipping them twice in $\mathrm{ddH}_{2} \mathrm{O}$. Sections were dehydrated and mounted as described in section 8.3.

\subsubsection{Bielschowsky silver impregnation for axonal architecture}

Bielschowsky method is improvisation over Fajersztajn technique of tissue staining using 'silver mirror reaction'. In Bielschowsky's method formalin fixed sections are incubated in the silver nitrate followed by ammoniacal silver solution (Bielschowsky, 1908). The prior treatment with silver nitrate provides active foci for subsequent silver deposition in the ammoniacal silver solution. This stepwise impregnation (silver nitrate-ammoniacal silver) seemed to improvise the staining by increasing the amount and the size of silver 
precipitates (Garven and Gairns, 1952; Uchihara, 2007). The detailed protocol for staining is outlines as follows.

The paraffinised brain sections were cut (5-7 $\mu \mathrm{m}$ thick), deparaffinized and rehydrated as described in section 8.3. Slides were incubated in $10 \%$ silver nitrate for $20 \mathrm{~min}$ and rinsed with $\mathrm{ddH}_{2} \mathrm{O}$. To the above $10 \%$ silver nitrate solution ammonia was added drop wise with constant and gently shaking till the precipitate was dissolved again. In this ammoniacal silver nitrate solution sections were incubated for $15 \mathrm{~min}$ in the dark. Slides were rinsed with ammoniacal- $\mathrm{H}_{2} \mathrm{O}$ (3 drops of ammonia were added to $\mathrm{ddH}_{2} \mathrm{O}$ ). To the above ammoniacal silver nitrate solution 3 drops of developer were added. Sliced were then incubated in this solution till the axons turn black and the background yellowish. This process can take 3-5 min and was controlled under the microscope. Slides were again rinsed with $\mathrm{ddH}_{2} \mathrm{O}$. In order to stabilize the silver ion deposits sections were fixed with $5 \%$ sodium thiosulfate for $3 \mathrm{~min}$. After washing in $\mathrm{ddH}_{2} \mathrm{O}$ for $5 \mathrm{~min}$, sections were dehydrated. Dehydration was carried out in varying concentration of alcohol $(50 \%, 70 \%, 90 \%$, and $100 \%$ ) for $5 \mathrm{~min}$ each. Finally sections were dipped for $5 \mathrm{~min}$ in Xylol/Isopropanol (1:1) and twice for 5 min each in Xylol and then mounted with Eukitt.

\subsubsection{Gallyas silver impregnation for myelin}

The physical development technique for staining myelin by deposition of silver particle is a qualitative method to visualize myelinated nerve fibers. The basis of this technique relies on the fact that myelin binds colloidal silver particles in a $0.1 \%$ ammoniacal silver nitrate solution of $\mathrm{pH}$ 7.5. The production of metallic silver by other tissue elements is suppressed by pretreated of the sections with a 2:1 mixture of pyridine and acetic anhydride for 30 min. The colloidal silver particles bound to the myelin are enlarged to microscopic dimensions by a special physical developer (Gallyas, 1979). The protocol for staining is outlines as follows.

The paraffinised brain sections were cut (5-7 $\mu \mathrm{m}$ thick), deparaffinized and rehydrated as described in section 8.3. Sections were pretreated with a 2:1 mixture of pyridine $(200 \mathrm{ml})$ and acetic anhydride $(100 \mathrm{ml})$ at $\mathrm{RT}$ for $30 \mathrm{~min}$. After washing three times with $\mathrm{ddH}_{2} \mathrm{O}$ for 10 min each, sections were incubated in pre-warmed (microwave for one min at 150 watts) incubation solution for $10 \mathrm{~min}$ at RT. Sections washed three times in $0.5 \%$ acetic acid for 5 min each. Sections were then 'physically developed' by incubating them in a developer 
solution for 5-10 min. The extent of silver ion deposition in the developing step was controlled under the microscope. Once the silver impregnation reaches a suitable level, slides were immediately transferred to $1.0 \%$ acetic acid and washed three times for $5 \mathrm{~min}$ each. Finally, slides were rinse well in $\mathrm{ddH}_{2} \mathrm{O}$. In order to stabilize the silver staining, slides were incubated in $2 \%$ sodium thiosulfate solution for $5 \mathrm{~min}$. After washing twice in $\mathrm{ddH}_{2} \mathrm{O}$ for 5 min each, sections were dehydrated and mounted as described in section 8.5.

\subsubsection{Detection of $\beta$-galactosidase in tissue sections (X-Gal staining)}

The bacterial enzyme $\beta$-galactosidase catalyzes the cleavage of the $\mathrm{O} 1$ bond of the sugar $\beta$ D-galactose to a substituent. Due to a broad substrate specificity the enzyme can also be used to cleave organic compounds such as 5-bromo4-chloro-3-indolyl- $\beta$-D-galactoside (XGal) giving rise to a colorful indigo-colored precipitate (5-bromo-4-chloro-3hydroxyindole) under oxidizing buffer conditions. Furthermore, this enzyme can be expressed in mammalian cells when placed under the appropriate regulatory elements and is usually well tolerated. This property of the enzyme allows the use of $\beta$-galactosidase in transgenic mice as a reporter for the detection of transgene activity or for the detection of promoter activity of an endogenous gene in 'knock-in' approaches (Goring et al., 1987; Sanes, 1994).

To detect $\beta$-galactosidase activity in transgenic mice, $50 \mu \mathrm{m}$ vibratome sections of $4 \%$ PFA fixed brains were placed in ' $\beta$-gal staining buffer' for $20 \mathrm{~min}$ to 24 hours at $37^{\circ} \mathrm{C}$ in the dark. Sections were washed in 1XPBS thrice for 15 min each, stopped the X-gal reaction. Sections were then mounted on 'superfrosted' slides, air-dried and cover-slipped with Immu-mount. Tissue sections can be stored for more than 1 year at RT in the dark without any detectable loss of tissue integrity or diffusion of the indigo-colored precipitates.

\subsubsection{DAB based Immunodetection on paraffin sections}

This method allows the immunodetection of proteins with mono- or polyclonal antibodies on tissue sections at a cellular resolution. The technique has been outlined in depth in (Harlow and Lane, 1988).

5-7 $\mu \mathrm{m}$ thick sections were cut from the paraffinised block of brain using a microtome. The brain sections were floated on a warm water bath $\left(42^{\circ} \mathrm{C}\right)$, placed on silanized or 
positively charged glass slides and were dried $\mathrm{ON}$ at $37^{\circ} \mathrm{C}$. They were incubated at $60^{\circ} \mathrm{C}$ for $10 \mathrm{~min}$ and then deparaffinised and rehydrated as described in section 8.3. Sections were incubated for $5 \mathrm{~min}$ in citrate buffer and then cooked for $10 \mathrm{~min}$ in boiling citrate buffer (at 650 watts in microwave oven). If required water was added during the boiling process to prevent complete drying of the sections. After this, sections were left in the citrate buffer for about $20 \mathrm{~min}$ to cool down. These sections were rinsed in Tris buffer containing 2\% milk powder for 5 min. They were fixed with cover-plates and then washed with Tris buffer ( + milk powder) so as to properly adjust the flow. Endogenous peroxidases were inactivated by incubating sections with $100 \mu 1$ of $3 \%$ hydrogen peroxide for $5 \mathrm{~min}$. To minimize the unspecific binding of the antibody and to reduce the background staining the blocking of free sites on sections were carried out by incubating them with $100 \mu$ l of goat-serum diluted in PBS/BSA (1:5) for 20 min at RT. Sections were then incubated with $100 \mu \mathrm{l}$ of the primary antibody diluted as par requirement with $\mathrm{PBS} / \mathrm{BSA}$, for about $60 \mathrm{~min}$ at $\mathrm{RT}$ or for $\mathrm{ON}$ at $4^{\circ} \mathrm{C}$. In order to remove excess or unbound primary antibodies, sections were washed with Tris buffer $(+2 \%$ milk-powder $)$. The sections were incubated with $100 \mu$ l of bridging antibody i.e. biotinylated secondary antibody (Dako LSAB2, yellow bottle) for $10 \mathrm{~min}$ at RT. Then they were rinsed with Tris buffer (+2\% milk-powder). The bridging antibodies were probed with $100 \mu \mathrm{l}$ of tertiary antibody i.e Horseradish Peroxidase Streptavidine complex (Dako LSAB2, red bottle), by incubating the sections for $10 \mathrm{~min}$ at RT. Then they were rinsed with the Tris buffer without milk-powder to wash off unspecifically bound antibodies. The binding site of antibodies was visualized by incubating the sections with $100 \mu \mathrm{l}$ of DAB ( $1 \mathrm{ml}$ Dako Substrate buffer + two drops of DAB, substrate for HRP) for $10 \mathrm{~min}$. The enzymatic reaction between HRP and DAB results in very a stable brown precipitate that can be visualized under microscope. Sections were rinsed twice with $\mathrm{ddH}_{2} \mathrm{O}$ for 5 min each. In order to make the proper contrast of the signal from the background, sections were counterstained for $30 \mathrm{sec}$ with Haematoxylin (in section 8.3). After washing once in $\mathrm{ddH}_{2} \mathrm{O}$ for $5 \mathrm{~min}$, sections were dehydrated and mounted as described in section 8.5.

\subsubsection{Fluorescent immunodetection on paraffin sections}

The protocol for 'DAB based immunodetection on paraffin sections' was followed till boiling with citrate buffer. These sections were rinsed three times in the Tris buffer 
containing $2 \%$ milk powder for 5 min each. To minimize the unspecific binding of the antibody and to reduce the background staining the blocking of free sites on sections were carried out by incubating them with $100 \mu$ of goat-serum diluted in PBS/BSA (1:5) for 20 min at RT. Sections were then incubated with $100 \mu 1$ of the primary antibody diluted as par requirement with $\mathrm{PBS} / \mathrm{BSA}$, for about 1 hour at $\mathrm{RT}$ or for overnight at $4^{\circ} \mathrm{C}$. Sections were rinsed three times in the Tris buffer containing 2\% milk-powder for 5 min each. To visualize the site of binding of primary antibodies, sections were incubated with $100 \mu 1$ of the fluorescently labeled antibodies diluted as par requirement with PBS/BSA, for about 1 hour at RT. Sections were then rinsed three times with the Tris buffer containing $2 \%$ milkpowder for $5 \mathrm{~min}$ each. To make the proper contrast of the signal from the background counterstaining was carried out with DAPI (binds to chromosomes in the nucleus), diluted with PBS/BSA $(0.5 \mu \mathrm{g} / \mathrm{ml}$ final conc.) for $5 \mathrm{~min}$ at RT. Finally sections were rinsed three times with Tris buffer without milk powder for $5 \mathrm{~min}$ each and were mounted in water based mounting medium such as Aquapoly mount.

\subsubsection{Fluorescent immunodetection on vibrotome sections}

3-5 $\mathrm{mm}$ thick brain sections were embedded in 3\% agar to cut vibrotome sections. $40-100$ $\mu \mathrm{m}$ thick vibrotome sections were cut and collected in 24 wells tissue culture plates containing $1 \mathrm{ml}$ of $1 \mathrm{X}$ PSB. Sections were permeabilized for proper diffusion of antibodies, with $600 \mu 1$ of $0.4 \%$ Triton X-100 in 1 XPBS for 30 min at RT. To minimize unspecific binding of the antibody and to reduce the background staining the blocking of free sites on sections were carried out by incubating them with $500 \mu 1$ of $4 \%$ horse-serum (HS) in $1 \mathrm{X}$ PBS containing $0.2 \%$ TritonX-100, for $60 \mathrm{~min}$ at RT. Sections were then incubated with $150 \mu \mathrm{l}$ of the primary antibody diluted as par requirement with $1 \% \mathrm{HS}$ in $1 \mathrm{X}$ PBS containing $0.05 \%$ TritionX-100, for $\mathrm{ON}$ at $4^{\circ} \mathrm{C}$. Sections were rinsed twice in $1 \mathrm{X}$ PBS for $5 \mathrm{~min}$ each. To visualize the site of binding of primary antibodies, sections were incubated with $200 \mu \mathrm{l}$ of the fluorescent labeled antibodies diluted as par requirement with $1.5 \% \mathrm{HS}$ in $1 \mathrm{X}$ PBS, for about 2 hours at RT. Sections were rinsed with $1 \mathrm{X}$ PBS for $5 \mathrm{~min}$ to remove any non specifically bound antibody. To make the proper contrast of the signal from the possible background counterstaining was carried out with DAPI (binds to chromosomes in the nucleus), diluted with PBS $(0.5 \mu \mathrm{g} / \mathrm{ml}$ final conc.) for $5 \mathrm{~min}$ at RT. Finally, sections were rinsed for 5 min with 1X PBS and mounted in Aquapoly mount. 


\subsubsection{Imaging oligodendrocyte morphology}

After perfusions, brains were postfixed in $4 \%$ paraformaldehyde for $1-2$ hour at $4{ }^{\circ} \mathrm{C}$. Coronal vibratome brain sections of $100 \mu \mathrm{m}$ thickness were cut. Sections were immunostained overnight at $4^{\circ} \mathrm{C}$ with anti-CNP primary antibody $(\mathrm{mM} ; 1: 300$, Sigma Aldrich) and Cy3-coupled anti mouse secary antibody and mounted on superfrost glass slides using Aqua Polymount (as described in section 8.10). CNP+ oligodendrocytes (OL) from layers 2-3 of the prefrontal cortex were randomly selected. A Zeiss laser scanning confocal microscope (Meta 510) was used to acquire z-stacks of OLs at optical sections of $0.53 \mu \mathrm{m}$ with a $63 \mathrm{X}$ objective (1.4 numerical aperture). Confocal z-stacks were used to trace 12-15 individual OLs with the AutoNeuron software package from the Neurolucida three-dimensional cell tracing system (MBF Biosciences, Williston, VT). Cell tracings were analysed with the Neuroexplorer software (MBF Biosciences, Williston, VT). Statistical Data analysis (two tailed t test with Welch's correction and 1 way ANOVA test or kruskal-walli's test) was performed using the GraphPad Prism software package.

\subsubsection{Confocal analysis}

Fluorescent images were captured on a confocal microscope (LSM 510; Carl Zeiss MicroImaging, Inc.) with a 40x or 63x oil plan-Apochromat objective (NA 1.4; Carl Zeiss MicroImaging, Inc). For final analysis, captured LSM images were exported as TIF or PNG images. Documentation and processing of images were done with Photoshop CS.

\subsubsection{Electrophysiological procedure for LTP measurement}

\subsubsection{Preparation of acute brain sections}

Hippocampal slice preparation and solution: Acute hippocampal sections were prepared from 2 year old mice. Mice were deeply anesthetized with diethyl ether before decapitation. The brain was quickly removed and immersed for 2-3 $\mathrm{min}$ in ice-cold artificial cerebrospinal fluid (ACSF). The ACSF had the following composition (in $\mathrm{mM}$ ): $130 \mathrm{NaCl}, 3.5 \mathrm{KCl}, 1.2 \mathrm{CaCl}$, 1.2 MgSO4, $24 \mathrm{NaHCO} 3,1.25 \mathrm{NaH} 2 \mathrm{PO} 4,10$ Glucose, with the $\mathrm{pH}$ adjusted to 7.4. Transverse sections of $400 \mu \mathrm{m}$ thickness were cut with a vibroslicer (752M, Campden Instruments, Loughborough, UK). Sections were then transferred to an interface-recording chamber of the Oslo type and allowed to recover for at 
least 90 min. The recording chamber was continuously perfused with ACSF, aerated with $95 \% \mathrm{O}_{2}$ and $5 \% \mathrm{CO}_{2}(3-4 \mathrm{ml} / \mathrm{min})$. The temperature was maintained at $34^{\circ} \mathrm{C}$.

\subsubsection{Extracellular recordings of hippocampal sections.}

The recording electrodes were pulled from thin-walled borosilicate glass capillaries (GC150TF-10, Harvard Apparatus, Holliston, MA, USA) using a horizontal FlamingBrown micropipette puller (P-80/PC, Sutter Instrument Co., Novato, CA, USA). They were filled with ACSF. Monopolar stimulation electrodes made from bare stainless steel microwire $(50 \mu \mathrm{m}$ diameter, AM-Systems) were used for stimulation. The stimuli were generated by photoelectric stimulus isolation units (Grass PSIU6) triggered by a stimulator (Grass S88). Extracellular field potential recordings were done using a custom-built DC amplifier. Data were digitized by a DigiData 1322A (Molecular Devices, Sunnyvale, CA, USA). Initial analysis of the data was done in Clampfit 9.0 (Molecular Devices, Sunnyvale, CA, USA). To evoke field excitatory postsynaptic potentials (fEPSPs), the stimulation electrode was placed in stratum radiatum at CA3/CA1 junction for the activation of Schaffer collaterals. The recording electrode was placed in the stratum radiatum of the CA1 region. The magnitude of fEPSPs was measured as slope between 20$80 \%$ level of the rising phase. For input-output relationship, fEPSPs were evoked with $0.1 \mathrm{~ms}$ stimuli at $0.25 \mathrm{~Hz}$ and an average of 4 consecutive responses was taken. fEPSP slopes were plotted against the stimulus intensity $(10$ to $150 \mu \mathrm{A})$. Paired-pulse facilitation (PPF) was measured at different interstimulus intervals $(25,50,75,100,125,150,175$ and $200 \mathrm{~ms}$ ) as the ratio of the slope of the sec fEPSP to the first fEPSP. Here also the paired stimuli were given at $0.25 \mathrm{~Hz}$ and an average of 4 consecutive responses was taken. To study long-term potentiation (LTP), baseline responses were evoked every $20 \mathrm{sec}$ for $5 \mathrm{~min}$ and LTP was induced by 4 trains separated by $20 \mathrm{sec}$, each train consisting of $100 \mathrm{~Hz}$ stimulation for $1 \mathrm{sec}$. The post-train responses were then measured every $20 \mathrm{sec}$ for $60 \mathrm{~min}$. LTP was measured as the average of responses between 50-60 min after induction. 
4. Results 


\subsection{Role of Neuregulin1 in CNS myelination}

Many CNS axons are first myelinated by oligodendrocytes (OL) and then by Schwann cells (SC) as they exit the spinal cord. For example, all primary sensory and lower motor axons maintain the same myelinated or unmyelinated fate through out their length. In certain pathological conditions SC can also invade the demyelinated CNS and ensheath central axons. These observations suggest that the axonal signals controlling myelin formation are conserved in the central and peripheral nervous systems (Colello and Pott, 1997; Duncan and Hoffman, 1997).

NRG1, expressed on the axonal surface, is an essential regulator of PNS myelination (reviewed in Nave and Salzer, 2006) and complete loss of NRG1 leads to impaired PNS myelination and sensory and motor neuron death (Taveggia et al., 2005; Wolpowitz et al., 2000). Sciatic nerves from heterozygous Nrg1 (Nrg1+/-) mouse mutants are hypomyelinated. Correspondingly, overexpression of axon-bound NRG1 type III under control of the neuronal ThyI promoter induces hypermyelination (Michailov et al., 2004). In contrast to PNS, overexpression of both NRG1 type I and NRG1 type III in the CNS causes hypermyelination of the axons in cortical grey matter and corpus callosum (Brinkmann and Agarwal et al.,). These observations suggested that OL are capable of responding to NRG1 signals and revealed an important difference between the CNS and PNS myelination.

\subsubsection{Consequence of NRG1 haploinsufficiency on the maintenance of white matter}

Since Nrg1 +/- mice exhibit a significant hypomyelination of axons in the PNS (Michailov et al., 2004; Taveggia et al., 2005), a corresponding hypomyelination in CNS white matter tracts was anticipated. Surprisingly, analysis of the optic nerve, corpus callosum, and spinal cord of adult $\mathrm{Nrg} 1+/$ - mice revealed no such reduction of myelin sheath thickness (Brinkmann and Agarwal et al.,). Nevertheless, a chronic deficit in NRG1 signaling from neurons to OL could have indirectly affected myelinated axons, due to insufficient support by glia cells. This hypothesis is supported by the studies that showed mutations in OL-specific genes can lead to the disruption of axonal integrity while OL and 
myelin are relatively unaffected (Griffiths et al., 1998; Lappe-Siefke et al., 2003). The possible lack of axonal support by glial cells in Nrg1 +/- mice may lead to myelin related axonal pathologies that are often associated with transport defects. These transport defects might further result in axonal swellings due to accumulation of amyloid precursor protein (APP). The progressive degeneration of these swollen axons leads to the formation of GFAP+ astroglial scars, a hallmark of ongoing neurodegeneration (Lappe-Siefke et al., 2003). We noticed few APP+ swellings in neocortex, corpus callosum, hippocampus, cerebellum and midbrain of $\mathrm{Nrg} 1+/-$ and wildtype mice brains (Fig. 5A). The absolute numbers of swellings were low and no considerable difference between mutant and wildtype mice was observed. Due to the lack of massive neurodegeneration in $\mathrm{Nrg} 1+/$ mice we observed negligible amount of GFAP+ glial scars (Fig. 5A).

Western blotting revealed that adult $\mathrm{Nrg} 1+/$ - mice express the same steady state level of NRG1 protein in the brain and spinal cord as wildtype controls (Fig. 5B). This surprising observation is in contrast to the finding in PNS of $\mathrm{Nrg1+/-} \mathrm{mice} \mathrm{that} \mathrm{have} \mathrm{reduced} \mathrm{levels} \mathrm{of}$ NRG1 protein in their sciatic nerves (Michailov et al., 2004). 
A

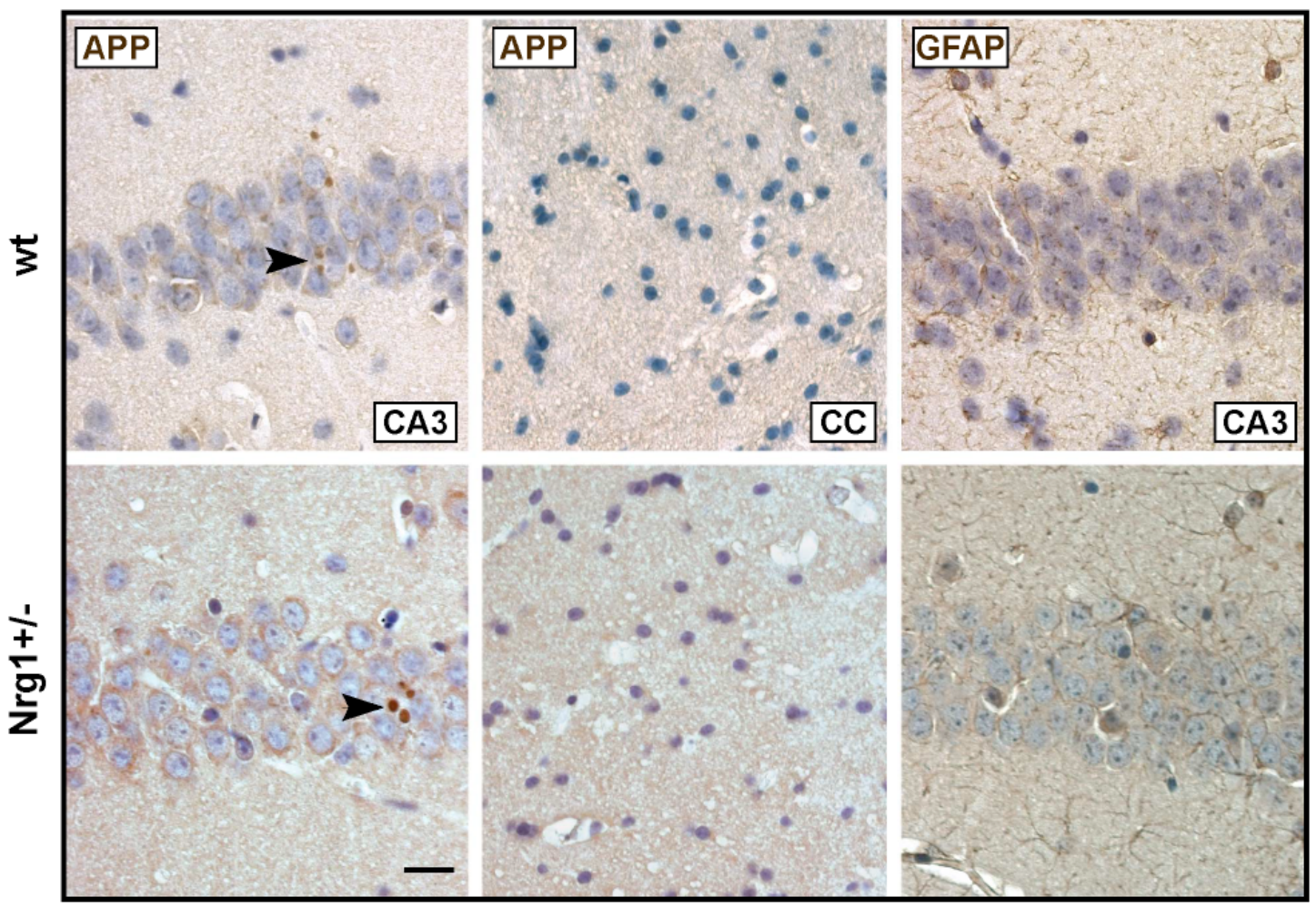

B
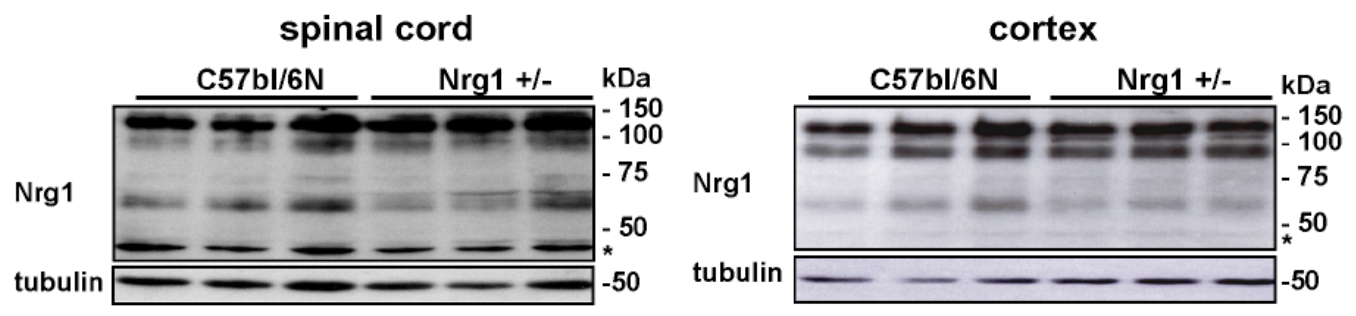

Fig. 5. Absence of neurodegeneration in mice with reduced Nrg1 gene dosage

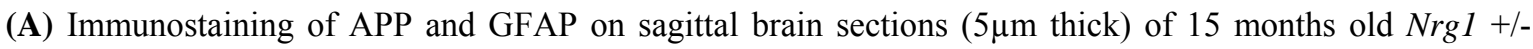
(bottom) and wildtype (top) mice could not show abnormally increased axonal swellings and astroglial scars, respectively. Very few APP positive swellings (black arrows heads) were visible in CA3 region of wildtype as well as in $\mathrm{Nrg1}+/$ - mice. These few APP positive swellings might represent age related axonal

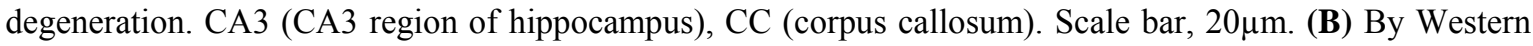
blot analysis, steady-state levels of the major NRG1 isoforms appear unaltered in protein lysates from forebrain (left) and spinal cord (right) of $\mathrm{Nrg} 1+/$ - heterozygotes (age 4-5 mo) compared to age-matched controls (3 mice per genotype; loading control, tubulin). Asterisks denote unspecific bands. 


\subsubsection{Myelination in the absence of NRG1}

Conventional Nrg1 null (Nrg1 -/-) mice die at embryonic (E) day 10.5, prior to the generation of OL. We therefore generated conditional null mutants to analyze possible defects of postnatal CNS myelination. Mice carrying two 'floxed' Nrg1 alleles readily recombine exons 7-9 (essential for the EGF-like signaling function) upon Cre expression in vivo (Li et al., 2002a). By cross-breeding floxed Nrg1 to CamKII-Cre mice (Minichiello et al., 1999), we obtained mutants lacking NRG1 in virtually all projection neurons of the forebrain (Fig. 6A, B) due to Cre recombination at around postnatal day (P) 5, i.e. after OL specification but prior to subcortical myelination. Surprisingly, these mutants revealed no obvious developmental abnormalities of the cortex, hippocampus, or the subcortical white matter, and showed no demyelination at older age (Fig. 6C, D). Although some myelination may have occurred prior to the complete loss of NRG1 protein, we conclude that axonal NRG1 is not required to maintain CNS myelin throughout adult life. A detailed behavioral analysis of these mice will be discussed in the next chapter. 
A

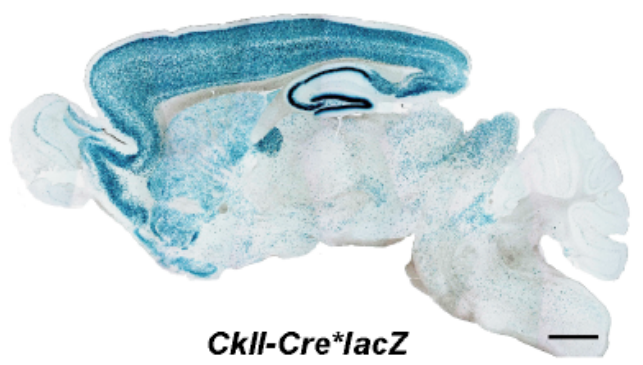

C

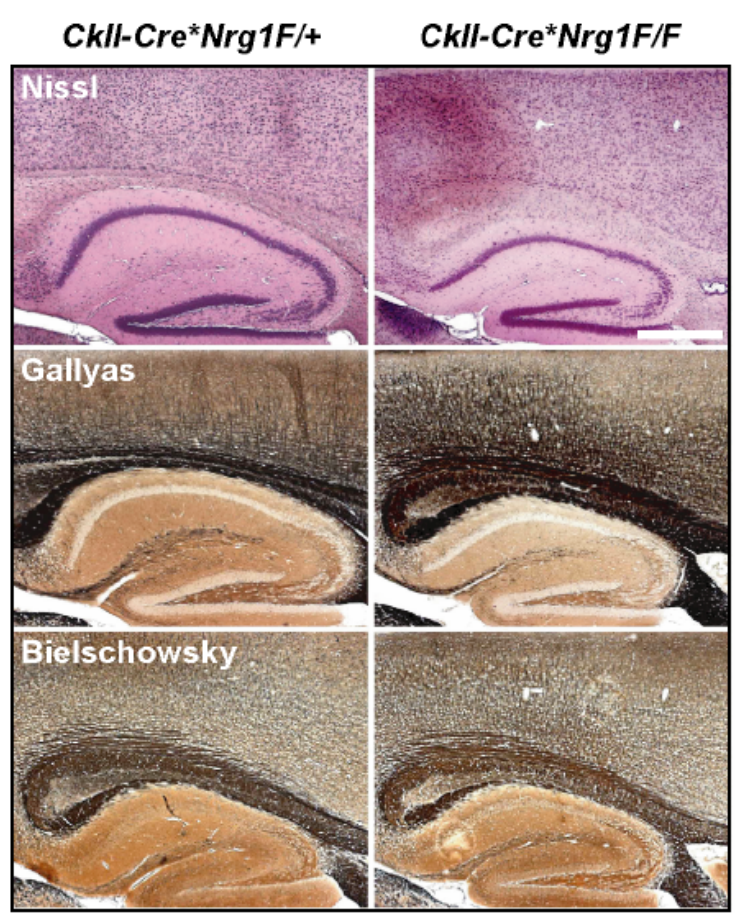

B

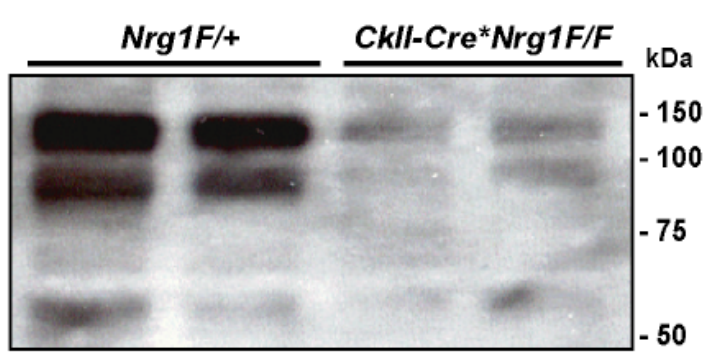

D

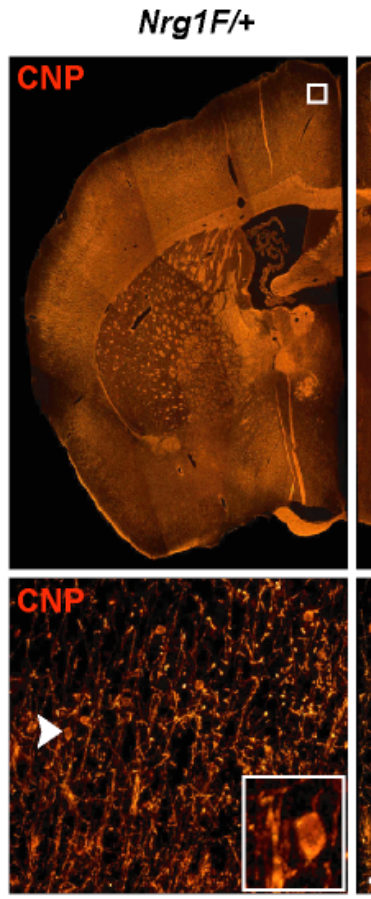

Ckll-Cre*Nrg1F/F

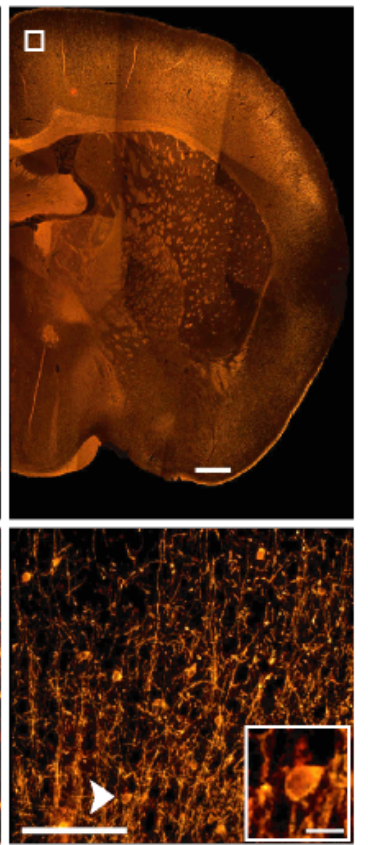

Fig. 6. Conditional inactivation of Nrg1 in postnatal forebrain projection neurons

(A) CamKII promoter-driven Cre expression (CkII-Cre) results in the recombination of the Rosa26lacZ reporter gene in the forebrain of CkII-Cre*lacZ double transgenic mice, as revealed by X-gal histochemistry of a sagittal brain section at P30. Scale bar, $1 \mathrm{~mm}$. (B) By Western blot analysis, forebrain protein lysates from two 2 months old Nrg1 mutants $\left(\mathrm{CkII}-\mathrm{Cre}{ }^{*} \mathrm{Nrg} 1 \mathrm{~F} / \mathrm{F}\right)$ demonstrate strong reduction of NRG1 protein levels compared to controls $(\mathrm{Nrg} 1 \mathrm{~F} /+)$. Molecular weights of protein markers are indicated on the right. (C) Neocortical and hippocampal morphology, axon numbers, and subcortical myelination appear unaltered in CkII-Cre*Nrg1F/F mutants. Nissl staining (top), Gallyas silver impregnation of myelinated fibers (middle), and Bielschowsky silver impregnation of axons (bottom) of sagittal paraffin sections $(5 \mu \mathrm{m})$ from mutant

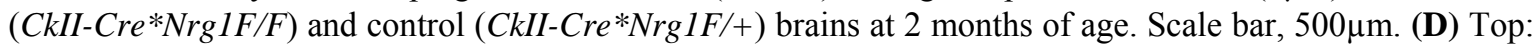
Immunostaining of CNP on a coronal brain section (7 $\mu \mathrm{m}$ paraffin) from a conditional mutant (CkIICre*Nrg1F/F, right half image) and a control animal ( $N r g 1 F /+$, left half) fails to show signs of CNS demyelination at age $12 \mathrm{mo}$. Scale bar, $500 \mu \mathrm{m}$. Bottom: Higher magnification of cortical layers II/III (boxed areas in top panel) reveals myelinated fibers. Individual CNP+ oligodendrocytes (white arrowhead) are shown enlarged in insets. Scale bars, $100 \mu \mathrm{m}$ and $10 \mu \mathrm{m}$ (insets). 
In order to address the developmental role of NRG1, we generated mutants in which Cre recombination occurs already during the embryonic period. By cross-breeding floxed Nrg1 with NEX-Cre mice (Goebbels et al., 2006), we disrupted NRG1 expression in virtually all newborn projection neurons of the cortex beginning at embryonic day (E) 12. Efficient Cre-mediated recombination was demonstrated by PCR analysis of brain genomic DNA at 3 months of age (Fig. 7A). Western blotting (Fig. 7B) and Quantitative RT-PCR (Fig. 7C) confirmed the reduction of NRG1, with residual expression most likely derived from glia (Esper et al., 2006).

Surprisingly, $N E X-C r e^{*} N r g 1^{\text {floxflox }}$ mutants $\left(' N C * F / F^{\prime}\right)$ were fully viable and indistinguishable in the cage from wildtype, floxed ('F/F' and ' $F /+$ '), or $N E X-C r e^{*} N r g 1^{f l o x /+}$ controls. By morphological and immunohistochemical criteria, the cortex and hippocampus appeared normal (Fig. 8A-D). The subcortical white matter with callosal axons from the overlying cortical projection neurons was well developed (Fig. 8A, B). Both compact and non-comapct myelin proteins were expressed at wildtype levels (Fig. $8 \mathrm{C}, \mathrm{D})$. We observed that myelinated fibers in the grey matter were normal in appearance when immunostained for 2'3'-cyclic nucleotide phosphodiesterase (CNP) (Fig. 8C, D) and myelin basic protein (MBP) (data not shown). 

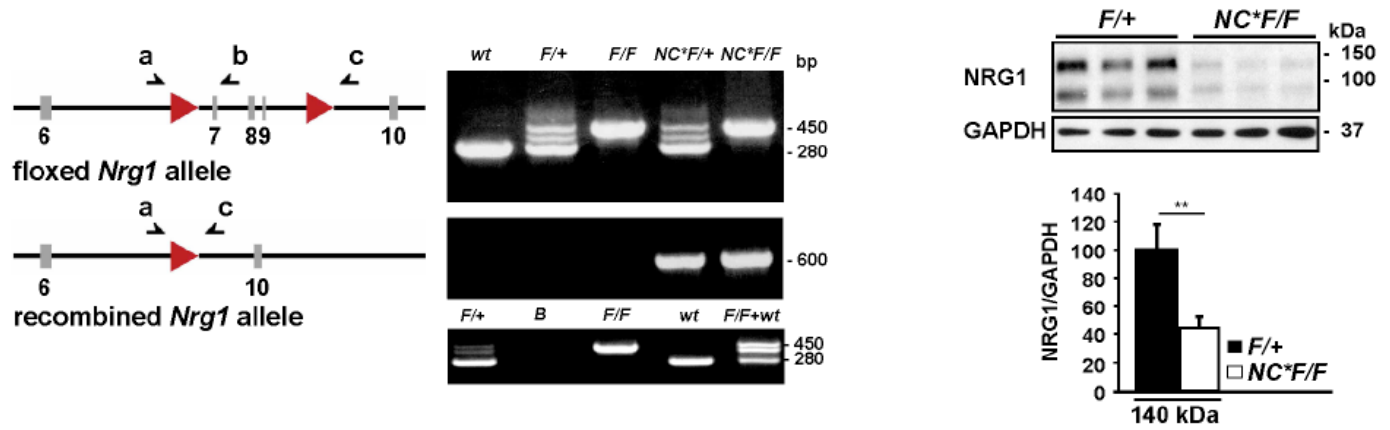

C
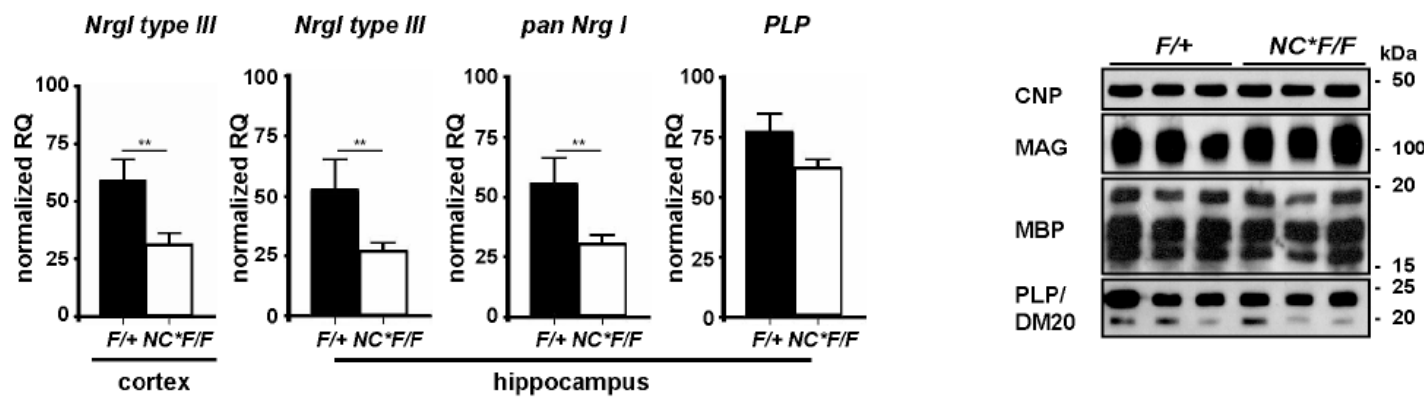

Fig. 7. Reduced NRG1 and normal levels of myelin protein in mice lacking NRG1 in postmitotic forebrain projection neurons

(A) Mice heterozygous $(F /+)$ or homozygous $(F / F)$ for the floxed Nrg1 allele, when expressing Cre under control of the NEX gene (NC), readily recombine the floxed Nrg1 allele. Left: Structure of the floxed Nrg1 allele (with loxP sites in red, flanking exons 7-9) before (top) and after Cre-mediated recombination (bottom). Arrows indicate positions of primers. Corresponding PCR products are depicted to the right: PCR of Nrg1 genomic DNA from neuronal tissue (olfactory bulb) of wildtype mice and NEX-Cre conditional mutants at 3 months of age. In the uppermost gel, intermediate size PCR products in lanes $F /+$ and $N C * F /+$ are heteroduplices (refer lowermost gel for details). In the presence of Cre recombinase $(N C)$, the excision of exons 7-9 from the conditional Nrg1 allele allows the amplification of a $500 \mathrm{bp}$ fragment (middle gel). Single step of denaturation $\left(95^{\circ} \mathrm{C}\right)$ and annealing of $F / F$ and $w t$ genotyping PCR products mixed in equal proportion $(F / F+w t)$ resulted in an intermediate heteroduplices in $F / F+w t$ lane. Lane B is control lane where template DNA was missing from the PCR reaction mixture (lowermost gel). (B) Top: Western blot of protein lysates revealing a loss of NRG1 in the neocortex of $N C^{*} F / F$ mutants compared to controls $(F /+)$ at 3 age months. Bottom: Densitometric quantification reveals a $\sim 60 \%$ reduction of 'full length' NRG1 type III $(\sim 140 \mathrm{kDa})$ in $N C^{*} F / F$ mutants compared to controls $(F /+)$. Peak intensities $( \pm$ SEM) were normalized to GAPDH. (C) Quantitative RT-PCR detecting mRNA in cortex (Nrg1 typeIII) and hippocampus (Nrg1 typeIII, pan-Nrg1 and PLP) of 3 months old wildtype mice ( $F /+$ black bars) and mutants ( $N C^{*} F / F$, white bars). Quantitative analysis revealed $\sim 50 \%$ reduction in Nrg1 type III mRNA in cortex and both pan-Nrg1 and Nrg1 type III mRNA in hippocampus. This observation indirectly points to the fact that pyramidal neurons mainly express Nrg1 type III isoform. Level of PLP mRNA is not altered in both wildtype and mutants hippocampus. Error bars: SEM. Significance test: two-tailed, t test with Welch's correction. (D) Semiquantitative comparison of myelination by Western blotting myelin-specific proteins from neocortical brain lysates of mutant mice $\left(N C^{*} F / F\right.$; age 3 months) and littermate controls $(F /+)$. Steady state levels of CNP, MAG, MBP, and $\mathrm{PLP} / \mathrm{DM} 20$ are normal. 
A

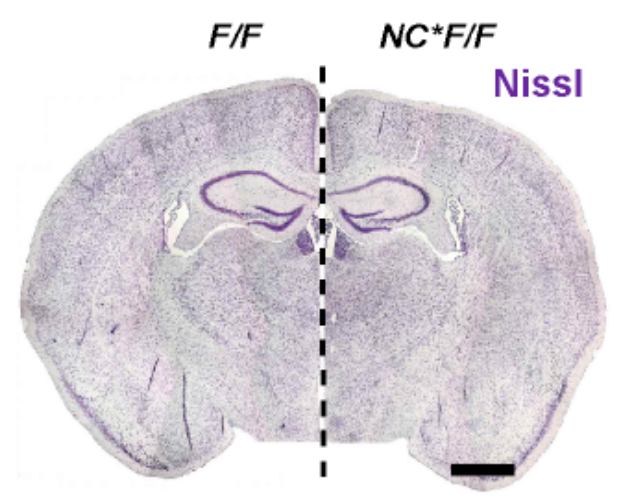

C

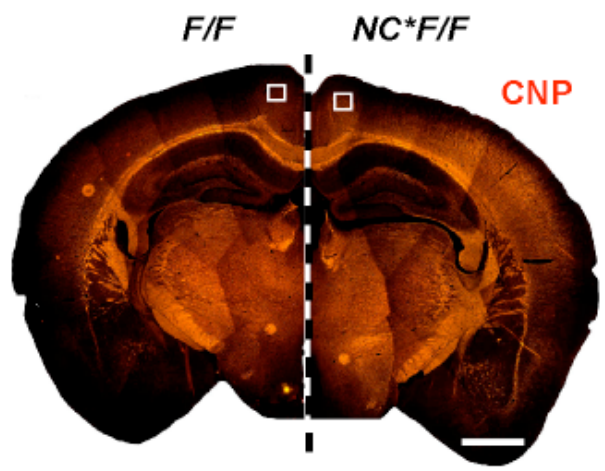

B

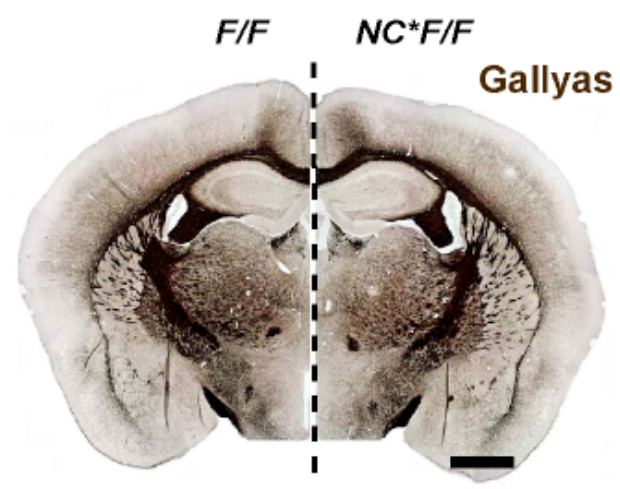

D

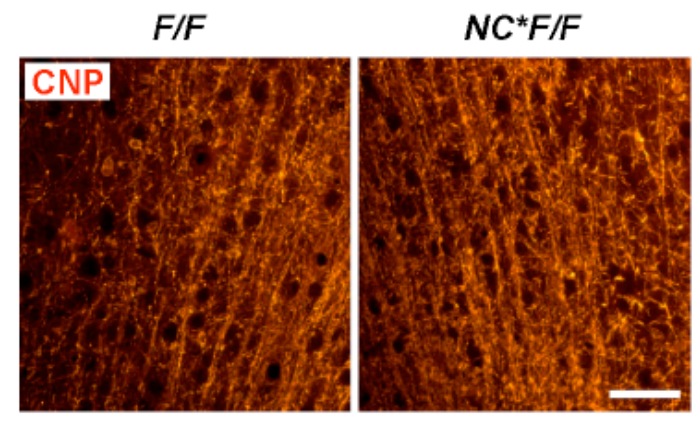

Fig. 8. Normal myelination in the absence of projection neuron derived NRG1

(A, B) Neocortical development (Nissl staining) and subcortical myelination (Gallyas silver impregnation) appear normal in mutant $\left(N C^{*} F / F\right)$ compared to controls $(F / F)$. Depicted are mirror images of coronal paraffin sections $(7 \mu \mathrm{m})$ obtained at age 3 months. Scale bars, $1 \mathrm{~mm}$. (C, D) Myelinated tracts in neocortex and corpus callosum of mutants $\left(N C^{*} F / F\right)$, as visualized by immunostaining for CNP. Shown are coronal paraffin sections $(7 \mu \mathrm{m})$ of 3 months old brains from mutants $\left(N C^{*} F / F\right.$; right hemisphere) and control mice $(F / F$; left hemisphere). Scale bar, $1 \mathrm{~mm}$. Enlargements (in E) reveal individual fibers in cortical layers II/III (boxed in upper panels). Scale bar, $50 \mu \mathrm{m}$.

Using electron microscopy, myelin in the corpus callosum (Fig. 9A) and the spinal cord (not shown) exhibited an intact ultrastructure (Brinkmann and Agarwal et al.,). There were no obvious differences in myelin sheath thickness or axonal size distribution (Fig. 9B, C). There is a clear evidence for premature myelination in transgenic mice that overexpress Nrg1 type III in neurons under control of Thy1.2 promoter (Thy1-III). In the developing optic nerves of ThyI-III transgenic mice at day P6 there is a 3-fold higher number of myelinated axons than in controls, without a corresponding shift of OL numbers 
(Brinkmann and Agarwal et al.,). To address a potential myelination delay in the absence of NRG1 we immunostained MBP at postnatal day (P) 10. Confocal microscopy revealed unaltered numbers of $\mathrm{MBP}+$ myelin profiles in the ventral corpus callosum of $N C^{*} \mathrm{~F} / \mathrm{F}$ mutants when compared to controls (Fig. 9D, E), demonstrating that also timely myelination does not depend on NRG1. Taken together, these results put forth that NRG1 could initiate the myelination program in CNS development, a function normally provided by a distinct (yet unknown) axonal signaling system.

Recently, hypomyelination in the CNS was reported in mice lacking the expression of BACE1, a protease required for NRG1 processing (Hu et al., 2006; Willem et al., 2006). This suggests that widespread BACE1 activity could provide a "paracrine" source of NRG1 originating from astrocytes (Esper et al., 2006) that are genetically 'wildtype' in $\mathrm{NEX}-\mathrm{Cr} \mathrm{N}^{*} \mathrm{Nrg} 1^{\text {flox/flox }}$ mice. In order to eliminate the glial contribution of NRG1, along with neuronal derived NRG1, we crossbred floxed Nrg1 and Emx1-Cre mice. In Emx1-Cre mice the expression of Cre starts at around day E10.5 in the ventricular zone of the developing forebrain (Gorski et al., 2002). The cell populations derived from Emx1+ cell lineage that are efficiently recombined in the brain of Emx1-Cre* $N r g 1^{\text {floxflox }}$ mutants include radial glia, Cajal-Retzius cells, glutamatergic neurons, astrocyes and OL (Fig. 10A) (Gorski et al., 2002). In contrast, most of the GABAergic interneurons are generated outside the Emx1+ lineage and are not recombined (Gorski et al., 2002). Efficient Cre-mediated recombination of the floxed Nrg1 allele in Emx1-Cre*Nrg1 $1^{\text {floxflox }}$ mutants (at 4 months of age) was demonstrated by Western blotting (Fig. 10B) and revealed a severe reduction of NRG1 protein levels. Thus demonstrating that majority of NRG1 in the cortex is derived from principal projection neurons and glial cells, most likely astrocytes (Esper et al., 2006). The residual expression of NRG1 is most likely derived from non-recombined few inefficiently recombined cells in the cortex or GABAergic interneurons (Gorski et al., 2002). 
A

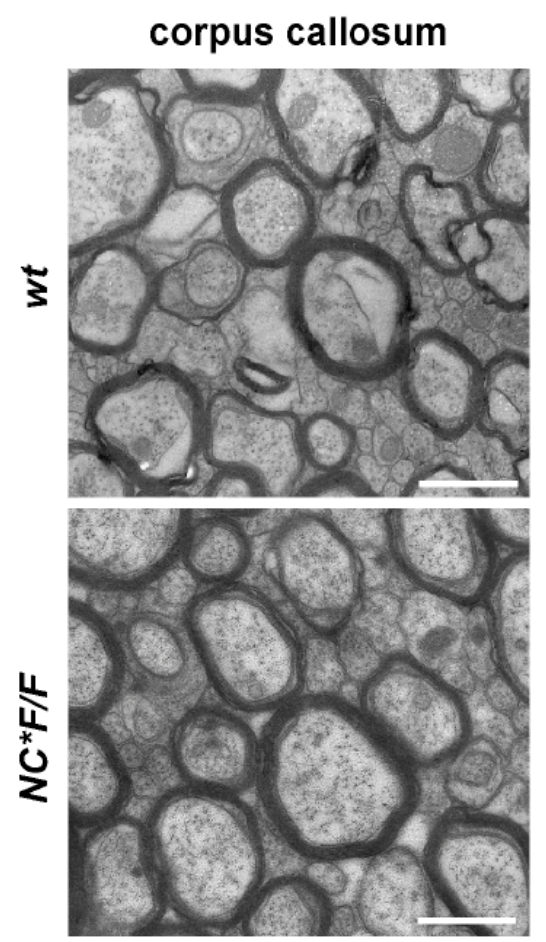

D

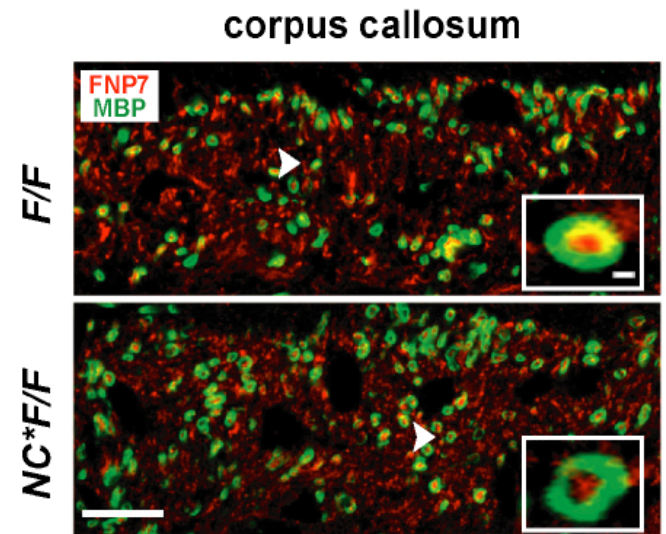

B

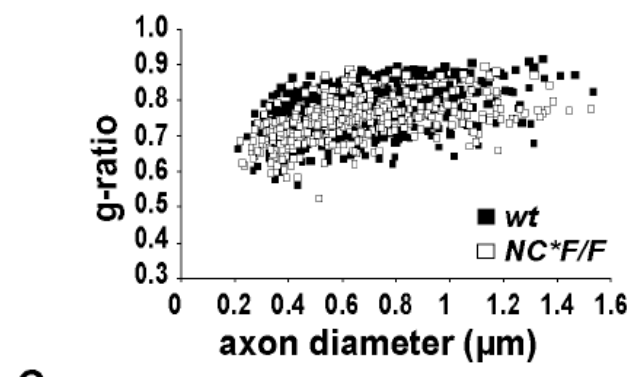

C

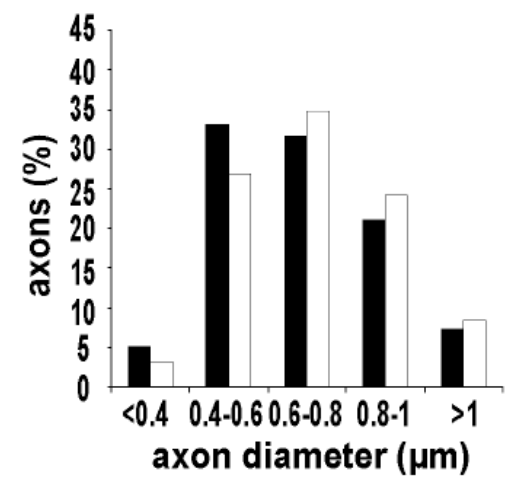

E

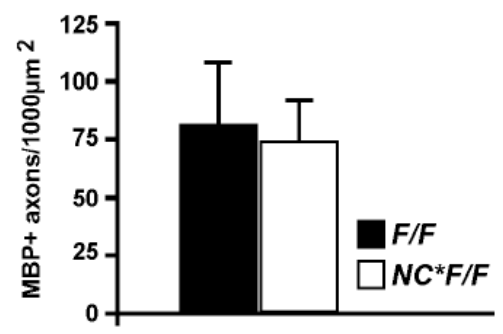

Fig. 9. Figure 9: Myelin ultrastructure and onset of myelination in the absence of projection neuron derived NRG1

(A) Electron microscopy reveals normally myelinated axons in the caudal corpus callosum of mutant $\left(N C^{*} F / F\right)$ and control mice (wt) at 5 weeks of age. Also myelin ultrastructure and membrane spacing are normal. Scale bars, $1 \mu \mathrm{m}$. (B) Normal myelin sheath thickness (g-ratios) in the corpus callosum of mutant and wildtype mice. Scatter blot was derived from electron micrographs of the corpus callosum from mutant $\left(N C^{*} F / F\right)$ and control (wt) mice, aged 5 weeks ( $\mathrm{n}=3$ per genotype). (C) Quantification of the axon size distribution in the corpus callosum reveals no obvious difference between mutant (white bars) and control (black bars) mice. (D) Callosal myelination in the absence of NRG1 is not delayed (age P10). Confocal microscopy of coronal vibratom sections $(100 \mathrm{~mm})$ immunostained for axons derived from projection neurons (FNP7, red) and myelin (MBP, green) demonstrates widespread myelination in the ventral corpus callosum of mutants $\left(N C^{*} F F\right)$ and control $(F / F)$ mice. Scale bar, $10 \mu \mathrm{m}$ (inset, $250 \mathrm{~nm}$ ). (E) Quantitation of MBP data in $\mathrm{D}(\mathrm{n}=3$ per genotype; \pm SEM). 
To our surprise Emx1-Cre*Nrg1 $1^{\text {floxflox }}$ mutants were fully viable and developed overall normal cage behavior. Even with such a drastic reduction in the NRG1 levels in Emx1$C r e^{*} N r g 1^{f l o x / f l o x}$ mutants, their brain morphology seems to be largely normal (Fig. 11A). By immunohistochemical analysis, we observed normal numbers of various neural cell populations including olig $2+\mathrm{OL}, \mathrm{NeuN}+$ neurons and GFAP + astrocytes, in the cortex and hippocampus of mutants when compared to wildtype brains (numbers not quantified) (Fig. 11B).

A

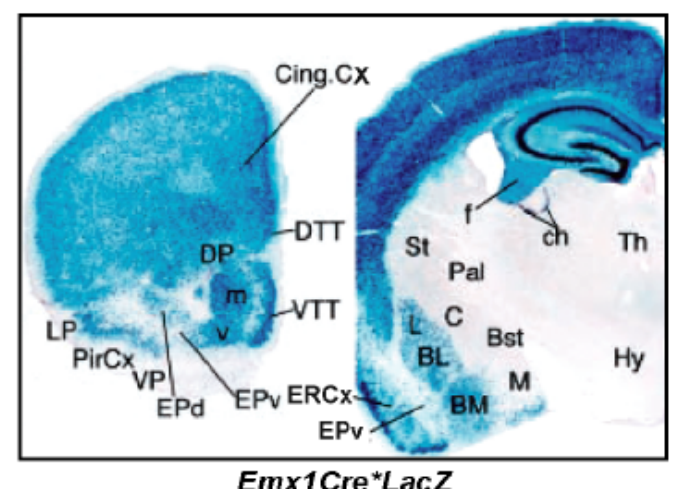

Emx1Cre*LacZ

C

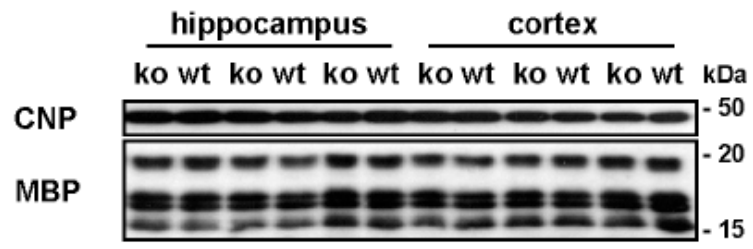

B
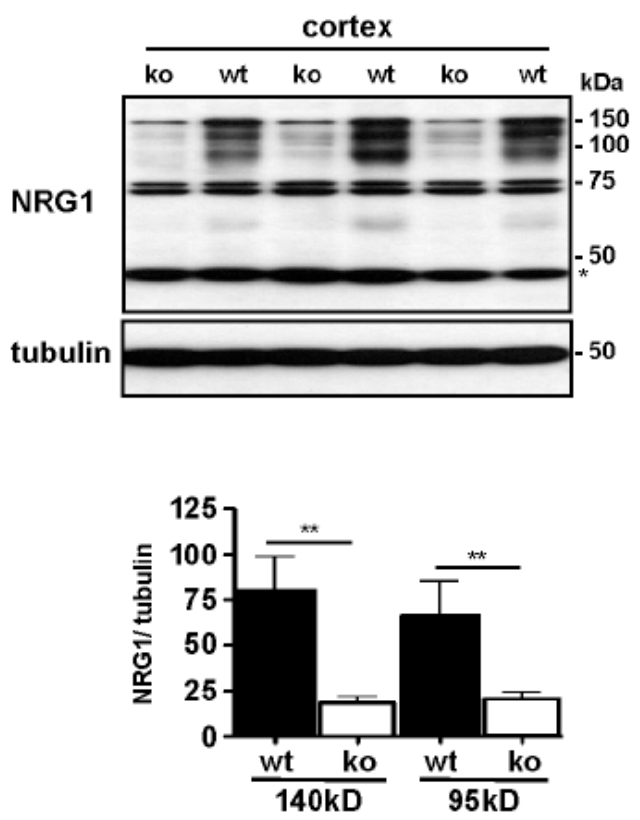

Fig. 10. Conditional inactivation of Nrg1 in Emx1+ cell linage at embryonic stage

(A) The expression of Emx1-Cre transgene starts at around E10.5 and leads to the recombination of the Rosa26lacZ reporter gene in forebrain projection neurons, astrocytes and OL, except GABAergic interneurons. It demonstrates the wide spread expression of Emx1-Cre in the forebrain grey and white matter (modified from Gorski et al., 2002). (B) Left: Western blot of cortical protein lysates revealing a loss of NRG1 in the neocortex of Emx1-Cre*NRG1F/F (ko) mutants compared to controls Nrg1 F/+ (wt) at 4 months of age. Right: Densitometric quantification revealed $\sim 70-80 \%$ reduction of 'full length' NRG1 type III $(\sim 140 \mathrm{kDa})$ and NRG1 typeI $(\sim 95 \mathrm{kDa})$ isoforms in mutant (ko) compared to control (wt) mice. Peak intensities $( \pm$ SEM) were normalized to tubulin. (C) Semiquantitative comparison of myelination by Western blotting myelin-specific proteins from cortical and hippocampal lysates of mutant mice (ko, age 4 months) and littermate controls (wt). Steady state levels of CNP and MBP are normal. 
A
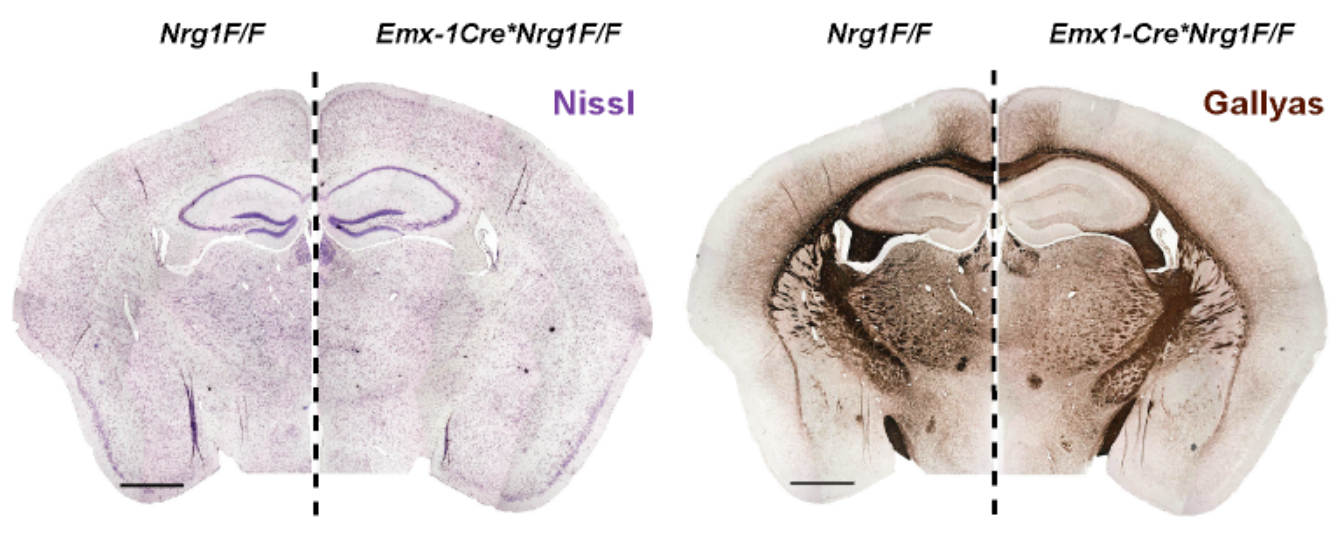

B
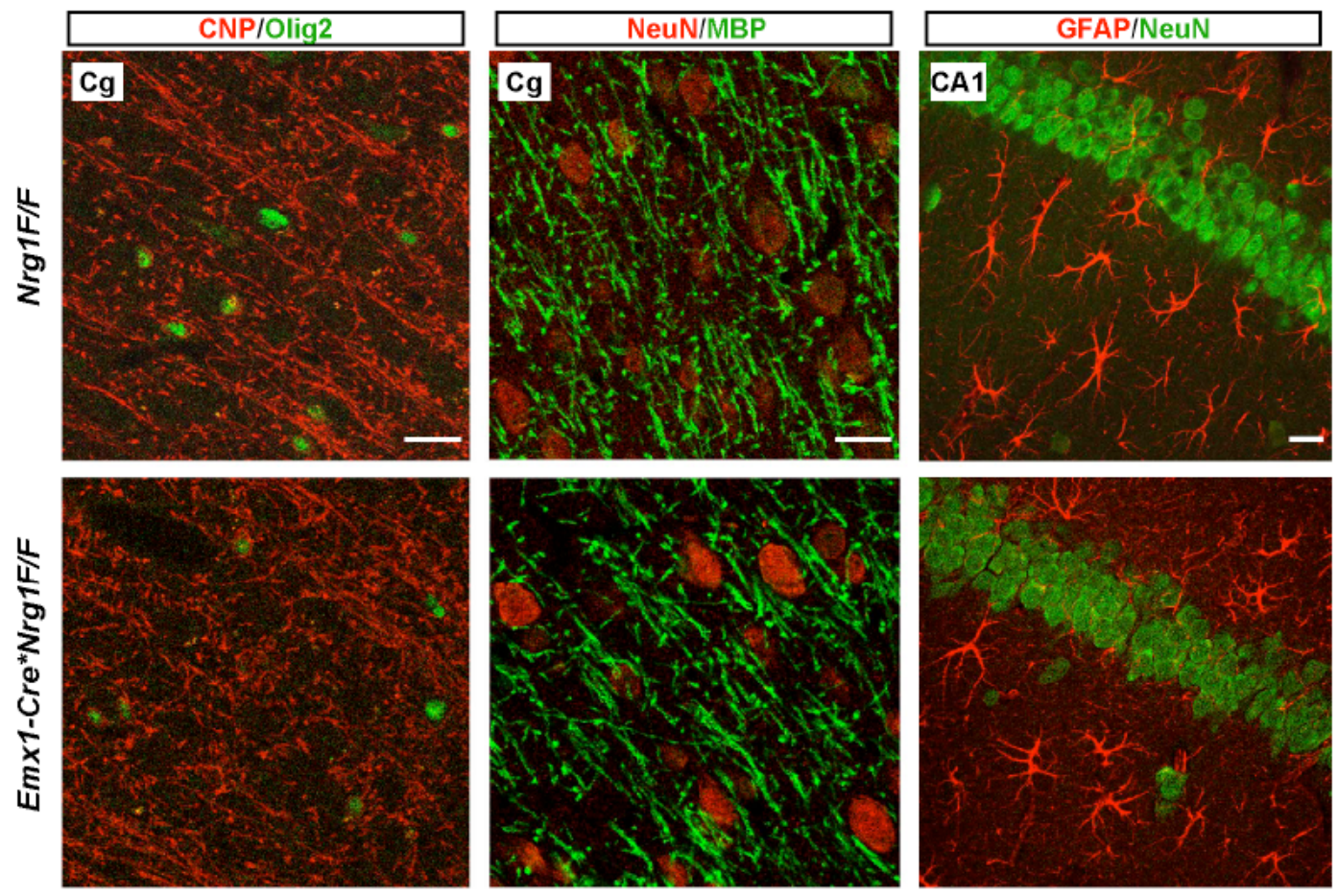

Fig. 11. Normal myelination and cell survival in the absence of NRG1 from forebrain

(A) Neocortical development (Nissl staining, left) and subcortical myelination (Gallyas silver impregnation, right) appear normal in mutant $\left(E m \times 1-C r e^{*} \mathrm{Nrg} 1 \mathrm{~F} / \mathrm{F}\right)$ compared to controls $(\mathrm{Nrg} 1 \mathrm{~F} / \mathrm{F})$. Depicted are mirror images of coronal paraffin sections $(7 \mu \mathrm{m})$ obtained at age 4 months. Scale bars, $1 \mathrm{~mm}$. (B) Myelinated axons (CNP and MBP), oligodendrocytes (olig2), neurons (NeuN) and astrocytes (GFAP) in neocortex of mutants $(E m \times 1-C r e * N r g 1 F / F)$, as visualized by immunostaining for their respective markers. Shown are coronal paraffin sections $(7 \mu \mathrm{m})$ of 4 months old brains from mutants and control mice $(\mathrm{Nrg} 1 \mathrm{~F} / \mathrm{F})$. Cingluate cortex $(\mathrm{CgCx})$ and $\mathrm{CA} 1$ region of hippocampus (CA1). Scale bars, $20 \mu \mathrm{m}$. 
We could show normal myelination of cortical axons, in the absence of NRG1 from neurons and glia in Emx-Cre*Nrg $1^{\text {flox/flox }}$ mice, by immunostaining and western blotting myelin protein such as CNP and MBP (Fig. 10C, 11B). Interestingly, Emx1$C r e^{*} N r g 1^{\text {flox/flox }}$ mutants are extremely susceptible to stressed conditions and exhibit epileptic seizures when subjected to mild stress ("handling induced seizures"). Further consequences of this phenotype will be discussed in detail in the next chapter.

To completely abolish Nrg1 expression in the developing CNS, we generated conditional mutants using Nestin-Cre mice (Tronche et al., 1999) (Fig. 12A). NestinCre*Nrg1 $1^{\text {flox/flox }}$ mutants died about $16 \mathrm{~h}$ after birth, i.e. later than conventional Nrg1 type III null mutants (Wolpowitz et al., 2000) but most likely with a lethal PNS defect (see below and Fig. 13A, B). When Nestin-Cre mutants were analyzed at birth, there was no detectable difference in brain morphology compared to controls (Fig. 14A). However, we could show increased number of apoptotic cells by Tunnel and haematoxylene staining mainly in corpus callosum, indusium griseum and neuroepithelium of mutants (Fig. 14B). Although we cannot comment upon the identity of the cell population undergoing apoptosis, based on their location it might be possible that they are oligodendroglial cells. Western blotting showed mutant brains to be completely NRG1-deficient. Also in spinal cord, NRG1 was dramatically reduced (Fig. 12B). 


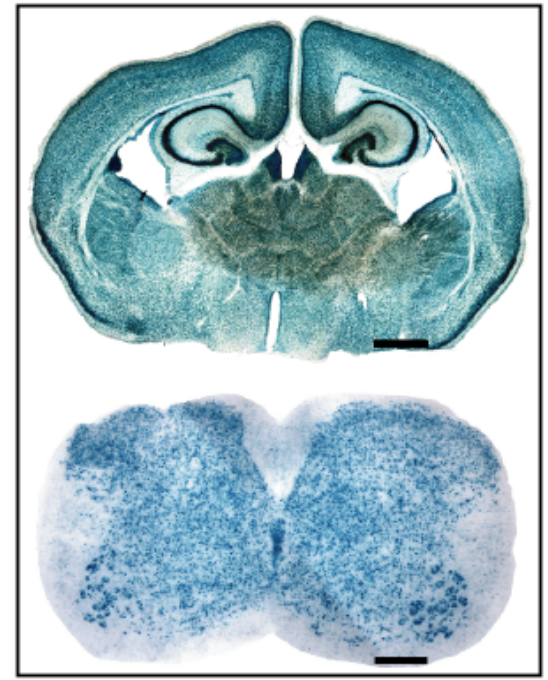

Nes-Cre*lacZ
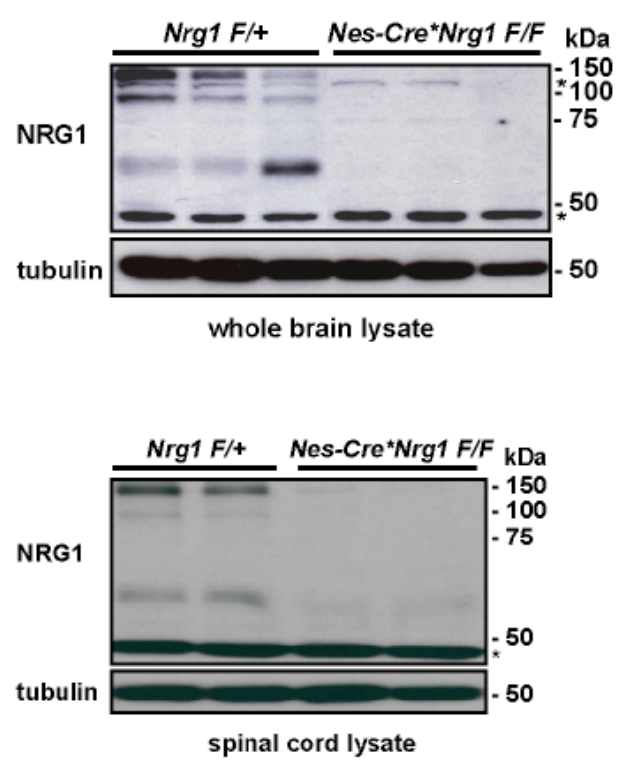

C
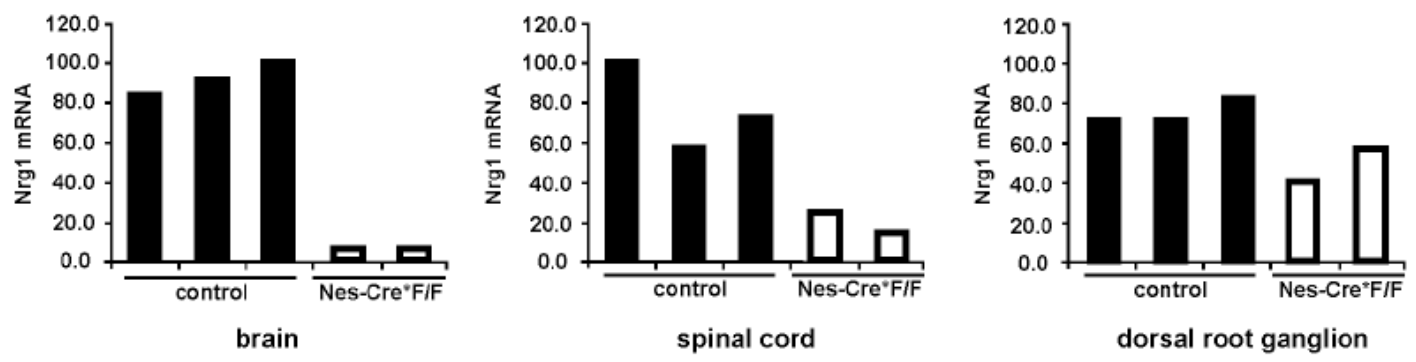

Fig. 12. Nestin-Cre driven recombination of floxed genes in brain and spinal cord

(A) Embryonic expression of a Nestin-Cre transgene causes recombination of the Rosa26lacZ reporter gene in virtually all neural cells of brain and spinal cord. Although this Cre transgenic line has been used by many investigators, $\beta$-galactosidase gene activation throughout brain and spinal cord is not documented (X-gal histochemistry of $50 \mu \mathrm{m}$ vibratome sections at age P8). Scale bars, $1 \mathrm{~mm}$ (brain) and $200 \mu \mathrm{m}$ (spinal cord). (B) NRG1 is virtually absent in the CNS of newborn Nes-Cre*Nrg1F/F mutant mice. Western blot analysis of protein lysates prepared from brain (top panel) and spinal cord (lower panel), comparing 3 control mice $(\mathrm{Nrg} 1 \mathrm{~F} /+$, left) and 3 conditional null mutants (Nes-Cre*Nrg1F/F, right). One brain (upper lane 3 ) was isolated 2 hours after natural death, showing some post mortem proteolysis. Molecular weights of marker proteins are indicated (asterisks denote unspecific bands; loading control, tubulin). (C) Quantitative RT-PCR detecting Nrg1 mRNA in whole brain (upper left), spinal cord (upper right) and dorsal root ganglia (lower left) of newborn wildtype mice ( $\mathrm{Nrg} 1 \mathrm{~F} /+$ and $\mathrm{Nrg} 1 \mathrm{~F} / \mathrm{F}$, black bars) and Nestin-Cre conditional mutants (Nes-Cre*Nrg1F/F, white bars). Residual expression in spinal cord preparations is most likely from DRG ganglia in which Cre recombination is incomplete. 
A
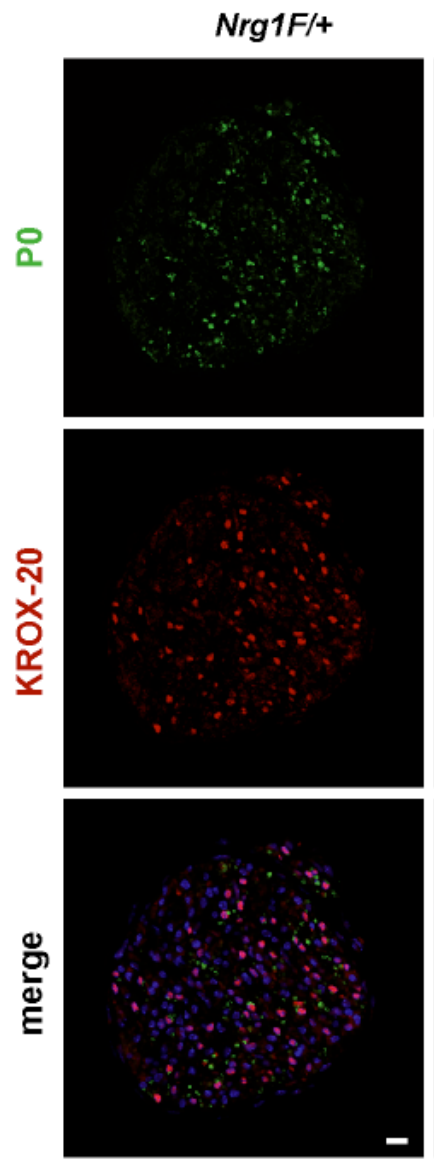

B
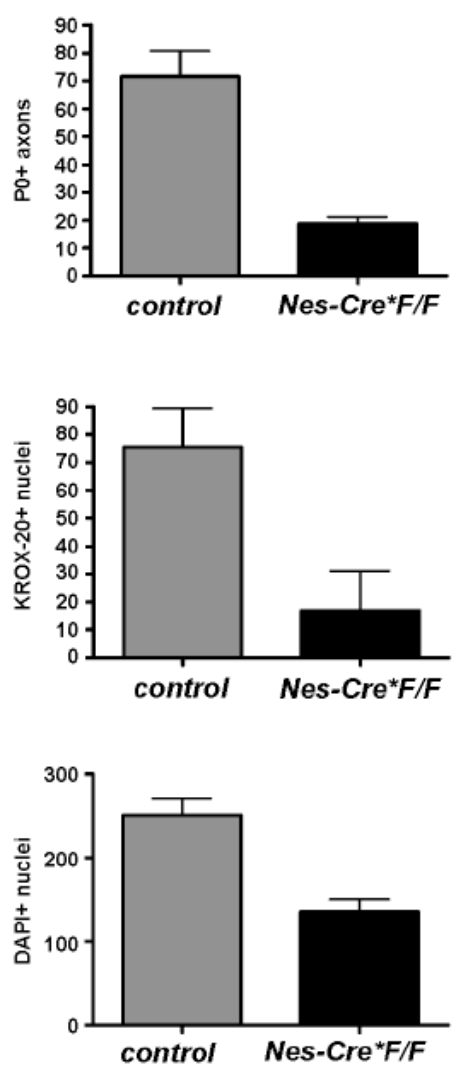

Fig. 13. Impaired peripheral myelination in Nestin-Cre*NRG1flox/flox mutants

(A) Confocal microscopy of coronal paraffin sections obtained from perinatal sciatic nerves. Immunostaining for Krox20 and myelin protein P0 reveals a severe reduction in the number of myelinating Schwann cells and myelinated axons in Nestin-Cre*NRG ${ }^{\text {floxflox }}$ mutants $\left(\mathrm{Nes}-\mathrm{Cr} e^{*} \mathrm{~F} / \mathrm{F}\right)$ compared to control mice $(\mathrm{F} /+)$. Scale bar, $10 \mu \mathrm{m}$. Note that only a fraction of DRG neurons is recombined (see Fig. 12). (B) Quantitation of the data in (A). $F /+$ and $F / F$ mice were taken as controls $(n=4)$; Nes-Cre*NRG ${ }^{\text {floxflox }}$ mice $(n=2)$. Error bars, \pm SEM. 
Quantitative RT-PCR confirmed the absence of NRG1 in brain and a severe reduction in spinal cord, with residual expression (Fig. 12C) most likely derived from the central branch of inefficiently recombined DRG neurons. Spinal cord ventral roots, harboring the peripheral aspects of motoneuron axons, as well as intercostal nerves, almost completely lacked MBP and myelin protein zero (MPZ or P0) immunostaining, demonstrating a block of SC differentiation in Nestin-Cre*Nrg1 $1^{\text {flox/flox }}$ mutants (Fig. 15A, middle and bottom panel). Accordingly, immunostaining of sciatic nerves derived from newborn Nestin-cre*Nrg1 floxflox mice revealed a strong reduction in the number of MPZstained myelin profiles and Krox20-stained myelinating SC (Fig. 13A, B).

Unexpectedly, the density of Olig2+ and MBP+ OL in the forebrain and spinal cord of these mice (Fig. 15B and not shown) did not obviously differ in mutants and controls (not quantified). Similary, in the spinal cord, there was no difference in the density of MBP+ myelin profiles in Nestin-cre*Nrg1 $1^{\text {floxflox }}$ mice at birth (Fig. 15B, upper panel). Thus, NRG1 signaling appears dispensable for spinal OL differentiation in vivo, at least until birth. Since Nestin-Cre*Nrg $1^{\text {flox/flox }}$ mice died many days prior to myelin formation in the subcortical white matter, we also compared long-term co-cultures of wildtype OL and cortical neurons, derived from embryonic wildtype or Nrg1 null mice. As expected, myelination of the NRG1-deficient CNS axons could be readily demonstrated by MBP immunostaining, and was independently observed in mixed brain cultures derived solely from Nestin-Cre*Nrg1 $1^{\text {flox/flox }}$ mice (Brinkmann and Agarwal et al.,). 
A
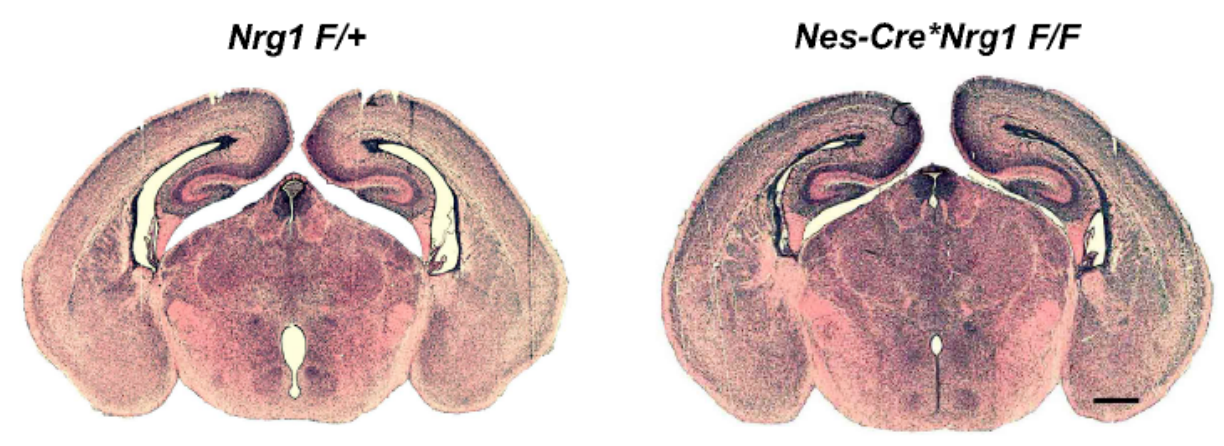

B

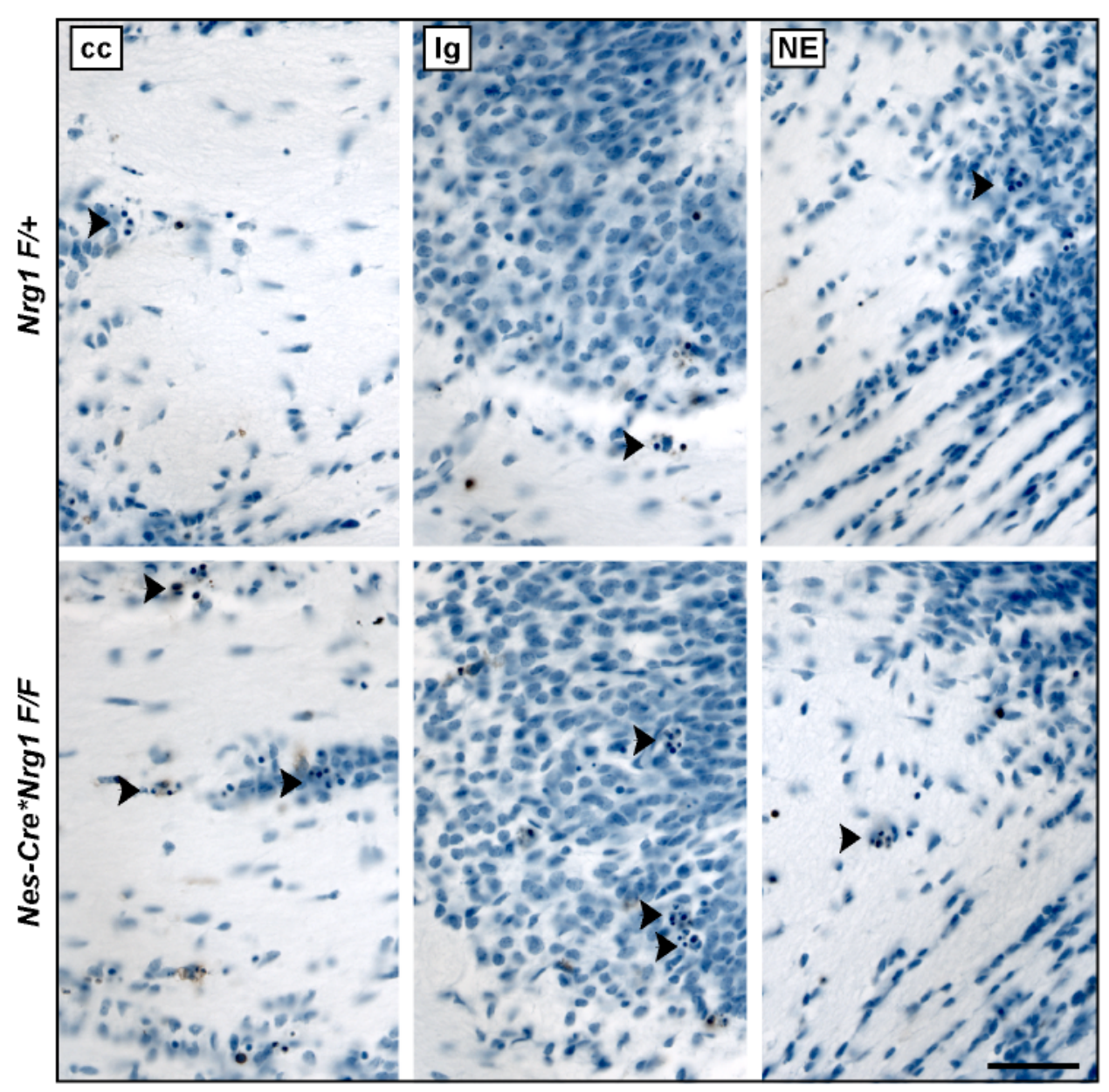

Fig. 14. Normal cortical development but increased apoptosis in the absence of NRG1

(A) Cortical and hippocampal development reveals no obvious delay or morphological of conditional Nrg1 mutants (Nestin-Cre*Nrg1F/F) that recombine in all neural cells (see Fig 8), beginning at E8.5. Shown are H\&E stained frontal brain sections ( $7 \mu \mathrm{m}$, paraffin) of newborn control $(\mathrm{Nrg} 1 \mathrm{~F} /+)$ and mutants. Scale bar, $500 \mu \mathrm{m}$. (B) Tunnel and Haematoxylene stained frontal brain sections (7 $\mu \mathrm{m}$, paraffin) of newborn control $(\mathrm{Nrg} 1 \mathrm{~F} /+)$ and mutants (Nestin-Cre* Nrg1F/F) revealed increased number of apoptotic and pycnotic nuclei in mutants. Arrowhead indicates clusters of tunnel+ apoptotic (brown) and pycnotic (dark blue) nuclei. Note, in mutants the number of cells undergoing apoptosis have substantially increased in indusium griseum (Ig) when compared to corpus callosum (cc) and neuroepithelium (NE). Scale bar, 50 $\mu \mathrm{m}$ 
A
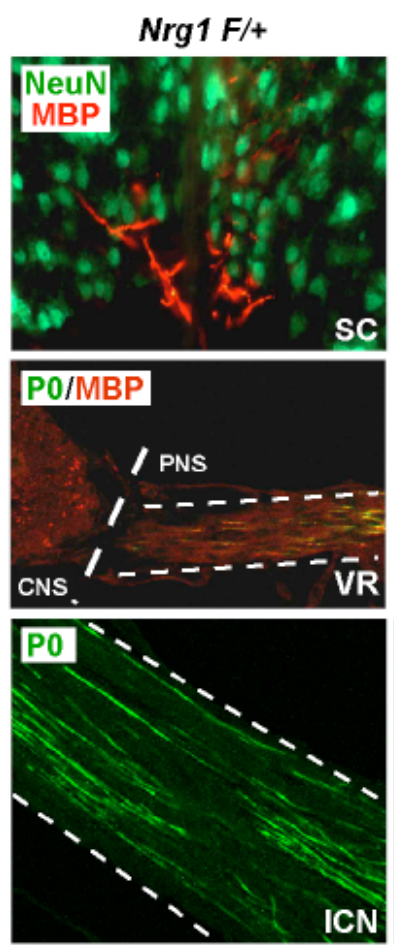

B
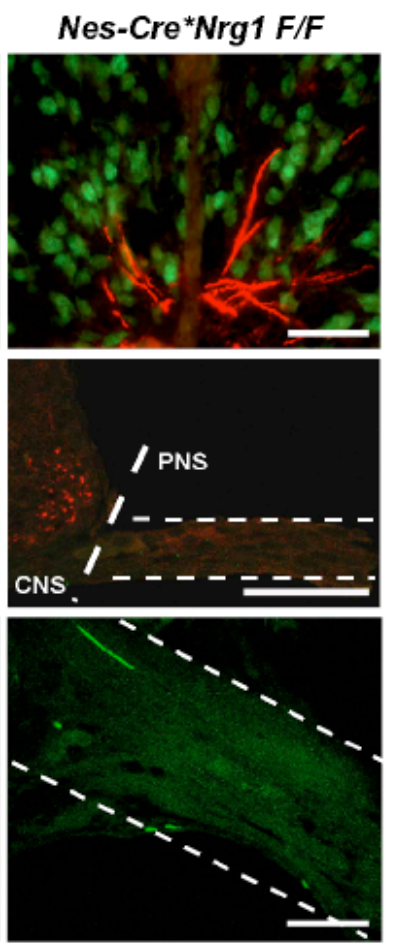

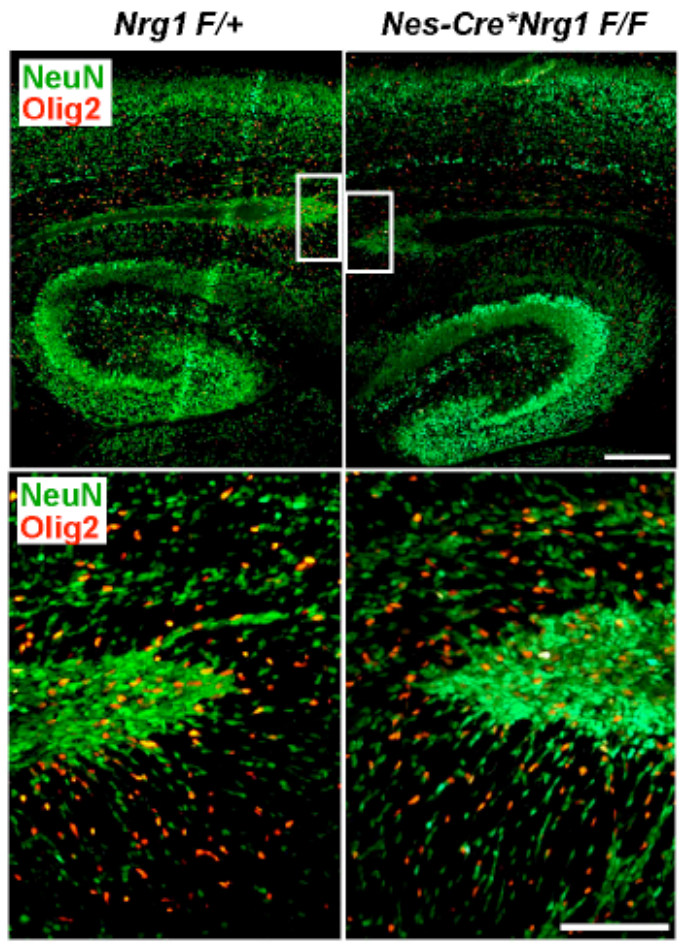

Fig. 15. Oligodendrocytes develop on schedule in the absence of NRG1

(A) Impaired peripheral but not central myelination. Top: Immunostaining of the ventro-medial spinal cord from newborn mice reveals the normal density of MBP+ myelin profiles (in red) in NRG1-deficient (Nes$\mathrm{Cre}^{*} \mathrm{Nrg} 1 \mathrm{~F} / \mathrm{F}$, right) and control mice (Nrg1F/+, left). Neurons are stained for NeuN (in green). Middle: Immunostaining of cross sections at the thoracic level for MBP (in red) and myelin protein MPZ (P0; in green). Note the almost complete absence of MBP and MPZ in the ventral roots (VR; also marked 'PNS') of newborn Nes-Cre*Nrg1F/F mutants (right). In contrast, littermate $\mathrm{Nrg} 1 \mathrm{~F} /+$ controls (left) exhibit numerous myelinated (MBP+/P0+, merged) axons. Note the presence of MBP+ oligodendrocytes in the ventro-lateral spinal chord (marked 'CNS') in both mutants and controls. Bottom: Immunostaining of longitudinal sections of the intercostal nerve (ICN) reveals absence of P0-stained fibers (in green) in newborn Nes-Cre* $\mathrm{Nrg} 1 \mathrm{~F} / \mathrm{F}$ mutants (right) when compared to littermate controls (left). Scale bars, $50 \mu \mathrm{m}$. (B) Olig2+ oligodendrocytes (in red) are present at a normal density and with a similar distribution in the forebrain of newborn mutant mice (Nes-Cre*Nrg1F/F, right) compared to controls ( $\mathrm{Nrg} 1 \mathrm{~F} /+$, left). Boxed areas in upper panel are enlarged in lower panel. Neurons are stained for NeuN (in green). Scale bars $200 \mu \mathrm{m}$ (upper panel), $100 \mu \mathrm{m}$ (lower panel). 


\subsubsection{Ectopic myelination in response to NRG1 type I and type III overexpression}

In NRG1 typeI and typeIII transgenic mouse lines, there is 2-fold increase of myelinated fibers in the cortical grey matter compared to controls. Interestingly, there is no such "ectopic" ensheathment of axons that normally remain unmyelinated (such as mossy fibers in the hippocampus) outside the cortex (Brinkmann and Agarwal et al.,). In both the transgenic lines small caliber axons within the cortex (layers II and III) show a significant hypermyelination. In Nrg1 type I transgenics hypermyelination was only a feature of axons thinner than $0.8 \mu \mathrm{m}$ (Brinkmann and Agarwal et al.). However, there was no corresponding increase in the density of (olig2+ and $\mathrm{CC} 1+$ ) OL.

The possible explanations for the 2-fold higher "myelin-to-oligodendrocyte" ratio in the cortex could be an increase of internodal length and/or a higher number of internodes (i.e. OL processes) in NRG1 overexpressing mice. Since an unbiased quantitation of internodal length is difficult within cortical sections, we performed confocal microscopy and threedimensional cell tracing of selected, singly located (CNP-stained) OL in layers II and III of the cingulate and primary motor cortex (Fig. 16A). In the absence of pathological signs, the avarage number of processes (Fig 16B), process branch points (Fig 16C), and process length including internodal myelin (Fig 16D) was not significantly altered in Nrg1 mutant and Nrg1 type III overexpressing mice. Only the average 'territory' of these OL (Fig 16E) was significantly higher in transgenics $(+50 \%)$, similar to the increased volume of the oligodendroglial somata (Fig 16F). Thus, cortical hypermyelination cannot be fully explained by a numerical increase of OL processes in the cortex of $\mathrm{Nrg} 1$ type III overexpressing mice. Amazingly, all quantified aspects of OL morphology remains primarily unaffected in the complete absence of projection neuron derived NRG1 (Fig. 16 A-F). 
A
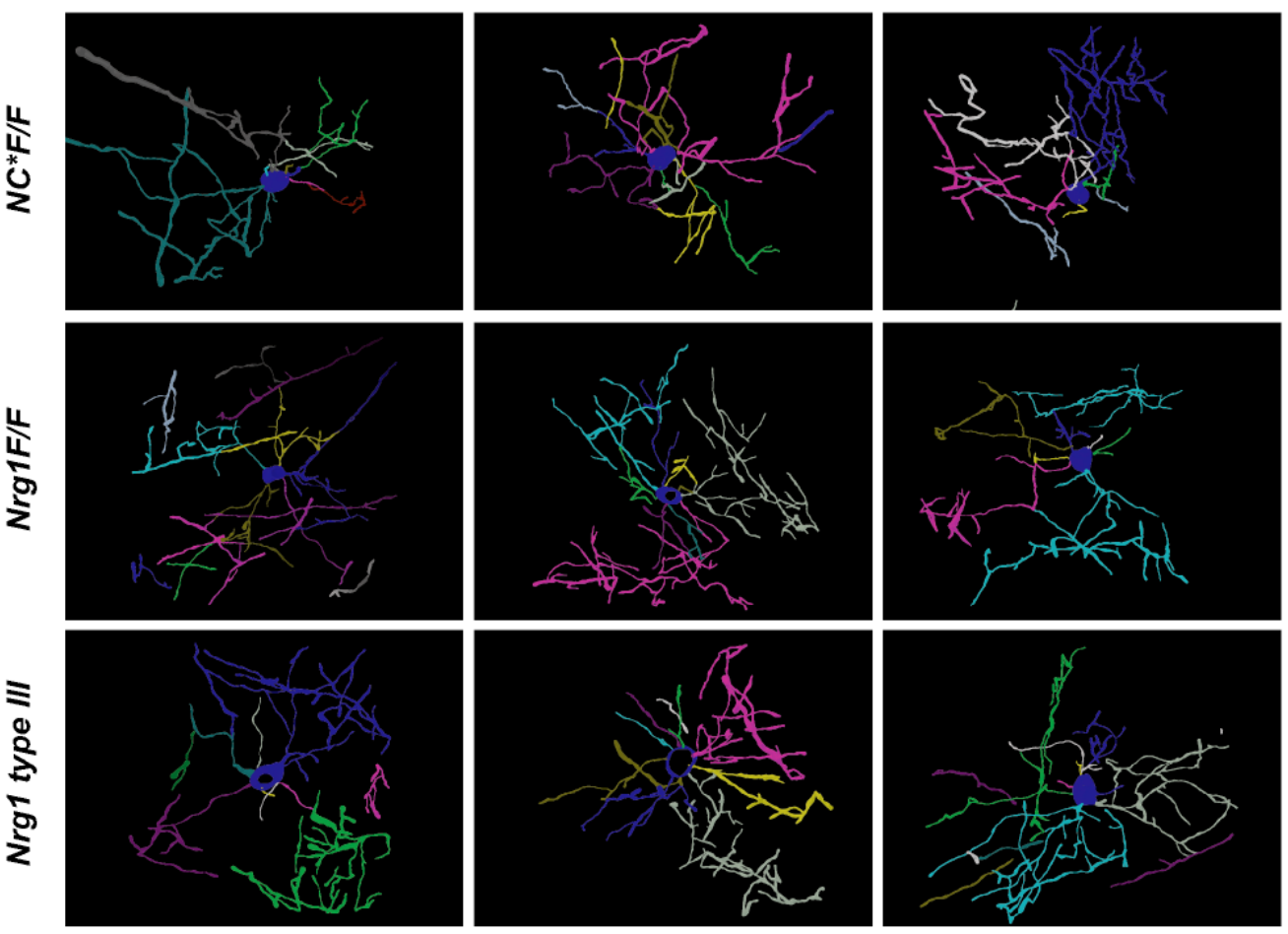

B

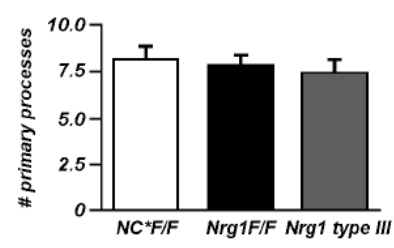

E

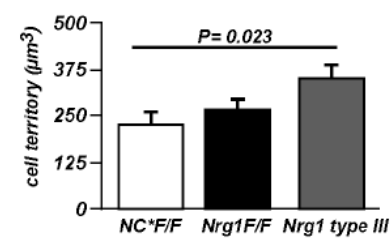

C
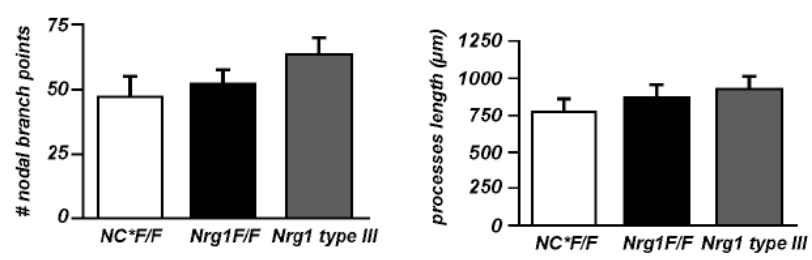

$\mathbf{F}$

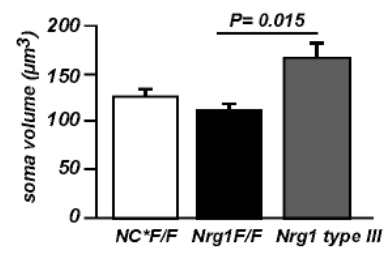

Fig. 16. Oligodendrocyte morphology in NRG1 mutants and overexpressors.

(A) Two-dimensional representations of three-dimensional tracings of CNP-stained oligodendrocytes from layers II and III of the cingulate and primary motor cortex (age 6 months). Three examples from NEXCre*Nrg $1^{\text {flox/flox }}$ mutant $(\mathrm{NC} * \mathrm{~F} / \mathrm{F})$, control $(\mathrm{Nrg} 1 \mathrm{~F} / \mathrm{F})$, and $\mathrm{Nrg} 1$ type III-overexpressing mice (Nrg1 type III) are shown. Each color represents a primary cell process. (B-E) Quantitation of primary process number (in B), number of nodal branch points (in C), avarage process length (including internodal myelin; in D), average $3 \mathrm{D}$ oligodendrocyte territory (in E), and average oligodendrocyte soma volume (in F), comparing $N E X$ $C r{ }^{*} F / F\left(N C^{*} F / F\right), N r g 1 F / F$ and $N r g 1$ type III mice (12-15 cells from three mice per genotype). Error bars: SEM. Significance test: two-tailed t test with Welch's correction or Kruskal-Walli's test. 


\subsubsection{Myelination in the absence of ErbB signaling}

The receptor tyrosine kinases ErbB2 and ErbB4 have been suggested to control CNS myelination in vivo (Vartanian et al., 1997), while ErbB3 is not required for oligodendrocytic differentiation (Schmucker et al., 2003). NRG1/ErbB signaling is completely abolished in the absence of ErbB4 and ErbB3 (as ErbB2 lacks ligand-binding activity). Myelination appeared normal in the CNS of mice that lacked ErbB4, but were rescued from embryonic lethality by means of a MHC-ErbB4 transgene expressed in the heart (Brinkmann, Agarwal et al.,)(Tidcombe et al., 2003). By electron microscopy homozygous ErbB4 null mutants had no dysmyelination phenotype and g-ratios of myelinated axons in ErbB4 null mutant mice were the same as in controls. As expected, mice lacking both ErbB3 and ErbB4 in OL and SC displayed severe defects in PNS myelination and died in the second postnatal week. In striking contrast, electron microscopy of the corpus callosum clearly demonstrated that OL in both ErbB3 single mutants and in ErbB3*ErbB4 double mutants were capable of myelinating callosal axons, at least up to this postnatal age (P11) (Brinkmann, Agarwal et al.,). Although one cannot rule out impairments in adult CNS myelination, we conclude that NRG/ErbB signaling is largely dispensable for myelination of the CNS in vivo. 


\subsection{Neuregulin1 and synaptic function}

NRG1/ErbB signaling in the central nervous system (CNS) has been implicated in a broad range of processes including neuronal migration, axonal pathfinding, and synaptic function (Flames et al., 2004; Hahn et al., 2006; Lopez-Bendito et al., 2006). Though there are numerous in vitro and few in vivo evidences underlining the importance of NRG1 in synaptic fine-tuning, the molecular mechanisms still remain elusive (Bjarnadottir et al., 2007; Chang and Fischbach, 2006; Huang et al., 2000; Kwon et al., 2005; Li et al., 2007; Ozaki et al., 1997; Woo et al., 2007). Nrg1 hypomorphic mice (Nrg1 +/-) exhibit subtle behavioral impairments, some of which have been associated with endophenotypes related to schizophrenia. These impairments in mouse behavior have been shown to be partially alleviated by treatment with antipsychotic drugs such as clozapine (Boucher et al., 2007; Gerlai et al., 2000; Karl et al., 2007; O'Tuathaigh et al., 2007a; O'Tuathaigh et al., 2008; Stefansson et al., 2002). In order to gain further insight into the synaptic function of NRG1 we carried out a detailed (behavioral, histological, electrophysiological and biochemical) analysis of various conditional NRG1 mutants that were already described in the previous section.

\subsubsection{Consequences of postnatal inactivation of Nrg1 in principal projection neurons}

We extensively analyzed the behavior of 3-4 month old mutants in which NRG1 was eliminated from forebrain projection neurons, beginning at postnatal day 5. In these mutants (CKII-Cre*Nrg1 ${ }^{\text {flox/flox }}$ ) NRG1 protein levels were reduced by $\sim 50 \%$ in the cortex, as demonstrated by western blotting (Fig. 6). CKII-Cre*Nrg1 $1^{\text {flox/flox }}$ mice developed normally and showed normal breeding and cage behavior when compared to their littermate controls (CKII-Cre*Nrg1 $1^{\text {flox/+ }}, \mathrm{Nrg}^{\text {flox/flox }}$ and $\left.\mathrm{Nrg} 1^{f l o x /+}\right)$. For behavioral analysis a large battery of tests was performed in collaboration with Prof. H. Ehrenreich and Dr. K. Radyushkin (Max-Planck-Institute of Experimental Medicine, Goettingen). For behavioral tests age-matched, group housed cohort of mutants (CKII-Cre*Nrg1 $\left.1^{\text {floxflox }}\right)$, heterozygous $\left(\mathrm{CKII}-\mathrm{Cr} e^{*} \mathrm{Nrg} 1^{f l o x /+}\right)$ and wildtype $\left(\mathrm{Nrg}^{f l o x /+}\right)$ controls were analyzed, with each genotype comprising a group of 12-15 male mice. The test-battery includes several behavioral test 
paradigms (open-field, prepulse inhibition, rotarod, social behavior, sucrose preference, 8arm maze, elevated plus maze, Pavlovian fear conditioning and hole board), which assess both simple exploratory behavior and complex cognitive modalities such as executive function, working memory, short- and long-term memory.

A

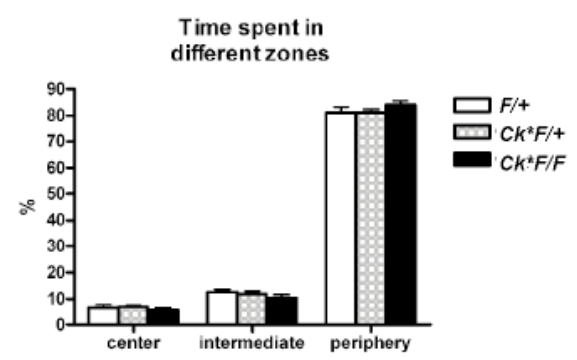

D

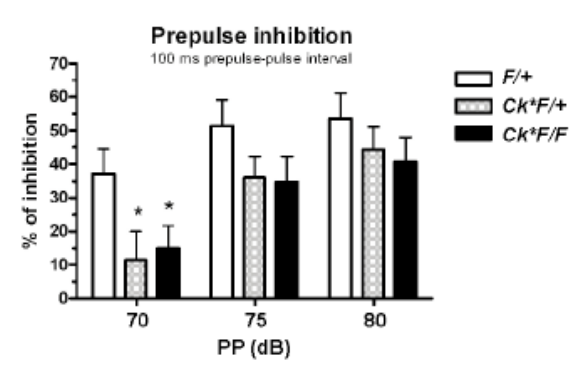

B

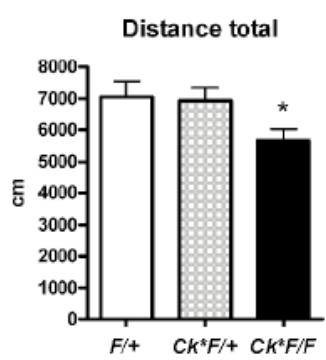

E

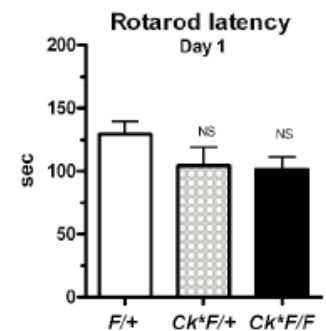

C

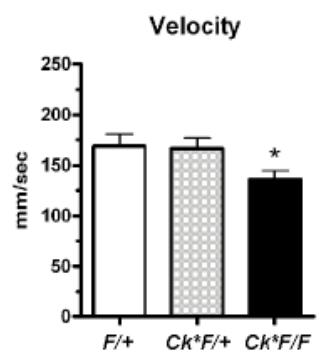

$\mathbf{F}$

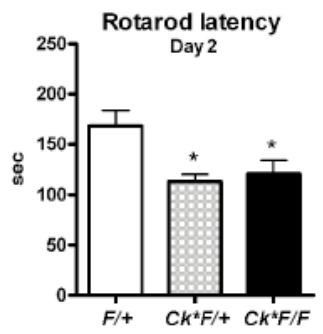

Fig. 17. Reduced motor activity in mice with postnatal-onset, projection neuron-restricted NRG1 inactivation

(A-F) Behavioral analysis of wildtype ( $\mathrm{Nrg} 1 \mathrm{~F} /+; \mathrm{n}=9$ ), heterozygous $\left(\mathrm{CKII}-\mathrm{Cr} e^{*} F /+; \mathrm{n}=11\right)$ and conditional null mutant $\left(C K I I-C r e^{*} F / F ; n=15\right)$ male mice demonstrates reduced motor activity in mutants. (A) CKII$\mathrm{Cre}{ }^{*} \mathrm{~F} / \mathrm{F}$ mice did not reveal any augmentation in the levels of anxiety or stress as time spent in all three zones (centre, intermediate and periphery) when tested in novel "open-field" arena was same for all three genotypes. (B, C) Mutants showed significant reduction in the total distance traveled (hypoactivity) in the open-field when compared to their littermates. (D) Prepulse inhibition (\%) of the acoustic startle response of mice was tested. Mice were subjected to a conditioning prepulse noise burst of 70,75 and $80 \mathrm{~dB}$, just prior $(100 \mathrm{~ms})$ to the unconditional noise burst of $120 \mathrm{~dB}$. Mutant $\left(C K I I-C r e^{*} \mathrm{~F} / \mathrm{F}\right)$ and heterozygous (CKII$\mathrm{Cre}^{*} \mathrm{~F} /+$ ) mice had almost equally impaired prepulse inhibition in comparison to their normal, littermate control ( $\mathrm{Nrg} 1 \mathrm{~F} /+)$ mice. (E, F) On the first day of analysis, the time spent on an accelerating rotarod by mutant $\left(\mathrm{CKII}-\mathrm{Cre}{ }^{*} \mathrm{~F} / \mathrm{F}\right)$ and heterozygous $\left(\mathrm{CKII}-\mathrm{Cre}{ }^{*} \mathrm{~F} /+\right)$ mice was shorter (but not significant) when compared to their control littermates. When tested on the second day, mutant and heterozygous mice spent significantly less time on the rotarod. The significant difference on the second day of trials in the motor learning task can be explained by a failure of the mutant and heterozygous mice to learn and improve on the task that is normally the case for wildtype. Error bars SEM, $(\mathrm{p}<0.05) *$ A. Agarwal (generated mice), Anja Ronnenberg (technician, conducted behavioral tests) and Dr. K. Radyushkin (analyzed data). 
Surprisingly, in most behavioral tests NRG1 mutants performed similar to controls. Nevertheless, in some test paradigms mutant mice showed significant differences when compared to control groups (Fig. 17 A-F). When mice were evaluated in the novel "openfield" test, mutants were significantly less active (hypoactive) than their littermate controls (Fig $17 \mathrm{~B}, \mathrm{C}$ ). This finding was in contrast to previous studies on $\mathrm{Nrg} 1+/$ - mice (Gerlai et al., 2000; Stefansson et al., 2002). Since mice are neophobic and find open spaces aversive, normal mice prefer to stay close to the walls of the "open-field" arena (thigmotaxis). The time spent by a mouse in the center of the arena can be quantified as the measures of anxiety. There was no difference between mutants and their normal littermate controls (Fig $17 \mathrm{~A}$ ), as mice of all the genotypes tested spent same time in all three regions namely centre, intermediate and periphery of the arena. Thereby, pointing to the fact that mutants are do not suffer from any anxiety with respect to their littermates.

Numerous studies indicate that various schizophrenic patients have impaired prepulse inhibition (PPI) (Braff and Geyer, 1990; Powell and Geyer, 2002). PPI is a psychometric measure of sensory gating that can be evaluated in a similar fashion in rodents and humans (Braff and Geyer, 1990). The auditory/perceptual systems of mutants are intact, since they showed normal acoustic startle responses to a single noise burst of $120 \mathrm{~dB}$. We found impaired PPI in NRG1 null mutants (CKII-Cre*Nrg1 ${ }^{\text {flox/flox }}$ ), which was already manifested in heterozygous (CKII-Cre*Nrg $1^{f l o x /+}$ ) mice, when compared to wild type $\left(\mathrm{Nrgl}^{f l o x /+}\right)$ controls. Interestingly, the difference in PPI could only be observed at a pre-pulse of $70 \mathrm{~dB}$; however at higher pre-pulse intensities (i.e. 75 and $80 \mathrm{~dB}$ ) there was a tendency for reduced PPI (Fig. 17 D). The abnormal PPI already in heterozygous (CKII$\left.C r e^{*} N r g 1^{f l o x /+}\right)$ mice was in accordance with the previously reported studies on $\mathrm{Nrg} 1+/$ mice (Gerlai et al., 2000; Stefansson et al., 2002).

The rotarod is a test widely used to assess motor performance in rats and mice (Karl et al., 2003; Luesse et al., 2001; Zausinger et al., 2000). The test measures the ability of the mouse to maintain itself on a rod that turns at accelerating speed. The performance in this test is affected by any kind of motor deficit and depends on intact nigrostriatal and dopaminergic connections (Lundblad et al., 2003). We observed subtle deterioration in the rotarod performance of both null mutants (CKII-Cre*Nrg1 $\left.1^{\text {floxflox }}\right)$ and heterozygous (CKIICre*Nrg1 $\left.1^{f l o x /+}\right)$ mice when compared to controls $\left(N r g 1^{f l o x /+}\right)$ (Fig. 17 E). At the second consecutive day of rotarod testing both null and heterozygous mutant mice exhibited 
significantly poorer performance suggesting impaired motor learning (Fig. 17 F). The comparable level of impairment in PPI and motor learning task in heterozygous and homozygous NRG1 mutants currently remains unexplained.

A

Fear conditioning

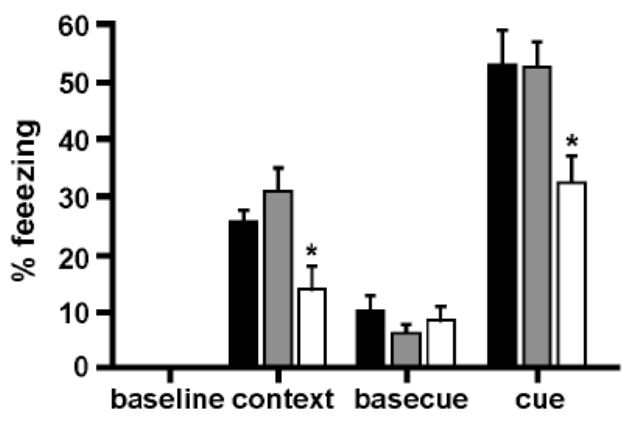

F/+ $\square$ CKII-Cre*Nrg1F/+ $\square$ CKII-Cre*Nrg1F/F
B

Relative distance

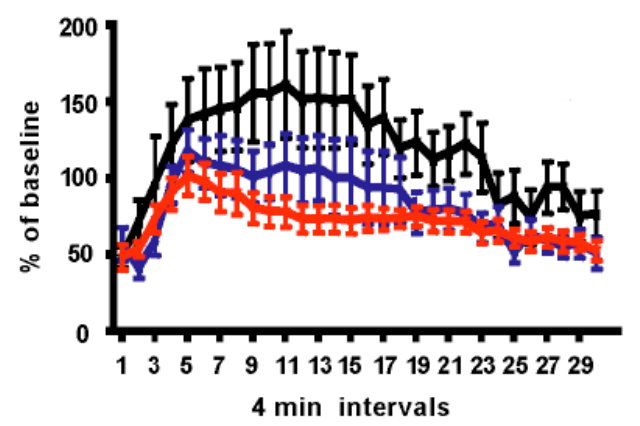

$\square \mathrm{F} /+\square \mathrm{CKI}-\mathrm{Cre}{ }^{\star} \mathrm{Nrg} 1 \mathrm{~F} /+\square \mathrm{CKII-Cre}{ }^{\star} \mathrm{Nrg} 1 \mathrm{~F} / \mathrm{F}$

Fig. 18. Mice lacking NRG1 in their projection neuron showed impaired behavior after aging and pharmacological treatment

(A) Absence of pyramidal neuron derived NRG1 affects both contextual and cued fear conditioning. The Pavlovian conditioned fear was assessed in 12-13 mo old control $(\mathrm{Nrg} 1 \mathrm{~F} /+$; $\mathrm{n}=9$ and CKII-Cre* $\mathrm{F} /+$; $\mathrm{n}=11)$ and NRG1 null mutant $\left(C K I I-C r e^{*} F / F ; n=15\right)$ male mice. Baseline: Mutants and control mice exhibited normal exploratory and absence of freezing behavior when subjected to a novel context (context 1) before the foot shock. Context: Average freezing responses to the fear-conditioning context (context 1) after sensitization by two pairings of CS (tone) and US (foot shock). $24 \mathrm{hr}$ after training, compared with littermate controls, mutant $\left(C K I I-C r e^{*} F / F\right)$ mice froze significantly less $(\sim 50 \%)$ when re-exposed to the fearconditioning context (context 1). Basecue: Mutants exhibited similar levels of freezing when compared to controls in another novel context (context 2). Cue: Compared to littermates, mutant displayed significantly reduced freezing when exposed to the CS (tone) in context 2. Mann-Whitney test, $\mathrm{P}<0.05$. (B) MK-801 induced hyperlocomotion is severely impaired in mice lacking NRG1. 13-14 mo old wildtype (Nrg1 F/+; n=9), heterozygous (CKII-Cre*F/+; $\mathrm{n}=11)$ and NRG1 null mutant $\left(C K I I-C r e^{*} F / F ; n=15\right)$ male mice were administered intraperitonially with MK-801 $(0.3 \mathrm{mg} / \mathrm{kg})$. Before injection of MK-801, mice were tested for a short interval in the open-field to calculate the baseline activity. After injection, mice were placed in the "open-field" arena. The locomotor counts were determined after every 4 min for a time interval of $2 \mathrm{hr}$. Compared to their wildtype littermates (black trace), mutant mice (red trace) showed significantly reduced hyperlocomotion induced by MK-801. The hyperactivity of the heterozygous mice (blue trace) was intermediate to that of wildtype and mutant mice. Each bar represents the mean \pm SEM $(p<0.01)$. * A. Agarwal (generated mice), Anja Ronnenberg (technician, conducted behavioral tests) and Dr. K. Radyushkin (analyzed data).

NMDA receptor-dependent LTP is a widely accepted molecular mechanism involved in the acquisition of conditional (Pavlovian) fear (Maren, 2001; Maren and Holt, 
2000; Maren and Quirk, 2004). NRG1 has been shown to be involved in the fine-tuning of NMDA receptor expression and functions in vitro (Bjarnadottir et al., 2007; Garcia et al., 2000; Gu et al., 2005; Hahn et al., 2006; Huang et al., 2000; Kwon et al., 2005; Li et al., 2007; Ozaki et al., 1997; Pitcher et al., 2008; Stefansson et al., 2002). To outline the in vivo involvement of NRG1 in learning and memory, the acquisition and retention of auditory cued and contextual fear conditioning was examined. We analyzed 12-13 month old male mice (the same cohort of mice used in our previous study) in a fear-conditioning paradigm by measuring the conditioned response $(\mathrm{CR})$ before and after presentation of the conditioned stimulus (CS) in a novel context. Specifically, fear memory was assessed by measuring the retention of CR (freezing responses) 24 hours after conditioning. Naive mice of all the genotypes tested showed similar baseline behavior (normal exploration with no freezing) when placed in the shocking chamber (context 1, for 2 min) and subjected to $\mathrm{CS}$ (a tone of $80 \mathrm{db}$, for $30 \mathrm{sec}$ ) (baseline in Fig. $19 \mathrm{~A}$ ). Moreover, during the conditioning phase the squeaking (vocalization) and jumping behavior in response to two pairings of CS (a tone of $80 \mathrm{db}$, for $30 \mathrm{sec}$ ) and the aversive unconditioned stimulus (US, mild electric foot shock, for $2 \mathrm{sec}$ ) separated by $15 \mathrm{sec}$ was comparable in all groups. Twenty-four hours later, retention of contextual fear conditioning was assessed by placing mice in the fearconditioning context (context 1) for $2 \mathrm{~min}$. The control group (CKII-Cre $\mathrm{Nrg}^{\text {flox/++}}$ and $N r g 1^{f l o x /+}$ ) showed a steady suppression of locomotor or exploratory activity, as a consequence of the freezing elicited by the context (context in Fig. $18 \mathrm{~A}$ ). In contrast, mutant mice (CKII-Cre*Nrg1 ${ }^{\text {flox/flox }}$ ) exhibited $\sim 50 \%$ reduced freezing responses to the context when compared to controls (context in Fig. 18 A). 2 hours later when these mice were placed in a novel shocking chamber (context 2, for $2 \mathrm{~min}$ ) all genotypes showed similar levels of freezing to the novel context (basecue in Fig. 18 A). Next, when mice were presented with the auditory CS (a tone of $80 \mathrm{db}$, for $2 \mathrm{~min}$ ) heterozygous (CKII$\left.\mathrm{Cre} \mathrm{Nrg}^{\mathrm{flox} /+}\right)$ and wildtype $\left(\mathrm{Nrg} 1^{f l o x /+}\right)$ mice exhibited a typical degree of freezing response, indicating a memory for the CS (cue in Fig. 18 A). In contrast, NRG1 null

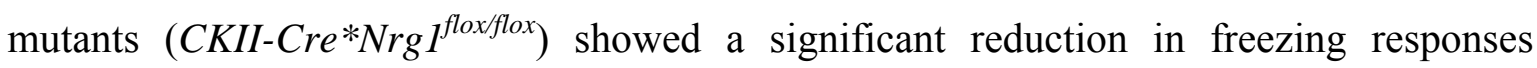
throughout the duration of the CS presentation, suggesting that the absence of NRG1 results in an impairment to acquire and/or retain memory for cued auditory fear conditioning (cue in Fig. $18 \mathrm{~A}$ ). The impaired fear response in CKII-Cre* $N r g 1^{\text {floxflox }}$ mice during the acquisition phase of fear conditioning was not caused by a deficit in detecting 
auditory stimuli as the same cohort of mice performed well in PPI measurements (at 3-4 months of age) (Fig. 17 D). Also, mutants showed similar response to pain stimuli as controls (data not shown). Taken together, chronic absence of NRG1 from cortical projection neurons leads to an impaired formation of conditioned fear memories for both contextual and auditory cues.

To further dissect the involvement of NRG1 in the modulation of NMDA receptor function, mice were injected with MK-801 (dizocilpine meleate) (Wong et al., 1986). MK801 is a non-competitive inhibitor of NMDA receptors and enhances locomotion (hyperactivity) in rodents and, at higher doses, induces stereotypic behaviors including head weaving and uncoordinated, ataxic gaits (Clineschmidt, 1982; Deutsch et al., 1997). Moreover, MK-801 treatment serves as a pharmacological model of schizophrenia (Rujescu et al., 2006; Thornberg and Saklad, 1996). The same cohort of mice (at 12-13 months) that was used for the above behavioral analysis was injected (intraperitonially, i.p.) with $0.3 \mathrm{mg} / \mathrm{kg}$ of MK-801 and tested in an "open-field" setting for hyperlocomotion. In control mice $\left(\mathrm{Nrg}^{f l o x /+}\right)$ locomoter activity was increased by three fold and mice remained hyperactive for several hours post injection (Fig. 18 B). In contrast, MK-801 induced hyperactivity in NRG1 mutant (CKII-Cre*Nrg1 $1^{\text {flox/flox }}$ ) was short-lived and quickly reached baseline values (Fig. 18 B). Importantly, MK-801 induced hyperactivity in heterozygous mutants (CKII-Cre*Nrg $1^{f l o x /+}$ ) was intermediate (Fig. 18 B), indicating that chronic haploinsufficiency might modulate NMDA receptor function (Bjarnadottir et al., 2007; Stefansson et al., 2002).

Long-term potentiation (LTP) at Schaffer collaterals and CA1 pyramidal neurons (Sch-CA1) synapses is essential for activity dependent synaptic strengthening and plasticity underlying learning and memory (Bliss and Collingridge, 1993). NRG1 signaling might modulate surface expression of neurotransmitter receptors and thereby play a critical role in mediating synaptic plasticity (Gu et al., 2005; Kwon et al., 2005). Results derived from fear conditioning and pharmacological treatment with MK-801 suggest a potential role of NRG1 in the modulation of NMDA receptor function. To gain further insight into the role of NRG1 in the regulation of synaptic transmission and plasticity, in collaboration with Dr. Weiqi Zhang (Centre of Physiology and Pathophysiology, University of Goettingen), field excitatory postsynaptic potentials (fEPSPs) were recorded in acute hippocampal slices from aged (24 months old) mice. 
A

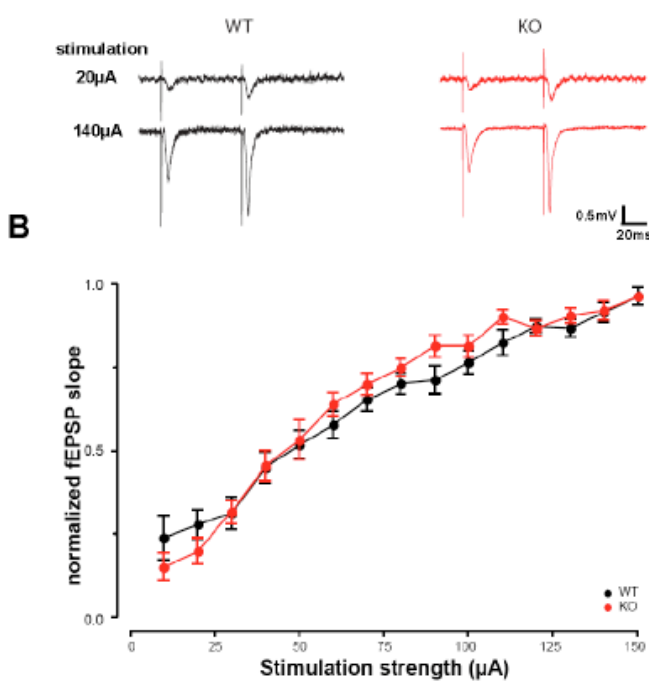

C

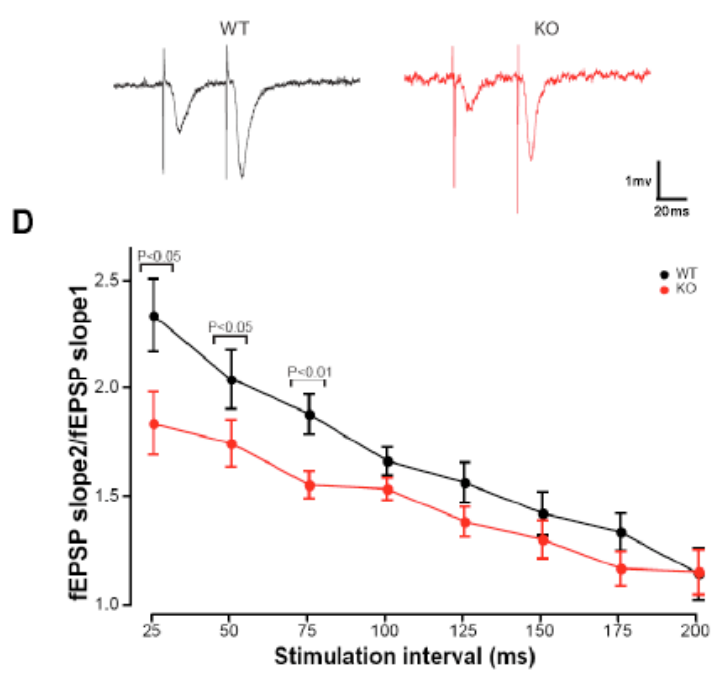

E

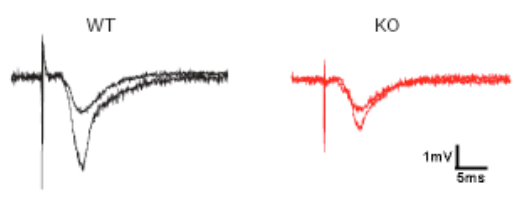

F

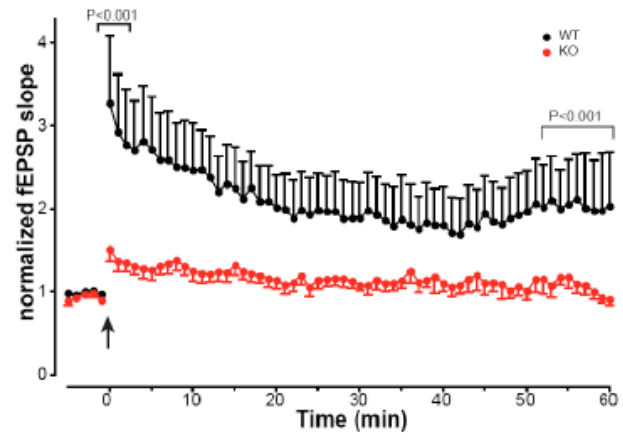

G

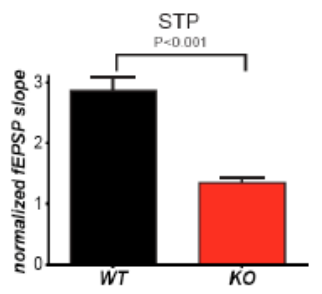

H

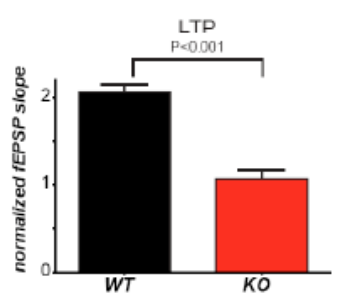

Fig. 19. Loss of NRG1 from pyramidal neurons leads to suppression of LTP induction at hippocampal Sch-CA1 synapses

(A, B) Basal excitatory synaptic transmission is not altered at Sch-CA1 synapses in mutant mice. The field excitatory synaptic potentials (fEPSP) were recorded at the Sch-CA1 synapses on brain slices $(300 \mu \mathrm{m}$ thick) from 21-24 mo old mutants $\left(C K I I-C r e^{*} F / F\right.$, red traces) and control (Nrg1 F/+, black traces) male mice ( $n=6$ each genotype). (A) Sample recordings at 50\% of maximal response (average of 4 traces) are shown for control and mutant mice. (B) Input-output curve as a measure of baseline excitatory synaptic transmission: fEPSP slope, plotted against the stimulation strength, is not altered in mutant mice compared to control. (C, D) Paired-pulse facilitation is reduced in mutants compared to control mice. (C) Sample traces for inter-stimulus intervals of $20 \mathrm{~ms}$ are presented for control and mutants. (D) Paired-pulse ratio (fEPSP slope for the 2nd stimulus/fEPSP slope for the 1st stimulus) at inter-stimulus intervals of $25-200 \mathrm{~ms}$ is significantly less in mutant mice as compared to control. 
(E-H) LTP is reduced at Sch-CA1 synapses in mutants. (E) Sample traces of responses are shown before and after high frequency stimulation (HFS; 4 x 100Hz for $1 \mathrm{~s}$ each, 20s interval). (F) Long-term potentiation elicited by HFS: The slopes of fEPSP are normalized to baseline and plotted against time. Time-point 0 represents the application of HFS (arrow). (G) The magnitude of STP, determined as maximal responses within $1 \mathrm{~min}$ after HFS, is significantly lesser in mutant mice compared to control. (H) The magnitude of LTP, determined as responses between 50 to 60 minutes after HFS, is significantly lesser in mutant mice as compared to control. * A. Agarwal (generated mice), Cornelia Hühne (technician, conducted electrophysiological recordings) and Dr. W. Zhang (analyzed data).

Electrical responses evoked in stratum radiatum of the CA1 region by stimulating Schaffer collaterals with increasing stimulus strengths were recorded. To plot the input-output relationship, half-maximal stimulation strength and mean field excitatory postsynaptic potential (fEPSP) slopes (between stimulus intensities of 10-150 $\mu \mathrm{A}$ and averaged from all the slices recorded) were calculated. In both control $\left(N r g 1^{f l o x /+}\right)$ and mutant $(\mathrm{CKII}-$ $\left.C r e^{*} N r g 1^{\text {flox/flox }}\right)$ mice no significant difference in baseline synaptic transmission was observed (Fig 19. A, B). Next, Paired-pulse facilitation (PPF), the shortest form of synaptic plasticity (Zucker and Regehr, 2002), was measured in the Sch-CA1 pathway at different inter-stimulus intervals ( 25 to $200 \mathrm{~ms}$ ). PPF values were derived by calculating the ratio of the second fEPSP slope to the first fEPSP slope and were significantly reduced in mutants when compared to controls slices (Fig. 19 C, D). Finally, slices (300 $\mu \mathrm{m}$ thick) were subjected to standard high frequency stimulation (HFS, 4x $100 \mathrm{~Hz}$ for $1 \mathrm{~s}$ each, 20s interval) in order to induce short-term potentiation (STP) and long-term potentiation (LTP) at the Sch-CA1 pathway. The magnitude of STP was defined as the maximal response within the first minute after induction by a train of $100 \mathrm{~Hz}$ stimuli. STP was significantly reduced in slices of mutant mice compared to controls (Fig. $19 \mathrm{E}-\mathrm{G}$; $N r g 1^{\text {flox/+ }}, 2.88 \pm 0.08$, $\mathrm{N}=6 ; C K I I-C r e^{*} N r g 1^{\text {flox/flox }}, 1.36 \pm 0.03, \mathrm{n}=6$ mice; $\left.\mathrm{P}<0.001\right)$. Furthermore, the magnitude of LTP determined as the average response, 50-60 minutes after induction, was also significantly reduced in slices of mutants when compared to controls (Fig. $19 \mathrm{E}, \mathrm{F}$ and $\mathrm{H} ; N r g 1^{f l o x /+}, 2.06 \pm 0.02, \mathrm{~N}=6 ;$ CKII-Cre ${ }^{*} N r g 1^{\text {flox/flox }}, 1.07 \pm 0.02, \mathrm{n}=6$ mice; $\mathrm{P}<$ 0.001). Taken together, these studies indicate that chronic loss of NRG1 from pyramidal neurons severely impairs LTP induction at the Sch-CA1 synapse at least at old stages. 
A

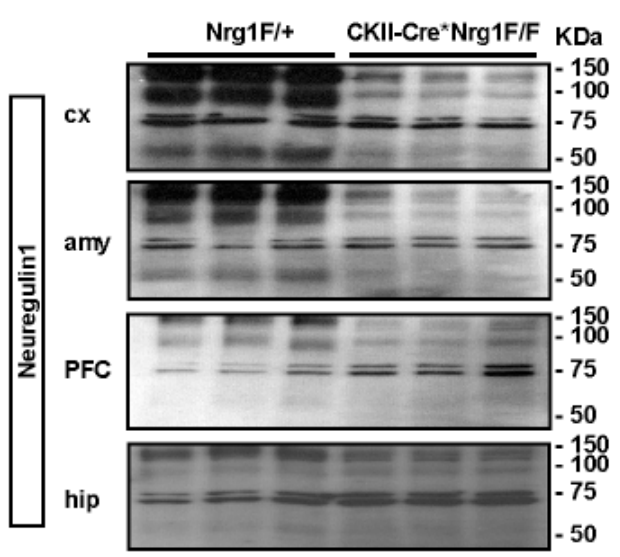

B
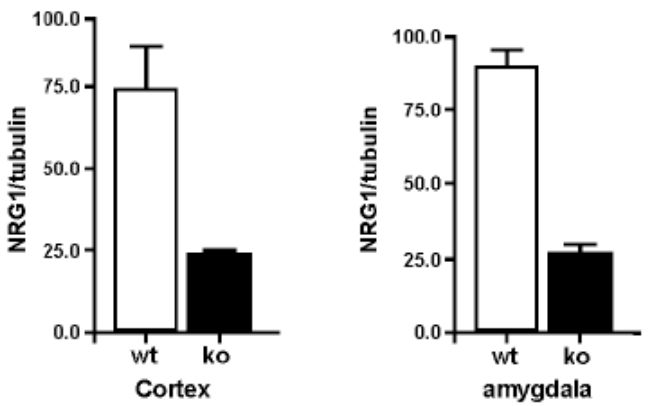

C
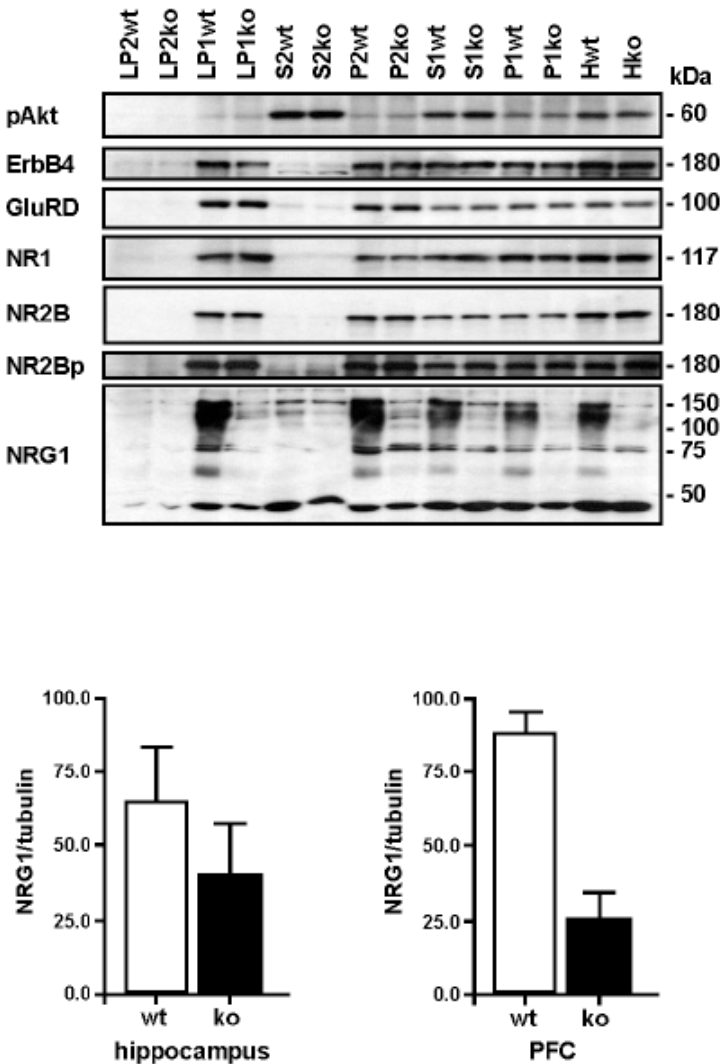

Fig. 20. Reduced levels of NRG1 but unaltered levels of synaptic proteins in cortical lysates and in 'synaptic vesicles' prepared from 15 mo old mice.

(A) Western blot analysis of protein lysates prepared from the cortex (cx), amygdala (amy), prefrontal cortex (PFC) and hippocampus (hip) of mutants $(C K I I-C r e * F / F, n=3)$ at 15 mo of age revealed a severe reduction in NRG1. The 'full length' NRG1 type III $(\sim 140 \mathrm{kDa})$ and NRG1 type I $(\sim 95 \mathrm{kDa})$ isoforms and C-terminal domain after processing of full length NRG1 by $\beta$-secratase $(\sim 60 \mathrm{kDa})$ were reduced in mutants compared to controls (Nrg1 F/+, $\mathrm{n}=3)$. Note, both hippocampus and PFC expressed NRG1 at lower levels when compared to the other brain areas such as cortex and amygdala. (B) Densitometric quantification revealed $\sim 70 \%$ reduction in the levels of 'full length' NRG1 type III ( 140 kDa) in cortical areas (cortex, amygdala and PFC) of mutants $\left(C K I I-C r e^{*} F / F, n=3\right)$ compared to controls $(\mathrm{Nrg} 1 \mathrm{~F} /+, \mathrm{n}=3)$. Note, in the hippocampus the level of 'full length' NRG1 type III is only reduced by $\sim 50 \%$. 'Integrated density' values of NRG1 were normalized to $\alpha$-tubulin and are presented as the mean values $( \pm$ SEM). (C) Analysis of synaptic proteins in subcellular fractions of protein lysates prepared from cerebral cortices of 15 mo old mutant (CkII-Cre*F/F, (ko) n=1) and control $(\mathrm{Nrg} 1 \mathrm{~F} /+,(\mathrm{wt}) \mathrm{n}=1)$ mice. After differential centrifugation of cortical extracts and hypotonic lysis of "crude synaptosomes", equal amounts of protein ( $20 \mu \mathrm{g}$ per lane) from each fraction were analyzed by western blotting. Synaptic membrane proteins, such as ErbB4 receptor, glutamate receptor subunit 4 (GluRD), NMDA receptor subunit 1 (NR1), phosphorylated and non-phosphorylated subunit 2B of NMDA receptor (NR2Bp and NR2B) and NRG1, enriched with heavier membranes (including the plasma membrane) containing fraction (LP1). The C-terminal domain ( $\sim 60 \mathrm{kDa})$ generated by processing of the 'full length' NRG1 by $\beta$-secretase, remains membrane bound and co-sediments with other synaptic membrane proteins in the LP1 fraction. The enrichment of phosphorylated Akt (pAkt) takes place with a population of crude membranes lighter than synaptosomes (S2), a pattern typical for soluble synaptic proteins. Levels of the analyzed synaptic proteins, except NRG1, remain unaltered in mutants when compared to control mice. H, Homogenate; P1, nuclear pellet; P2, crude synaptosomal pellet; LP1, lysed synaptosomal membranes; LP2, crude synaptic vesicle fraction; S1, supernatant after synaptosome sedimentation; S2, cytosolic fraction (with crude membranes lighter than synaptosomes). 
A

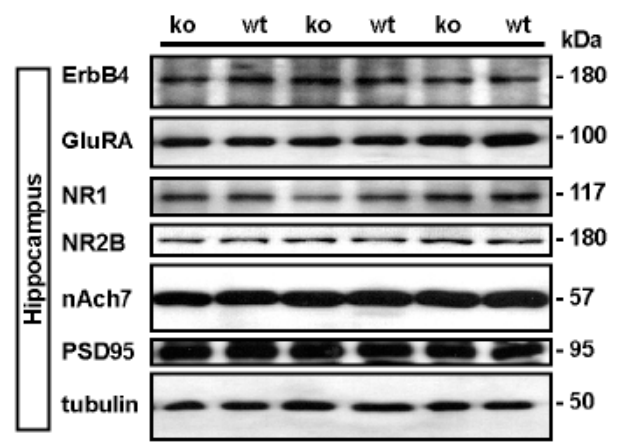

B

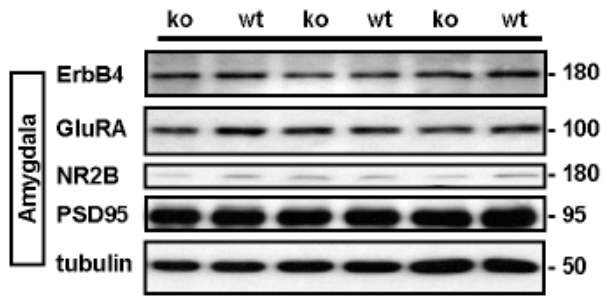

C hippocampus
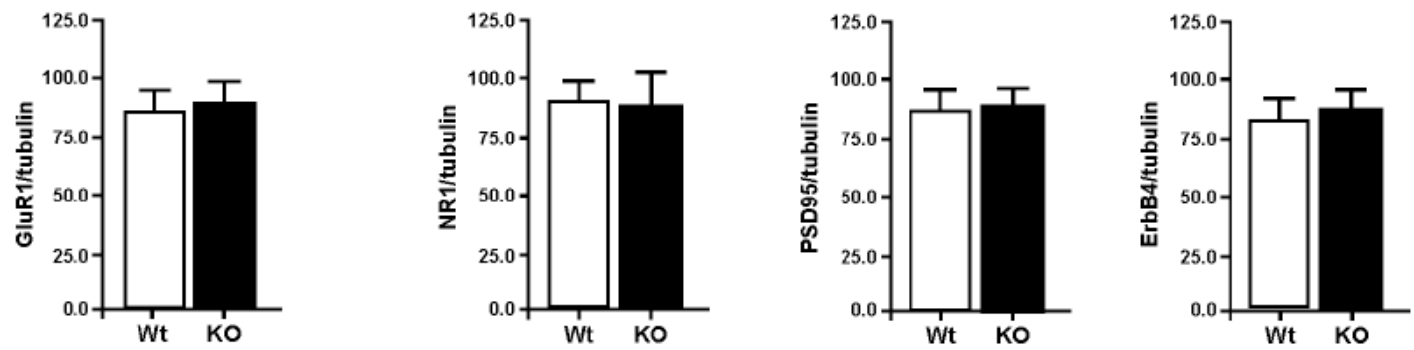

D
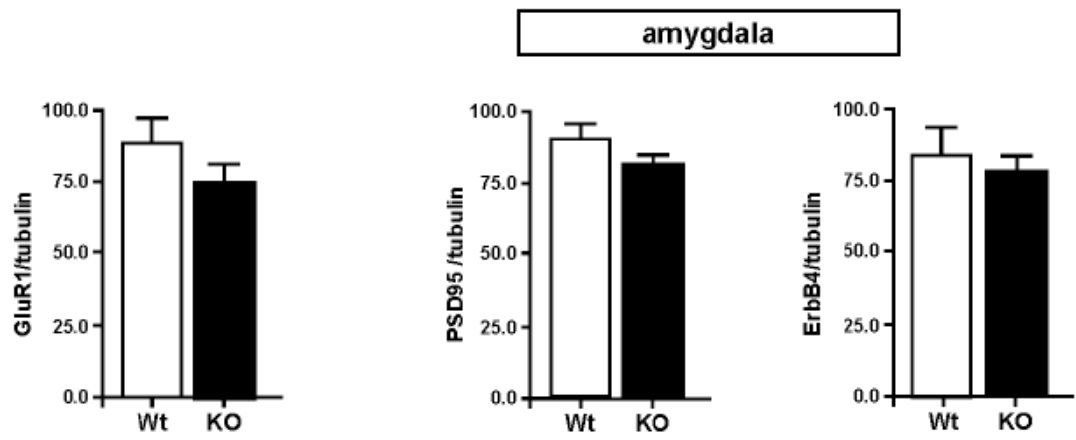

Fig. 21. Unaltered levels of synaptic proteins in the cortical lysates prepared from mice that have undergone behavioral analysis and were treated with MK-801

(A, B) Semiquantitative comparison of the levels of synaptic protein by western blotting of protein lysates prepared from hippocampus and amygdala of mutants $\left(C K I I-C r e^{*} F / F(k o), n=3\right)$ and littermate controls (Nrg1 F/+ (wt), n=3) after treatment with MK-801 at 15 mo of age. ErbB4 (ErbB4 receptors), NR1 and NR2B (NMDA receptor subunit 1 and subunit 2B), GluRA (glutamate receptor subunit 1), nAch7 (nicotinic acetylcholine receptor $\alpha 7$ subunit and (PSD95postsynaptic density 95). (C, D) Densitometric quantification revealed steady state levels of all the synaptic proteins tested in the hippocampus and amygdala of mutants compared to control mice. There might be a slight decrease (not significant) in the levels of GluRA in the protein lysates prepared from amygdala. Quantification of proteins that were analyzed at least twice by western blotting is shown. 'Integrated density' values of proteins were normalized to that of $\alpha$-tubulin and are presented as the mean values $( \pm \mathrm{SEM})$. 
In order to identify potential underlying molecular mechanism of neurotransmitter receptor control by NRG1, we quantified the expression of various neurotransmitter receptors by western blotting. Protein lysates were prepared from various brain regions (hippocampus, amygdala, pre-frontal cortex (PFC) and cortex) of 15 month old mutant $\left(\mathrm{CKII-Cre} * \mathrm{Nrg} 1^{\text {flox/flox }}\right)$ and control $\left(\mathrm{Nrg}^{\text {flox/+ }}\right)$ mice that had undergone behavioral analysis and pharmacological (MK-801) interventions. In cortical lysates derived from mutant brains NRG1 was reduced by $\sim 70 \%$ when compared to littermate contols (Fig. 20 A, B). Moreover, pyramidal neuron derived expression levels of NRG1 in various brain regions seemed to differ, with PFC and hippocampus expressing NRG1 at lower levels. In contrast there was no corresponding change in the amount of various synaptic proteins such as, glutamate receptors (AMPA and NMDA), ErbB4 receptors, postsynaptic density 95 (PSD95) and $\alpha-7$ subunit of neuronal acetylcholine receptor in protein lysates prepared from hippocampus (Fig. $21 \mathrm{~A}, \mathrm{C}$ ) of mutants. Although there seemed to be slightly reduced levels of synaptic proteins such as, GluR1 and PSD95 in protein lysates prepared from amygdala of mutants, these differences were not statistically significant (Fig. 21 B, D). Nevertheless, it is conceivable that altered levels of neurotransmitter receptors in distinct micro-domains (such as the synapse) will be undetectable in protein lysates prepared from whole cortex or hippocampus. Consequently, to study synaptically targeted receptors we performed a sub-cellular fractionation of protein extracts to isolate "crude synaptic vesicles " from the cortex of mutant and control mice. Surprisingly, levels and phosphorylation state of all receptors and signaling proteins tested remained unchanged (in all subcellular fractions) in mutants when compared to control mice (Fig. $20 \mathrm{C}$ ). In addition, the subcellular localization of endogenous NRG1 in the adult brain still remains unknown. However, in accordance to its observed in vitro functions, it is tempting to speculate that NRG1 is located at presynaptic boutons (Fischbach, 2007). In line with this hypothesis, we probed for NRG1 in "crude synaptic vesicle" preparations. Interestingly, NRG1 exhibits progressive enrichment with synaptic plasma membrane proteins, such as the NMDA receptor (NR1), that sediment with heavy membranes released by hypotonic rupturing of synaptosomes (LP1). The localization to LP1 thus supports a specific expression of NRG1 at the synaptic plasma membrane (Fig. $20 \mathrm{C}$ ). It is noteworthy that the c-terminal domain ( $\sim 60 \mathrm{kDa})$ generated by processing of 'full length' NRG1 by metalloproteases (or possibly $\beta$-secretase) remains membrane bound and also co-sediments with NR1 and 'full length' 
NRG1 in the LP1 fraction.

Possible minor changes in the level of synaptic proteins in specific brain areas, such as the CA1 region of the hippocampus cannot be quantified by commonly used biochemical methods. Therefore we immunostained for several pre- and postsynaptic proteins (such as Vglut1, Vglut2, NR1, PSD95) on brain slices from 15 months old mutant and control mice (the same cohort of mice used for behavioral and pharmacological analysis). Overall, the staining pattern for the above markers appeared largely unaltered. When certain brain areas such as hippocampus (Fig. 22 A) and motor/somatosensory cortex (layer V) (Fig. 22 B) were analyzed in more detail by confocal microscopy a possible reduction in the numbers of synaptic boutons in the hippocampus (CA1) of mutants was observed. Since the above analysis is qualitative, it will be important to quantify the numbers of these synaptic boutons to draw any further mechanistic conclusion concerning the role of NRG1/ErbB signaling in synaptic plasticity. 
A
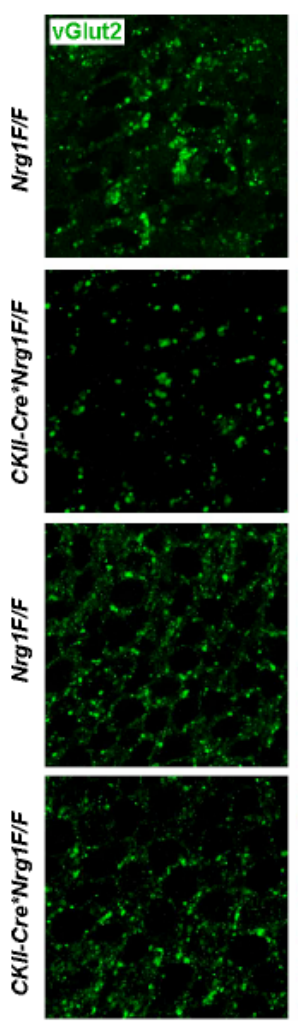
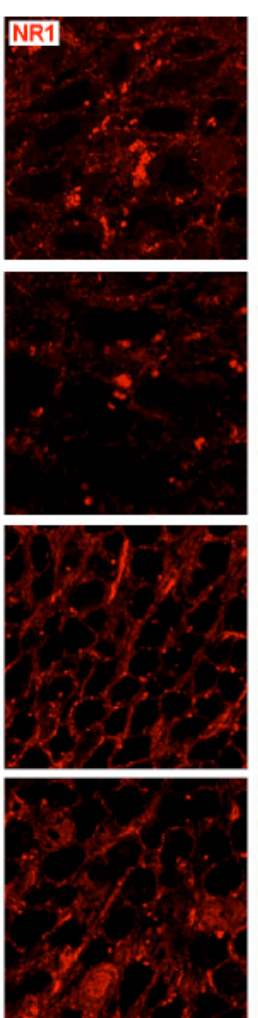
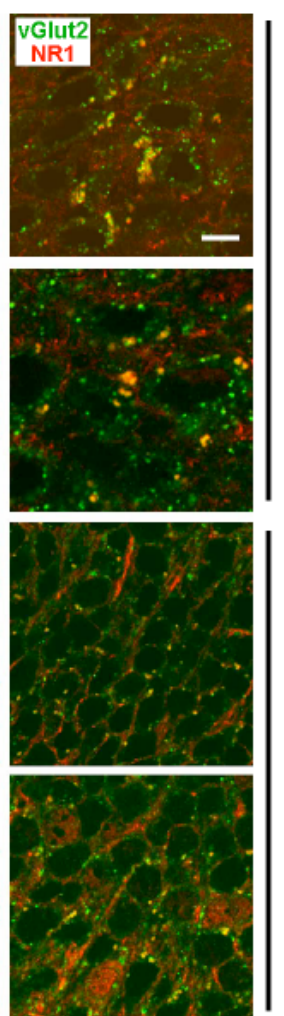

B
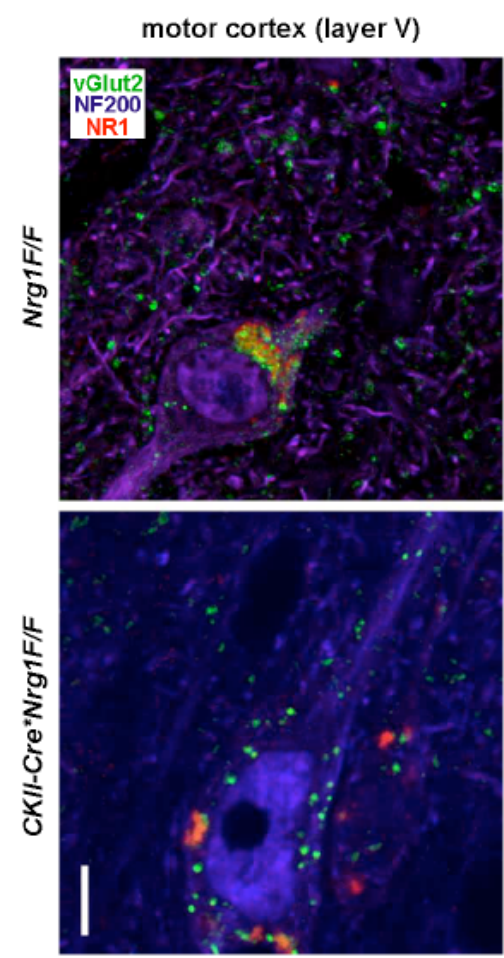

Fig. 22. Reduced number of synaptic boutons in mutants that have undergone behavioral analysis and were treated with MK-801

Confocal microscopy of $4 \%$ PFA fixed, $100 \mu \mathrm{m}$ thick vibrotome sections obtained from the cortex and hippocampus of 15 mo old mutant $\left(C k I I-C r e^{*} F / F, n=3\right)$ and control $(N r g 1 F /+, n=3)$ mice. (A) Immunostaining for presynaptic (Vglut2), postsynaptic (NR1) and neurofilament (NF200) markers revealed a reduction in the number (not quantified) of synaptic boutons in CA2/CA3 junction of hippocampus and in the dentate gyrus (hilus) of mutants when compared to control mice. (B) No major reduction in the levels of above markers could be shown in the cortex (motor cortex, layer V) of mutant and control mice (not quantified). Scale bar, $5 \mu \mathrm{m}$.

Synaptic dysfunction, substantial loss of synapses and axons may precede neurodegeneration in the progression of several neurological disorders, including Alzheimer's, Huntington's, Parkinson's and Prion's disease (reviewed in Saxena and Caroni, 2007). A possible synaptic dysfunction in (CKII-Cre*Nrg1 $\left.1^{\text {flox/flox }}\right)$ mutants might as well lead to increased neurodegeneration that aggravates with age. However, none of the pathological hallmarks of neurodegeneration, such as astrogliosis (accumulation of GFAP+ astrocyctes), microgliosis (invasion of mac3+ activated microglia) and block of axonal transport (APP+ axonal swellings) was increased in the cortex, hippocampus and white matter of 13 months old (CKII-Cre*Nrg1 $\left.1^{\text {flox/flox }}\right)$ mutants when compared to their age matched control littermates $\left(\mathrm{Nrg}^{\text {flox/+}}\right)$ (Fig. 23). 


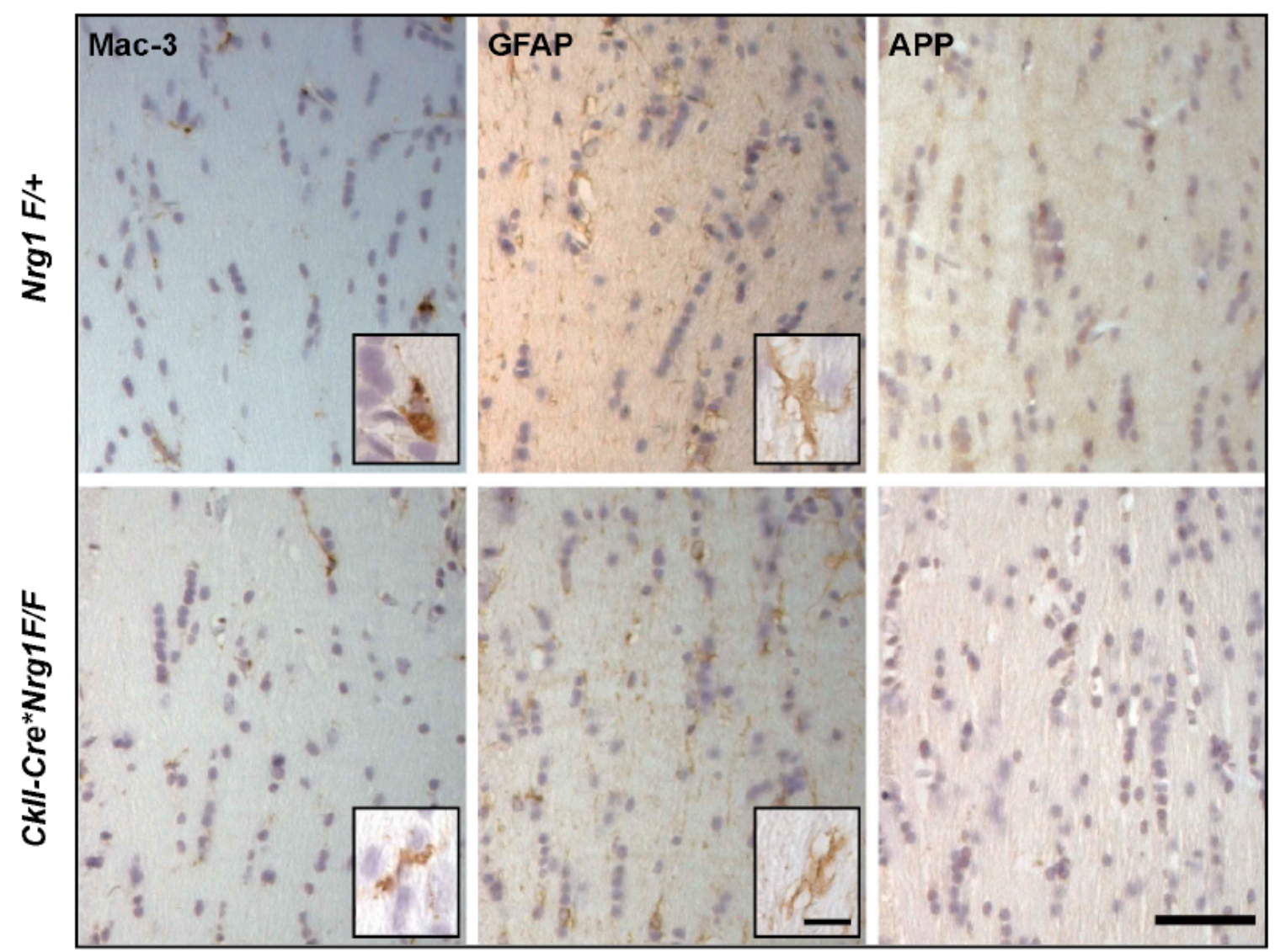

Fig. 23. Normal levels of ongoing neurodegeneration in the aged mice lacking NRG1 in their projection neurons

Immunostaining of markers of neurodegeneration such as Mac3 (activated microglia), GFAP (astrogliosis) and APP (axonal swellings) on coronal brain sections ( $7 \mu \mathrm{m}$ paraffin) from mutants (CkII-Cre*F/F, lower panel) and controls ( $\mathrm{Nrg} 1 \mathrm{~F} /+$, upper panel) failed to exhibit severe neurodegeneration in the corpus callosum (CC) of mutants, at 12 mo of age. Higher magnification in CC (boxed area) shows the cell morphology of an activated microglia and an astrocyte. All sections were counter stained with hematoxylin and revealed beaded pattern of oligodendrocyte nuclei in the CC. Scale bars, $50 \mu \mathrm{m}$ and $10 \mu \mathrm{m}$ (insets).

\subsubsection{Consequences of embryonal inactivation of Nrg1}

Apart from a possible role of NRG1/ErbB4 signaling in the fine-tuning of glutamatergic synapses, it has also been implicated in the establishment of inhibitory circuits in the forebrain. ErbB4 has been shown to be expressed in a subpopulation of interneurons migrating from the medial ganglionic eminences (MGE) to the cerebral cortex (Yau et al., 2003). Mice lacking ErbB4 exhibit a reduced number of GABAergic interneurons in the cortex and hippocampus (Flames et al., 2004). Thus, NRG1/ErbB signaling might play an important role in the tangential migration of interneurons from the sub-pallium to the developing cortex. The early lethality of NRG1 null mutants has so far 
prevented a detailed analysis of the role of NRG1 in the development of cortical GABAergic interneurons (Flames et al., 2004; Meyer and Birchmeier, 1995). Here, we have analyzed cortical interneuron development in two NRG1 mutants (Nex$C r e^{*} N r g 1^{\text {flox/flox }}$ and Emx1-Cre*Nrg1 $1^{\text {floxflox }}$ ), in which NRG1 is inactivated in the forebrain at embryonic stages, but which survive until adulthood.

\subsubsection{Embryonic inactivation of Nrg1 in post-mitotic projection neurons}

Mice lacking NRG1 in principal projection neurons beginning at $\sim \mathrm{E} 12$ (Nex$\left.C r e^{*} \operatorname{Nrg} 1^{\text {flox/flox }}\right)$ age normally and exhibit normal cage behavior without any noticeable neurological deficits (Fig. 7). However, a detailed behavioral analysis has not been performed. There were no major histopathological abnormalities, such as impaired cortical (Nissl stain) or axonal (Bielschowsky silver impregnation) cytoarchitecture in mutants when compared to their heterozygous (Nex-Cre*Nrg $\left.1^{f l o x /+}\right)$ and wildtype (Nrg1 $1^{\text {flox/flox }}$ and $N r g 1^{f l o x /+}$ ) littermates (Fig. 24 A, B).

A

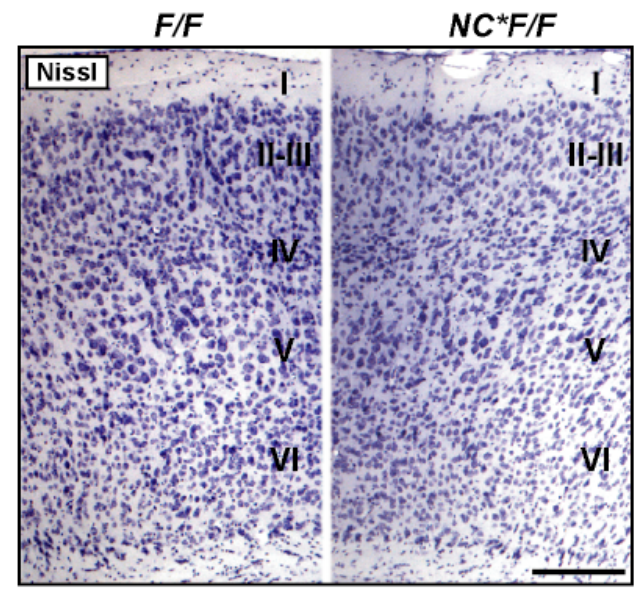

B

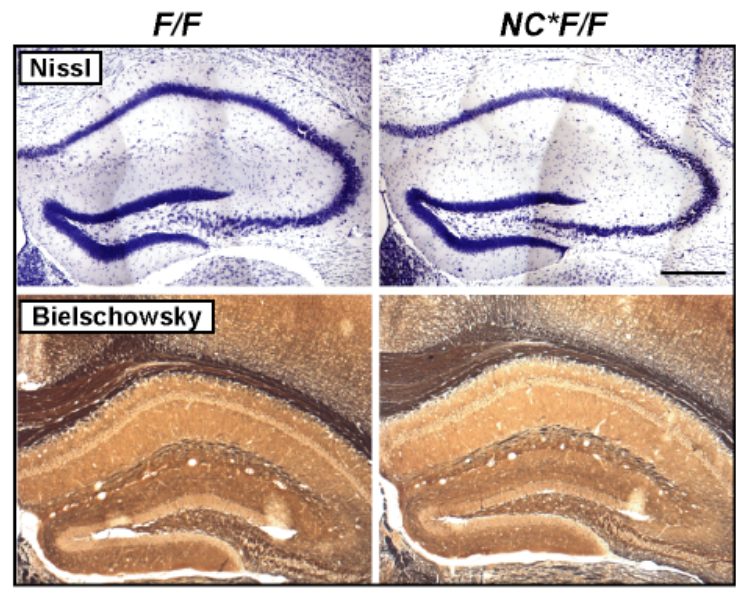

Fig. 24. Normal histology and no major axonal degeneration in mice lacking NRG1 embryonically from post-mitotic neurons

(A, B) Histological analysis of coronal brain sections from 3 months old NRG1 mutants $(N C * F / F, n=3)$ by cresyl violet (Nissl) staining and Bielschowsky silver impregnation demonstrate largely unaffected cortical development. (A) The cortical layering (layers I-VI) is regular in the motor cortex (MCx) of both mutants and control mice. (B) The hippocampus is normally developed and showed no sign of major axonal degeneration in mutants when compared to control $(F / F, n=3)$ mice. Scale bars, $100 \mu \mathrm{m}$ and $200 \mu \mathrm{m}$. 
A

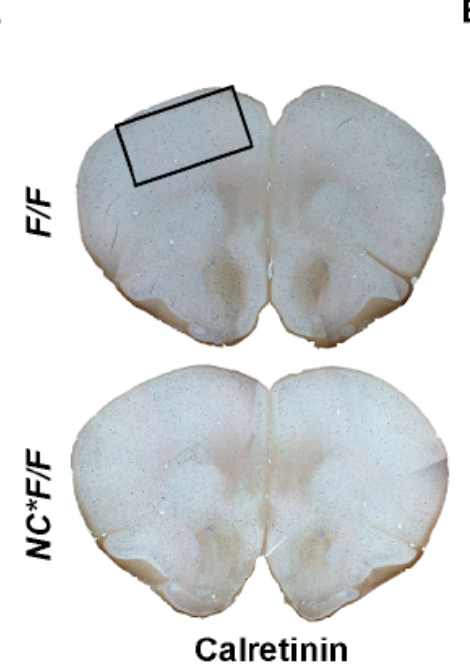

D

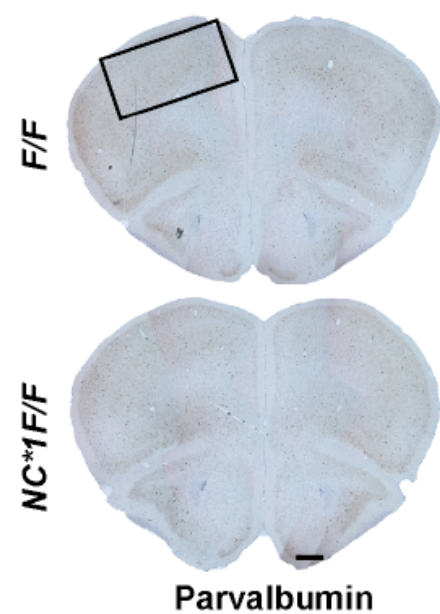

G

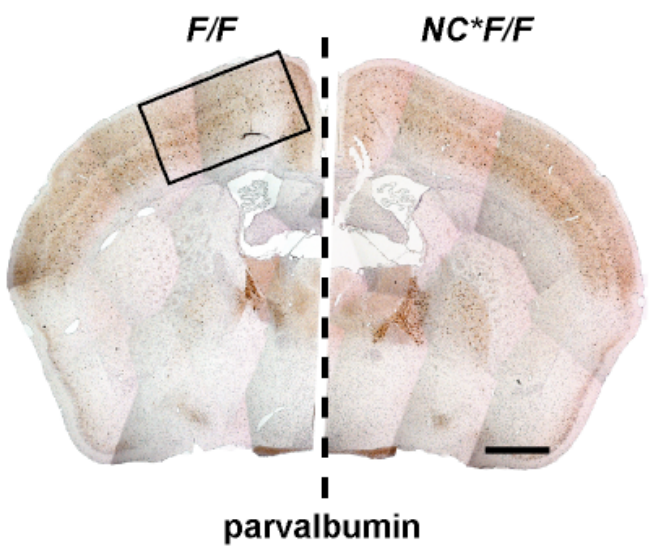

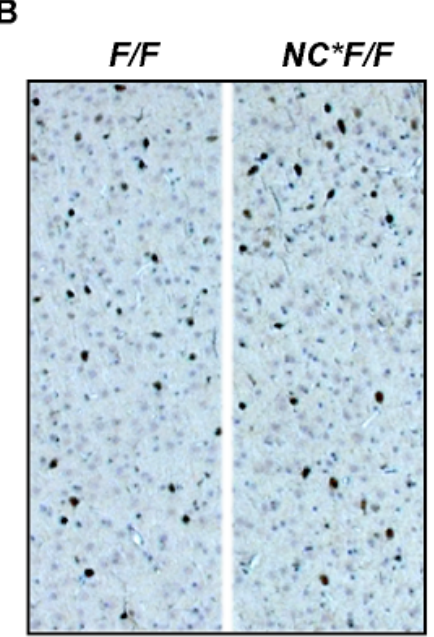

E

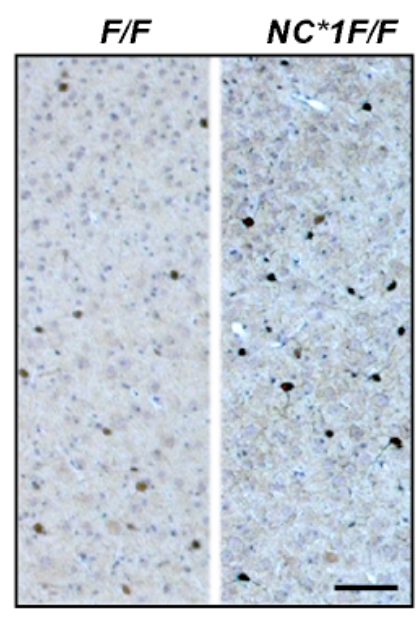

H
C

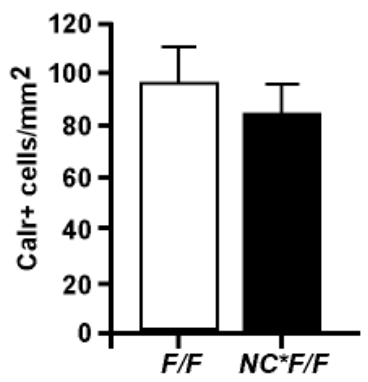

F

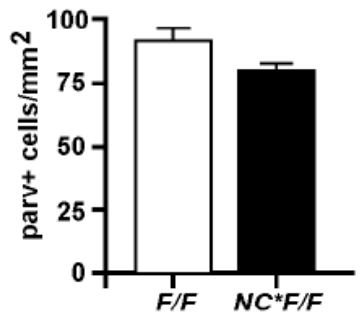


Fig. 25. Normal development of the parvalbumin+ and calbindin+ interneuron lineage in the absence of projection neuron-derived NRG1

Immunostaining for parvalbumin (parv) and calretinin (calr) on the coronal brain sections ( $7 \mu \mathrm{m}$ thick, paraffin) revealed widespread distribution of parv $(\mathbf{A}, \mathbf{B}, \mathbf{G}, \mathbf{H})$ and calr $(\mathbf{D}, \mathbf{F})$ positive interneurons in the rostral (A, D; bregma $2.10 \mathrm{~mm}$ ) and caudal (G; bregma $-0.82 \mathrm{~mm}$ ) part of the brain of NRG1 mutants $(N C * F / F, n=3)$ and controls $(F / F, n=3)$, as depicted in their representative sections. (A, D) The boxed area denotes primary and secondary motor cortex (M1/M2) and in (G) M1/M2 and primary somatosensory area (fore- and hindlimbs). In these brain areas parv + or calr + interneurons were counted for mutants and controls. (B, E, H) are magnified sub-region in the boxed area to show the staining pattern of parv + and calb + interneurons in various cortical layers. (C, F, I) Quantification of parv + and calr + cells revealed a slight decrease (not significant) in the number of both interneuronal populations in NRG1 mutants compared to controls. Note, the decrease in the number of parv+ interneurons seemed to be more prominent in the caudal (G, I) part of the brain. Scale bars; (A, D) $500 \mu \mathrm{m}, \mathbf{( B , E , ~ H ) ~} 100 \mu \mathrm{m}$, (G) $1 \mathrm{~mm}$.

Both membrane-associated NRG1 type III and secreted NRG1 type I have been shown to control migration of interneurons and guidance of thalamocortical axons (Flames et al., 2004; Lopez-Bendito et al., 2006). The lack of NRG1 from principal projection neurons therefore might hamper the proper placement of interneurons in the neocortex. Cortical interneurons can be grouped into three major classes based on the expression of $\mathrm{Ca}^{2+}$ binding proteins, such as calbindin (calb), calretinin (calr) and parvalbumin (parv). A slight decrease (not significant) in the number of calr+ (Fig. 25 A-C) and parv+ (Fig. 25 D-I) interneurons was observed in the motor cortex (M1/M2) of mutants (Nex-Cre*Nrg1 flox/flox, $\mathrm{n}=3$ ) when compared to wildtype (Nrg $1^{\text {flox/flox }}, \mathrm{n}=3$ ) littermates. Interestingly, the difference between the controls and mutants becomes more prominent in the caudal (Fig. $25 \mathrm{G}$ ) with respect to rostral (Fig. 25 D) part of the brain. Since the differences are subtle it will be important to increase the number of mice in both control and mutant groups in order to get a clearer image.

By quantitative real-time PCR changes in mRNA levels of several neuronal receptors and interneuronal proteins were analyzed. For the preliminary screening of a large number of differentially regulated genes hippocampal mRNA from mutants and control mice ( $n=6$ per genotype) were pooled and used to synthesize pooled-cDNA for both mutant and controls. Expression of most genes analyzed was unaltered in the mutants when compared to controls (Fig. 26 A-D). However, there was a significant decrease in the mRNA levels of calretinin (three-fold) and ErbB2 (two-fold) in mutants when compared to the controls (Fig. 26 A, C). In contrast, there was two-fold increase in ErbB3 mRNA levels in mutants (Fig. 26 A-C). In accordance to mRNA expression, most of the neurotransmitter receptors and other synaptic proteins analyzed by western blotting of protein lysates 
prepared from the hippocampus and cortex (data not shown) were unaltered (Fig. 26 D).

A

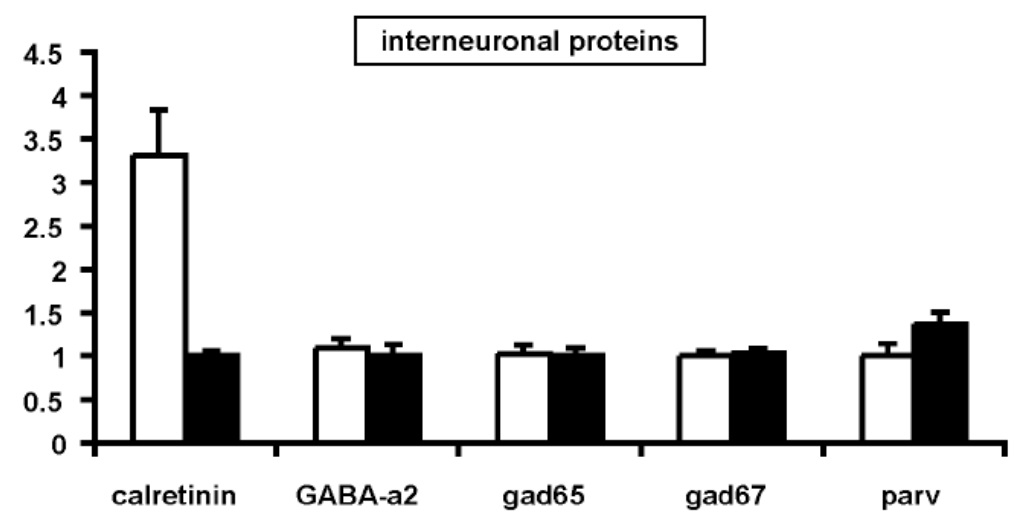

B

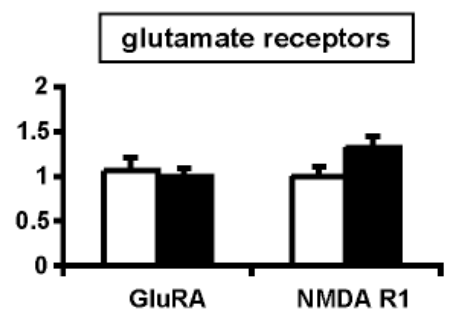

D

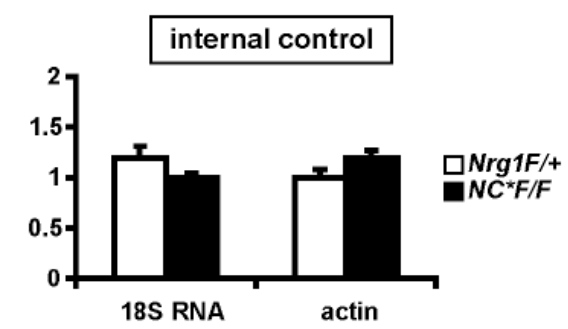

C

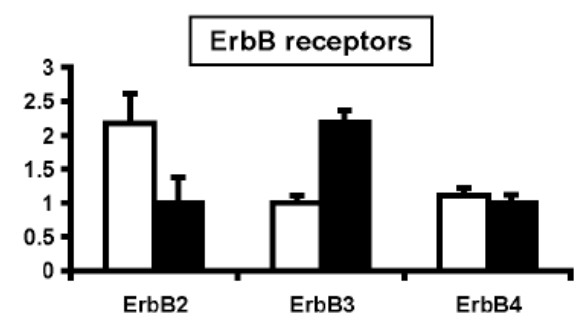

E

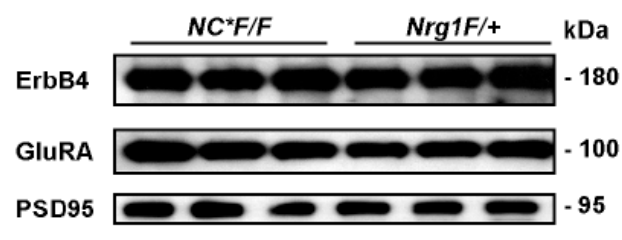

Fig. 26. Increased expression of ErbB3 and parvalbumin but decreased expression of calretinin and ErbB2 in mutants lacking NRG1 from their projection neurons

(A-D) Quantitative real-time PCR on pooled-cDNA derived from hippocampus of mutants $\left(N C^{*} F / F, n=6\right)$ and controls $(\mathrm{Nrg} 1 \mathrm{~F} /+, \mathrm{n}=6)$ at 3 mo of age. (A, C) mRNA levels of ErbB3 (two-fold) and parvalbumin (slightly) have increased in mutants. mRNA levels of calretinin (by three-fold) and ErbB2 (by two folds) have significantly decreased in mutants. The expression levels of other genes tested were at steady state levels in mutants when compared to control mice. For the relative quantification 18S RNA and $\beta$-actin were used as internal controls (housekeeping genes). GABA-a2 (GABA receptor subunit $\alpha 2)$, GluRA (glutamte receptor subunit 1), parv (parvalbumin), NMDAR1 (NMDA receptor subunit 1) and ErbB2/3/4 (ErbB receptor 2/3/4). (E) Western blot analysis of protein extracts prepared from the neocortex of 3 mo old control mice $(\mathrm{Nrg} 1 \mathrm{~F} /+, \mathrm{n}=3)$ and mutants $\left(N C^{*} F / F, \mathrm{n}=3\right)$ revealed unaltered levels of ErbB4 receptor $(\mathrm{ErbB} 4)$, AMPA receptor (GluR1) and postsyanptic protein (PSD95).These data are in line with the real-time PCR data. 


\subsubsection{Embryonic inactivation of Nrg1 in forebrain neurons, astrocytes and oligodendrocytes}

To gain further insight into the role of glial cell derived NRG1 signaling in the formation of cortical inhibitory circuits we generated Emx1-Cre*Nrg1 $1^{\text {floxflox }}$ mice. As previously described these mice lacks NRG1 from most neuronal (except interneurons), oligodendroglial and astrocytic cells of the forebrain. In contrast to Nex-Cre*Nrg $1^{\text {flox flox }}$ mice, Emx1-Cre*Nrg1 floxflox mice lack any paracrine signaling by glial contributed NRG1. Accordingly a stronger reduction of NRG1 protein

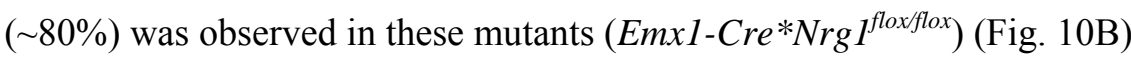

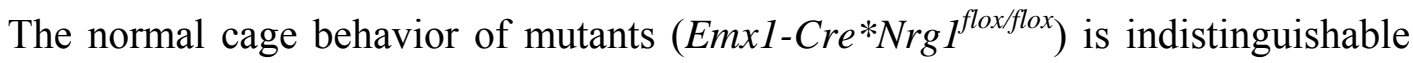
from their heterozygous $\left(E m x 1-C r e^{*} N r g 1^{f l o x /+}\right)$ and control $\left(\mathrm{Nrg}^{\text {flox/+ }}\right)$ littermates. There is no obvious evidence of ataxia, tremors, spasticity or movement disorder in mutants. Though these mice breed normally and produce litters of normal size (6-8 pups/litter) the male/female ratio is significantly shifted towards $\sim 0.35$ i.e. thrice as many female than male $\left(E m x 1-C r e^{*} N r g 1^{\text {floxflox }}\right)$ mutants are born. The normal 1:1 sex ratio remains unaltered in heterozygous and control mice (Emx1-Cre*Nrg1 $1^{\text {flox/+ }}, \mathrm{Nrg} 1^{\text {flox/flox }}$ and $N r g 1^{\text {flox/+ }}$ ) (Table

1). The reason for this preferential loss of mutant $\left(E m x 1-C r e^{*} N r g 1^{\text {floxflox }}\right)$ male embryos is currently unknown but might be due to the implantation failure or prenatal loss (Bacon and McClintock, 1999).

Although mutants seemed inconspicuous, they were more vulnerable to routine handling induced stress. Handling per se frequently precipitated epileptic convulsions (seizures) suggesting that mild stress or fear induced such seizures. Seizures consisted of occasional squeaking (i.e. vocalization just prior to seizures), sitting in "kangaroo posture" (i.e sitting on hindlimbs with forepaws drawn up) (Fig. 27 D), watering of mouth, myoclonic movement of forelimbs, erection of tail (Fig. 27 C), body stiffening, loss of postural control and falling (Fig 27 A, B), occasionally followed by focal clonic movements of forelimbs and hindlimbs (Fig. 27 A, B). Typically, the episode lasted for 2030 seconds, followed by extensive grooming (mainly cleaning of face because of salivation), generalized body weakness, slight decrease in activity and ultimately complete recovery within few minutes (see attached video). 

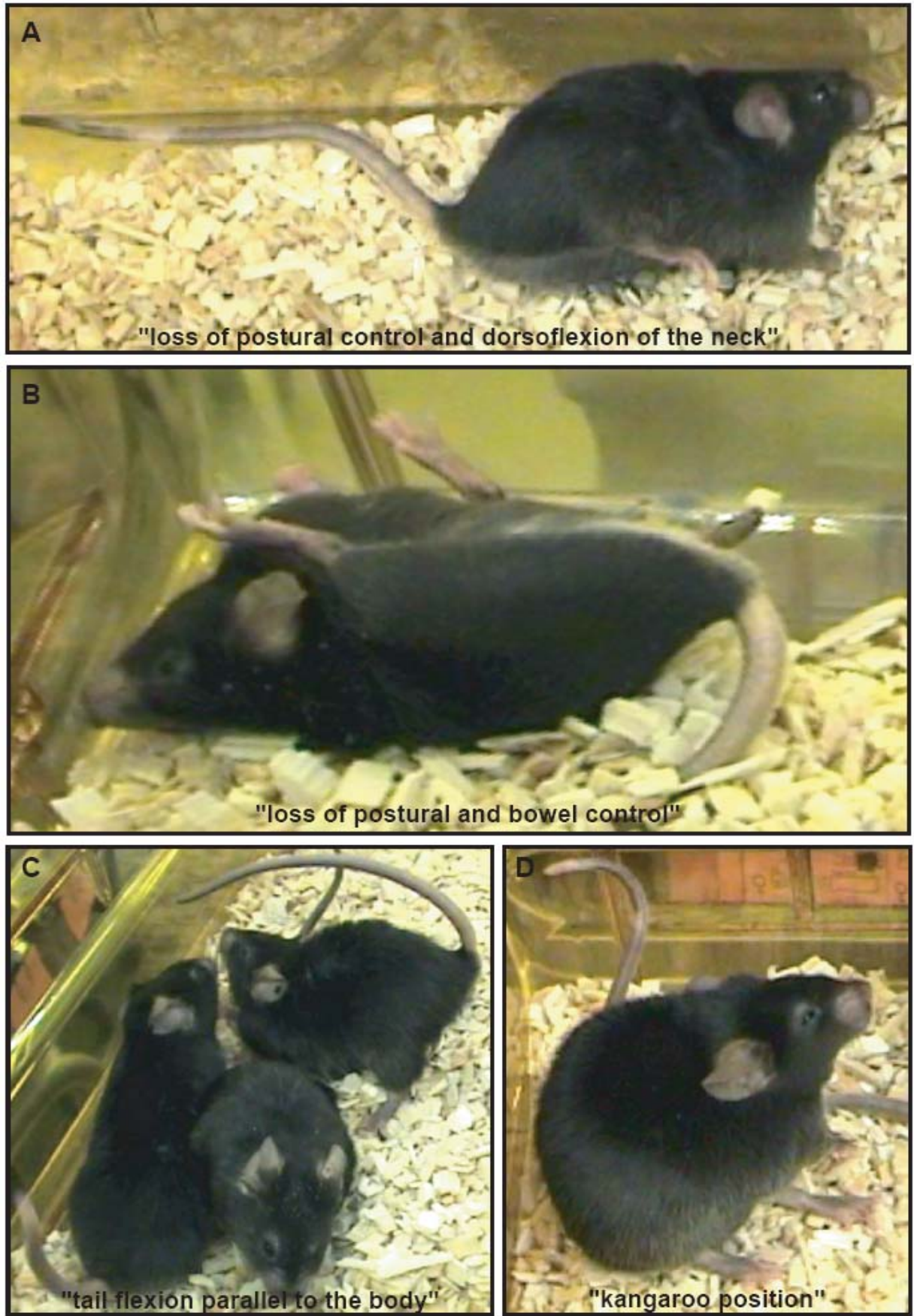

Fig. 27. Characteristic features of "handling-induced seizures" in mice lacking NRG1 from neural precursors

Seizures start with a loss postural control and might proceed as shown in (A, B) or as (C, D). It is important to note that (A-D) is not the precise sequence in which seizures are manifested, only some characteristic features are shown. (A, B) After the loss of postural control mice undergo tonic extension of fore and hindlimbs, the dorsoflexion of the neck, the tail gets stiffed and loss of bowel control. (C) Few seconds after the regain of the postural control, the complete body of the mouse stiffens and the tail is flexed almost parallel to the body with the tip of the tail almost reaching the snout. (D) Few seconds after the episode in (C). Note the "kangaroo posture" i.e. sitting on hindlimbs and forelimbs free in the air, stiffed tail, salivation and then cleaning of face. 
Although we have not looked carefully for spontaneous seizures, they seemed to be rare. About half of mutants ( $50 \%$, both sexes affected) exhibited such "handling induced seizures", which were also observed in $\sim 20 \%$ of the littermates $\left(E m x 1-C r e^{*} \mathrm{Nrg}^{\text {flox/+ }}\right.$, $N r g 1^{\text {floxflox }}$ and $N r g 1^{f l o x /+}$ ). Seizures usually occurred in 6-8 weeks old mice and persisted throughout adulthood.

\begin{tabular}{|c|c|c|c|c|c|c|c|}
\hline Genotype & Total & Male & Female & Male\% & Female\% & Genotype\% & Expected\% \\
\hline Emx1Cre*Nrg1F/F & 47 & 12 & 35 & 25.53 & 74.47 & 23.5 & 25 \\
\hline Emx1Cre*Nrg1F/+ & 65 & 26 & 39 & 40.00 & 60.00 & 32.5 & 25 \\
\hline Nrg1F/F & 37 & 16 & 21 & 43.24 & 56.76 & 18.5 & 25 \\
\hline Nrg1F/+ & 51 & 22 & 29 & 43.14 & 56.86 & 25.5 & 25 \\
\hline Size of colony & 200 & 76 & 124 & 38.00 & 62.00 & NA & NA \\
\hline
\end{tabular}

Table 1: Altered sex ratio in mice lacking NRG1 from forebrain neurons and glial cells.

To generate NRG1 null mutants we crossbred $\mathrm{Nrg} 1 \mathrm{~F} / \mathrm{F}$ (male) to Emx1Cre*Nrg1F/+ (female). Pups were born in accordance with Mendelian ratio ( $25 \%$ for each genotype, shown as geotype\%) and were of the following genotypes: $\mathrm{Nrg} 1 \mathrm{~F} / \mathrm{F}, \mathrm{Nrg} 1 \mathrm{~F} /+, \mathrm{Em} \times 1 \mathrm{Cre}{ }^{*} \mathrm{Nrg} 1 \mathrm{~F} /+$ (heterozygous) and $\mathrm{Em} \times 1 \mathrm{Cr}{ }^{*} \mathrm{Nrg} 1 \mathrm{~F} / \mathrm{F}$ (null mutant, red). In all genotypes, except null mutants, male to female ratio was close to the normal and reflected the trend of sex ratio that can be observed in the total colony. In an ideal situation male $\%$ (and female $\%$ ) $=50 \%$ (number of males or females in a given genotype/total number of mice in that genotype), genotype $\%=25 \%$ (total number of mice in a given genotype/total number of mice in a colony) and expected $\%=25 \%$ (expected Mendelian ratio for each genotype). NA; not applicable.

Epilepsy is characterized by localized bursts of electrical hyperactivity in the cortex, which ultimately can lead to excitotoxicity and cell death (Bozzi et al., 2000). Importantly, Hematoxylin-Eosin (HE) staining of cortex and hippocampus of mutants (Emx1-Cre*Nrg1 $\left.{ }^{\text {flox/flox }}\right)$ did not reveal any gross morphological changes (Fig. 28).

The absence of excitotoxic cell dealth in the cortex and hippocampus of mutants (at 4 months of age) was demonstrated by the lack of Tunnel positive or pycnotic nuclei (markers of apoptotic cell death) (data not shown). This is in line with several other mouse mutants that exhibited "handling or stress induced seizures" but are anatomically normal with no major changes or cell death in the cortical morphology (Erickson et al., 1996; Kash et al., 1997; Prosser et al., 2001). On western blot no major changes in protein levels were observed for GABAaR $\alpha 1$ subunit, GAD67, CaM KinaseII $\alpha$, ErbB4 and NR1 in cortical and hippocampal lysates prepared from mutants and wildtype (Fig. 29 A, C). 


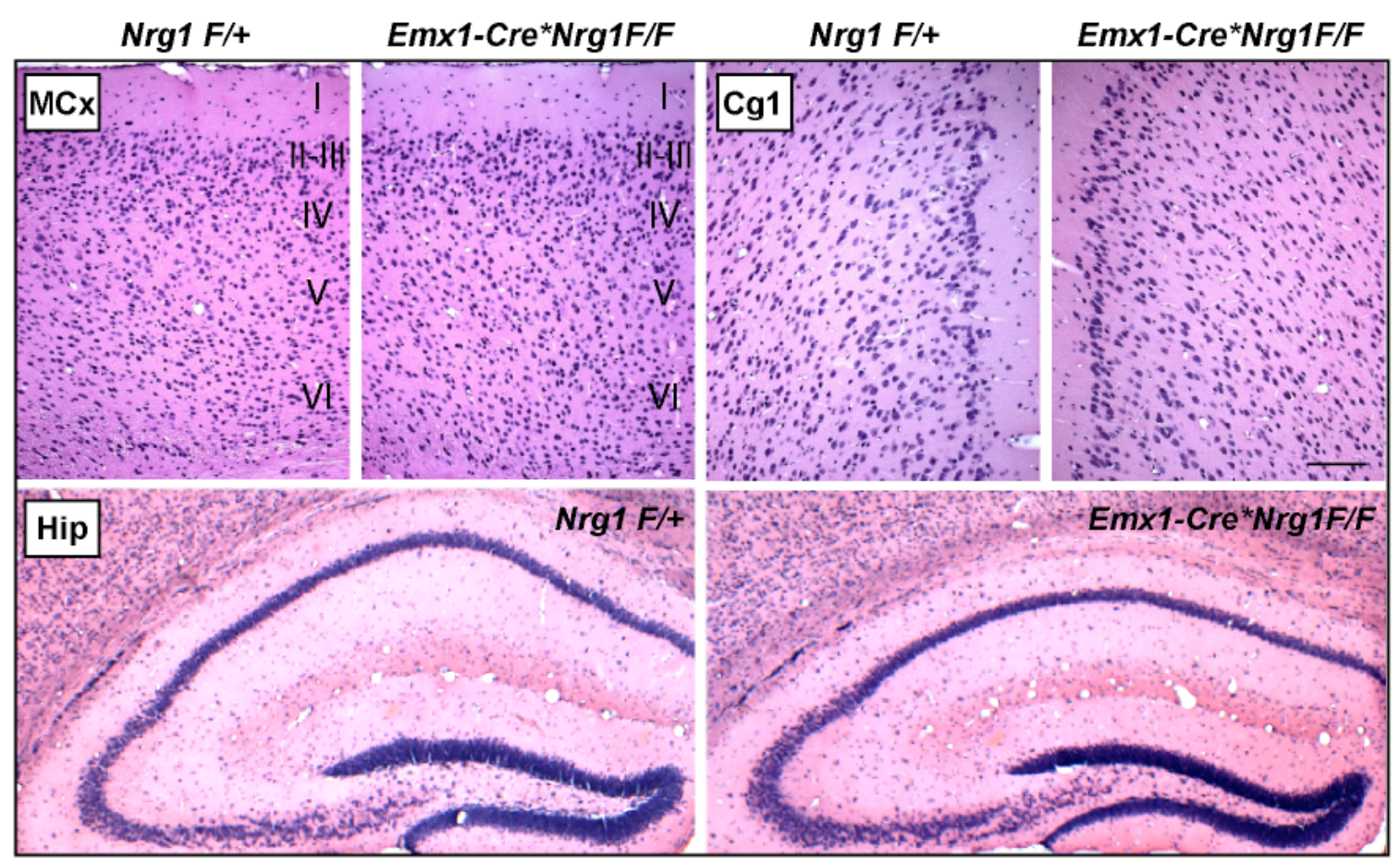

Fig. 28. Undisturbed cortical layering and hippocampal morphology in mice lacking NRG1 from neural precursors

The cortex developed normally in 2 mo old mutants $\left(E m x 1-C r e^{*} F / F\right)$ compared to controls $(\mathrm{Nrg} 1 \mathrm{~F} / \mathrm{F})$ as revealed by HE staining of coronal brain sections $(5 \mu \mathrm{m}$, paraffin). The cortical layering is undisturbed and each layer is designated by roman numerals (I-VI). The cell populations in the rostral part of the brain and hippocampus also seemed to be morphologically normal, without sever excitotoxicity mediated cell death induced by seizures. MCx (Motor cortex), Cg1 (cingulated cortex area 1) and Hip (hippocampus). Scale bars, $100 \mu \mathrm{m}$.

Interestingly, there seemed to be a slight increase in GAD65 expression in mutants when compared to controls (Fig. 29 A, B). Also in "crude synaptic vesicles" preparations from control and mutant cortices (probed for NR1, synaptophysin and NRG1), no major alterations in expression levels were observed (Fig. 29 D) except for NRG1 (Fig. 29 E). Additionally, NRG1/ErbB signaling has shown to be modulated by interaction of postsynaptic ErbB4 receptors with PSD95 (Huang et al., 2000). So, in line with this hypothesis we carried co-immunoprecipitation of various synaptic proteins with ErbB4 receptor antibody. We couldn't show any impairment in the interaction of ErbB4 with PSD95 and ErbB2 in mutants where virtually NRG1 is lacking from hippocampal pyramidal neurons and glial cells. Currently, analysis of other synaptic proteins is in progress. 
A

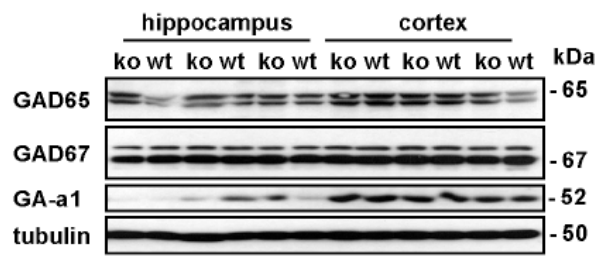

C

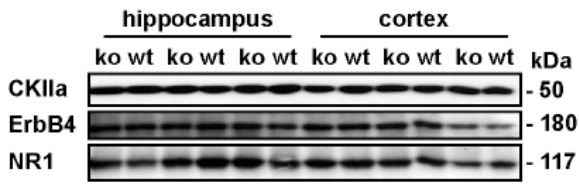

E

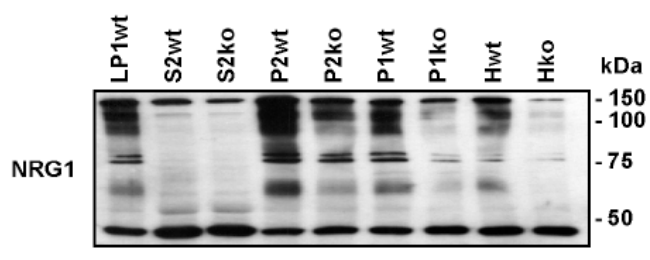

B

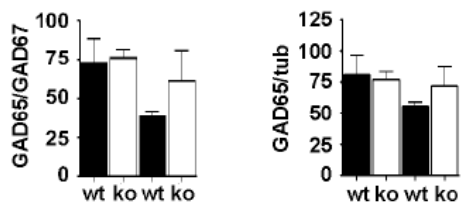

D

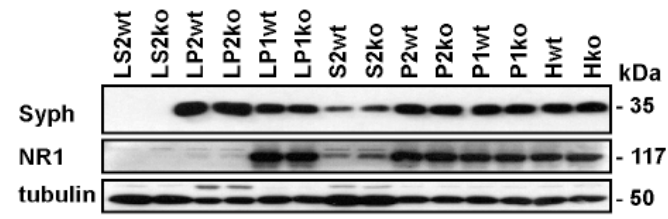

$\mathbf{F}$

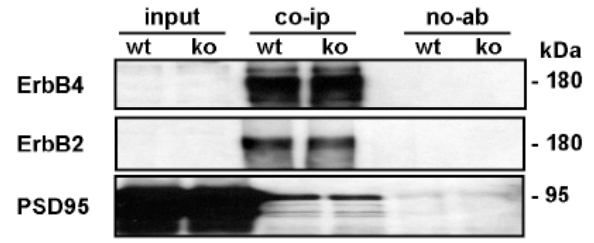

Fig. 29. Unaltered protein levels in cortical lysates and "synaptic vesicles" prepared from mice lacking NRG1 from neural precursors

(A-C) Semiquantitative comparison of levels of interneuronal and synaptic proteins by western blotting of protein lysates prepared from cortex and hippocampus of mutants $\left(E m x 1-C r e^{*} F / F(\mathrm{ko}), \mathrm{n}=3\right)$ and littermate controls $(\mathrm{Nrg} 1 \mathrm{~F} /+(\mathrm{wt}), \mathrm{n}=3)$ at 4 mo of age. The protein level of GAD65 was increased in the hippocampus of mutants. All other proteins immunoblotted were at steady state levels in mutants when compared to controls. NR1 (NMDA receptor subunit 1), ErbB4 (ErbB4 receptor), CKIIa (Cam KinaseII $\alpha$ ) and GA-a1 $\left(\mathrm{GABA}_{\mathrm{A}}\right.$ receptor $\alpha 1$ subunit). (B) Densitometric quantification revealed increased levels of GAD65 in the protein lysates prepared from hippocampus (but not in cortex) of mutants. 'Integrated density' values of GAD65 were normalized to GAD67 or $\alpha$-tubulin and are presented as the mean values $( \pm$ SEM). (D, E) Analysis of synaptic proteins in subcellular fractions of protein lysates prepared from cerebral cortices of 4 mo old mutant $\left(E m x I-C r e^{*} F / F\right.$, (ko) $\left.n=1\right)$ and control $(N r g 1 F /+$, (wt) $n=1)$ mice. After differential centrifugation of cortical extracts, equal amounts of protein $(20 \mu \mathrm{g}$ per lane) from each fraction were analyzed by western blotting. Synaptic membrane proteins, such as NMDA receptor subunit 1 (NR1), and NRG1, were enriched with heavier membranes in LP1 fraction. The c-terminal domain ( $60 \mathrm{kDa})$ generated by processing of the 'full length' NRG1 by $\beta$-secretase, remains membrane bound and co-sediments in the LP1 fraction. The enrichment synaptophysin (Syph) occurs in a crude synaptic vesicle fraction (LS2), a pattern typical for synaptic vesicle proteins. Levels of the analysed synaptic proteins, except NRG1, remain unaltered in mutants when compared to the wildtype control mice. Note, $\alpha$-tubulin co-sediments in all the subcellular fractions as a contaminant. H, Homogenate; P1, nuclear pellet; P2, crude synaptosomal pellet; LP1, lysed synaptosomal membranes; LP2, crude synaptic vesicle fraction; S1, supernatant after synaptosome sedimentation; S2, cytosolic fraction (F) Unaltered interaction between ErbB4 and ErbB2 and PSD-95 in mutants lacking NRG1 from neural precursors. Crude synaptosomal fraction (P2) was prepared from cortex of mutants $(E m x I-C r e * F / F, \quad(k o) n=1)$ and controls (Nrg1F/+, (wt) n=1) for coimmunoprecipitation of synaptic proteins. P2 was solubilized with $1 \%$ TritonX-100, and the resulting detergent extract (input) was used to co-immunoprecipitate (co-ip) synaptic proteins using ErbB4 antibody (sc-283). The immunoprecipitates were analyzed by western blotting for ErbB2, ErbB4 and PSD-95. 'no-ab' indicates precipitation reactions in the absence of ErbB4 antibody. The interaction between ErbB4 and other synaptic proteins, such as ErbB2 and PSD95 was unaltered in the absence of NRG1 signaling in mutants. 
To study potential changes in the number or localization of interneurons in the cortex and hippocampus of mutants, immunostaining for several interneuronal markers, such as calb, calr, and parv was performed. Here, a significant increase $(\sim 10 \%)$ in the number of parv+ interneurons was observed in the mutant when compared to controls (Fig. 30). Though the most significant difference was observed in more caudal parts of the brain (motor and somatosensory cortex), there was a tendency towards increased numbers already in more rostral area of the forebrain (motor cortex, M1/M2). To quantify the total number of cortical GABAergic interneurons immunostaining for GAD67 was carried out (Esclapez et al., 1994; Esclapez et al., 1993). Not significant changes in the number of GAD67+ interneurons were detected in mutants. Further analysis with other interneuronal markers, such as GABA and calbindin, is ongoing. For the quantification of subtle phenotypes the number of mice and brain sections will be increased. 
A

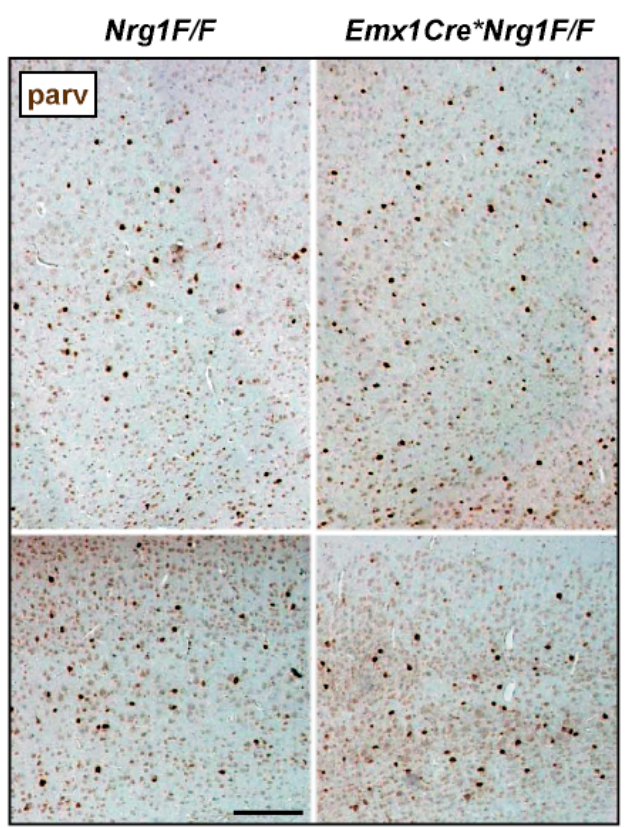

B

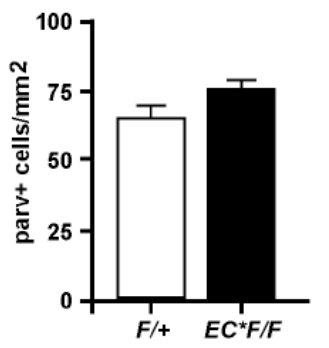

C

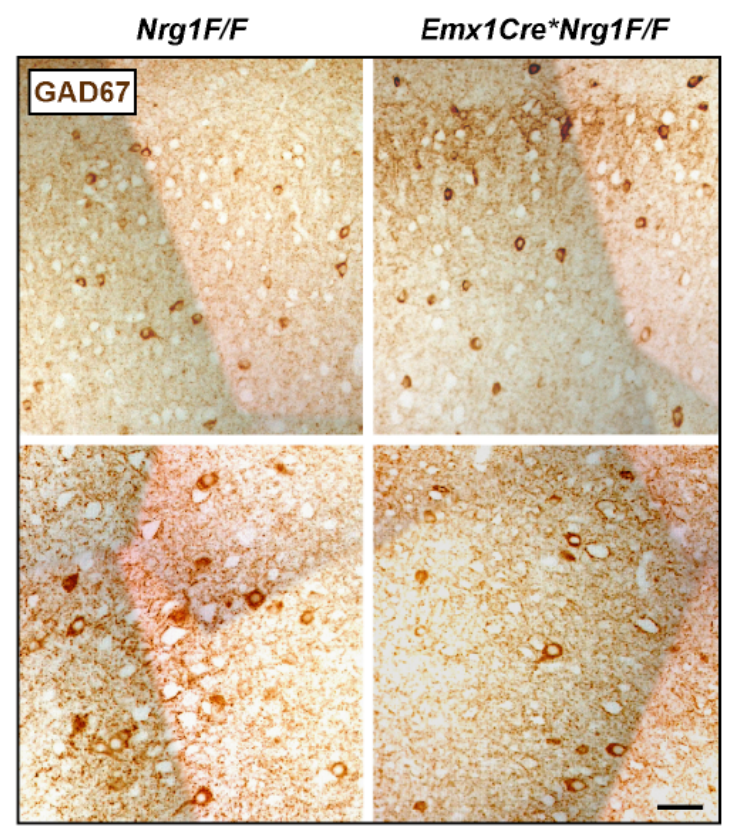

D

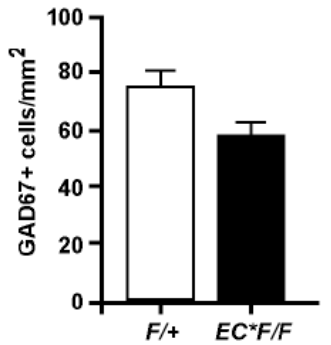

Fig. 30. Increased parv+ but decreased GAD67+ interneuron numbers in mice lacking NRG1 from neural precursors

(A, C) Immunostaining for parvalbumin (parv) and GAD67 on brain sections ( $7 \mu \mathrm{m}$ thick, paraffin) revealed a normal distribution of parv (A) and GAD67 (C) positive interneurons in the motor cortex (top: rostral and bottom: caudal part of the brain) of NRG1 mutants $\left(E m \times 1-C r e^{*} F / F, n=3\right)$ and controls $(N r g 1 F /+, n=3)$. (B) Quantification of parv+ interneurons revealed a significant increase ( $\sim 10 \%)$ in NRG1 mutants compared to controls. (D) GAD67+ interneurons were slightly decreased (but not significant) in NRG1 mutants compared to controls. Similar area was used for counting parv + cells as described in Fig. 25, the coordinates of the plane of section is as follows: rostral (bregma $=2.10 \mathrm{~mm}$ ) and caudal (bregma $=-1.70 \mathrm{~mm}$ ). Scale bar; $50 \mu \mathrm{m}$. 


\subsection{Generation of a NEX-CreERT2 knock-in mouse line}

Several strategies have been developed to the study function of a gene in vivo, such as generation of transgenic animals through pronuclear injection (Brinster et al., 1982; Gordon et al., 1980; McKnight et al., 1983), targeted gene ablation in embryonic stem (ES) cells and more recently by conditional ablation of gene in a specific cell type (Doetschman et al., 1987; Gu et al., 1994; Thomas and Capecchi, 1987).

At the beginning of the project evidence was lacking that forebrain specific NRG1 conditional mutants (CkII-Cre*Nrg1F/F, Nex-Cre*Nrg1F/F, Emx1-Cre*Nrg1F/F) would survive until adulthood, the prerequisite for studying CNS myelination and synaptic plasticity (Flames et al., 2004; Meyer and Birchmeier, 1995). Conditional mutagenesis permits the spatial control over genomic DNA manipulations in vivo, however standard versions of Cre or Flp recombinase do not allow for temporal control. Therefore, we decided to generate a novel mouse line that expresses a modified Cre recombinase (CreERT2) that is fused to a mutated human oestrogen receptor (ER) ligand-binding domain (LBD) (Feil et al., 1997). In the absence of tamoxifen, a synthetic ligand of the ER, the CreERT2 variant is located in the cytoplasm and is inactive. Addition of tamoxifen induces nuclear transfer and site-specific recombination of loxP-flanked genomic DNA, both in vitro and in vivo (Feil et al., 1997). To direct expression of CreERT2 to principal neurons of the telencephalon we chose regulatory sequences from the Nex gene. Nex belongs to the NeuroD-family of neuronal basic helix-loop-helix (bHLH) proteins and is predominantly expressed in the dorsal telencephalon (Bartholoma and Nave, 1994; Goebbels et al., 2006). To mimic the endogenous Nex expression pattern, the coding region of the Nex gene was replaced by a CreERT2 expression cassette using homologous recombination in ES cells (Fig. 31). A similar approach using the original Cre version lead to the generation of a mouse line, in which Cre recombinase faithfully reproduces endogenous Nex expression patterns (Nex-Cre) (Goebbels et al., 2006). Nex-Cre mice have been used and described in the previous sections of this thesis. In the NexCreERT2 mouse line it was expected to observe most prominent CreERT2 mediated recombination in neocortex and hippocampus, starting from embryonic day 12.5. Within the dorsal telencephalon, CreERT2 mediated recombination was supposed to be restricted to postmitotic projection neurons and dendate gyrus granule cells, and to be completely 
absent from proliferating neural precursors, interneurons, oligodendrocytes, and astrocytes.

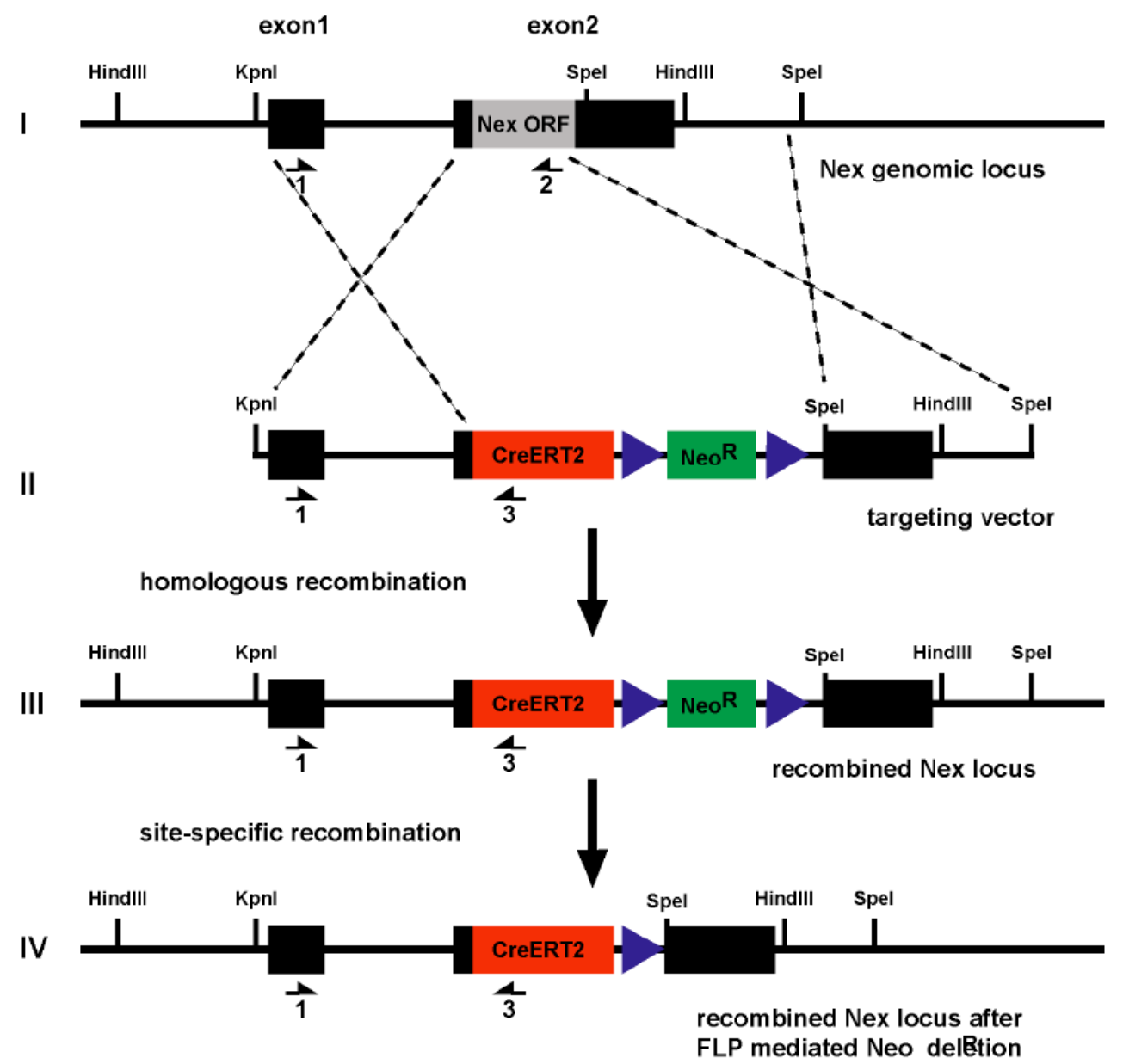

Fig. 31. Strategy to knock in CreERT2 into the murine Nex gene

(I) Genomic structure of the wildtype Nex allele. The locus comprises two exons (black boxes, exon 1 and exon 2). The entire coding region is located on exon 2 (gray box). (II) pAA-NEXCreERT2 targeting vector. The construct harbors 5' and 3' homology arms (black boxes and thick lines), the CreERT2-cDNA fused to the start-codon of the Nex gene (red box) and a neomycin resistance cassette (green box) flanked by two FRT sites (blue triangles). (III) pAA-NEXCreERT2 allele after homologous recombination in mouse ES cells. (IV) pAA-NEXCreERT2 allele after site-specific recombination of the NeoR cassette in vivo by breeding NexCreERT2 mice to FLP deletor transgenic mice. The small black arrows in allelic diagrams (I-IV) represent the location of various primers used for characterization and genotyping of NexCreERT2 mice.

\subsubsection{Cloning of 'pAA-NEXCreERT2' gene targeting vector}

As a first step, we cloned a gene-targeting vector harbouring $5^{\prime}$ and $3^{\prime}$ homology arms, the CreERT2-cDNA fused to the start-codon of the Nex gene and a neomycin resistance cassette flanked by two FRT sites. (Fig. 31 II). For construction of the pAA- 
NexCreERT2 targeting vector, we used Nex genomic DNA fragments from the pNexCre targeting vector (used for generation of the Nex-Cre mouse line) (Goebbels et al., 2006) and the CreERT2 sequence from plasmid pCreERT2 (Metzger and Chambon, 2001). The CreERT2 sequence used in this study is an improved version of the original tamoxifeninducible Cre recombinase (Feil et al., 1997; Metzger and Chambon, 2001). The "short arm" of the targeting vector was represented by a $1.47 \mathrm{~kb}$ DNA fragment located immediately upstream of the coding region. We cloned the 5' part of the "short arm" as a $\mathrm{KpnI} / \mathrm{XhoI}$ fragment (824 bp) into pBluescript-KS (Stratagene). The 3' part of the "short arm" was generated by PCR using primers KICreERNEX1-s; 5'- AGA CTT CCG TGG CTC TTA GAAC -3' and KICreERNEX2-as; 5'- CAT GGT TCT TTA ACC TTA ATT TAC $-3^{\prime}$ and pNexCre as template DNA. The 5' part of the CreERT2 coding sequence was generated by PCR using primers KICreERNEX3-s; 5'- ATT AAG GTT AAA GAA CCA TG TCC AAT TTA CTG ACC G -3' and KICreERNEX4-as; 5'- TTC GGA TCC GCC GCA TAA CCAG -3' and pCreERT2 as template DNA. Subsequently, the 3' part of the "short arm" was fused to the 5' part of CreERT2 by "gene SOEing" PCR (Horton, 1995, 1997) with primers KICreERNEX1-s and KICreERNEX4-as and subcloned as a Xhol/BamHI fragment into the targeting vector. The CreERT2 coding sequence was completed by subcloning a $1.8 \mathrm{~kb}$ long BamHI/SalI fragment (that also contained a SV40 polyadenylation signal) from plasmid pCreERT2. Next, we amplified a neomycin resistance gene flanked by FRT site from pFRTNeo by PCR with primers SpeINeo-s; 5'GCG CGC CAC TAG TCT CGA GAC CGG T -3' and NdeINeo-as; 5'- GGG AAT TCC ATA TGG CGA TCG CGG CCG GCC AGA TCTC -3' and subcloned the PCR product as NdeI/SpeI fragment ( 3 ' to the CreERT2 coding sequence). Finally, the targeting vector (was accomplished by cloning a $5.3 \mathrm{~kb}$ SpeI fragment (served as the "long arm"), harboring the $3^{\prime}$ region of exon 2 and downstream sequences of the Nex gene. The final targeting vector (pAA-NexCreERT2) was verified by restriction analysis, DNA sequencing and Flp-mediated recombination in vitro (Fig. $32 \mathrm{~A}, \mathrm{~B}$ ). 
A

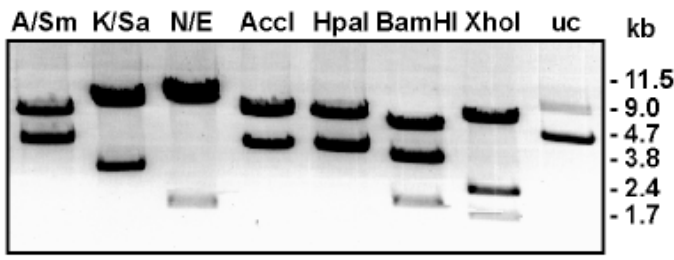

C
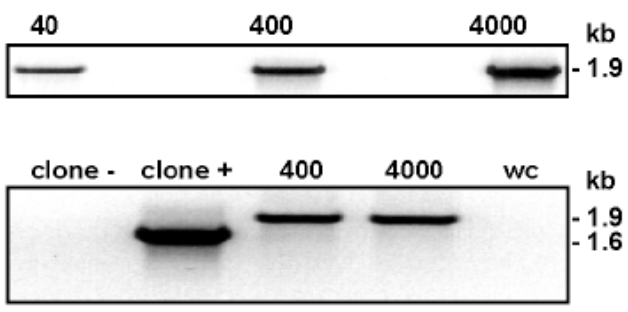

E

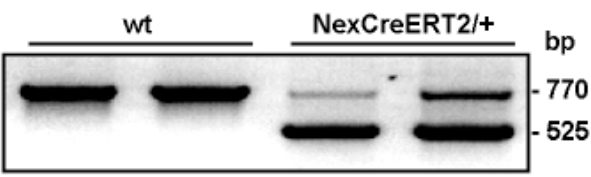

B

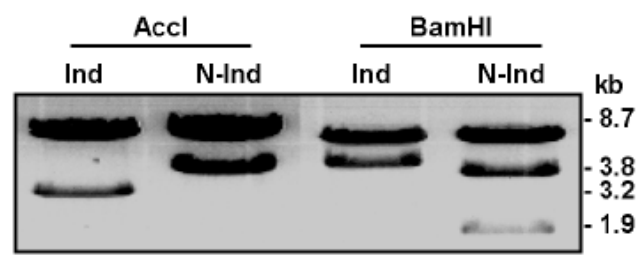

D

ES cell clones

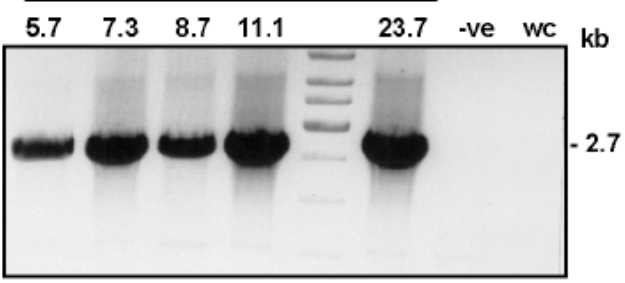

BamHI digested
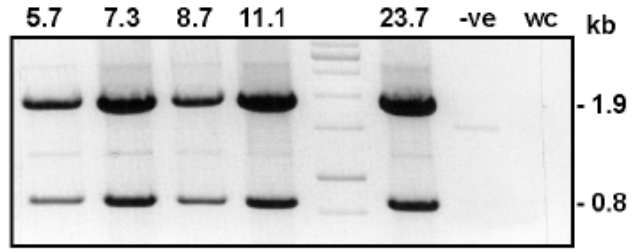

Fig. 32. Characterization of the targeting vector and PCR based strategy for the screening of homologously targeted ES cells.

The pAA-NexCreERT2 gene targeting vector was verified by restriction analysis (fingerprinting) and Flpmediated recombination in vitro. (A) The integrity and correctness of the targeting vector was confirmed by digestion with several combinations of restriction enzymes. The following enzymes (with the exact size of the fragments generated by each enzyme) were used for the fingerprinting: ApaI/SmaI (A/Sm; 8405 and 4736 bp), KpnI/SacII (K/Sa; 10275 and 2868 bp), NotI/EcoRV (N/E; 11518 and 1623 bp), AccI (8697 and 4444 bp), HpaI (8640 and 4501 bp), BamHI (7376, 3862 and 1903 bp), XhoI (9018, 2440 and 1638 bp) and uncut (uc) plasmid. Each digestion reaction exhibited the bands of expected sizes. On the right side of the gel, band sizes are marked in $\mathrm{kb}$ (for a quick overview of the fingerprint pattern) (B) The site-specific recombination of the NeoR cassette was demonstrated by successful FLP mediated recombination of the targeting vector in EL-250 bacterial strain. EL-250 bacteria were transformed with the targeting vector and recombination was induced by $0.5 \% \mathrm{~L}$-arabinose leading to the excision of the NeoR cassette. The targeting vector with or without recombination of the NeoR cassette can be identified by its specific restriction digestion pattern. EL250 bacteria transformed with the targeting vector but not induced (N-Ind) give rise to two or three fragments after restriction digestion with AccI (8697 and 4444 bp) or BamHI (7376, 3862 and 1903 bp), respectively. In contrast, the induction (Ind) of recombination in the transformed EL-250 bacteria results in two fragments after restriction digestion with both AccI (3246 and $8697 \mathrm{bp}$ ) and BamHI (7376 and $4567 \mathrm{bp}$ ). (C) A sensitive nested PCR based screening strategy was used to detect the single homologous integration event in a targeted ES cell clone. The primer combinations are shown in Fig. 31: outer primer (4 and 7) and inner primer (5 and 6) pairs. The upper gel shows the PCR product $(1.9 \mathrm{~kb})$ amplified from 40,400 and 4000 copies of 'control plasmid' as template DNA. The lower representative gel shows the PCR product (1634 bp) amplified from genomic DNA derived from an ES cell clone that was homologously targeted (clone+). Note: ES cells that have not undergone homologous recombination (clone-) don't show any band. 400 and 4000 is the copy number of the 'control plasmid' used as a positive control and water (wc) was used as negative control in the screening process. 
D) 5 positive clones $(5.7,7.3,8.7,11.1$ and 23.7) out of 288 screened clones demonstrated proper homologues recombination and were further verified by combining the sensitivity of PCR and specificity of restriction enzymes. The upper gel shows the PCR amplified product $(2.7 \mathrm{~kb})$ when genomic DNA from positive ES cell clones was used as a template. The primers combinations (5 and 8) and their location are shown in (Fig. 31). The tail genomic DNA of Nex-Cre/+ mouse (-ve) and water (wc) was used as negative controls for the PCR reaction. The lower gel shows the PCR product $(2.7 \mathrm{~kb})$ after BamHI restriction digestion resulting in two fragments of the size $1.9 \mathrm{~kb}$ and $800 \mathrm{bp}$. This further verified the identity of the positive ES cell clones before injection into blastocysts. (E) The representative gel shows the genotyping PCR product on genomic DNA isolated from tails of wildtype (wt, $770 \mathrm{bp}$ ) and heterozygous (NexCreERT2/+, 770 and $525 \mathrm{bp}$ ) mice. The primer (1-3) combination used for the genotyping PCR is indicated in Fig. 31 .

\subsubsection{Gene targeting in ES cells by homologous recombination}

To achieve Cre recombinase expression under control of the murine Nex locus, we replaced the coding region of $\mathrm{Nex}$ (Nex ORF, on exon 2) by a CreERT2 expression cassette (pAA-NexCreERT2) using homologous recombination in ES cells (Fig. 31 II). We electroporated mouse ES cells (SV129/OLA) with the SacII linearized targeting vector (pAA-NexCreERT2). Based on a nested PCR screening strategy we identified several ES cell clones harboring the correct genomic targeting event (Fig. 32 C).

Four of these ES cell clones, in which CreERT2-cDNA was stably integrated in the Nex genomic locus, were used to generate chimeric mice by injection into $\mathrm{C} 57 \mathrm{bl} / 6$ derived blastocysts (Fig. 32 D). The germ line transmission was verified by breeding highly chimeric founders to $\mathrm{C} 57 \mathrm{Bl} / 6$ wild-type mice. Heterozygous offspring are currently being backcrossed to FLP-deletor mice (C57B1/6 background) to remove the Neomycin selection cassette (Fig. 31 III, 32 B). Routine genotyping of offspring was performed by PCR (Fig. $32 \mathrm{E})$.

\subsubsection{Characterization of NexCreERT2 mice}

NexCreERT2 mice were analyzed for Cre expression by breeding NexCreERT2 chimeras $(\sim 90 \%)$ to 'enhanced yellow fluorescent protein' (EYFP) reporter mice that express EYFP upon Cre mediated deletion of a floxed stop-cassette (Akagi et al., 1997; Soriano, 1999). In order to induce Cre mediated recombination; 23 days old reporter $\left(E_{Y F P} P^{f l o x /+}\right)$ and double transgenic (NexCreERT2*EYFP $\left.P^{f l o x /+}\right)$ mice were intraperitoneally (i.p.) injected with tamoxifen ( $100 \mathrm{mg} / \mathrm{kg}$, i.e. $100 \mu \mathrm{lof} 10 \mathrm{mg} / \mathrm{ml}$ sunflower oil solution) for 10 consecutive days. Double transgenic mice that were not injected with tamoxifen, served as a control for the leakiness of CreERT2 activity in the absence of tamoxifen 
(Casanova et al., 2001; Hirrlinger et al., 2006). 4 days after the last injection tamoxifen induced $\left(\right.$ EYFP $^{\text {flox/+ }}$ and NexCreERT2*EYFP $\left.P^{\text {flox/+ }}\right)$ and non-induced $\left(\right.$ NexCreERT2*EYFP $\left.{ }^{f l o x /+}\right)$ mice were analyzed by immunostaining for EYFP. As expected most prominent CreERT2 mediated recombination was observed in the hippocampus and was restricted to postmitotic projection neurons of the CA1-CA3 region (Fig. $33 \mathrm{~A}, \mathrm{~B}$ ).

A
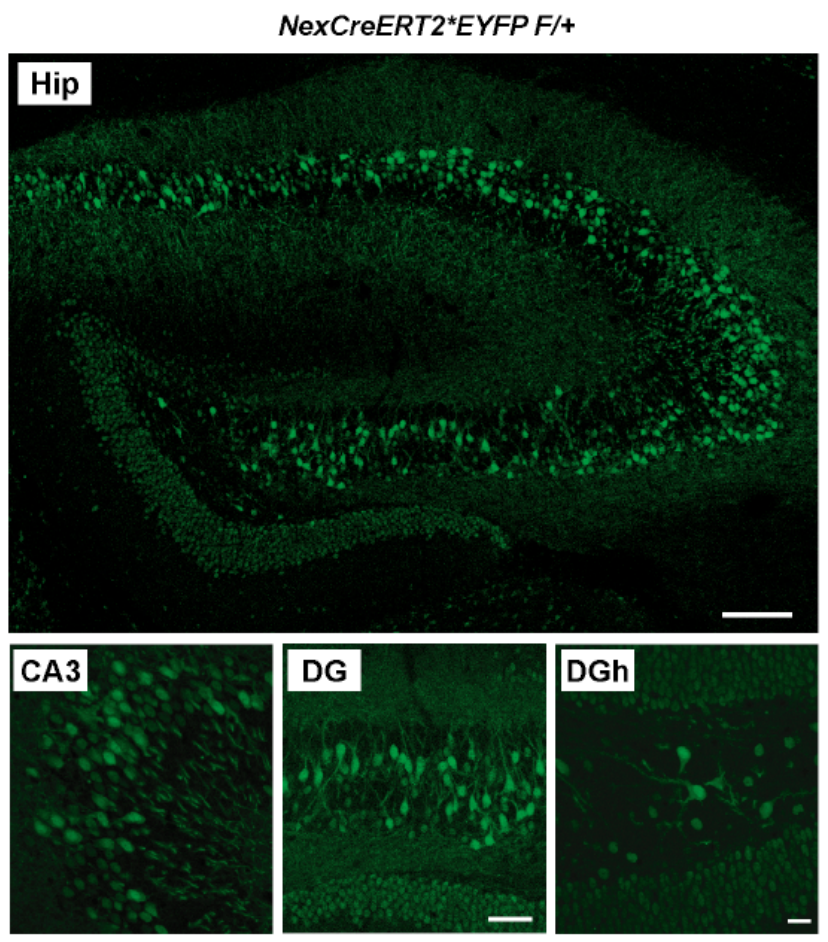
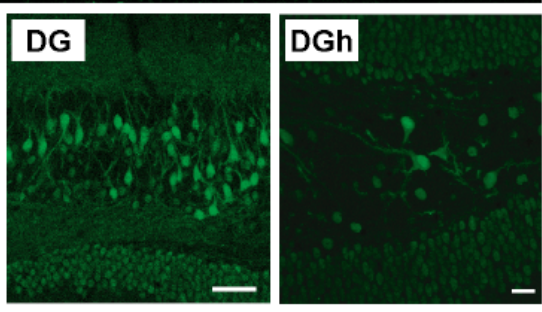

B

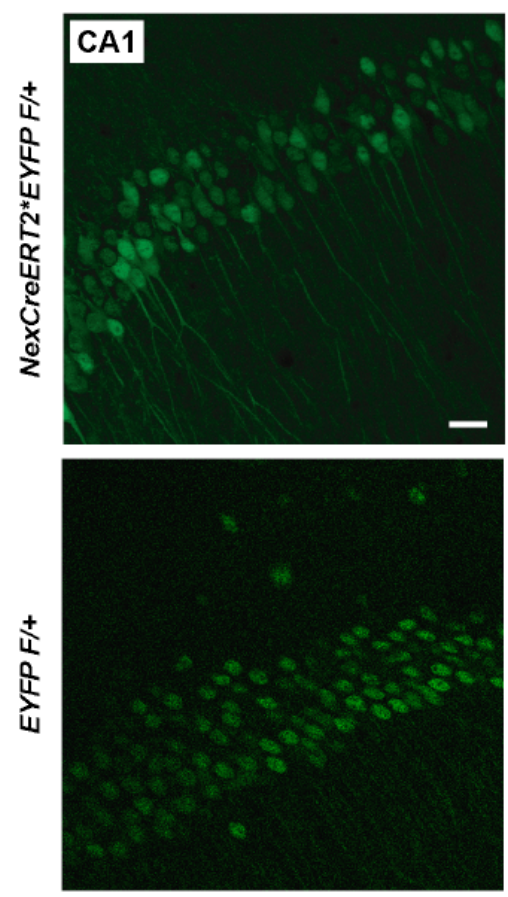

Fig. 33. :Tamoxifen induced gene recombination in hippocampal projection neuron.

After induction of recombination in double transgenic (NexCreERT2*EYFP flox/+ $)$ mice, the expression of EYFP in the hippocampus was analyzed by immunohistochemistry. (A) Immunostaining for EYFP on coronal brain sections $(100 \mu \mathrm{m}$ thick, vibrotome sections) of NexCreERT2*EYFP flox/+ revealed intense staining in the projection neurons of hippocampus as seen in the overview image. Lack of recombination in dentate granular cells is revealed by the absence of EYFP staining in the dentate gyrus (DG). An efficient recombination in the hippocampus can be depicted by maximum-intensity projection images of confocal Zstacks acquired from various sub-regions such as CA3, DG and hilar region of DG (DGh). The morphology and extensive arborization of EYFP+ cells in these sub-regions resemble that of projection neurons except for few EYFP+ cells in DGh that are most likely mossy hilar cells. Scale bars, $100 \mu \mathrm{m}$ (Hip), $50 \mu \mathrm{m}$ (DG) and $20 \mu \mathrm{m}$ (DGh and CA3). (B) (top) The maximum-intensity projection of confocal Z-stacks acquired from CA1 region of the hippocampus exhibits fine details of each recombined EYFP+ projection neuron. (bottom) The control mouse brain section (tamoxifen induced $E Y F P^{f l o x /+}$ ) immunostained for EYFP shows the strong background staining in the cell soma of the CA1 region. Note the absence of staining from the cell processes in the control mice. Scale bars, $20 \mu \mathrm{m}$. 
Conversely, EYFP staining was absent from the dentate granular (DG) cells but present in the hilar region (DGh), most likely in calretinin positive mossy cells (Fig. 33 A) (Fujise et al., 1998; Schwab et al., 1998). Thus, in line with previous observations the Nex promoter was not active in DG cells of adult mice. In DG granular cells Nex mediated activity starts perinatally and rapidly declines to undetectable levels by postnatal day $(\mathrm{P})$ 10 (Goebbels et al., 2006). Interestingly, only few pyramidal neurons were recombined in the cerebral cortex, most of which were located in the motor/somatosensory cortex and amygdala (Fig. 34 A, B). Although cells at different recombination stages were observed, those recombined early during the tamoxifen induction phase had accumulated sufficient EYFP to trace their complete arbor in a golgi-like staining pattern (Fig. 34 A).

Since the NexCreERT2 mouse line was generated only very recently sufficient numbers of double transgenic mice for an extensive analysis were not available. However, based on the location and cellular morphology it is most likely that Cre mediated recombination was absent from dendate gyrus granule cells, interneurons, oligodendrocytes, and astrocytes. Taken together, these data demonstrate that CreERT2 under the control of the Nex promoter after induction with tamoxifen faithfully reproduces the endogenous Nex expression pattern. Moreover, the absence of EYFP+ cells in the control (non-induced NexCreERT2*EYFP flox/+ and induced EYFP ${ }^{\text {flox/+ }}$ ) demonstrated the tightly regulated nature of the system. 
A

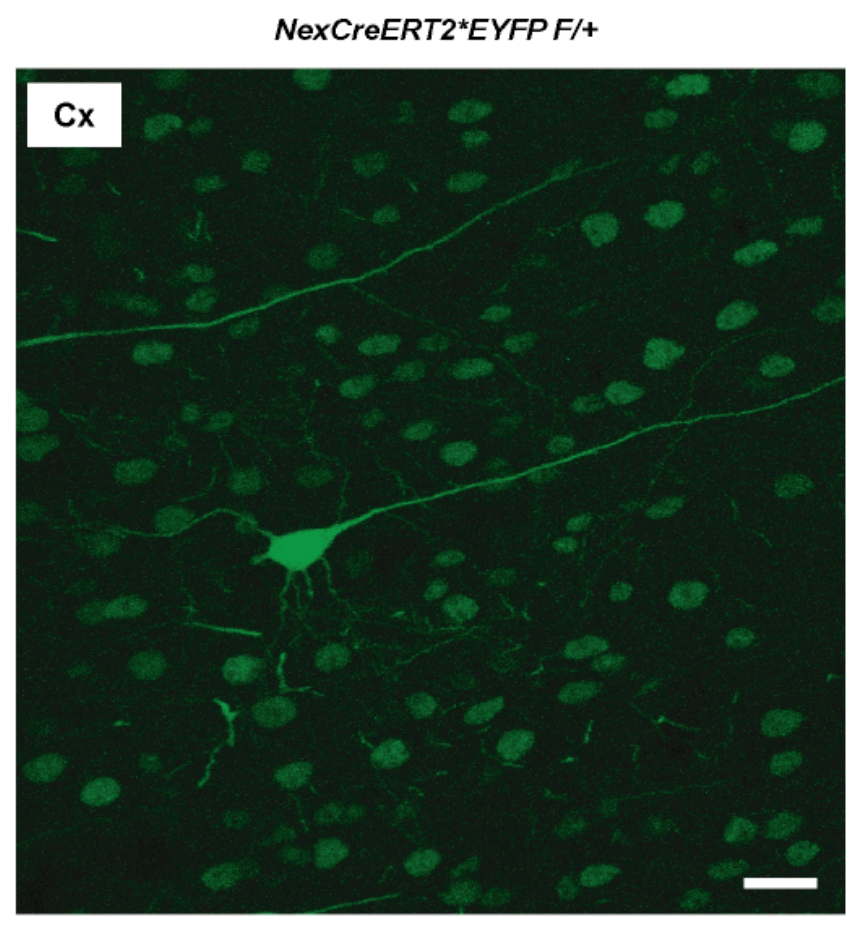

B
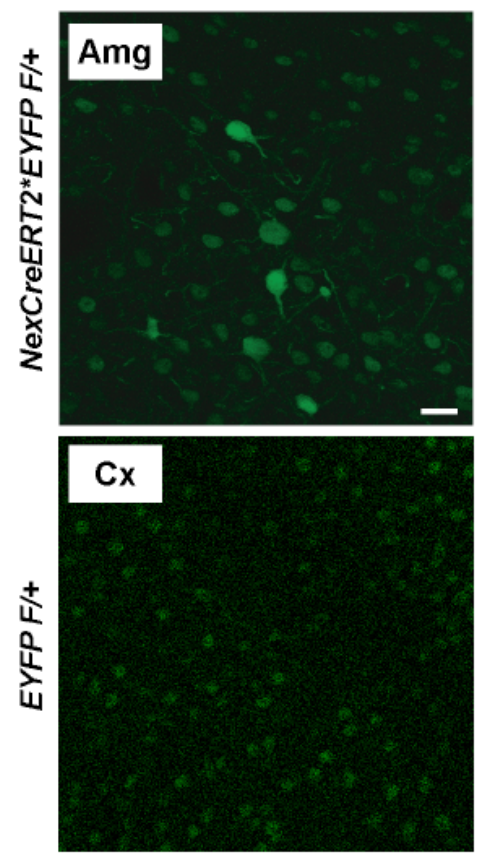

Fig. 34. Tamoxifen induced gene recombination in cortical projection neuron.

(A) Immunostaining of EYFP on coronal brain section (100 $\mu \mathrm{m}$ thick, vibrotome sections) of revealed strong staining of few projection neurons that have recombined in the cortex of NexCreERT2*EYFP ${ }^{\text {flox } /+}$ (tamoxifen induced) mouse. The maximum-intensity projection of confocal Z-stacks acquired from layer $\mathrm{V}$ of the cortex exhibits fine cellular details of a recombined projection neuron. (B) (top) Several neurons in amygdala showed immunostaining for EYFP. (bottom) The control mouse brain section (tamoxifen induced EYFP flox/+ ) immunostained for EYFP shows the background staining the in the cortex. Note the absence of staining from the cell processes in the control mice. Note the absence of staining from the cell processes in the control mice. Scale bar, $20 \mu \mathrm{m}$.

Once the NexCreERT2 mouse colony has been fully established, an extensive characterization will be performed by cross-breeding to a recently published global doublefluorescent Cre reporter mouse line $(\mathrm{mT} / \mathrm{mG})$ (Muzumdar et al., 2007). This reporter mouse line express membrane targeted tdTomato ("mT") prior to Cre excision and membrane targeted EGFP ("mG") following Cre excision. $m T / m G$ mice will be used to directly visualize in intact tissue recombined and non-recombined cells (without any need of immunostaining). 
5. Discussion 


\subsection{Neuregulin1 and myelination}

In the PNS, the entire program of glial differentiation and myelination is controlled by NRG1 type III (Garratt et al., 2000a; Jessen and Mirsky, 2005; Nave and Salzer, 2006), and many studies have reported that in vitro and ex vivo oligodendrocytes (OL) respond to NRG1 (Calaora et al., 2001; Canoll et al., 1996; Fernandez et al., 2000; Flores et al., 2000; Sussman et al., 2005; Vartanian et al., 1999; Vartanian et al., 1997). This suggested that NRG1 might also be the growth factor responsible for regulating CNS myelination, a finding that would have important clinical implications. In multiple sclerosis the endogenous repair of demyelinated lesions could be NRG1 dependent (ffrench-Constant et al., 2004). Moreover, schizophrenia is a complex disease that has been associated with single nucleotide polymorphisms in NRG1 (Hall et al., 2006; Stefansson et al., 2002) and independently with myelin abnormalties (Davis et al., 2003; Hakak et al., 2001). Thus, the control of subcortical myelination by NRG1 could be a missing link (Corfas et al., 2004).

\subsubsection{The role of Neuregulins and ErbB receptors in myelination}

Using a large set of conditional null mutant mice, we have studied the function of $\mathrm{NRG1/ErbB} \mathrm{signaling} \mathrm{in} \mathrm{oligodendrocytic} \mathrm{differentiation} \mathrm{and} \mathrm{myelination} \mathrm{in} \mathrm{vivo.} \mathrm{We}$ analyzed mice with Cre-mediated Nrg1 null mutations in forebrain neural precursors cells (Emx1-Cre) and in cortical projection neurons, occurring either before or after oligodendrocytic specification, i.e. at E12 (NEX-Cre) or at P5 (CamKII-Cre). Contrary to our expectations, the complete absence of neuronal and glial NRG1 did not perturb OL development and myelination in vivo. Even Nestin-Cre*Nrg1 $1^{\text {flox/flox }}$ mice, devoid of NRG1 from CNS, exhibited normal specification of OL that developed on schedule. These mice die perinatally and the cause of death is presumably unrelated to CNS myelination. Although there is a slight increase in the number of apoptotic cells in the neuroepithelium, indusium griseum and corpus callosum of mutants, brain morphology at birth appears unaltered. The identity of apoptotic cells is currently unknown.

Can these results be explained by functional compensation between NRG1 and the structurally related growth factor Neuregulin-2 (NRG2) (Carraway et al., 1997)? Nrg2 null mutant mice are myelinated (Britto et al., 2004), but coexpression of NRG1 and NRG2 
within the CNS is limited (Busfield et al., 1997; Longart et al., 2004) (Lai et al., unpublished data). Moreover, NRG2 is primarily targeted to dendrites, and the axons of NRG2 expressing hippocampal and cerebellar granule cells are mostly unmyelinated. Secondly, transgenic overexpression of NRG2 failed to increase myelin thickness in the CNS (Fischer, Schwab, Lai, and Nave, unpublished observation). Thirdly, NRG2 is expressed in both motoneurons (Rimer et al., 2004) and DRG neurons (Brinkmann and Agarwal et. al., submitted), but obviously fails to compensate for the lack of NRG1 expression in the PNS. Another candidate for compensation is Neuregulin-3 (NRG3), a more distantly-related growth factor that is widely expressed in the CNS (Zhang et al., 1997). Again, NRG3 null mutants are viable and normally myelinated (Müller and Birchmeier, unpublished observation).

In contrast to our observations in loss-of-function mutants, the neuronal overexpression of NRG1 in transgenic mice stimulated myelination, with little difference between NRG1 type III and type I isoforms (Brinkmann and Agarwal et al., submitted). Perinatal overexpression of NRG1 type III also increased the soma size of OL. In contrast, proliferation of OL precursors was unaltered. Thus, neuronal NRG1 type III (even at severalfold elevated expression levels) appears ineffective in stimulating OPC proliferation. We hypothesize that NRG1 promotes OL growth by activating the $\mathrm{PI3K} / \mathrm{TOR} / \mathrm{S} 6 \mathrm{~K}$ pathway, because a similar 'uncoupling' of OL proliferation and differentiation can be observed in conditional mutants of the Pten gene (Goebbels and Nave, unpublished observations).

At the receptor level, only ErbB3 and ErbB4 bind to Neuregulins. ErbB1/EGFR can regulate OL precursor development (Aguirre et al., 2007), but fails to bind Neuregulins. ErbB2 has no functional ligand binding domain. Thus, OL lacking both ErbB3 and ErbB4 are incapable of transmitting signals from any of the 3 known Neuregulins. Most importantly, they still myelinate CNS axons (Brinkmann and Agarwal et. al., submitted). This finding demonstrates that, indeed, Neuregulin signaling is dispensible for CNS myelination, at least during postnatal stages. Testing a possible role of Neuregulins in (adult) myelin maintenance awaits inducible ErbB mutant mice.

Our results are at odds with previous reports suggesting that NRG1 is required for OL survival and differentiation (Calaora et al., 2001; Canoll et al., 1996; Flores et al., 2000; Kim et al., 2003; Sussman et al., 2005; Vartanian et al., 1999; Vartanian et al., 
1997), and demonstrate the importance of in vivo analyses. However, two reports of CNS hypomyelination in mice overexpressing 'dominant-negative' ErbB proteins under control of oligodendrocyte-specific promoters are more difficult to reconcile (Kim et al., 2003). Unspecific side effects are the most likely explanation. For example, truncated ErbB receptors could 'trap' wildtype ErbB4 (heterodimers) at the cell surface and reduce their turnover, thereby affecting unrelated PDZ binding proteins in a dominant-negative fashion. We also note a general susceptibilty of OL to membrane protein overexpression when under control of a strong myelin promoter (Kagawa et al., 1994; Readhead et al., 1994; Tuohy et al., 2004; Turnley et al., 1991).

Interestingly, a mild CNS hypomyelination (in addition to peripheral dysmyelination) was reported for Bace1 mutant mice (Hu et al., 2006). While PNS effects in these mice were likely NRG1-dependent (Willem et al., 2006), our data suggest that in the CNS other proteins must be the relevant BACE1 targets. Not only could the unknown trigger of CNS myelination require proteolytic cleavage. Also the b2 subunit of the voltage-gated sodium channel (Kim et al., 2007) is a candidate for BACE1 processing, as timely myelination requires electrical activity of axons.

\subsubsection{Possible roles of NRG1/ErbB signaling in oligodendrocytes}

If not required for myelination, are other oligodendroglial functions regulated by neuregulins in the CNS? OL are known to express NMDA, AMPA and kainate receptors, similar to neurons and astrocytes, which coexpress ErbB4 with these glutamate receptors (Wong, 2006; Verkhratsky and Kirchhoff, 2007). Since NRG1/ErbB signaling has been implicated in the subcellular targeting and endocytosis of synaptic glutamate receptors (Gu et al., 2005), it may serve a similar function for glutamate receptors on OL.

NRG1 may also have more subtle functions in cortical myelination. This relates to the observation of a 2-fold higher density of myelinated axons within the cortex of NRG1 transgenic mice (a number unmatched by an increase of OL density) (Brinkmann and Agarwal et. al., submitted). Does NRG1 stimulate the generation of myelinating glial processes as suggested by Roy et al., 2007? Also cultured neurons and OL reportedly increase the number of processes when NRG1 is added to the medium (Canoll et al., 1999; Canoll et al., 1996). However, by three-dimensional cell tracing, cortical OL revealed 
about the same number of primary and secondary branches (per cell), independent of the axonal NRG1 expression level. Thus, the increased 'myelin-to-oligodendrocyte' ratio is more likely caused by slightly longer internodes (which are virtually impossible to quantify in the cortex).

In conclusion, our data suggest that although CNS evolution has made vertebrate OL independent from NRG1, presumably the ancestral signal on axons that is necessary and sufficient for myelination by Schwann cells. Perhaps, a simple system (represented by NRG1 type III/ErbB signaling to Schwann cells) has been superseded in the CNS by a complex system that includes neuronal activity as a myelination signal. Recently identified signaling components that serve different roles in CNS and PNS myelination include (activity-dependent release of) ATP and purinergic receptors (Fields and Burnstock, 2006; Stevens et al., 2002). An activity-based system of myelination control is an attractive candidate, as it is "functional" in mice and lost in in vitro systems. In addition, the excess of NRG1 in vivo still enhances intracortical OL growth and myelination, when "added" to the unknown physiological trigger of CNS myelination, possibly through converging second messenger pathways. Taken together, it seems that although CNS has evolved a complex machinery for myelination it still preserved its response to NRG1/ErbB signaling and may use it as a 'survival strategy'. For instance, in in vitro systems the myelination process looses track of most of its intricate in vivo interactions. Thus, for the myelination to continue in vitro the basic survivals mechanisms involving NRG1/ErbB signaling might come into play. Moreover, if this signaling is perturbed during in vitro studies the complete myelination program collapses. These arguments bring us to the important point that previously reported in vitro studies are not to be ignored but have to be dealt with extra care. Finally, one can conclude that NRG1 is not the master regulator of CNS myelination, but might influence the basic myelination program in the absence of the actual regulator of myelination or during some pathological conditions such as multiple sclerosis (Cannella et al., 1999; Marchionni et al., 1999; Marchionni et al., 1996). 


\subsection{Neuregulin1 and synaptic function}

NRG1 is an attractive susceptibility gene for schizophrenia (Stefansson et al., 2002), because this factor has been implicated in the control of neuronal migration and synaptic plasticity all processes independently associated with schizophrenia (Bartzokis, 2002; Corfas et al., 2004). Several in vitro studies have isuggested that NRG1 also plays multiple functions in the control of excitatory and inhibitory brain circuits; however, the relevance of these studies in vivo remains controversial. In order to address some of the controversial issues and to shed some light on the physiological functions of NRG1 we carried out extensive analysis using a battery of cell-type and stage-specific conditional null mutant mice.

\subsubsection{Behavioral consequences of forebrain specific inactivation of NRG1}

Conditional null mutants (CKII-Cre*Nrg1 $1^{\text {flox/flox }}$ ) lacking NRG1 specifically in projection neurons of the forebrain were hypoactive in the "open-field" and exhibited reduced prepulse inhibition and impaired motor learning. However, performance in several other behavioral paradigms assessed (social behavior, sucrose preference, 8-arm maze, elevated plus maze and hole board) mutants was normal. Furthermore, already heterozygous (CKII-Cre*Nrg1 $1^{f l o x /+}$ ) mice exhibited reduced prepulse inhibition and impairments in motor learning. In contrast, previously reported behavioral studies have shown that panNRG1 heterozygous mutants $(\mathrm{Nrg} 1+/-)$ are hyperactive in the "open-field" and revealed an impaired response to social novelty and improved performance in both rotarod and T-maze test. (Boucher et al., 2007; Gerlai et al., 2000; Karl et al., 2007; O'Tuathaigh et al., 2007a; O'Tuathaigh et al., 2008; Stefansson et al., 2002). Similarly, behavioral studies carried out on ErbB4 mutants also yielded inconsistent results (Gerlai et al., 2000; Golub et al., 2004; Thuret et al., 2004). In one study, for ErbB4 heterozygous mutants, but not ErB2 and ErbB3, displayed hyperactivity in the "open-field" test (Gerlai et al., 2000; Stefansson et al., 2002). In contrast, conditional null mutants (Nestin$C r e^{*} E r b B 4^{f l o x /}$ ) lacking ErbB4 in all neural cells exhibited hypoactivity in a similar test setting. Surprisingly, spatial learning and memory performance in the Morris water maze was disrupted in heterozygous $\left(E r b B 4^{\text {flox/- }}\right)$ male mutants but not in homozygous mice 
$\left(\right.$ Nestin-Cre*ErbB4 $\left.{ }^{f l o x /-}\right)$ (Golub et al., 2004). Another study using the same ErbB4

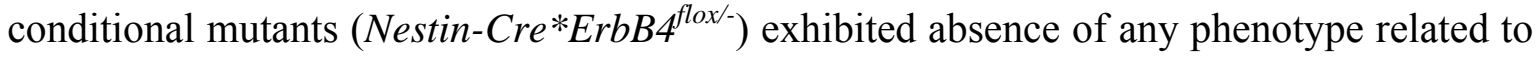
hyperactivity or impaired rotarod performance (Thuret et al., 2004). Importantly, mice heterozygous for a immunoglobulin domain-specific mutation of the NRG1 gene (lacking both NRG1 type I and type II isoforms) performed normally in several activity tests, suggesting that type III isoforms of NRG1 are responsible for controlling normal motor behavior (Rimer et al., 2005).

How can inconsistencies in behavioral studies be explained? Differences in the genetic background, which are likely to exist in studies using several different alleles, can contribute to different outcomes, especially if observed effects or behavior impairments are subtle. Several recent evidences point towards the possibility of an interaction of 'modifier' genes from one or both of the parental strains (usually 129/Sv and C57BL6) with the mutated gene and/or flanking genes proximal to it (Morice et al., 2004; Waddington et al., 2005). In addition, subtle differences in the behavioral outcome can also be simply due to different housing conditions and experimental design (Karl et al., 2007). Nevertheless, the discrepancy in locomotor data from various NRG1 mutants is unlikely to result from background strain differences as each of these mutants have been reported to be sufficiently backcrossed C57BL6 (Gerlai et al., 2000; O'Tuathaigh et al., 2006; Rimer et al., 2005; Stefansson et al., 2002). The contradicting outcomes between conventional $(N R G 1+/-)$ and conditional (CKII-Cre*Nrg1 $\left.1^{\text {flox/flox }}\right)$ NRG1 mutants are more likely be attributed to developmental versus concurrent effects. The inactivation of NRG1 in forebrain projection neurons of CKII-Cre*Nrg1 $1^{\text {floxflox }}$ mutants starts after postnatal day (P) 5 (Gummert and Schwab unpublished data) (Minichiello et al., 1999). This leaves a sufficient time window for developmental processes, such as neuronal migration and differentiation and axon guidance that are modulated by NRG1/ErbB signaling to proceed normally (Anton et al., 2004; Buonanno and Fischbach, 2001; Flames et al., 2004; Ghashghaei et al., 2006; Lopez-Bendito et al., 2006; Rio et al., 1997). Importantly, the half-life of NRG1 protein still unknown. Since recombination starts at around $\sim$ P5 in CKIICre*Nrg1flox/flox mutants, the demand of highly dynamic processes (such as myelination and synapse formation) for NRG1 during the early postnatal phase might be fulfilled by presence of the residual NRG1. Thus, a time course study of NRG1 protein levels in the brain of NRG1 conditional mutants might provide further relevant information. In contrast, 
in $N R G 1+/-$ mice the early developmental processes are exposed to half the gene dosage already at early timepoint, which possibly results in different pathophysiology and up/downregulation of crucial signaling pathways. Although highly speculative, behavioral phenotypes observed in adult CKII-Cre*Nrg1 $1^{\text {flox/flox }}$ mutants might be due to the lack of NRG1 at synapses. While those observed in Nrg1+/- could result from abnormal brain development. Moreover, normal expression of NRG1 by glial cells (mainly astrocytes) in CKII-Cre*Nrg1 $1^{\text {floxflox }}$ mutants but not in Nrg1+/- mutants should also be taken into account. Finally, NRG1 is a potent growth factor that regulates the development of several organs, such as heart, muscles, breasts and brain (Falls, 2003b). Thus while in the conditional null mutant NRG1 inactivation is restricted to nervous tissuem, in Nrg1+/mutants NRG1 is reduced in the whole body including brain. Possible behavioural impairments due to the partial inactivation of Nrg1 in tissue other than brain should therefore be taken into account.

Several factors might contribute to similar levels of impairment in behavioral performance of heterozygous and homozygous NRG1 mutants (CKII-Cre*Nrg1 $1^{\text {floxflox }}$ and CKII-Cre*Nrg1 $\left.1^{\text {flox/+ }}\right)$. One of the most important one that should be addressed is a genetic factor differing between conditional NRG1 mutants (CKII-Cre ${ }^{*} \mathrm{Nrg} 1^{\text {flox/flox }}$ and CKII$\left.\mathrm{Cre} \mathrm{Nrg}^{\mathrm{flox} /+}\right)$ and wildtype $\left(\mathrm{Nrg}^{\text {flox/+ }}\right)$ controls is the expression of cre recombinase. In the presence of cre conditional heterozygous and null mutants did not display histological and biochemical differences in the characteristics of. However, it will be important to experimentally rule out any deleterious effect of cre expression by analyzing transgenic mice that only habor the cre transgene. The other possibility is that the complete (in CKII$C r e^{*} N r g 1^{f l o x / f l o x}$ ), but not the partial loss of NRG1 (in CKII-Cre* $N r g 1^{f l o x /+}$ ) exceeds a threshold for eliciting a compensatory response. This differential regulation of compensatory mechanisms between conditional heterozygous and null mutants can result in varying phenotypes in both of these genotypes (Golub et al., 2004; O'Tuathaigh et al., 2007a).

Since Nrg1- $\alpha$ is also expressed in the human and murine brains (Bernstein et al., 2006) another crucial issue that still remains to be addressed is the importance of Nrg1- $\alpha$ isoform in the development of brain. Our preliminary electrophysiological data have suggested that $\mathrm{Nrg} 1-\alpha$ null mutant $\left(\mathrm{Nrg} 1^{\text {flox/flox }}\right)$ mice might have significant impairments in their brain (Agarwal, Trembak, Schwab and Zhang unpublished data). 


\subsubsection{NRG1/ErbB signaling in the regulation of neurotransmitter receptors}

One of the NRG1 isoforms was cloned based on its capability to induce expression and localization of nAch at the neuromuscular junction (Falls, 2003a, b). In the CNS presynaptic NRG1 can activate ErbB4, which is located at the postsynaptic membrane (Yang et al., 1998). ErbB4 colocalizes with NMDA receptors via postsynaptic density 95 (PSD95) protein complex and modulates NMDA function (Huang et al., 2000). Thus, in pyramidal neuron specific conditional null mutants $\left(C K I I-C r e^{*} N r g 1^{\text {flox/flox }}\right)$ absence of NRG1/ErbB4 signaling from hippocampus might lead to NMDA receptor hypofunction. In line with the above hypothesis, NRG1 conditional null mutants showed severe impairments in memory and learning when tested in a fear-conditioning paradigm. Although basal synaptic transmission was unaffected and only minor changes in paired-pulse facilitation ratios were present, we observed strong suppression of long-term potentiation (LTP) at Sch-CA1 synapses in NRG1 conditional null mutants. Since NMDA receptor-dependent LTP is a widely accepted molecular mechanism involved in the acquisition of conditional (Pavlovian) fear (Maren, 2001; Maren and Holt, 2000; Maren and Quirk, 2004) we speculated that NRG1 mutants display a reduced number of functional NMDA receptors. While we were unable to show a reduction in the levels of NMDA and AMPA receptors in a synaptosomal preparation, immunohistochemical data indicated a mild reduction in NMDA receptor subunit1 (NR1) positive synaptic puncta in the hippocampus of NRG1 mutants $\left(C K I I-C r e^{*} N r g 1^{\text {flox/flox }}\right)$ (preliminary data). These observations were in line with previous studies that showed that pan NRG1 hypomorphic mice $(\mathrm{Nrg} 1+/-)$ have a reduced number of functional NMDA receptors (Stefansson et al., 2002). In addition, several studies have shown that NRG1 modulates the expression, activation and phosphorylation status of NMDA receptors in an activity dependent manner (Bjarnadottir et al., 2007; Hahn et al., 2006; Kwon et al., 2005; Ozaki et al., 1997; Stefansson et al., 2002).

To further investigate the possibility of NMDA receptor hypofunction in NRG1 mutants, we treated null mutant mice with MK-801 $(0.3 \mathrm{mg} / \mathrm{kg})$, a non-competitive antagonist of NMDA receptor that induces hyperactivity (Deutsch et al., 1997; Wong et al., 1986). Moreover, MK-801 treatment serves as a pharmacological model of schizophrenia (Rujescu et al., 2006; Thornberg and Saklad, 1996). To our surprise NRG1 mutants failed to exhibit MK-801 induced hyperactivity in the "open-field" arena when compared to control mice. How can this observation be explained in light of our previous data that are 
compatible with NMDA receptors hypofunction in NRG1 mutants (CKII-Cre*Nrg1 $\left.{ }^{\text {flox/flox }}\right)$ ? NMDA receptor subunit1 (NR1) deficient mice exhibited either normal $(0.2 \mathrm{mg} / \mathrm{kg})$ or reduced $(0.5 \mathrm{mg} / \mathrm{kg})$ locomotor activity, but never increased activity, upon MK-801 administration (Duncan et al., 2002; Mohn et al., 1999). This dosage dependent effect of MK-801 points towards a possible involvement of other neurotransmitter receptor systems that might be activated and/or blocked. Second, MK-801 not only is a potent blocker of NMDA receptor but also blocks open channel of nicotinic acetylcholine receptors (nAch) (Amador and Dani, 1991; Csernansky et al., 2005; Mastropaolo et al., 2004). Thus, the potency of MK-801 to block various neurotransmitters suggests that in vivo its pharmacologic action involves complicated interactions of different neurotransmitter systems. Third, impaired neuronal plasticity (as revealed by LTP measurements and behavioral testing) and protection from MK-801 induced hyperactivity might result from alterations in completely different brain circuits. For instance, lesions of output nuclei of the nucleus accumbens (ventral pallidum and ventrolateral/ventromedial thalamus) can completely block the motor response induced by MK-801 (De Leonibus et al., 2001) and in fear-conditioning paradigm hippocampus have an important role to play (Maren, 2001). Nevertheless, these seemingly independent brain regions are interconnected by the hippocampal-ventral tegmental area (Hip-VTA) loop (Lisman and Grace, 2005). By the Hip-VTA loop hippocampus conveys novel information to VTA via subiculum, nucleus accumbens and ventral pallidum. Novelty-dependent firing of VTA cells enforces dopamine release within the hippocampus. As a consequence, the Hip-VTA loop produces a dopamine-dependent enhancement of LTP and learning (Lisman and Grace, 2005). Thus, the Hip-VTA pathway acts as a "gatekeeper" of the information that will flow during longterm memory formation and appears to be a critical component of brain memory systems. Interestingly, all major components of the Hip-VTA pathway express NRG1 or its receptor ErbB4 and some coexpress both ligand and receptor (Corfas et al., 1995; Steiner et al., 1999; Woo et al., 2007). Since the molecular players of the Hip-VTA loop are not well studied, one can speculate that some of the components in this pathway might communicate via NRG1/ErbB4 signaling. Finally, NRG1/ErbB signaling not only influences NMDA receptor function but has also been shown to be required for activitydependent GABA release and synaptic incorporation and stabilization of AMPA receptor (Li et al., 2007; Woo et al., 2007). In addition, NRG1 has been shown to modulate the 
expression of $\mathrm{GABA}_{\mathrm{A}}$ and neuronal acetylcholine (nAch) receptors (Esper et al., 2006; Rieff et al., 1999; Yang et al., 1998). Taken together, NRG1/ErbB signaling might be involved in the coordination of several neurotransmitter systems (cholinergic, dopaminergic, GABAergic and glutamatergic) in various brain regions (involved in memory, learning and motor activity). Thus, it would be too simple to explain our observations solely on the 'NMDA receptor hypothesis'. Taken together, it is quite likely that in NRG1 conditional mutants several other synaptic modalities, such as glutametergic (AMPA and kinate), GABAergic and cholinergic neurotransmitter receptor systems, are differentially disrupted in distinct brain areas, a scenario that demands more detailed analysis.

Nevertheless, the chronic absence of NRG1 from pyramidal neurons does not result in increased neurodegeneration. This points to the possibility that NRG1 in the mature brain is mainly involved in the fine-tuning of synaptic plasticity, but not in the maintenance of synapses per se. Thus, the chronic loss of NRG1 might result in severe cognitive deficits but not in major loss of synapses. Interestingly, in schizophrenia there are no signs of severe neurodegeneration or synaptic losses, but patients suffer from cognitive impairments (Harrison, 1999). In contrast, most of the neurodegenerative disorders such as Alzheimer's, Parkinson's and Huntington's diseases are characterized by the severe loss of synapses which precedes the observed neurological deficits (Saxena and Caroni, 2007). Thus, our mouse models will allow us to study the molecular machinery involved in precise functioning of synapses without being influenced by neurodegenerative processes.

Another interesting question that remains unanswered is the location of endogenous NRG1. Based on western blotting data derived from "crude synaptic vesicle" preparations we speculate that both type I and type III isoforms of NRG1 are located at synapses and mostly remain membrane bound. This suggests that presynaptic NRG1 might preferentially perform a juxtacrine mode of signaling via postsynaptic ErbB receptors. We propose that at synapses, glial cells (mainly astrocytes) might be the main source of secreted NRG1 and not neurons. The first step to understand the importance of glial derived NRG1 at synapses will be the comparative analysis of impaired synaptic functions in $N e x-C r e * N r g 1^{\text {floxflox }}$ (lacking NRG1 from principal projection neurons) and Emx1-Cre*Nrg1 ${ }^{\text {flox/flox }}$ mutants (lacking NRG1 from principal projection neurons and glial cells). Interestingly, the $\sim 60$ 
$\mathrm{kDa}$ carboxy-terminal domain of NRG1 supposedly generated by $\beta$-secretase activity also co-sediments with synaptic membrane proteins (such as NMDA receptors) during the subcellular fractionation process. Thus one might speculate that at synapses TACE or $\gamma$ secretase activity is minimal and does not lead to the release of a carboxy-terminal domain into the synaptoplasm. This is in contrast to some studies which claim that at the active synapse the binding of NRG1 to its receptor ErbB4 leads to the cleavage of an intracellular C-terminal domain (ICD) of NRG1 that is retrogradly transported to the nucleus, thereby controlling the transcription of certain genes (Bao et al., 2003; Role and Talmage, 2007). In light of our observation the relevance of synaptic activity dependent back-signaling might be questionable.

\subsubsection{NRG1/ErbB signaling in cortical inhibition}

To study the entire spectrum of NRG1 functions in the adult brain the generation of a mouse mutant completely lacking NRG1 in the brain, while surviving until adulthood, was a prime necessity. Previous trials to generate such a mouse mutant failed, since even conditional inactivation of NRG1 in the telencephalon using Foxg1-Cre mice caused perinatal death, possibly due to cre mediated inactivation of NRG1 in the mid-hind brain junction and in pharyngeal pouches (Flames et al., 2004; Hebert and McConnell, 2000; Lopez-Bendito et al., 2006). To our surprise forebrain specific conditional null mutants of NRG1 using the Emx1-Cre driver line, in which recombination starts at embryonic day (E) 10 in neural precursor cells, were largely normal and survived until adulthood. These mutants $\left(E m \times 1-C r e^{*} N r g 1^{f l o x f l o x}\right)$ lack NRG1 from both neurons and glial cells (radial glia, astrocytes and OL), except interneurons that migrate from ganglionic eminences to the cortex. About $50 \%$ of the conditional null mutants $\left(E m x 1-C r e * N r g 1^{\text {flox/flox }}\right)$ exhibited "handling-induced seizures" suggesting a possible loss of cortical inhibition. Remarkably, also $\sim 20 \%$ of heterozygous and control littermates $\left(E m x 1-C r e^{*} N r g 1^{f l o x /+}, N r g 1^{\text {flox/flox }}\right.$ and $N r g 1^{f l o x /+}$ ) exhibited seizures. Several studies have shown that cross breeding of two inbred strains can give rise to a recombinant inbred (RI) mouse strain with increased susceptibility to epilepsy (Frankel et al., 1994). Therefore, we speculate that by crossbreeding C57B1/6*FVB males $\left(N r g 1^{\text {floxflox }}\right)$ to $\mathrm{C} 57 \mathrm{~B} 1 / 6$ females $\left(E m x 1-C r e^{*} N r g 1^{f l o x /+}\right)$ might have generated offspring that are prone to "handling-induced seizures" (Frankel et al., 1994). Importantly, these occasional seizures are further aggravated by the absence of NRG1. 
Interestingly, one study has shown that treatment of hippocampal slice cultures with NRG1 might lead to the reduction in GABAergic synaptic activity occurring during early postnatal development in CA1 pyramidal neurons (Okada and Corfas, 2004). Thus, alterations in NRG1 levels in the hippocampus during early developmental stages might contribute to epilepsy. Additionally, there are several other mouse mutants that exhibit "handling-induced seizures", such as mice deficient in GAD65, dopamine receptor D2, neuropeptide Y (NPY), GABA B1 $_{1}$ subunit and G protein $\gamma 3$ subunit (Bozzi et al., 2000; Erickson et al., 1996; Kash et al., 1997; Prosser et al., 2001; Schwindinger et al., 2004). The epileptic manifestations in NRG1 null mutants were similar to that of GAD65 null mutants. Although we were unable to show reduction in levels of GAD65 and GAD67 in protein lysates prepared from null mutant $\left(E m \times 1-C r e^{*} N r g 1^{\text {flox/flox }}\right)$ brains, numbers of GAD67+ interneurons were slightly decreased $(\sim 10 \%)$ in the motor cortex of null mutants as revealed by immunohistochemistry. The pathological mechanism that induces epileptic seizures in mutants needs further investigation and might involve the interaction of unknown epilepsy susceptibility gene and NRG1.

\subsubsection{NRG1/ErbB signaling in neuronal migration}

Radial glia (in cerebrum and cerebellum) and interneurons (mainly parvalbumin+ cells) express ErbB receptors while NRG1 is expressed in migrating and post-mitotic projection neurons in cerebral cortex and granular cells in the cerebellum (Anton et al., 1997; Flames et al., 2004; Rio et al., 1997; Yau et al., 2003). NRG1 is required for the normal development of radial glial cells. In the cerebral cortex, the deletion of ErbB2 leads to abnormal radial glia formation and indirectly perturbs the radial migration of projection neurons (Anton et al., 1997; Schmid et al., 2003). In addition, ErbB4 receptor null mutants show defects in the tangential migration of GABAergic interneurons from the ganglionic eminence to the neocortex (Flames et al., 2004). In the cerebellum, NRG1 induces astrocytes to adopt a radial glia phenotype in vitro, which in turn are required to support neuronal migration (Rio et al., 1997). In combination, ErbB2 and ErbB4 might influence both radial migration of neocortical projection neurons and tangential migration of inhibitory neurons during early developmental stages.

We hypothesized that NRG1 null mutants (Emx1-Cre*Nrg1 $\left.1^{f l o x / f l o x}\right)$ might have similar neuronal migration deficits in the cerebral cortex (but not in the cerebellum where 
Emx1 is not expressed). Surprisingly, we did not observe major defects in cortical layer formation or the development of other neural cell populations. Since most of our analysis was performed in adult mice we speculate that previously reported migration defects both in vitro and in vivo might be rather a delay in the migration program and that mutants recover postnatally. However, when we looked for migration defects in several interneuronal populations we found subtle but significant increases in the number of parvalbumin + interneurons in the cortex of null mutants. In contrast to our finding in NRG1 mutants the number of GABAergic interneurons in the cortex of ErbB4 null mutants was reduced (Flames et al., 2004). To address this discrepancy it will be important to determine the number of other inhibitory neuron classes, such as calbindin + and calretinin+ interneurons and compare them with the total number of cortical GABergic interneurons. It is conceivable that while the number of parvalbumin + interneurons is increased other interneurons are decreased such that the total number of GABergic interneurons is reduced in NRG1 mutants. Moreover, mutants lacking NRG1 from their principal projection neurons $\left(\mathrm{Nex}-\mathrm{Cr} \mathrm{N}^{*} \mathrm{Nrg} 1^{\text {floxflox }}\right)$ did not show significant differences in the number of parvalbumin+ intereneurons. Taken together, one might speculate that for proper functioning and/or migration of interneurons, astrocyte derived NRG1 plays a distinct role. In schizophrenia, mRNA levels of several markers for GABAergic interneurons (including GAD67, GAT1 and parvalbumin) have been shown to be down regulated while NRG1 mRNA might be up regulated (reviewed in Harrison and Law, 2006; Lewis et al., 2005). In contrast we have found a slight increase in parvalbumin mRNA levels in $\left(\mathrm{Nex}-\mathrm{Cr} e^{*} \mathrm{Nrg} 1^{\text {floxflox }}\right)$ mutants, while there was a severe reduction in levels of calretinin mRNA. With our current data we cannot explain the exact mechanism that might be involved in NRG1 mediated regulation of interneuronal marker expression, but our ongoing analysis might shed some light on this issue.

\subsubsection{NRG1/ErbB signaling in neuropsychiatric disorders}

Our observations that $\mathrm{NRG1/ErbB}$ signaling might play an important role in neurotransmitter receptor function and cortical interneuron development provide a coherent biological context whereby NRG1 may confer susceptibility to some forms of schizophrenia. An interesting aspect, which still remains unexplored, is the possibility that NRG1 might act as a communication bridge between excitatory and inhibitory brain 
circuits. For instance, both NMDA receptors and GABAergic interneurons function suboptimally in the frontal cortex and temporal lobes of patients suffering from schizophrenia (Coyle, 2004). Can these two distinct pathological mechanisms be related to each other via NRG1? Interestingly, in limbic cortex NMDA receptors on the GABAergic interneurons are highly sensitive to NMDA antagonists, such as MK-801, when compared to those on pyramidal neurons ( $\mathrm{Li}$ et al., 2002b). The loss of the NMDA receptor component of the EPSC on hippocampal GABAergic neurons disrupts memory and cognitive processing quite similar to that seen in patients suffering from schizophrenia (Moghaddam and Jackson, 2003). Moreover, recent studies have shown that chronic treatment of rats with MK-801 resulted in down-regulation in the expression of GAD67 and GAT1 in the frontal cortex (Paulson et al., 2003). ErbB4 expression is maintained in a subpopulation of cortical interneurons (mainly parvalbumin+ interneurons) in the postnatal cortex (Yau et al., 2003). In addition, ErbB4 can modulate interneuronal synaptic plasticity by associating with postsynaptic PDZ binding proteins (Buonanno and Fischbach, 2001). Our studies suggest that NRG1 can modulate the function of glutamatergic neurotransmitter receptors. Taken together, it is plausible that NRG1 might influence the function of glutamatergic neurotransmitter receptors, such as NMDA receptors on interneuronal populations and hypofunction of these NMDA receptor subsequently leads to the dysregulation of interneuronal functions.

These possibilities demand answer to another important question: What is the source of NRG1 that regulates the interneuronal development? From our preliminary results we speculate that there are two major sources, astrocyte derived soluble NRG1 (type I) and projection neuron derived membrane bound NRG1 (type III). Based on this hypothesis, it is tempting to speculate that an alteration in the expression pattern of the different isoforms of NRG1 at different stages of development may lead to abnormal cortical GABAergic interneurons function varying from migration deficits to activity dependent modulation of neurotransmitter receptor function.

Although it is difficult to make predictions across species, our data suggest that small alterations of NRG1 expression are highly unlikely to explain the documented white matter abnormalities in patients (Davis et al., 2003). However, our ongoing in depth analysis of various NRG1 mutants supports the previous in vitro studies that suggest NRG1 might play an important role in synaptic fine-tuning. 
6. References 
Adlkofer, K., and Lai, C. (2000). Role of neuregulins in glial cell development. Glia 29, 104-111.

Akagi, K., Sandig, V., Vooijs, M., Van der Valk, M., Giovannini, M., Strauss, M., and Berns, A. (1997). Cre-mediated somatic site-specific recombination in mice. Nucleic acids research 25, 1766-1773.

Akbarian, S., Sucher, N.J., Bradley, D., Tafazzoli, A., Trinh, D., Hetrick, W.P., Potkin, S.G., Sandman, C.A., Bunney, W.E., Jr., and Jones, E.G. (1996). Selective alterations in gene expression for NMDA receptor subunits in prefrontal cortex of schizophrenics. J Neurosci 16, 19-30.

Aloisi, F. (2003). Growth factors. Neurol Sci 24 Suppl 5, S291-294.

Amador, M., and Dani, J.A. (1991). MK-801 inhibition of nicotinic acetylcholine receptor channels. Synapse (New York, N.Y 7, 207-215.

Anton, E.S., Ghashghaei, H.T., Weber, J.L., McCann, C., Fischer, T.M., Cheung, I.D., Gassmann, M., Messing, A., Klein, R., Schwab, M.H., et al. (2004). Receptor tyrosine kinase ErbB4 modulates neuroblast migration and placement in the adult forebrain. Nat Neurosci 7, 13191328 .

Anton, E.S., Marchionni, M.A., Lee, K.F., and Rakic, P. (1997). Role of GGF/neuregulin signaling in interactions between migrating neurons and radial glia in the developing cerebral cortex. Development (Cambridge, England) 124, 3501-3510.

Bacon, S.J., and McClintock, M.K. (1999). Sex ratio bias in postpartum-conceived Norway rat litters is produced by embryonic loss in midpregnancy. Journal of reproduction and fertility 117 , 403-411.

Bansal, R. (2002). Fibroblast growth factors and their receptors in oligodendrocyte development: implications for demyelination and remyelination. Developmental neuroscience 24, 35-46.

Bao, J., Lin, H., Ouyang, Y., Lei, D., Osman, A., Kim, T.W., Mei, L., Dai, P., Ohlemiller, K.K., and Ambron, R.T. (2004). Activity-dependent transcription regulation of PSD-95 by neuregulin-1 and Eos. Nat Neurosci 7, 1250-1258.

Bao, J., Wolpowitz, D., Role, L.W., and Talmage, D.A. (2003). Back signaling by the Nrg-1 intracellular domain. The Journal of cell biology 161, 1133-1141.

Barres, B.A., and Barde, Y. (2000). Neuronal and glial cell biology. Curr Opin Neurobiol 10, 642648.

Barres, B.A., Lazar, M.A., and Raff, M.C. (1994). A novel role for thyroid hormone, glucocorticoids and retinoic acid in timing oligodendrocyte development. Development (Cambridge, England) 120, 1097-1108.

Barres, B.A., and Raff, M.C. (1999). Axonal control of oligodendrocyte development. The Journal of cell biology 147, 1123-1128.

Bartholoma, A., and Nave, K.A. (1994). NEX-1: a novel brain-specific helix-loop-helix protein with autoregulation and sustained expression in mature cortical neurons. Mechanisms of development 48, 217-228. 
Bartzokis, G. (2002). Schizophrenia: breakdown in the well-regulated lifelong process of brain development and maturation. Neuropsychopharmacology 27, 672-683.

Bartzokis, G., Nuechterlein, K.H., Lu, P.H., Gitlin, M., Rogers, S., and Mintz, J. (2003). Dysregulated brain development in adult men with schizophrenia: a magnetic resonance imaging study. Biological psychiatry 53, 412-421.

Baulieu, E.E., and Schumacher, M. (2000). Progesterone as a neuroactive neurosteroid, with special reference to the effect of progesterone on myelination. Human reproduction (Oxford, England) 15 Suppl 1, 1-13.

Baumann, N., and Pham-Dinh, D. (2001). Biology of oligodendrocyte and myelin in the mammalian central nervous system. Physiological reviews 81, 871-927.

Ben Geren, B. (1954). The formation from the Schwann cell surface of myelin in the peripheral nerves of chick embryos. Exp Cell Res 7, 558-562.

Bernstein, H.G., Lendeckel, U., Bertram, I., Bukowska, A., Kanakis, D., Dobrowolny, H., Stauch, R., Krell, D., Mawrin, C., Budinger, E., et al. (2006). Localization of neuregulin-1alpha (heregulin-alpha) and one of its receptors, ErbB-4 tyrosine kinase, in developing and adult human brain. Brain research bulletin 69, 546-559.

Berthold, C.H. (1968a). Ultrastructure of postnatally developing feline peripheral nodes of Ranvier. Acta Societatis Medicorum Upsaliensis 73, 145-168.

Berthold, C.H. (1968b). Ultrastructure of the node-paranode region of mature feline ventral lumbar spinal-root fibres. Acta Societatis Medicorum Upsaliensis 73, Suppl 9:37-70.

Bielschowsky, M. (1908). Eine Modifikation meines Silver-imprägnationsverfahrens zur Darstellung der Neurofibrillen. J für Psychologie Neurologie 12, 135-137.

Birnboim, H.C., and Doly, J. (1979). A rapid alkaline extraction procedure for screening recombinant plasmid DNA. Nucleic acids research 7, 1513-1523.

Bjarnadottir, M., Misner, D.L., Haverfield-Gross, S., Bruun, S., Helgason, V.G., Stefansson, H., Sigmundsson, A., Firth, D.R., Nielsen, B., Stefansdottir, R., et al. (2007). Neuregulin1 (NRG1) signaling through Fyn modulates NMDA receptor phosphorylation: differential synaptic function in NRG1+/- knock-outs compared with wild-type mice. J Neurosci 27, 4519-4529.

Black, J.A., and Waxman, S.G. (1988). The perinodal astrocyte. Glia 1, 169-183.

Blakemore, W.F. (1969). Schmidt-Lantermann incisures in the central nervous system. Journal of ultrastructure research 29, 496-498.

Bliss, T.V., and Collingridge, G.L. (1993). A synaptic model of memory: long-term potentiation in the hippocampus. Nature 361, 31-39.

Bonifacino, J.S., Dell' Angelica, E.C., and Springer, T.A. (1999). Immunoprecipitation. Current Protocols in Protein Science. John Wiley \& Sons, Inc. 9.8.1.

Boucher, A.A., Arnold, J.C., Duffy, L., Schofield, P.R., Micheau, J., and Karl, T. (2007). Heterozygous neuregulin 1 mice are more sensitive to the behavioural effects of Delta9tetrahydrocannabinol. Psychopharmacology 192, 325-336. 
Bozzali, M., and Wrabetz, L. (2004). Axonal signals and oligodendrocyte differentiation. Neurochemical research 29, 979-988.

Bozzi, Y., Vallone, D., and Borrelli, E. (2000). Neuroprotective role of dopamine against hippocampal cell death. J Neurosci 20, 8643-8649.

Braff, D.L., and Geyer, M.A. (1990). Sensorimotor gating and schizophrenia. Human and animal model studies. Arch Gen Psychiatry 47, 181-188.

Brinster, R.L., Chen, H.Y., Warren, R., Sarthy, A., and Palmiter, R.D. (1982). Regulation of metallothionein--thymidine kinase fusion plasmids injected into mouse eggs. Nature 296, 39-42.

Britto, J.M., Lukehurst, S., Weller, R., Fraser, C., Qiu, Y., Hertzog, P., and Busfield, S.J. (2004). Generation and characterization of neuregulin-2-deficient mice. Molecular and cellular biology 24, 8221-8226.

Bullock, T.H., and Horridge, G.A. (1965). Stucture and Function of the Nervous System of Invertebrates. Freeman and Co: San Francisco.

Bunge, M.B., Bunge, R.P., and Pappas, G.D. (1962). Electron microscopic demonstration of connections between glia and myelin sheaths in the developing mammalian central nervous system. The Journal of cell biology 12, 448-453.

Bunge, R.P. (1968). Glial cells and the central myelin sheath. Physiological reviews 48, 197-251.

Buonanno, A., and Fischbach, G.D. (2001). Neuregulin and ErbB receptor signaling pathways in the nervous system. Curr Opin Neurobiol 11, 287-296.

Busfield, S.J., Michnick, D.A., Chickering, T.W., Revett, T.L., Ma, J., Woolf, E.A., Comrack, C.A., Dussault, B.J., Woolf, J., Goodearl, A.D., and Gearing, D.P. (1997). Characterization of a neuregulin-related gene, Don-1, that is highly expressed in restricted regions of the cerebellum and hippocampus. Mol Cell Biol 17, 4007-4014.

Butt, A.M., Ibrahim, M., Ruge, F.M., and Berry, M. (1995). Biochemical subtypes of oligodendrocyte in the anterior medullary velum of the rat as revealed by the monoclonal antibody Rip. Glia 14, 185-197.

Calaora, V., Rogister, B., Bismuth, K., Murray, K., Brandt, H., Leprince, P., Marchionni, M., and Dubois-Dalcq, M. (2001). Neuregulin signaling regulates neural precursor growth and the generation of oligodendrocytes in vitro. J Neurosci 21, 4740-4751.

Cannella, B., Pitt, D., Marchionni, M., and Raine, C.S. (1999). Neuregulin and erbB receptor expression in normal and diseased human white matter. Journal of neuroimmunology 100, 233242.

Canoll, P.D., Kraemer, R., Teng, K.K., Marchionni, M.A., and Salzer, J.L. (1999). GGF/neuregulin induces a phenotypic reversion of oligodendrocytes. Mol Cell Neurosci 13, 79-94.

Canoll, P.D., Musacchio, J.M., Hardy, R., Reynolds, R., Marchionni, M.A., and Salzer, J.L. (1996). $\mathrm{GGF} /$ neuregulin is a neuronal signal that promotes the proliferation and survival and inhibits the differentiation of oligodendrocyte progenitors. Neuron 17, 229-243.

Carlsson, M., and Carlsson, A. (1990). Interactions between glutamatergic and monoaminergic 
systems within the basal ganglia--implications for schizophrenia and Parkinson's disease. Trends in neurosciences 13, 272-276.

Carraway, K.L., 3rd, Weber, J.L., Unger, M.J., Ledesma, J., Yu, N., Gassmann, M., and Lai, C. (1997). Neuregulin-2, a new ligand of ErbB3/ErbB4-receptor tyrosine kinases. Nature 387, $512-$ 516.

Caruthers, M.H., Beaucage, S.L., Becker, C., Efcavitch, J.W., Fisher, E.F., Galluppi, G., Goldman, R., deHaseth, P., Matteucci, M., McBride, L., and et al. (1983). Deoxyoligonucleotide synthesis via the phosphoramidite method. Gene amplification and analysis 3, 1-26.

Casanova, E., Fehsenfeld, S., Mantamadiotis, T., Lemberger, T., Greiner, E., Stewart, A.F., and Schutz, G. (2001). A CamKIIalpha iCre BAC allows brain-specific gene inactivation. Genesis $31,37-42$.

Chang, Q., and Fischbach, G.D. (2006). An acute effect of neuregulin 1 beta to suppress alpha 7containing nicotinic acetylcholine receptors in hippocampal interneurons. J Neurosci 26, 1129511303.

Charles, P., Hernandez, M.P., Stankoff, B., Aigrot, M.S., Colin, C., Rougon, G., Zalc, B., and Lubetzki, C. (2000). Negative regulation of central nervous system myelination by polysialylated-neural cell adhesion molecule. Proceedings of the National Academy of Sciences of the United States of America 97, 7585-7590.

Clarke, E.C., and O'Malley, C.D. (1968). The Human Brain and Spinal Cord. Berkely: University of California Press. .

Clineschmidt, B.V. (1982). Effect of the benzodiazepine receptor antagonist Ro 15-1788 on the anticonvulsant and anticonflict actions of MK-801. European journal of pharmacology 84, 119121.

Colello, R.J., and Pott, U. (1997). Signals that initiate myelination in the developing mammalian nervous system. Mol Neurobiol 15, 83-100.

Colognato, H., Baron, W., Avellana-Adalid, V., Relvas, J.B., Baron-Van Evercooren, A., GeorgesLabouesse, E., and ffrench-Constant, C. (2002). CNS integrins switch growth factor signalling to promote target-dependent survival. Nature cell biology 4, 833-841.

Conradi, S. (1969). Observations on the ultrastructure of the axon hillock and initial axon segment of lumbosacral motoneurons in the cat. Acta physiologica Scandinavica 332, 65-84.

Conradi, S., and Skoglund, S. (1969). Observations on the ultrastructure of the initial motor axon segment and dorsal root boutons on the motoneurons in the lumbosacral spinal cord of the cat during postnatal development. Acta physiologica Scandinavica 333, 53-76.

Corfas, G., Rosen, K.M., Aratake, H., Krauss, R., and Fischbach, G.D. (1995). Differential expression of ARIA isoforms in the rat brain. Neuron 14, 103-115.

Corfas, G., Roy, K., and Buxbaum, J.D. (2004). Neuregulin 1-erbB signaling and the molecular/cellular basis of schizophrenia. Nat Neurosci 7, 575-580.

Coyle, J.T. (2004). The GABA-glutamate connection in schizophrenia: which is the proximate cause? Biochemical pharmacology 68, 1507-1514. 
Csernansky, J.G., Martin, M., Shah, R., Bertchume, A., Colvin, J., and Dong, H. (2005). Cholinesterase inhibitors ameliorate behavioral deficits induced by MK-801 in mice. Neuropsychopharmacology 30, 2135-2143.

Davis, K.L., Stewart, D.G., Friedman, J.I., Buchsbaum, M., Harvey, P.D., Hof, P.R., Buxbaum, J., and Haroutunian, V. (2003). White matter changes in schizophrenia: evidence for myelinrelated dysfunction. Arch Gen Psychiatry 60, 443-456.

De Leonibus, E., Mele, A., Oliverio, A., and Pert, A. (2001). Locomotor activity induced by the non-competitive N-methyl-D-aspartate antagonist, MK-801: role of nucleus accumbens efferent pathways. Neuroscience 104, 105-116.

Deadwyler, G.D., Pouly, S., Antel, J.P., and Devries, G.H. (2000). Neuregulins and erbB receptor expression in adult human oligodendrocytes. Glia 32, 304-312.

Deutsch, S.I., Rosse, R.B., and Mastropaolo, J. (1997). Behavioral approaches to the functional assessment of NMDA-mediated neural transmission in intact mice. Clinical neuropharmacology $20,375-384$.

Doetschman, T., Gregg, R.G., Maeda, N., Hooper, M.L., Melton, D.W., Thompson, S., and Smithies, O. (1987). Targetted correction of a mutant HPRT gene in mouse embryonic stem cells. Nature 330, 576-578.

Duncan, D. (1934). The Importance of Diameter as a Factor in Myelination. Science 79, 363.

Duncan, G., Miyamoto, S., Gu, H., Lieberman, J., Koller, B., and Snouwaert, J. (2002). Alterations in regional brain metabolism in genetic and pharmacological models of reduced NMDA receptor function. Brain research 951, 166-176.

Duncan, I.D., and Hoffman, R.L. (1997). Schwann cell invasion of the central nervous system of the myelin mutants. J Anat 190 ( Pt 1), 35-49.

Edgar, J.M., and Garbern, J. (2004). The myelinated axon is dependent on the myelinating cell for support and maintenance: molecules involved. Journal of neuroscience research 76, 593-598.

Edwards, G.A., Ruska, H., and De Harven, E. (1958). Electron microscopy of peripheral nerves and neuromuscular junctions in the wasp leg. The Journal of biophysical and biochemical cytology 4, 107-114.

Erickson, J.C., Clegg, K.E., and Palmiter, R.D. (1996). Sensitivity to leptin and susceptibility to seizures of mice lacking neuropeptide Y. Nature 381, 415-421.

Escher, P., Lacazette, E., Courtet, M., Blindenbacher, A., Landmann, L., Bezakova, G., Lloyd, K.C., Mueller, U., and Brenner, H.R. (2005). Synapses form in skeletal muscles lacking neuregulin receptors. Science 308, 1920-1923.

Esclapez, M., Tillakaratne, N.J., Kaufman, D.L., Tobin, A.J., and Houser, C.R. (1994). Comparative localization of two forms of glutamic acid decarboxylase and their mRNAs in rat brain supports the concept of functional differences between the forms. J Neurosci 14, 18341855.

Esclapez, M., Tillakaratne, N.J., Tobin, A.J., and Houser, C.R. (1993). Comparative localization of mRNAs encoding two forms of glutamic acid decarboxylase with nonradioactive in situ 
hybridization methods. The Journal of comparative neurology 331, 339-362.

Esper, R.M., Pankonin, M.S., and Loeb, J.A. (2006). Neuregulins: versatile growth and differentiation factors in nervous system development and human disease. Brain Res Brain Res Rev 51, 161-175.

Falls, D.L. (2003a). Neuregulins and the neuromuscular system: 10 years of answers and questions. Journal of neurocytology 32, 619-647.

Falls, D.L. (2003b). Neuregulins: functions, forms, and signaling strategies. Exp Cell Res 284, 1430.

Falls, D.L., Rosen, K.M., Corfas, G., Lane, W.S., and Fischbach, G.D. (1993). ARIA, a protein that stimulates acetylcholine receptor synthesis, is a member of the neu ligand family. Cell 72, 801815.

Feil, R., Wagner, J., Metzger, D., and Chambon, P. (1997). Regulation of Cre recombinase activity by mutated estrogen receptor ligand-binding domains. Biochemical and biophysical research communications $237,752-757$.

Fernandez, P.A., Tang, D.G., Cheng, L., Prochiantz, A., Mudge, A.W., and Raff, M.C. (2000). Evidence that axon-derived neuregulin promotes oligodendrocyte survival in the developing rat optic nerve. Neuron 28, 81-90.

ffrench-Constant, C., Colognato, H., and Franklin, R.J. (2004). Neuroscience. The mysteries of myelin unwrapped. Science 304, 688-689.

Fields, R.D., and Burnstock, G. (2006). Purinergic signalling in neuron-glia interactions. Nat Rev Neurosci 7, 423-436.

Fischbach, G.D. (2007). NRG1 and synaptic function in the CNS. Neuron 54, 495-497.

Flames, N., Long, J.E., Garratt, A.N., Fischer, T.M., Gassmann, M., Birchmeier, C., Lai, C., Rubenstein, J.L., and Marin, O. (2004). Short- and long-range attraction of cortical GABAergic interneurons by neuregulin-1. Neuron 44, 251-261.

Fleischhauer, K., and Wartenberg, H. (1967). [Electron microscopic studies of the growth of nerve fibers and of the appearance of myelin shealth in the corpus callosum of the cat]. Z Zellforsch Mikrosk Anat 83, 568-581.

Flores, A.I., Mallon, B.S., Matsui, T., Ogawa, W., Rosenzweig, A., Okamoto, T., and Macklin, W.B. (2000). Akt-mediated survival of oligodendrocytes induced by neuregulins. J Neurosci 20, 7622-7630.

Flynn, S.W., Lang, D.J., Mackay, A.L., Goghari, V., Vavasour, I.M., Whittall, K.P., Smith, G.N., Arango, V., Mann, J.J., Dwork, A.J., et al. (2003). Abnormalities of myelination in schizophrenia detected in vivo with MRI, and post-mortem with analysis of oligodendrocyte proteins. Molecular psychiatry 8, 811-820.

Foong, J., Symms, M.R., Barker, G.J., Maier, M., Miller, D.H., and Ron, M.A. (2002). Investigating regional white matter in schizophrenia using diffusion tensor imaging. Neuroreport 13, 333-336. 
Fraher, J.P., Kaar, G.F., Bristol, D.C., and Rossiter, J.P. (1988). Development of ventral spinal motoneurone fibres: a correlative study of the growth and maturation of central and peripheral segments of large and small fibre classes. Progress in neurobiology 31, 199-239.

Frankel, W.N., Taylor, B.A., Noebels, J.L., and Lutz, C.M. (1994). Genetic epilepsy model derived from common inbred mouse strains. Genetics 138, 481-489.

Fujise, N., Liu, Y., Hori, N., and Kosaka, T. (1998). Distribution of calretinin immunoreactivity in the mouse dentate gyrus: II. Mossy cells, with special reference to their dorsoventral difference in calretinin immunoreactivity. Neuroscience 82, 181-200.

Gallagher, S.R. (2006). Electrophoretic Separation of Proteins. Current Protocols in Molecular Biology. John Wiley \& Sons, Inc. 10.2.1.

Gallyas, F. (1979). Silver staining of myelin by means of physical development. Neurological research 1, 203-209.

Garcia, R.A., Vasudevan, K., and Buonanno, A. (2000). The neuregulin receptor ErbB-4 interacts with PDZ-containing proteins at neuronal synapses. Proceedings of the National Academy of Sciences of the United States of America 97, 3596-3601.

Garratt, A.N., Britsch, S., and Birchmeier, C. (2000a). Neuregulin, a factor with many functions in the life of a schwann cell. Bioessays 22, 987-996.

Garratt, A.N., Voiculescu, O., Topilko, P., Charnay, P., and Birchmeier, C. (2000b). A dual role of erbB2 in myelination and in expansion of the schwann cell precursor pool. J Cell Biol 148, 1035-1046.

Garven, H.S., and Gairns, F.W. (1952). The silver diammine ion staining of peripheral nerve elements and the interpretation of the results: with a modification of the Bielschowsky-Gros method for frozen sections. Quarterly journal of experimental physiology and cognate medical sciences 37, 131-142.

Genoud, S., Lappe-Siefke, C., Goebbels, S., Radtke, F., Aguet, M., Scherer, S.S., Suter, U., Nave, K.A., and Mantei, N. (2002). Notch1 control of oligodendrocyte differentiation in the spinal cord. The Journal of cell biology 158, 709-718.

Gerard, G.F., D'Alessio, J.M., Kotewicz, M.L., and Noon, M.C. (1986). Influence on stability in Escherichia coli of the carboxy-terminal structure of cloned Moloney murine leukemia virus reverse transcriptase. DNA (Mary Ann Liebert, Inc 5, 271-279.

Gerecke, K.M., Wyss, J.M., and Carroll, S.L. (2004). Neuregulin-1beta induces neurite extension and arborization in cultured hippocampal neurons. Mol Cell Neurosci 27, 379-393.

Geren, B.B., and Raskind, J. (1953). Development of the Fine Structure of the Myelin Sheath in Sciatic Nerves of Chick Embryos. Proceedings of the National Academy of Sciences of the United States of America 39, 880-884.

Geren, B.B., and Schmitt, F.O. (1954). The Structure of the Schwann Cell and Its Relation to the Axon in Certain Invertebrate Nerve Fibers. Proceedings of the National Academy of Sciences of the United States of America 40, 863-870.

Gerlai, R., Pisacane, P., and Erickson, S. (2000). Heregulin, but not ErbB2 or ErbB3, heterozygous 
mutant mice exhibit hyperactivity in multiple behavioral tasks. Behavioural brain research 109, 219-227.

Ghashghaei, H.T., Weber, J., Pevny, L., Schmid, R., Schwab, M.H., Lloyd, K.C., Eisenstat, D.D., Lai, C., and Anton, E.S. (2006). The role of neuregulin-ErbB4 interactions on the proliferation and organization of cells in the subventricular zone. Proceedings of the National Academy of Sciences of the United States of America 103, 1930-1935.

Givogri, M.I., Costa, R.M., Schonmann, V., Silva, A.J., Campagnoni, A.T., and Bongarzone, E.R. (2002). Central nervous system myelination in mice with deficient expression of Notch1 receptor. Journal of neuroscience research 67, 309-320.

Gledhill, R.F., and McDonald, W.I. (1977). Morphological characteristics of central demyelination and remyelination: a single-fiber study. Annals of neurology 1, 552-560.

Goebbels, S., Bormuth, I., Bode, U., Hermanson, O., Schwab, M.H., and Nave, K.A. (2006). Genetic targeting of principal neurons in neocortex and hippocampus of NEX-Cre mice. Genesis 44, 611-621.

Golub, M.S., Germann, S.L., and Lloyd, K.C. (2004). Behavioral characteristics of a nervous system-specific erbB4 knock-out mouse. Behavioural brain research 153, 159-170.

Gordon, J.W., Scangos, G.A., Plotkin, D.J., Barbosa, J.A., and Ruddle, F.H. (1980). Genetic transformation of mouse embryos by microinjection of purified DNA. Proc Natl Acad Sci U S A $77,7380-7384$.

Goring, D.R., Rossant, J., Clapoff, S., Breitman, M.L., and Tsui, L.C. (1987). In situ detection of beta-galactosidase in lenses of transgenic mice with a gamma-crystallin/lacZ gene. Science (New York, N.Y 235, 456-458.

Gorski, J.A., Talley, T., Qiu, M., Puelles, L., Rubenstein, J.L., and Jones, K.R. (2002). Cortical excitatory neurons and glia, but not GABAergic neurons, are produced in the Emx1-expressing lineage. J Neurosci 22, 6309-6314.

Gottesman, I. (1991). Schizophrenia genesis: The origin of madness (New York: W. H. Freeman).

Greenberg, M.M., Leitao, C., Trogadis, J., and Stevens, J.K. (1990). Irregular geometries in normal unmyelinated axons: a 3D serial EM analysis. Journal of neurocytology 19, 978-988.

Griffiths, I., Klugmann, M., Anderson, T., Yool, D., Thomson, C., Schwab, M.H., Schneider, A., Zimmermann, F., McCulloch, M., Nadon, N., and Nave, K.A. (1998). Axonal swellings and degeneration in mice lacking the major proteolipid of myelin. Science 280, 1610-1613.

Grinspan, J. (2002). Cells and signaling in oligodendrocyte development. Journal of neuropathology and experimental neurology 61, 297-306.

Gu, H., Marth, J.D., Orban, P.C., Mossmann, H., and Rajewsky, K. (1994). Deletion of a DNA polymerase beta gene segment in T cells using cell type-specific gene targeting. Science 265, 103-106.

Gu, Z., Jiang, Q., Fu, A.K., Ip, N.Y., and Yan, Z. (2005). Regulation of NMDA receptors by neuregulin signaling in prefrontal cortex. J Neurosci 25, 4974-4984. 
Gunther, J. (1976). Impulse conduction in the myelinated giant fibers of the earthworm. Structure and function of the dorsal nodes in the median giant fiber. The Journal of comparative neurology 168, 505-531.

Hahn, C.G., Wang, H.Y., Cho, D.S., Talbot, K., Gur, R.E., Berrettini, W.H., Bakshi, K., Kamins, J., Borgmann-Winter, K.E., Siegel, S.J., et al. (2006). Altered neuregulin 1-erbB4 signaling contributes to NMDA receptor hypofunction in schizophrenia. Nat Med 12, 824-828.

Hakak, Y., Walker, J.R., Li, C., Wong, W.H., Davis, K.L., Buxbaum, J.D., Haroutunian, V., and Fienberg, A.A. (2001). Genome-wide expression analysis reveals dysregulation of myelinationrelated genes in chronic schizophrenia. Proc Natl Acad Sci U S A 98, 4746-4751.

Hall, J., Whalley, H.C., Job, D.E., Baig, B.J., McIntosh, A.M., Evans, K.L., Thomson, P.A., Porteous, D.J., Cunningham-Owens, D.G., Johnstone, E.C., and Lawrie, S.M. (2006). A neuregulin 1 variant associated with abnormal cortical function and psychotic symptoms. Nat Neurosci 9, 1477-1478.

Hama, K. (1966). The fine structure of the Schwann cell sheath of the nerve fiber in the shrimp (Penaeus japonicus). The Journal of cell biology 31, 624-632.

Hames, B.D.a.R., D. (1990). Gel Electrophoresis of Proteins: A Practical Approach, 2nd ed. Oxford University Press, New York.

Hardy, R., and Reynolds, R. (1991). Proliferation and differentiation potential of rat forebrain oligodendroglial progenitors both in vitro and in vivo. Development (Cambridge, England) 111, 1061-1080.

Hardy, R., and Reynolds, R. (1993). Neuron-oligodendroglial interactions during central nervous system development. Journal of neuroscience research 36, 121-126.

Harlow, E., and Lane, D. (1988). Antibodies: a laboratory manual. Cold Spring Harbor, NY: Cold Spring Harbor Laboratory

Harrison, P.J. (1999). The neuropathology of schizophrenia. A critical review of the data and their interpretation. Brain 122 ( Pt 4), 593-624.

Harrison, P.J., and Law, A.J. (2006). Neuregulin 1 and schizophrenia: genetics, gene expression, and neurobiology. Biological psychiatry 60, 132-140.

Harrison, P.J., and Owen, M.J. (2003). Genes for schizophrenia? Recent findings and their pathophysiological implications. Lancet 361, 417-419.

Harrison, P.J., and Weinberger, D.R. (2005). Schizophrenia genes, gene expression, and neuropathology: on the matter of their convergence. Molecular psychiatry 10, 40-68; image 45.

Hebert, J.M., and McConnell, S.K. (2000). Targeting of cre to the Foxg1 (BF-1) locus mediates loxP recombination in the telencephalon and other developing head structures. Developmental biology 222, 296-306.

Hell, J.W., and Jahn, R. (1994). Preparation of Synaptic Vesicles from Mammalian Brain. Cell Biology: A Laboratory Handbook. Academic Press, Inc.

Hellemans, J., Mortier, G., De Paepe, A., Speleman, F., and Vandesompele, J. (2007). qBase 
relative quantification framework and software for management and automated analysis of realtime quantitative PCR data. Genome biology 8, R19.

Hempstead, B.L., and Salzer, J.L. (2002). Neurobiology. A glial spin on neurotrophins. Science 298, 1184-1186.

Hess, A., and Young, J.Z. (1952). The nodes of Ranvier. Proceedings of the Royal Society of London. Series B, Containing papers of a Biological character 140, 301-320.

Heuser, J.E., and Doggenweiler, C.F. (1966). The fine structural organization of nerve fibers, sheaths, and glial cells in the prawn, Palaemonetes vulgaris. The Journal of cell biology 30, 381403.

Hildebrand, C. (1971). Ultrastructural and light-microscopic studies of the nodal region in large myelinated fibres of the adult feline spinal cord white matter. Acta physiologica Scandinavica 364, 43-79.

Hildebrand, C., and Hahn, R. (1978). Relation between myelin sheath thickness and axon size in spinal cord white matter of some vertebrate species. Journal of the neurological sciences 38 , 421-434.

Hildebrand, C., Remahl, S., Persson, H., and Bjartmar, C. (1993). Myelinated nerve fibres in the CNS. Progress in neurobiology 40, 319-384.

Hildebrand, C., and Waxman, S.G. (1984). Postnatal differentiation of rat optic nerve fibers: electron microscopic observations on the development of nodes of Ranvier and axoglial relations. The Journal of comparative neurology 224, 25-37.

Hirrlinger, P.G., Scheller, A., Braun, C., Hirrlinger, J., and Kirchhoff, F. (2006). Temporal control of gene recombination in astrocytes by transgenic expression of the tamoxifen-inducible DNA recombinase variant CreERT2. Glia 54, 11-20.

Hof, P.R., Haroutunian, V., Copland, C., Davis, K.L., and Buxbaum, J.D. (2002). Molecular and cellular evidence for an oligodendrocyte abnormality in schizophrenia. Neurochemical research 27, 1193-1200.

Hof, P.R., Haroutunian, V., Friedrich, V.L., Jr., Byne, W., Buitron, C., Perl, D.P., and Davis, K.L. (2003). Loss and altered spatial distribution of oligodendrocytes in the superior frontal gyrus in schizophrenia. Biological psychiatry 53, 1075-1085.

Horiuchi, K., Zhou, H.M., Kelly, K., Manova, K., and Blobel, C.P. (2005). Evaluation of the contributions of ADAMs 9,12,15, 17, and 19 to heart development and ectodomain shedding of neuregulins beta1 and beta2. Developmental biology 283, 459-471.

Horton, R.M. (1995). PCR-mediated recombination and mutagenesis. SOEing together tailor-made genes. Molecular biotechnology 3, 93-99.

Horton, R.M. (1997). In vitro recombination and mutagenesis of DNA. SOEing together tailormade genes. Methods in molecular biology (Clifton, N.J 67, 141-149.

Hu, Q.D., Ang, B.T., Karsak, M., Hu, W.P., Cui, X.Y., Duka, T., Takeda, Y., Chia, W., Sankar, N., $\mathrm{Ng}$, Y.K., et al. (2003). F3/contactin acts as a functional ligand for Notch during oligodendrocyte maturation. Cell 115, 163-175. 
Hu, X., Hicks, C.W., He, W., Wong, P., Macklin, W.B., Trapp, B.D., and Yan, R. (2006). Bace1 modulates myelination in the central and peripheral nervous system. Nat Neurosci 9, 15201525 .

Huang, Y.Z., Won, S., Ali, D.W., Wang, Q., Tanowitz, M., Du, Q.S., Pelkey, K.A., Yang, D.J., Xiong, W.C., Salter, M.W., and Mei, L. (2000). Regulation of neuregulin signaling by PSD-95 interacting with ErbB4 at CNS synapses. Neuron 26, 443-455.

Hursh, J.B. (1939). Conduction velocity and diameter of nerve fibers. American Journal of Physiology 127, 131-139.

Huxley, A.F., and Stampfli, R. (1949). Evidence for saltatory conduction in peripheral myelinated nerve fibres. The Journal of physiology 108, 315-339.

Ichimura, T., and Ellisman, M.H. (1991). Three-dimensional fine structure of cytoskeletalmembrane interactions at nodes of Ranvier. Journal of neurocytology 20, 667-681.

Jahn, R., and Sudhof, T.C. (1993). Synaptic vesicle traffic: rush hour in the nerve terminal. Journal of neurochemistry $61,12-21$.

Jaworski, A., and Burden, S.J. (2006). Neuromuscular synapse formation in mice lacking motor neuron- and skeletal muscle-derived Neuregulin-1. J Neurosci 26, 655-661.

Jessen, K.R., and Mirsky, R. (2005). The origin and development of glial cells in peripheral nerves. Nat Rev Neurosci 6, 671-682.

Kagawa, T., Ikenaka, K., Inoue, Y., Kuriyama, S., Tsujii, T., Nakao, J., Nakajima, K., Aruga, J., Okano, H., and Mikoshiba, K. (1994). Glial cell degeneration and hypomyelination caused by overexpression of myelin proteolipid protein gene. Neuron 13, 427-442.

Karl, T., Duffy, L., Scimone, A., Harvey, R.P., and Schofield, P.R. (2007). Altered motor activity, exploration and anxiety in heterozygous neuregulin 1 mutant mice: implications for understanding schizophrenia. Genes, brain, and behavior 6, 677-687.

Karl, T., Pabst, R., and von Horsten, S. (2003). Behavioral phenotyping of mice in pharmacological and toxicological research. Exp Toxicol Pathol 55, 69-83.

Kash, S.F., Johnson, R.S., Tecott, L.H., Noebels, J.L., Mayfield, R.D., Hanahan, D., and Baekkeskov, S. (1997). Epilepsy in mice deficient in the $65-\mathrm{kDa}$ isoform of glutamic acid decarboxylase. Proceedings of the National Academy of Sciences of the United States of America 94, 14060-14065.

Kim, J.Y., Sun, Q., Oglesbee, M., and Yoon, S.O. (2003). The role of ErbB2 signaling in the onset of terminal differentiation of oligodendrocytes in vivo. J Neurosci 23, 5561-5571.

Kotewicz, M.L., D'Alessio, J.M., Driftmier, K.M., Blodgett, K.P., and Gerard, G.F. (1985). Cloning and overexpression of Moloney murine leukemia virus reverse transcriptase in Escherichia coli. Gene 35, 249-258.

Kramer, R., Bucay, N., Kane, D.J., Martin, L.E., Tarpley, J.E., and Theill, L.E. (1996). Neuregulins with an Ig-like domain are essential for mouse myocardial and neuronal development. Proceedings of the National Academy of Sciences of the United States of America 93, 48334838 . 
Kusano, K., and LaVail, M.M. (1971). Impulse conduction in the shrimp medullated giant fiber with special reference to the structure of functionally excitable areas. The Journal of comparative neurology 142, 481-494.

Kwon, O.B., Longart, M., Vullhorst, D., Hoffman, D.A., and Buonanno, A. (2005). Neuregulin-1 reverses long-term potentiation at CA1 hippocampal synapses. J Neurosci 25, 9378-9383.

Laemmli, U.K. (1970). Cleavage of structural proteins during the assembly of the head of bacteriophage T4. Nature 227, 680-685.

Lai, C., and Feng, L. (2004). Neuregulin induces proliferation of neural progenitor cells via PLC/PKC pathway. Biochemical and biophysical research communications 319, 603-611.

Lane, N.J. (1981). Invertebrate neuroglia-junctional structure and development. J. exp. Biol. 95, 733.

Lanterman, A.J. (1877). Uber den feineren Bau der markhaltigen Nervenfasern. Archiv für Mikroskopische Anatomie, 1-8.

Lappe-Siefke, C., Goebbels, S., Gravel, M., Nicksch, E., Lee, J., Braun, P.E., Griffiths, I.R., and Nave, K.A. (2003). Disruption of Cnp1 uncouples oligodendroglial functions in axonal support and myelination. Nat Genet 33, 366-374.

Law, A.J., Shannon Weickert, C., Hyde, T.M., Kleinman, J.E., and Harrison, P.J. (2004). Neuregulin-1 (NRG-1) mRNA and protein in the adult human brain. Neuroscience 127, 125136.

Lee, E.C., Yu, D., Martinez de Velasco, J., Tessarollo, L., Swing, D.A., Court, D.L., Jenkins, N.A., and Copeland, N.G. (2001). A highly efficient Escherichia coli-based chromosome engineering system adapted for recombinogenic targeting and subcloning of BAC DNA. Genomics 73, 5665.

Lee, K.F., Simon, H., Chen, H., Bates, B., Hung, M.C., and Hauser, C. (1995). Requirement for neuregulin receptor erbB2 in neural and cardiac development. Nature 378, 394-398.

Lentz, T.L., and Barrnett, R.J. (1965). Fine Structure of the Nervous System of Hydra. American zoologist 5, 341-356.

Levi, J.U., Cowden, R.R., and Collins, G.H. (1966). The microscopic anatomy and ultrastructure of the nervous system in the earthworm (Lumbricus sp.) with emphasis on the relationship between glial cells and neurons. The Journal of comparative neurology 127, 489-510.

Lewis, D.A., Hashimoto, T., and Volk, D.W. (2005). Cortical inhibitory neurons and schizophrenia. Nat Rev Neurosci 6, 312-324.

Lewis, D.A., and Moghaddam, B. (2006). Cognitive dysfunction in schizophrenia: convergence of gamma-aminobutyric acid and glutamate alterations. Archives of neurology 63, 1372-1376.

Li, B., Woo, R.S., Mei, L., and Malinow, R. (2007). The neuregulin-1 receptor erbB4 controls glutamatergic synapse maturation and plasticity. Neuron 54, 583-597.

Li, L., Cleary, S., Mandarano, M.A., Long, W., Birchmeier, C., and Jones, F.E. (2002a). The breast proto-oncogene, HRGalpha regulates epithelial proliferation and lobuloalveolar development in 
the mouse mammary gland. Oncogene 21, 4900-4907.

Li, Q., Clark, S., Lewis, D.V., and Wilson, W.A. (2002b). NMDA receptor antagonists disinhibit rat posterior cingulate and retrosplenial cortices: a potential mechanism of neurotoxicity. $\mathrm{J}$ Neurosci 22, 3070-3080.

Lisman, J.E., and Grace, A.A. (2005). The hippocampal-VTA loop: controlling the entry of information into long-term memory. Neuron 46, 703-713.

Liu, Y., Ford, B., Mann, M.A., and Fischbach, G.D. (2001). Neuregulins increase alpha7 nicotinic acetylcholine receptors and enhance excitatory synaptic transmission in GABAergic interneurons of the hippocampus. J Neurosci 21, 5660-5669.

Loeb, J.A., Hmadcha, A., Fischbach, G.D., Land, S.J., and Zakarian, V.L. (2002). Neuregulin expression at neuromuscular synapses is modulated by synaptic activity and neurotrophic factors. J Neurosci 22, 2206-2214.

Longart, M., Liu, Y., Karavanova, I., and Buonanno, A. (2004). Neuregulin-2 is developmentally regulated and targeted to dendrites of central neurons. J Comp Neurol 472, 156-172.

Lopez-Bendito, G., Cautinat, A., Sanchez, J.A., Bielle, F., Flames, N., Garratt, A.N., Talmage, D.A., Role, L.W., Charnay, P., Marin, O., and Garel, S. (2006). Tangential neuronal migration controls axon guidance: a role for neuregulin-1 in thalamocortical axon navigation. Cell 125, 127-142.

Lowry, O.H., Rosebrough, N.J., Farr, A.L., and Randall, R.J. (1951). Protein measurement with the Folin phenol reagent. The Journal of biological chemistry 193, 265-275.

Luesse, H.G., Schiefer, J., Spruenken, A., Puls, C., Block, F., and Kosinski, C.M. (2001). Evaluation of R6/2 HD transgenic mice for therapeutic studies in Huntington's disease: behavioral testing and impact of diabetes mellitus. Behavioural brain research 126, 185-195.

Lundblad, M., Vaudano, E., and Cenci, M.A. (2003). Cellular and behavioural effects of the adenosine A2a receptor antagonist KW-6002 in a rat model of 1-DOPA-induced dyskinesia. Journal of neurochemistry $84,1398-1410$.

Lunn, K.F., Baas, P.W., and Duncan, I.D. (1997). Microtubule organization and stability in the oligodendrocyte. J Neurosci 17, 4921-4932.

Marchionni, M.A., Cannella, B., Hoban, C., Gao, Y.L., Garcia-Arenas, R., Lawson, D., Happel, E., Noel, F., Tofilon, P., Gwynne, D., and Raine, C.S. (1999). Neuregulin in neuron/glial interactions in the central nervous system. GGF2 diminishes autoimmune demyelination, promotes oligodendrocyte progenitor expansion, and enhances remyelination. Advances in experimental medicine and biology 468, 283-295.

Marchionni, M.A., Kirk, C.J., Isaacs, I.J., Hoban, C.J., Mahanthappa, N.K., Anton, E.S., Chen, C., Wason, F., Lawson, D., Hamers, F.P., et al. (1996). Neuregulins as potential drugs for neurological disorders. Cold Spring Harbor symposia on quantitative biology 61, 459-472.

Maren, S. (2001). Neurobiology of Pavlovian fear conditioning. Annual review of neuroscience 24, 897-931.

Maren, S., and Holt, W. (2000). The hippocampus and contextual memory retrieval in Pavlovian 
conditioning. Behavioural brain research 110, 97-108.

Maren, S., and Quirk, G.J. (2004). Neuronal signalling of fear memory. Nat Rev Neurosci 5, 844852.

Mastropaolo, J., Rosse, R.B., and Deutsch, S.I. (2004). Anabasine, a selective nicotinic acetylcholine receptor agonist, antagonizes MK-801-elicited mouse popping behavior, an animal model of schizophrenia. Behavioural brain research 153, 419-422.

Matthews, M.A., and Duncan, D. (1971). A quantitative study of morphological changes accompanying the initiation and progress of myelin production in the dorsal funiculus of the rat spinal cord. The Journal of comparative neurology 142, 1-22.

Maturana, H.R. (1960). The fine anatomy of the optic nerve of anurans--an electron microscope study. The Journal of biophysical and biochemical cytology 7, 107-120.

McDonald, W.I., and Ohlrich, G.D. (1971). Quantitative anatomical measurements on single isolated fibres from the cat spinal cord. Journal of anatomy 110, 191-202.

McKinnon, R.D., Matsui, T., Dubois-Dalcq, M., and Aaronson, S.A. (1990). FGF modulates the PDGF-driven pathway of oligodendrocyte development. Neuron 5, 603-614.

McKnight, G.S., Hammer, R.E., Kuenzel, E.A., and Brinster, R.L. (1983). Expression of the chicken transferrin gene in transgenic mice. Cell 34, 335-341.

McMorris, F.A., and Dubois-Dalcq, M. (1988). Insulin-like growth factor I promotes cell proliferation and oligodendroglial commitment in rat glial progenitor cells developing in vitro. Journal of neuroscience research 21, 199-209.

McMorris, F.A., and McKinnon, R.D. (1996). Regulation of oligodendrocyte development and CNS myelination by growth factors: prospects for therapy of demyelinating disease. Brain pathology (Zurich, Switzerland) 6, 313-329.

Metzger, D., and Chambon, P. (2001). Site- and time-specific gene targeting in the mouse. Methods (San Diego, Calif 24, 71-80.

Meyer, D., and Birchmeier, C. (1995). Multiple essential functions of neuregulin in development. Nature 378, 386-390.

Meyer, D., Yamaai, T., Garratt, A., Riethmacher-Sonnenberg, E., Kane, D., Theill, L.E., and Birchmeier, C. (1997). Isoform-specific expression and function of neuregulin. Development (Cambridge, England) 124, 3575-3586.

Mi, H., Deerinck, T.J., Jones, M., Ellisman, M.H., and Schwarz, T.L. (1996). Inwardly rectifying $\mathrm{K}+$ channels that may participate in $\mathrm{K}+$ buffering are localized in microvilli of Schwann cells. $\mathrm{J}$ Neurosci 16, 2421-2429.

Michailov, G.V., Sereda, M.W., Brinkmann, B.G., Fischer, T.M., Haug, B., Birchmeier, C., Role, L., Lai, C., Schwab, M.H., and Nave, K.A. (2004). Axonal neuregulin-1 regulates myelin sheath thickness. Science 304, 700-703.

Minichiello, L., Korte, M., Wolfer, D., Kuhn, R., Unsicker, K., Cestari, V., Rossi-Arnaud, C., Lipp, H.P., Bonhoeffer, T., and Klein, R. (1999). Essential role for TrkB receptors in hippocampus- 
mediated learning. Neuron 24, 401-414.

Moghaddam, B., and Jackson, M.E. (2003). Glutamatergic animal models of schizophrenia. Annals of the New York Academy of Sciences 1003, 131-137.

Mohn, A.R., Gainetdinov, R.R., Caron, M.G., and Koller, B.H. (1999). Mice with reduced NMDA receptor expression display behaviors related to schizophrenia. Cell 98, 427-436.

Morell, P., and Norton, W.T. (1980). Myelin. Scientific American 242, 88-90, 92, 96 passim.

Morice, E., Denis, C., Giros, B., and Nosten-Bertrand, M. (2004). Phenotypic expression of the targeted null-mutation in the dopamine transporter gene varies as a function of the genetic background. The European journal of neuroscience 20, 120-126.

Morris, J.K., Lin, W., Hauser, C., Marchuk, Y., Getman, D., and Lee, K.F. (1999). Rescue of the cardiac defect in ErbB2 mutant mice reveals essential roles of ErbB2 in peripheral nervous system development. Neuron 23, 273-283.

Mullis, K., Faloona, F., Scharf, S., Saiki, R., Horn, G., and Erlich, H. (1986). Specific enzymatic amplification of DNA in vitro: the polymerase chain reaction. Cold Spring Harbor symposia on quantitative biology 51 Pt 1, 263-273.

Murray, J.A., and Blakemore, W.F. (1980). The relationship between internodal length and fibre diameter in the spinal cord of the cat. Journal of the neurological sciences 45, 29-41.

Muzumdar, M.D., Tasic, B., Miyamichi, K., Li, L., and Luo, L. (2007). A global doublefluorescent Cre reporter mouse. Genesis 45, 593-605.

Nagy, A., Baker, R.R., Morris, S.J., and Whittaker, V.P. (1976). The preparation and characterization of synaptic vesicles of high purity. Brain research 109, 285-309.

Nathans, D., and Smith, H.O. (1975). Restriction endonucleases in the analysis and restructuring of dna molecules. Annual review of biochemistry 44, 273-293.

Nave, K.A., and Salzer, J.L. (2006). Axonal regulation of myelination by neuregulin 1. Curr Opin Neurobiol 16, 492-500.

Ni, C.Y., Murphy, M.P., Golde, T.E., and Carpenter, G. (2001). gamma -Secretase cleavage and nuclear localization of ErbB-4 receptor tyrosine kinase. Science 294, 2179-2181.

Nisonoff, A. (1984). Introduction to Molecular Immunology. Sinauer Associates, Sunderland, Mass.

O'Tuathaigh, C.M., Babovic, D., O'Meara, G., Clifford, J.J., Croke, D.T., and Waddington, J.L. (2007a). Susceptibility genes for schizophrenia: characterisation of mutant mouse models at the level of phenotypic behaviour. Neuroscience and biobehavioral reviews 31, 60-78.

O'Tuathaigh, C.M., Babovic, D., O'Sullivan, G.J., Clifford, J.J., Tighe, O., Croke, D.T., Harvey, R., and Waddington, J.L. (2007b). Phenotypic characterization of spatial cognition and social behavior in mice with 'knockout' of the schizophrenia risk gene neuregulin 1. Neuroscience 147, $18-27$.

O'Tuathaigh, C.M., O'Connor, A.M., O'Sullivan, G.J., Lai, D., Harvey, R., Croke, D.T., and Waddington, J.L. (2008). Disruption to social dyadic interactions but not emotional/anxiety- 
related behaviour in mice with heterozygous 'knockout' of the schizophrenia risk gene neuregulin-1. Progress in neuro-psychopharmacology \& biological psychiatry 32, 462-466.

O'Tuathaigh, C.M., O'Sullivan, G.J., Kinsella, A., Harvey, R.P., Tighe, O., Croke, D.T., and Waddington, J.L. (2006). Sexually dimorphic changes in the exploratory and habituation profiles of heterozygous neuregulin-1 knockout mice. Neuroreport 17, 79-83.

Okada, M., and Corfas, G. (2004). Neuregulin1 downregulates postsynaptic GABAA receptors at the hippocampal inhibitory synapse. Hippocampus 14, 337-344.

Owen, M., M, O.D., and II, G. (2003). Psychiatric genetics and genomics (Oxford: Oxford University Press).

Owen, M.J., Craddock, N., and O'Donovan, M.C. (2005a). Schizophrenia: genes at last? Trends Genet 21, 518-525.

Owen, M.J., O'Donovan, M.C., and Harrison, P.J. (2005b). Schizophrenia: a genetic disorder of the synapse? BMJ (Clinical research ed 330, 158-159.

Ozaki, M., Sasner, M., Yano, R., Lu, H.S., and Buonanno, A. (1997). Neuregulin-beta induces expression of an NMDA-receptor subunit. Nature 390, 691-694.

Park, S.K., Miller, R., Krane, I., and Vartanian, T. (2001). The erbB2 gene is required for the development of terminally differentiated spinal cord oligodendrocytes. The Journal of cell biology 154, 1245-1258.

Paulson, L., Martin, P., Persson, A., Nilsson, C.L., Ljung, E., Westman-Brinkmalm, A., Eriksson, P.S., Blennow, K., and Davidsson, P. (2003). Comparative genome- and proteome analysis of cerebral cortex from MK-801-treated rats. Journal of neuroscience research 71, 526-533.

Penfield, W. (1932). Cytology and Cellular Pathology of the Nervous System (New York: Paul B. Hoeber, Inc.).

Peters, A. (1960). The structure of myelin sheaths in the central nervous system of Xenopus laevis (Daudin). The Journal of biophysical and biochemical cytology 7, 121-126.

Peters, A., Palay, S.L., and Webster, H.D.F. (1991). The Fine Structure of the Nervous System: The Neurons and the Supporting Cells, 3rd edn (New York: Oxford University Press).

Peterson, G.L. (1979). Review of the Folin phenol protein quantitation method of Lowry, Rosebrough, Farr and Randall. Analytical biochemistry 100, 201-220.

Pfeiffer, S.E., Warrington, A.E., and Bansal, R. (1993). The oligodendrocyte and its many cellular processes. Trends in cell biology 3, 191-197.

Pitcher, G.M., Beggs, S., Woo, R.S., Mei, L., and Salter, M.W. (2008). ErbB4 is a suppressor of long-term potentiation in the adult hippocampus. Neuroreport 19, 139-143.

Poliak, S., and Peles, E. (2003). The local differentiation of myelinated axons at nodes of Ranvier. Nat Rev Neurosci 4, 968-980.

Pongrac, J., Middleton, F.A., Lewis, D.A., Levitt, P., and Mirnics, K. (2002). Gene expression profiling with DNA microarrays: advancing our understanding of psychiatric disorders. Neurochemical research 27, 1049-1063. 
Powell, S.B., and Geyer, M.A. (2002). Developmental markers of psychiatric disorders as identified by sensorimotor gating. Neurotoxicity research 4, 489-502.

Prosser, H.M., Gill, C.H., Hirst, W.D., Grau, E., Robbins, M., Calver, A., Soffin, E.M., Farmer, C.E., Lanneau, C., Gray, J., et al. (2001). Epileptogenesis and enhanced prepulse inhibition in GABA(B1)-deficient mice. Mol Cell Neurosci 17, 1059-1070.

Raabe, T.D., Clive, D.R., Wen, D., and DeVries, G.H. (1997a). Neonatal oligodendrocytes contain and secrete neuregulins in vitro. Journal of neurochemistry 69, 1859-1863.

Raabe, T.D., Suy, S., Welcher, A., and DeVries, G.H. (1997b). Effect of neu differentiation factor isoforms on neonatal oligodendrocyte function. Journal of neuroscience research 50, 755-768.

Raff, M.C., Lillien, L.E., Richardson, W.D., Burne, J.F., and Noble, M.D. (1988). Platelet-derived growth factor from astrocytes drives the clock that times oligodendrocyte development in culture. Nature 333, 562-565.

Raine, C.S. (1982). Differences between the nodes of Ranvier of large and small diameter fibres in the P.N.S. Journal of neurocytology 11, 935-947.

Ranvier, L.-A. (1871). Contributions a i'histologie et a la physiologie des nerf peripheriques. Comptes Rendus de l'Academie Science (Paris), 1168-1171.

Readhead, C., Schneider, A., Griffiths, I., and Nave, K.A. (1994). Premature arrest of myelin formation in transgenic mice with increased proteolipid protein gene dosage. Neuron 12, 583595.

Remahl, S., and Hildebrand, C. (1982). Changing relation between onset of myelination and axon diameter range in developing feline white matter. Journal of the neurological sciences 54, 33-45.

Richardson, W.D., Pringle, N., Mosley, M.J., Westermark, B., and Dubois-Dalcq, M. (1988). A role for platelet-derived growth factor in normal gliogenesis in the central nervous system. Cell 53, 309-319.

Richardson, W.D., Smith, H.K., Sun, T., Pringle, N.P., Hall, A., and Woodruff, R. (2000). Oligodendrocyte lineage and the motor neuron connection. Glia 29, 136-142.

Rieff, H.I., Raetzman, L.T., Sapp, D.W., Yeh, H.H., Siegel, R.E., and Corfas, G. (1999). Neuregulin induces GABA(A) receptor subunit expression and neurite outgrowth in cerebellar granule cells. J Neurosci 19, 10757-10766.

Riethmacher, D., Sonnenberg-Riethmacher, E., Brinkmann, V., Yamaai, T., Lewin, G.R., and Birchmeier, C. (1997). Severe neuropathies in mice with targeted mutations in the ErbB3 receptor. Nature 389, 725-730.

Rimer, M., Barrett, D.W., Maldonado, M.A., Vock, V.M., and Gonzalez-Lima, F. (2005). Neuregulin-1 immunoglobulin-like domain mutant mice: clozapine sensitivity and impaired latent inhibition. Neuroreport 16, 271-275.

Rimer, M., Prieto, A.L., Weber, J.L., Colasante, C., Ponomareva, O., Fromm, L., Schwab, M.H., Lai, C., and Burden, S.J. (2004). Neuregulin-2 is synthesized by motor neurons and terminal Schwann cells and activates acetylcholine receptor transcription in muscle cells expressing ErbB4. Mol Cell Neurosci 26, 271-281. 
Rio, C., Rieff, H.I., Qi, P., Khurana, T.S., and Corfas, G. (1997). Neuregulin and erbB receptors play a critical role in neuronal migration. Neuron 19, 39-50.

Ritchie, J.M. (1984). Physiological basis of conduction in myelinated nerve fibers. In: Myelin, Ed. P. Morell, Plenum Press: New York.

Robertson, J.D. (1958). The ultrastructure of Schmidt-Lanterman clefts and related shearing defects of the myelin sheath. The Journal of biophysical and biochemical cytology 4, 39-46.

Rodriguez-Pena, A. (1999). Oligodendrocyte development and thyroid hormone. Journal of neurobiology 40, 497-512.

Role, L.W., and Talmage, D.A. (2007). Neurobiology: new order for thought disorders. Nature 448, 263-265.

Rosenbluth, J. (1999). A brief history of myelinated nerve fibers: one hundred and fifty years of controversy. Journal of neurocytology 28, 251-262.

Roy, K., Murtie, J.C., El-Khodor, B.F., Edgar, N., Sardi, S.P., Hooks, B.M., Benoit-Marand, M., Chen, C., Moore, H., O'Donnell, P., et al. (2007). Loss of erbB signaling in oligodendrocytes alters myelin and dopaminergic function, a potential mechanism for neuropsychiatric disorders. Proceedings of the National Academy of Sciences of the United States of America 104, 81318136.

Rujescu, D., Bender, A., Keck, M., Hartmann, A.M., Ohl, F., Raeder, H., Giegling, I., Genius, J., McCarley, R.W., Moller, H.J., and Grunze, H. (2006). A pharmacological model for psychosis based on N-methyl-D-aspartate receptor hypofunction: molecular, cellular, functional and behavioral abnormalities. Biological psychiatry 59, 721-729.

Rushton, W.A. (1951). A theory of the effects of fibre size in medullated nerve. The Journal of physiology 115, 101-122.

Rydmark, M., and Berthold, C.H. (1983). Electron microscopic serial section analysis of nodes of Ranvier in lumbar spinal roots of the cat: a morphometric study of nodal compartments in fibres of different sizes. Journal of neurocytology 12, 537-565.

Salzer, J.L. (2003). Polarized domains of myelinated axons. Neuron 40, 297-318.

Sandrock, A.W., Jr., Dryer, S.E., Rosen, K.M., Gozani, S.N., Kramer, R., Theill, L.E., and Fischbach, G.D. (1997). Maintenance of acetylcholine receptor number by neuregulins at the neuromuscular junction in vivo. Science 276, 599-603.

Sandrock, A.W., Jr., Goodearl, A.D., Yin, Q.W., Chang, D., and Fischbach, G.D. (1995). ARIA is concentrated in nerve terminals at neuromuscular junctions and at other synapses. J Neurosci 15, 6124-6136.

Sanes, J.R. (1994). Lineage tracing. The laatest in lineaage. Curr Biol 4, 1162-1164.

Sardi, S.P., Murtie, J., Koirala, S., Patten, B.A., and Corfas, G. (2006). Presenilin-dependent ErbB4 nuclear signaling regulates the timing of astrogenesis in the developing brain. Cell 127, 185197.

Saxena, S., and Caroni, P. (2007). Mechanisms of axon degeneration: from development to disease. 
Progress in neurobiology 83, 174-191.

Schaeffer, L., de Kerchove d'Exaerde, A., and Changeux, J.P. (2001). Targeting transcription to the neuromuscular synapse. Neuron 31, 15-22.

Schmid, R.S., McGrath, B., Berechid, B.E., Boyles, B., Marchionni, M., Sestan, N., and Anton, E.S. (2003). Neuregulin 1-erbB2 signaling is required for the establishment of radial glia and their transformation into astrocytes in cerebral cortex. Proceedings of the National Academy of Sciences of the United States of America 100, 4251-4256.

Schmidt, H.D. (1874). On the construction of the dark or double-bordered nerve fiber. The Monthly Microscopical Journal, 200-221.

Schmidt, W.J. (1936). Doppelbrechung und Feinbau der Markscheiden der Nervenfasern. Zeitschrift für Zellforschung und mikroskopische ANATOMIE, 657-676.

Schmitt, F.O. (1941). X-ray diffraction studies of the nerve myelin sheath. Journal of Cellular and Comparative Physiology, 31-41.

Schmucker, J., Ader, M., Brockschnieder, D., Brodarac, A., Bartsch, U., and Riethmacher, D. (2003). erbB3 is dispensable for oligodendrocyte development in vitro and in vivo. Glia 44, $67-$ 75.

Schwab, M.H., Druffel-Augustin, S., Gass, P., Jung, M., Klugmann, M., Bartholomae, A., Rossner, M.J., and Nave, K.A. (1998). Neuronal basic helix-loop-helix proteins (NEX, neuroD, NDRF): spatiotemporal expression and targeted disruption of the NEX gene in transgenic mice. $\mathrm{J}$ Neurosci 18, 1408-1418.

Schwindinger, W.F., Giger, K.E., Betz, K.S., Stauffer, A.M., Sunderlin, E.M., Sim-Selley, L.J., Selley, D.E., Bronson, S.K., and Robishaw, J.D. (2004). Mice with deficiency of G protein gamma3 are lean and have seizures. Molecular and cellular biology 24, 7758-7768.

Seggie, J., and Berry, M. (1972). Ontogeny of interhemispheric evoked potentials in the rat: significance of myelination of the corpus callosum. Experimental neurology 35, 215-232.

Soriano, P. (1999). Generalized lacZ expression with the ROSA26 Cre reporter strain. Nat Genet $21,70-71$.

Srinivas, S., Watanabe, T., Lin, C.S., William, C.M., Tanabe, Y., Jessell, T.M., and Costantini, F. (2001). Cre reporter strains produced by targeted insertion of EYFP and ECFP into the ROSA26 locus. BMC developmental biology 1,4 .

Stefansson, H., Sigurdsson, E., Steinthorsdottir, V., Bjornsdottir, S., Sigmundsson, T., Ghosh, S., Brynjolfsson, J., Gunnarsdottir, S., Ivarsson, O., Chou, T.T., et al. (2002). Neuregulin 1 and susceptibility to schizophrenia. Am J Hum Genet 71, 877-892.

Stefansson, H., Steinthorsdottir, V., Thorgeirsson, T.E., Gulcher, J.R., and Stefansson, K. (2004). Neuregulin 1 and schizophrenia. Annals of medicine 36, 62-71.

Steiner, H., Blum, M., Kitai, S.T., and Fedi, P. (1999). Differential expression of ErbB3 and ErbB4 neuregulin receptors in dopamine neurons and forebrain areas of the adult rat. Experimental neurology 159, 494-503. 
Steinthorsdottir, V., Stefansson, H., Ghosh, S., Birgisdottir, B., Bjornsdottir, S., Fasquel, A.C., Olafsson, O., Stefansson, K., and Gulcher, J.R. (2004). Multiple novel transcription initiation sites for NRG1. Gene 342, 97-105.

Stevens, B., Porta, S., Haak, L.L., Gallo, V., and Fields, R.D. (2002). Adenosine: a neuron-glial transmitter promoting myelination in the CNS in response to action potentials. Neuron 36, 855868.

Stewart, D.G., and Davis, K.L. (2004). Possible contributions of myelin and oligodendrocyte dysfunction to schizophrenia. International review of neurobiology 59, 381-424.

Sussman, C.R., Vartanian, T., and Miller, R.H. (2005). The ErbB4 neuregulin receptor mediates suppression of oligodendrocyte maturation. J Neurosci 25, 5757-5762.

Tasaki, I. (1939). The electro-saltatory transmission of the nerve impulse and the effect of narcosis upon the nerve fiber. The American Journal of Physiology 127, 211-227.

Tasaki, I. (1982). Physiology and Electrochemistry of Nerve Fibers, Academic Press: New York.

Taveggia, C., Zanazzi, G., Petrylak, A., Yano, H., Rosenbluth, J., Einheber, S., Xu, X., Esper, R.M., Loeb, J.A., Shrager, P., et al. (2005). Neuregulin-1 type III determines the ensheathment fate of axons. Neuron 47, 681-694.

Thomas, K.R., and Capecchi, M.R. (1987). Site-directed mutagenesis by gene targeting in mouse embryo-derived stem cells. Cell 51, 503-512.

Thornberg, S.A., and Saklad, S.R. (1996). A review of NMDA receptors and the phencyclidine model of schizophrenia. Pharmacotherapy 16, 82-93.

Thuret, S., Alavian, K.N., Gassmann, M., Lloyd, C.K., Smits, S.M., Smidt, M.P., Klein, R., Dyck, R.H., and Simon, H.H. (2004). The neuregulin receptor, ErbB4, is not required for normal development and adult maintenance of the substantia nigra pars compacta. Journal of neurochemistry $91,1302-1311$.

Tidcombe, H., Jackson-Fisher, A., Mathers, K., Stern, D.F., Gassmann, M., and Golding, J.P. (2003). Neural and mammary gland defects in ErbB4 knockout mice genetically rescued from embryonic lethality. Proc Natl Acad Sci U S A 100, 8281-8286.

Tkachev, D., Mimmack, M.L., Ryan, M.M., Wayland, M., Freeman, T., Jones, P.B., Starkey, M., Webster, M.J., Yolken, R.H., and Bahn, S. (2003). Oligodendrocyte dysfunction in schizophrenia and bipolar disorder. Lancet 362, 798-805.

Towbin, H., Staehelin, T., and Gordon, J. (1979). Electrophoretic transfer of proteins from polyacrylamide gels to nitrocellulose sheets: procedure and some applications. Proceedings of the National Academy of Sciences of the United States of America 76, 4350-4354.

Tronche, F., Kellendonk, C., Kretz, O., Gass, P., Anlag, K., Orban, P.C., Bock, R., Klein, R., and Schutz, G. (1999). Disruption of the glucocorticoid receptor gene in the nervous system results in reduced anxiety. Nat Genet 23, 99-103.

Tuohy, T.M., Wallingford, N., Liu, Y., Chan, F.H., Rizvi, T., Xing, R., Bebo, B., Rao, M.S., and Sherman, L.S. (2004). CD44 overexpression by oligodendrocytes: a novel mouse model of inflammation-independent demyelination and dysmyelination. Glia 47, 335-345. 
Turnley, A.M., Morahan, G., Okano, H., Bernard, O., Mikoshiba, K., Allison, J., Bartlett, P.F., and Miller, J.F. (1991). Dysmyelination in transgenic mice resulting from expression of class I histocompatibility molecules in oligodendrocytes. Nature 353, 566-569.

Uchihara, T. (2007). Silver diagnosis in neuropathology: principles, practice and revised interpretation. Acta Neuropathol 113, 483-499.

Uranova, N., Orlovskaya, D., Vikhreva, O., Zimina, I., Kolomeets, N., Vostrikov, V., and Rachmanova, V. (2001). Electron microscopy of oligodendroglia in severe mental illness. Brain research bulletin $55,597-610$.

Vartanian, T., Corfas, G., Li, Y., Fischbach, G.D., and Stefansson, K. (1994). A role for the acetylcholine receptor-inducing protein ARIA in oligodendrocyte development. Proceedings of the National Academy of Sciences of the United States of America 91, 11626-11630.

Vartanian, T., Fischbach, G., and Miller, R. (1999). Failure of spinal cord oligodendrocyte development in mice lacking neuregulin. Proc Natl Acad Sci U S A 96, 731-735.

Vartanian, T., Goodearl, A., Viehover, A., and Fischbach, G. (1997). Axonal neuregulin signals cells of the oligodendrocyte lineage through activation of HER4 and Schwann cells through HER2 and HER3. J Cell Biol 137, 211-220.

Voyvodic, J.T. (1989). Target size regulates calibre and myelination of sympathetic axons. Nature $342,430-433$.

Waddington, J.L., O'Tuathaigh, C., O'Sullivan, G., Tomiyama, K., Koshikawa, N., and Croke, D.T. (2005). Phenotypic studies on dopamine receptor subtype and associated signal transduction mutants: insights and challenges from 10 years at the psychopharmacology-molecular biology interface. Psychopharmacology 181, 611-638.

Wang, S., Sdrulla, A.D., diSibio, G., Bush, G., Nofziger, D., Hicks, C., Weinmaster, G., and Barres, B.A. (1998). Notch receptor activation inhibits oligodendrocyte differentiation. Neuron 21, 63-75.

Waxman, S.G. (1997). Axon-glia interactions: building a smart nerve fiber. Curr Biol 7, R406-410.

Weinberger, D.R. (2005). Genetic mechanisms of psychosis: in vivo and postmortem genomics. Clinical therapeutics 27 Suppl A, S8-15.

Willem, M., Garratt, A.N., Novak, B., Citron, M., Kaufmann, S., Rittger, A., DeStrooper, B., Saftig, P., Birchmeier, C., and Haass, C. (2006). Control of peripheral nerve myelination by the beta-secretase BACE1. Science 314, 664-666.

Wolpowitz, D., Mason, T.B., Dietrich, P., Mendelsohn, M., Talmage, D.A., and Role, L.W. (2000). Cysteine-rich domain isoforms of the neuregulin-1 gene are required for maintenance of peripheral synapses. Neuron 25, 79-91.

Wong, E.H., Kemp, J.A., Priestley, T., Knight, A.R., Woodruff, G.N., and Iversen, L.L. (1986). The anticonvulsant MK-801 is a potent N-methyl-D-aspartate antagonist. Proceedings of the National Academy of Sciences of the United States of America 83, 7104-7108.

Woo, R.S., Li, X.M., Tao, Y., Carpenter-Hyland, E., Huang, Y.Z., Weber, J., Neiswender, H., Dong, X.P., Wu, J., Gassmann, M., et al. (2007). Neuregulin-1 enhances depolarization-induced 
GABA release. Neuron 54, 599-610.

Xie, F., Raetzman, L.T., and Siegel, R.E. (2004). Neuregulin induces GABAA receptor beta2 subunit expression in cultured rat cerebellar granule neurons by activating multiple signaling pathways. Journal of neurochemistry 90, 1521-1529.

Yang, X., Kuo, Y., Devay, P., Yu, C., and Role, L. (1998). A cysteine-rich isoform of neuregulin controls the level of expression of neuronal nicotinic receptor channels during synaptogenesis. Neuron 20, 255-270.

Yarden, Y., and Sliwkowski, M.X. (2001). Untangling the ErbB signalling network. Nature reviews 2, 127-137.

Yasuda, T., Grinspan, J., Stern, J., Franceschini, B., Bannerman, P., and Pleasure, D. (1995). Apoptosis occurs in the oligodendroglial lineage, and is prevented by basic fibroblast growth factor. Journal of neuroscience research 40, 306-317.

Yau, H.J., Wang, H.F., Lai, C., and Liu, F.C. (2003). Neural development of the neuregulin receptor ErbB4 in the cerebral cortex and the hippocampus: preferential expression by interneurons tangentially migrating from the ganglionic eminences. Cereb Cortex 13, 252-264.

Zausinger, S., Hungerhuber, E., Baethmann, A., Reulen, H., and Schmid-Elsaesser, R. (2000). Neurological impairment in rats after transient middle cerebral artery occlusion: a comparative study under various treatment paradigms. Brain research 863, 94-105.

Zhang, D., Sliwkowski, M.X., Mark, M., Frantz, G., Akita, R., Sun, Y., Hillan, K., Crowley, C., Brush, J., and Godowski, P.J. (1997). Neuregulin-3 (NRG3): a novel neural tissue-enriched protein that binds and activates ErbB4. Proc Natl Acad Sci U S A 94, 9562-9567.

Zucker, R.S., and Regehr, W.G. (2002). Short-term synaptic plasticity. Annual review of physiology 64, 355-405. 
7. Appendices 


\subsection{Appendix A: Abbreviations}

\begin{tabular}{|c|c|}
\hline Amg & Amygdala \\
\hline$\beta \mathrm{ME}$ or $2 \mathrm{ME}$ & Beta-mercaptoethanol \\
\hline $\mathrm{bp}$ & Base pairs \\
\hline BSA & Bovine serum albumin \\
\hline${ }^{\circ} \mathrm{C}$ & Degrees Celsius (centigrades) \\
\hline CA1/CA3 & CA1/CA3 region of Hippocampus \\
\hline $\mathrm{cc}$ & corpus callosum \\
\hline $\mathrm{CNP}$ & 2'3'-cyclic nucleotide 3'phosphodiesterase \\
\hline CNS & Central nervous system \\
\hline CRD & cysteine-rich domain of NRG1 type III \\
\hline $\mathrm{Cx}$ & cortex \\
\hline $\mathrm{ddH}_{2} \mathrm{O}$ & double distilled (or miliQ) water \\
\hline ddDNA & double stranded DNA \\
\hline DAB & 3,3'- Diaminobenzidine \\
\hline DMSO & Dimethylsulfoxide \\
\hline DRG & Dorsal root ganglia \\
\hline $\mathrm{E}$ & Embroynic day \\
\hline EDTA & Ethylenediaminetetraacetic acid \\
\hline EPSP & excitatory postsynaptic potential \\
\hline ES & Embryonic stem cell \\
\hline f.c. & final concentration \\
\hline G418 & Geneticin (gentamicin) \\
\hline $\mathrm{HE}$ & Haematoxylin-Eosin staining \\
\hline Hip & Hippocampus \\
\hline HS & Horse serum \\
\hline IP & Immunoprecipitation \\
\hline $\mathrm{Kb}$ & Kilobases \\
\hline $\mathrm{kDa}$ & Kilodalton \\
\hline ko & knock-out (null mutant) \\
\hline LB & Luria-Bertani broth \\
\hline LTP & Long-term potentiation \\
\hline M & Molar \\
\hline $\mathrm{mM}$ & millimolar \\
\hline $\mathrm{mA}$ & milliAmpere \\
\hline $\min$ & minutes \\
\hline $\mathrm{ml}$ & milliliter \\
\hline mo & month \\
\hline$\mu \mathrm{g}$ & microgram \\
\hline$\mu 1$ & microliter \\
\hline
\end{tabular}




\begin{tabular}{|c|c|}
\hline ng & nanogram \\
\hline$\mu \mathrm{m}$ & micrometer \\
\hline nAch & nicotinic acetylcholine receptor \\
\hline $\mathrm{nm}$ & nanometer \\
\hline $\mathrm{NR} 1 / 2$ & NMDA receptor subunit $1 / 2$ \\
\hline NRG1 & Neuregulin 1 \\
\hline OD & optical density \\
\hline OL & Oligodendrocytes \\
\hline ON & overnight \\
\hline $\mathrm{P}$ & Postnatal day \\
\hline PAGE & Polyacrylamid gel electrophorese \\
\hline PBS & Phosphate buffered saline \\
\hline PFA & Paraformaldehyde \\
\hline $\mathrm{PFC}$ & Prefrontal cortex \\
\hline PLP & Proteolipid protein \\
\hline PMSF & Phenylmethanesulphonlyflouride \\
\hline PNS & Peripheral nervous system \\
\hline PPI & pre-pulse inhibition \\
\hline PSD-95 & Postsynpatic density 95 \\
\hline Rpm & Rotations per minute \\
\hline RQ & Relative qunatity \\
\hline RT & Room temperature \\
\hline RT-PCR & quantitative real time PCR \\
\hline $\mathrm{SC}$ & Schwann cell \\
\hline $\mathrm{SCH}$ & Schizophrenia \\
\hline sec & seconds \\
\hline SDS & Sodium dodecyl sulfate \\
\hline SEM & standard error mean \\
\hline ssDNA & single stranded DNA \\
\hline TBS & Tris buffered saline \\
\hline TBE & Tris-Borat-EDTA \\
\hline TEMED & Tetramethylendiamin \\
\hline Tris-HCl & Tris-(hydroxymethyl)-aminomethan titred with $\mathrm{HCl}$ \\
\hline WB & western blotting \\
\hline wt & wildtype (control) \\
\hline $\mathrm{U}$ & Unit, (for enzyme activities) \\
\hline $\mathrm{V}$ & Volt \\
\hline
\end{tabular}




\subsection{Appendix B: Publications}

Brinkmann, B. G.*, Agarwal, A.*, Sereda, M. W., Garratt, A.N., Müller, T., Wende, H., Nawaz, S., Humml, C., Velanac, V., Radyushkin, K., Goebbels, S., Fischer, T. M., Lai, C., Ehrenreich, H., Birchmeier, C., Schwab, M. H., and Nave, K.-A. (2008). Neuregulin-1/ErbB signaling serves distinct functions in myelination of the peripheral and central nervous system. Neuron (revised version submitted). *Equal contribution.

Agarwal, A., Radyushkin, K., Boretius, S., Frahm, J., Zhang, W., Nave, K.-A., Ehrenreich, H., and Schwab, M. H. (2008). Impaired synaptic plasticity in mice lacking cortical Neuregulin1. (manuscript in preparation).

Agarwal, A., Schwab, M. H., and Nave, K.-A. (2008). Tamoxifen-Inducible Cre mediated partial recombination in principle projection neurons of neocortex and hippocampus. (manuscript in preparation) 


\subsection{Appendix C: Curriculum Vitae}

Personal details:

Surname:

Forename:

Nationality:

Date and place of birth:

Age:

Private address:

Work address:
Agarwal
Amit
India

September 13th, 1980, Koderma, India

27 years old

Am Ebelhof 6 2OG/Links,

37075 Göttingen, Germany

Tel: +49-551-9809494, +49-176-70048388

Ranchi Patna Road, Jhumritelaiya, 825409 Jharkhand, India.

Tel: +91-6534-222717, 223319

MPI of Experimental Medicine

Department of Neurogenetics

Herman-Rein Strasse 3

37075, Göttingen, Germany.

Tel. +49 $5513899-742$

Fax: +49 $5513899-753$

E-mail: agarwal@em.mpg.de

\section{Scientific education.}

University entrance qualification:

All India Secondary School Certificate Examination (AISSCE) ${ }^{*}$ (May 1998, D.A.V. Public School, Bokaro, India)

University Joint Entrance Examination (All India Rank: 1, July 1999, Guru Gobind Singh Indraprastha University, School of Biotechnology, Delhi, India).

University studies:

May 2005 - present:

$\mathrm{PhD}$ Scholar,

Max-Planck-Institut für Experimentelle

Medizin, Göttingen, Germany. 
September 2003 - present:

August 1999 - July 2003:
Graduate student,

International Max Plank Research School,

$\mathrm{MSc} / \mathrm{PhD}$ Program in Neuroscience,

Georg-August-Universität,

Göttingen, Germany.

Bachelor of Technology (B.Tech) in

Biotechnology (8 semesters),

Guru Gobind Singh Indraprastha University,

School of Biotechnology, Delhi, India.

\section{Intermediate and final examination.}

August 2004:

August 1999 - July 2003:

\section{Master Thesis Project.}

Oct 2004 - April 2005:
Master's Examination in Neuroscience

Program, Georg-August-Universität,

Göttingen, Germany.

Average grade $=1.7$

Bachelor's Examination in Biotechnology

Guru Gobind Singh Indraprastha University,

School of Biotechnology, Delhi, India.

Average CPI (Cumulative Performance Index) = 74.7

Final Exam CPI = 89.6 (Excellent)

Role of Neuregulin1 in Oligodendroglial Survival and Axonal Maintenance.

(Supervisor: Prof. Dr. Klaus-Armin Nave, Department of Neurogenetics, Max Planck Institute for Experimental Medicine (MPI-EM), Göttingen).

Master thesis grade $=1.3($ Excellent $)$ 


\section{Research project.}

PhD thesis:

Location of project:

Commencement of project:

\section{Scholarships/Awards.}

$1999-2003$

$2003-2004$

$2003-2004$
'Cortical development and myelination in the absence of Neuregulin1, a schizophrenia susceptibility gene'.

MPI of Experimental Medicine

Department of Neurogenetics

Herman-Rein Strasse 3

37075, Göttingen, Germany.

Supervisor: Prof. Dr. Klaus Armin Nave

April, 2005

"University Scholarship of Full Tuition Fee Waiver", G.G.S. Indraprashtha University, Delhi - For being All India Rank -1 in the Combined Entrance Exam (CEE) for admission in the Biotechnology program.

Qualified GATE (Graduate Aptitude Test for Engineering) in the field of Life Science (Full Scholarship for two years. Supported by AICTE, Government of India, for pursuing Masters of Technology in any Engineering College in India) - 94 percentile.

Stipend for master studies in neurosciences, International Max Planck Research School, Göttingen. 
$2004-2008$

\section{Poster presentation.}

Non-scientific activities.

Vocational training:

English language (Test of English as a Foreign language (TOEFL), total score 250 of 300,2002 ).

Learned Sanskrit (one of the oldest root language of India) for 5 years and

Basic German language course (Georg-August Universität Göttingen, 2003)

\section{Administrative skills and experiences:}

October 2001-March 2003: President of "Biotechnological Research and Information Society" (BRaInS) - the academic and cultural society of School of Biotechnology, 
G.G.S. Indraprashtha University, Delhi.

Conducted symposiums and conferences inviting scientists from varied field in order to share their life time experiences. Dr. Yellapragada SubbaRow Memorial Lecture and Fifty years of DNA double helix.

Participated, organised and chaired several Journal Clubs (during my undergraduate studies) focusing on varied scientific topics ranging from Nanotechnology to Astronomy.

Organised 'NEURIZONS' - $31^{\text {st }}$ May to $2^{\text {nd }}$ June 2007- $2^{\text {nd }}$ International meeting of Neurosciences, solely conducted by graduate students of IMPRSNeuroscience students. 